\title{
HEALTH EFFECTS OF RISK-ASSESSMENT CATEGORIES
}

\author{
C.F. Kramer, K. Rybicka, A. Knutson, and S.C. Morris
}

औरำ

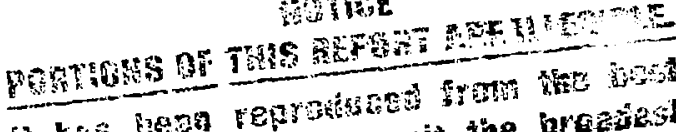

\section{October 1983}

BIOMEDICAL AND ENVIRONMENTAL ASSESSMENT DIVISION DEPARTMENT OF APPLIED SCIENCE BROOKHAVEN NATIONAL LABORATORY ASSOCIATED UNIVERSITIES, INC.

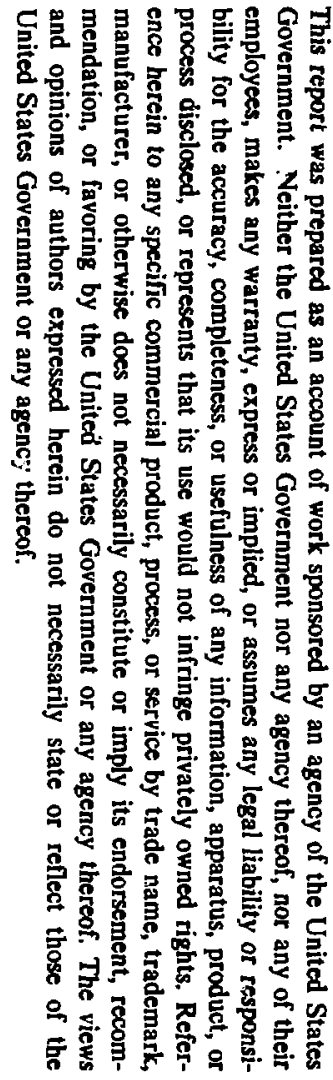

Research Supported by the Office of Research and Development, Office of Environmental Process and Effects Research,

Energy and Air Division, U.S. Environmental Protection Agency

\section{A.A. Moghissi, Project Officer}

Under EPA Agreement No. 79-D-X0533 with the UNITED STATES ENVIRONMENTAL PROTECTION AGENCY

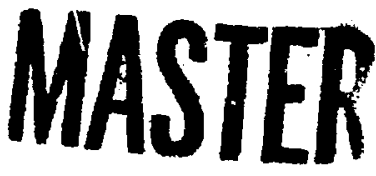




\section{DISCLAIMER}

This report was prepared as an account of work sponsored by an agency of the United States Government. Neither the United States Government nor any agency thereof, nor any of their employees, nor any of their contractors, subcontractors, or their employees, makes any warranty, express or implied, or assumes any legal liability or responsibility for the accuracy, completeness, or usefulness of any information, apparatus, product, or process disclosed, or represents that its use would not infringe privately owned rights. Reference herein to any specific commercial product, process, or service by trade name, trademark, manufacturer, or otherwise, does not necessarily constitute or imply its endorsement, recommendation, or favoring by the United States Government or any agency, contractor or subcontractor thereof. The views and opinions of authors expressed herein do not necessarily state or reflect those of the United States Government or any agency, contractor or subcontractor thereof.

\section{Printed in the United States of America}

Available from

National Technical Information Service

U.S. Department of Commerce

5285 Port Royal Road

Springfield, VA 22161

NTIS price codes:

Printed Copy: A19; Microfiche Copy: A01 
TABLE OF CONTENTS

$\underline{\text { Page }}$

Abstract ............................ v

Acknowledgnents. . . . . . . . . . . . . . . . . . v1

Preface. ............................. vil

Introduction ........................... 1

Chapter 2

Summary Tables. . . . . . . . . . . . . . . 5

Chapter 3

Review of Individual Risk-Assessment Categorles . . . . . 9 9

RAC $\# 1$ Carbon Monoxide. ............... 10

RAC $\# 2$ Sulfur Dioxide................. 13

RAC \#3 Nitrogen 0xides. ................. 17

RAC \#4 Acid Gases ................... 23

RAC 55 Aikaline Gases .................. 28

RAC \#6 Hydrocarbon Gases. . . . . . . . . . . . . 31

RAC $\$ 7$ Formaldehyde ................. 37

RAC \#8 Volatile organochlorines .............. 41

RAC \#9 Volatile Carboxylic Aclds .............. 59

RAC \#10 Volatile 0 and S Heterocyclics ............ 62

RAC \#11 Volatile N Heterocyclics ............. 66

RAC *12 Benzene. ..................... 72

RAC \#13 Aliphatic/Alicyclic Hydrocarbons . . . . . . . 80

RAC \#14 Mono/Diaromatic Hydrocarbons (Excluding Benzene) •. . 87

RAC $\$ 15$ Polycyclic Aromatic Hydrocarbons . . . . . . . . 104

RAC \#16 Aliphatic Amines . . . . ........... 126

RAC \#17 Aromatic Amines (Excluding N-Heterocyclics). . . . . 129

RAC \#18 Alkaline Nitrogen Heterocyclics........... 136

RAC \#19 Neutral N, 0, S Heterocyclics (Exluding

RAC \#20 Carboxylic Acids (Excluding "Volatiles") • • • • 139

RAC \#21 Phenols. .................. 149

RAC \#22 Aldehydes and Ketones ["Carbonyls"] (Excluding

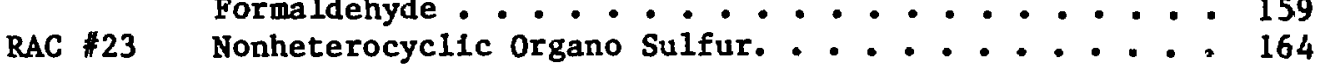

RAC \#24 Alcohols .................... 174

RAC \#25 N1otroaromatics .................. 181

RAC \#26 Esters ....................... 187

RAC \#27 Amides ..................... 190

RAC \#28 Nitriles ................... 194

RAC 29 TARS ..................... 200 
RAC 30

RAC \# 31

RAC \#32

RAC \$33

RAC 34

RAC *35

RAC $\$ 37$

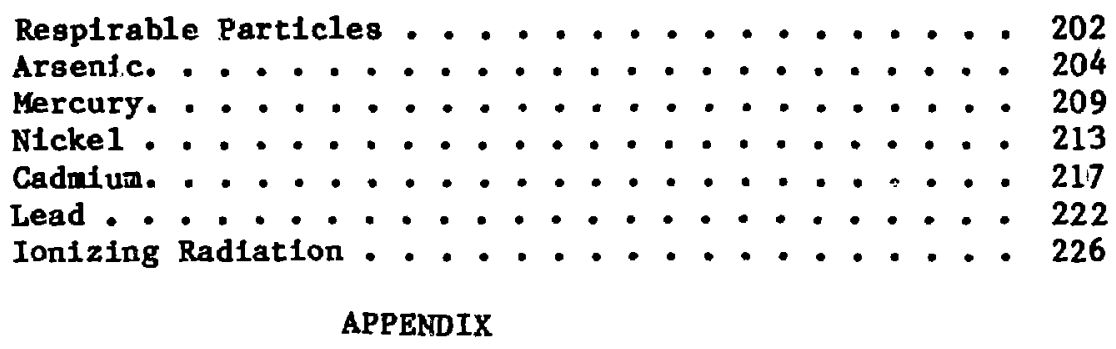

APPENDIX 


\section{ABSTRACT}

Environmental and occupational health effects associated with exposures to various chemfcals are a subject of increasing concern. One recently developed methodology for assessing the health impacte of various chemical compounds involves the classification of similar chemicals into risk-assessment categorles (RACs).

This report reviews documented human health effects for a broad range of pollutsnts, classified by RACs. It complements other studies that have estimated human health effects by RAC based on analysis and extrapolation of data from animal research. 


\section{ACKNOWLEDGMENTS}

This work was supported by the Energy and Air Division, Office of Research and Development, U.S. Environmental Protection Agency. We thank A.A. Moghissi, EPA Profect officer, for his support and encouragement, and M. Carter for providing support for $K$. Rybicka during part of the effort. We are Indebted to J. Brower of the BNL Center for Assessnent of Chenical and Physical Hazards for developing the search strategy on human health effects and for assistance with computerized bibliographic searches; to J.I. Baranctk, M.A. Kramer, Knud Knudsen, P.D. Moskowitz, J. Nagy, R. Novak, and R. Szymanski for their contributions to this document; to Dr. Leonard D. Hamilton, Head, Biomedical and Environmental Assessment Division, for his support; and to A. Link for organizing and typing this report and $P$. Miller for reviewing the report. 


\section{INTRODUCTION}

Introduction to Larger Profect and RAC Concept

The U.S. Environmental Protection Agency (EPA) is developing methods to assess health and environmental risks of complex technologies producing a diverse range of pollutants. Many of these pollutants are unregulated and have relatively undefined effects. Assessments must encompass exposure via alr, water, and food chains. In addition to estimating risk to humans and the environment, the program will help summarize the directions of present research and define spectfic research needs for an assosiated biomedical and environmental research effort.

An adequate chemical-by-chemical health effects risk assessment is precluded because of the vast number if chemicals involved, the inability to characterize these compounds fully, the fact that many are chemically transformed in the environment, and gans in toxicological information. To come to grips with this problem, the concept of Risk-Assessment Categories (RACs) was developed (4). Thls approach groups compounds by chemical structure and other characteristics. Criteria used for the grouping and the current listing of 38 RACs are included in an appendix.

Within the context of the RAC approach, methods were developed to assess health risks using both animal and human data. All health risks are eventually to be considered, but the initial effort, based on animal studies, focused on cancer risks (5-7).

Overall program objectives involve quantifying: 1) emissions to varfous media by RAC; 2) environtental transport, dispersion, and population exposure through various media; and 3) health impact. The first two steps are largely belng carried out at Oak Ridge National Laboratory. Purpose and Objectives of This Effort

This review surveys health effects in man of exposure to a broad range of pollutants organized by RAC. Becisse of limitations on the kind of studies that can be done, human data cannot generally be as definitive as animal or cellular level experimental results. Since the results are to be 
applied to man, it is important that all direct observations in man be considered. The human information also supplements results of animal data In the information used to develop dose-response functions for risk assessment.

About the Report

The report is organized by. RAC. Since these categories are not included in computerized bibliographic data sources, a literature review had to be based on individual compounds, and the results then organized by RAC. Some RACs are single substances (e.g., formaldehyde and benzene). Others are groups with relatively few members (e.g., aliphatic hydrocarbons with four or less carbons and radionuclides in the coal fuel cycle). In these categories, all member compounds were considered. Still other RACs are, for practical purposes, open ended (e.g., alkyl derivatives of polycyclic aromatics). For these categories, example compounds provided in the EPA listing (see Appendix) were considered. In addition, various lists of synfuel-related compounds were used to identify compounds of interest which were then classified by RAC. Lists of possible carcinogens were also used so as not to miss any potentiaI carcinogenic properties in a RAC. Chemical Abstract Service (CAS) numbers were determined for each substance to ease computer searches.

Computerized bibliographic searches were made on Toxline, Medline, Registry. of Toxic Effects of Chemicals (RTEC), and the Toxicology Data Bank. These searches identified articles linking the substances with human health effects through key words such as occupational health, epidemiology, etc. Searches were made by CAS number to avold missing citations using various names for the same compound. The initial set of computerized searches was made in the summer of 1982 and updating searches were made in June-August, 1983.

Where avallable, authoritative review articles were used as the source of information. Other review sources included EPA and National Institute of Occupational Safety and Health (NIOSH) documents such as air quality criteria documents. Standard texts such as Proctor and Hughes (9), Gosselin et al. (2), Patty (8), and Sax (11) were used extensively. Other general sources included the Merck Index (12), the Encyclopedia of Chemical Technology (3), the ACGIH TLV Documentation Manual (1), and the National Toxicology Program 2nd Annual Report on Carcinogens (10). Sources 
identified in computerized searches were used for updating. Most of the updated Information was based on abstracts. Original research articles were viewed only if abstracts did not provide clear or sufficient information.

Physiologic effects of chemicals on any organ system were considered using epidemiological and clinical studies on humans. Late in the study, experimental data using human cells in vitro were also included for some RACs. These add information on metabolic mechanisms involved in the action of given chemicals. In general, animal studies were not drawn upon, although some specific data or comparative human and animal studies were occastonally included. Animal studies were the focus of a separate report in the case of carcinogenic effects (7). The animal literature for other kinds of effects will be the subject of future work.

While Individual substances within each RAC are related, there are varlations of both kind and magnitude in their health impact. For example, several RACs contain compounds that are carcinogens, as well as other compounds that are not carcinogens or for which carcinogenicity is unknown. In each RAC review, effects of individual compounds are discussed and a summary checklist developed. These checklists are further summarized in Chapter 2 to provide a listing of the kinds of effect produced within each RAC.

While no rigid format has been imposed on the RAC reviews, a general 1ist of factors to be considered was developed. Among these are: 1) a description of the RAC, with the range of individual compounds included, usual state, and other pertinent physical and chemical properties; 2) general status of knowledge of human effects for substances in the RAC; 3 ) background levels of exposure, threshold limit values (TLVs), short-term exposire limits (STELs) (1), and standards; 4) kinds of effects; 5) mechanisms; 6) dose-response information; and 7) references. of course, many of these factors are not applicable or are unknown for some RACs. Some factors more important for particular RACs have been given greater emphasis.

In a number of instances, synergistic health effects have been reported between different pollutants and there are probably many potential synergistic effects not yet discovered. Studies of these effects are occasionally mentioned, but their detailed analysis is beyond the scope 
of this report. The number of possible combinations are extensive and a comprehensive approach to this problem has not yet been developed.

References

1. ACGIH. 1980. Documentation of the threshold 11mit values. Fourth Edition. American Conference of Governmental Industrial Hyglenists Inc., $\mathbf{O H}$.

2. Gosselin, R.E., H.C. Hodge, R.P. Smith, and M.N. Gleason. 1979. Clincial toxicology of commercial products. The Williams \& Wilkins Co., MD, pp. 86-92.

3. Kirk-0thmer. 1978. Encyclopedia of chemical technology, Volume 1. Third Edition. John Wiley \& Sons, NY.

4. Moghissi, A.A. and G.J. Foley. 1982. Assessment of environmental 1mpact of coal-conversion and oil shale technologies. In Health Inpacts of Different Sources of Energy, International Atomic Energy Agéncy, Vienna, pp. 665-673.

5. Morris, S.C., H.C. Thode, Jr., J.I. Baranc1k, H. Fischer, P.D. Moskowitz, J. Nagy, and L.D. Hamilton. 1982a. Methods for assessing cancer risks using animal and human data. Brookhaven National Laboratory, Upton, NY.

6. Morris, S.C., J.I. Barancik, H. Fischer, L.D. Hamilton, S. Jones, P.D. Moskowitz, J. Nagy, S. Rabinowitz, and H.C. Thode, Jr. 1932b. Extrapolation to health risk: Use of comparative approaches. Proceedings of the Fifth Oak Ridge Life Sciences Symposium, October 24-27,1982 (1n press).

7. Morris, S.C., H.C. Thode, Jr., H. Fischer, S. Jones, P.D. Moskowitz, J. Nagy, S. Rabinowitz, and L.D. Hamilton. 1983. Cancer risks from unit exposures to different risk assessment categories: A cata base and preliminary appli.ution. Brookhaven National Laboratory, Upton, NY.

8. Patty, F.A. 1982. Fatty's Industrial hygiene and toxicology, Volumes $2 A, 2 B$, and 2C. Third Revised Edition. John Wiley \& Sons, NY.

9. Proctor, N.H. and J.P. Hughes. 1978. Chemical hazards of the workplace. J.B. Lippincott Company, PA.

10. Public Health Service. 1981. Second annual report on carcinogens. U.S. Department of Public Healtiı and Human Services.

11. Sax, N.I. 1975. Dangerous properties of industrial materials. Fourth Edition. Van Nostrand Reinhold Company, NY.

12. The Merck Index. 1976. An encyclopedia of chemicals and drugs. Ninth edition. Merck \& Co., Inc., Rahway, NJ. 
The available human literature on health effects of exposure to pollutants is reviewed by RAC in the following chapters. The sumary table wich follows, consolidates the kinds of effects found by RAC. Each " $x$ " Indicates evidence found in the human literature that at least one substance reviewed within that RAC affects that organ system. A question mark, "?," Indicates: 1) there is some evidence of effect in animal 1iterature and a corresponding effect is expected in man, but no direci. human evidence exists, 2) an effect is hypothesized based on experience with similar compounds, or 3 ) there are inconclusive human data. In the last case, the decision to use an " $x$ " or a "?" was judgmental.

The table is more a guide to the scope of the report than a presentation of Independently useful information. An effect may be based on one substance in an RAC containing many othe $i$ substances which do not produce that effect. The reader should refer to the Individual RAC reviews following to determine the context of the indicated effect as well as to discover the extent of any mechanistic or dose-response information.

In general, reliable, quantitative dose-response information based on numan data is scarce. The kinds of experiments that can be done are limited and numbers are necessarily small in human experimental studies. observational studies are subject to countless difficulties in Interpretation due to uncontrolled factors. Epldemiological studies usually involve a broad mix of concurrent exposures, making associations with a particular agent difficult.

Nonetheless, the human 1iterature is important. It represents direct observation in humans when estimating health effects. It can best be used together with animal data. Human 1iterature can suggest animal experiments, it can be used to verify and calibrate dose-response information derived from animal data, and it can suggest spectfic additional human studles which may be useful. 


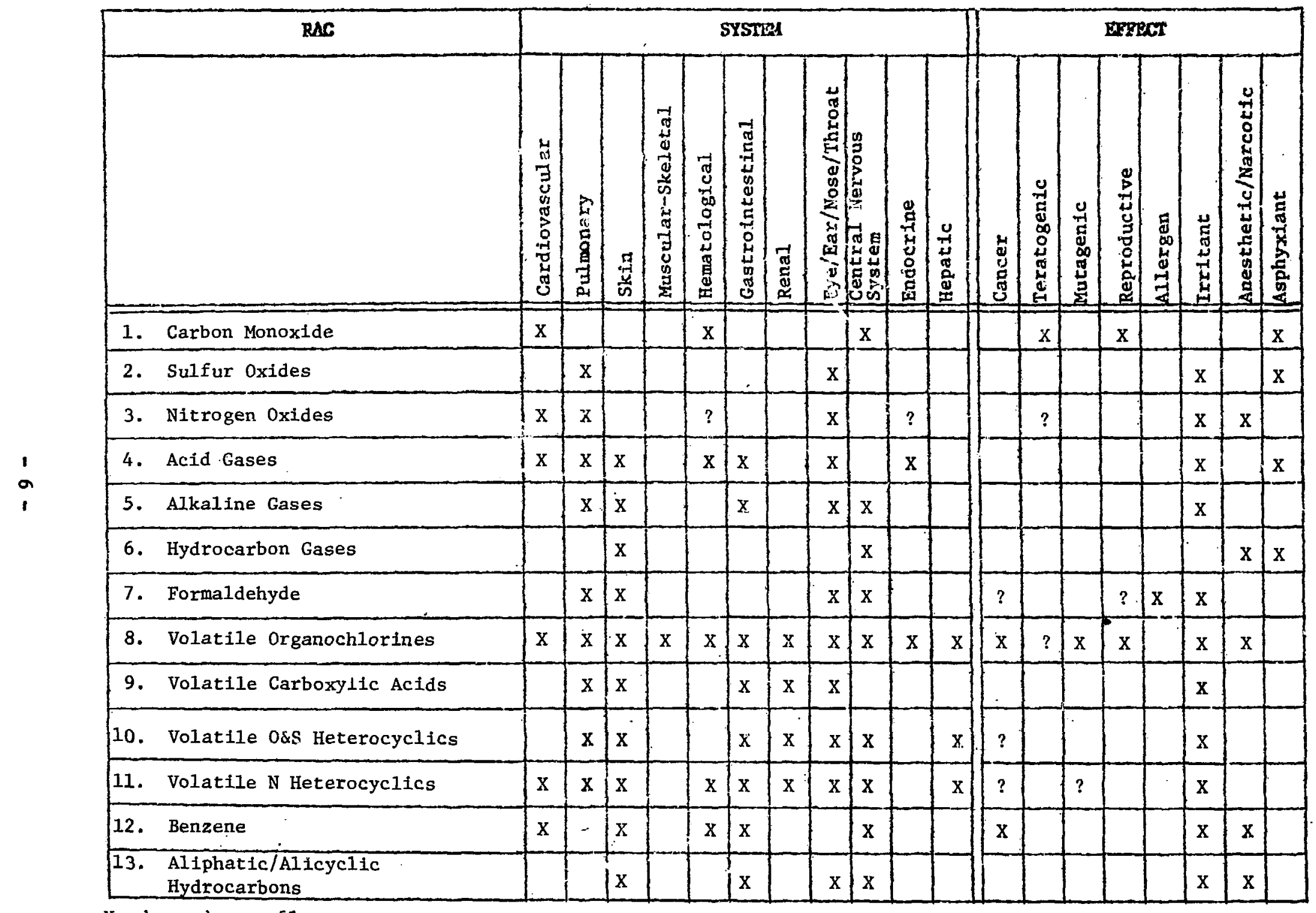

\section{$X=$ known human effect}

? = based on animal data, experience with similar compounds, or inconclusive human data 


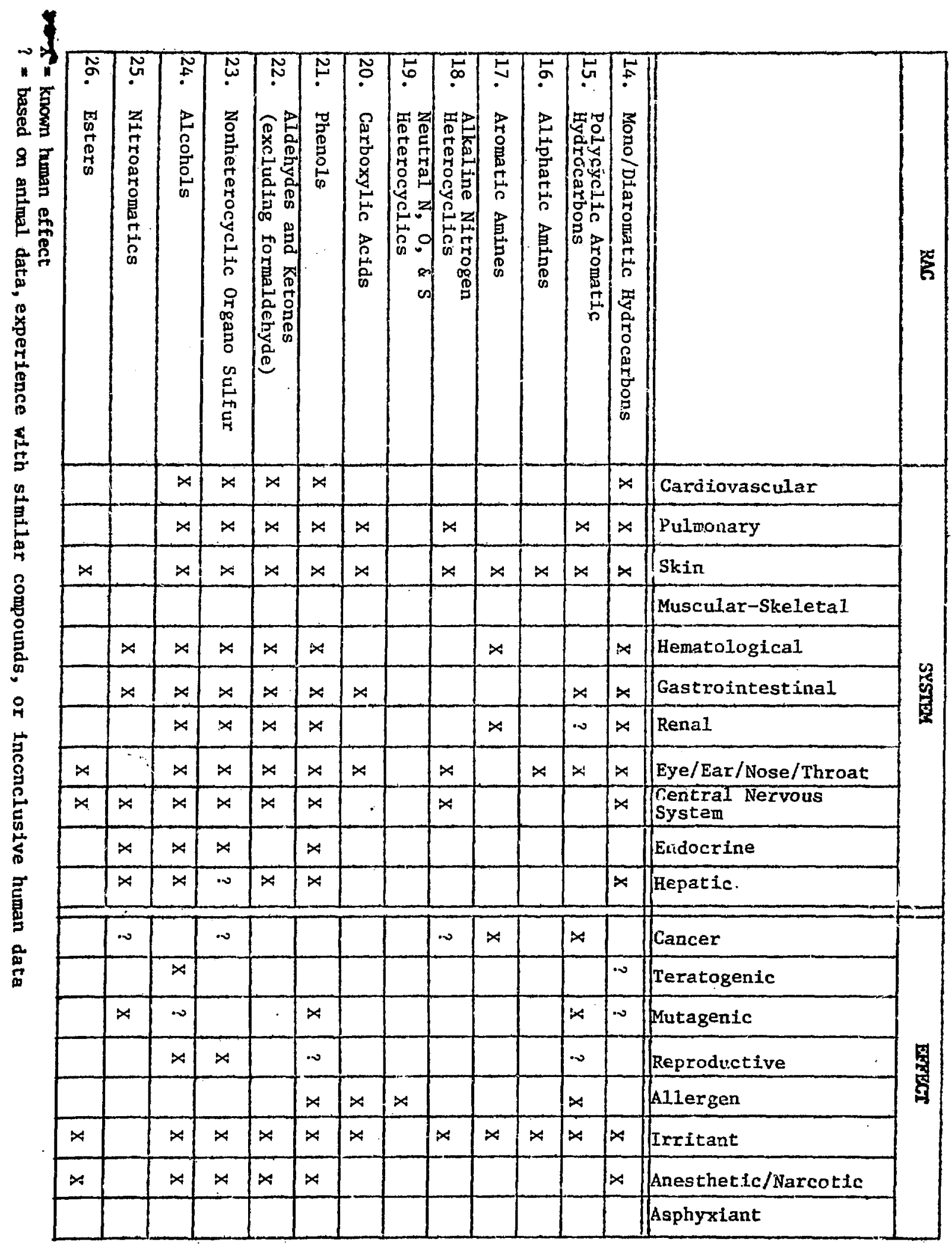




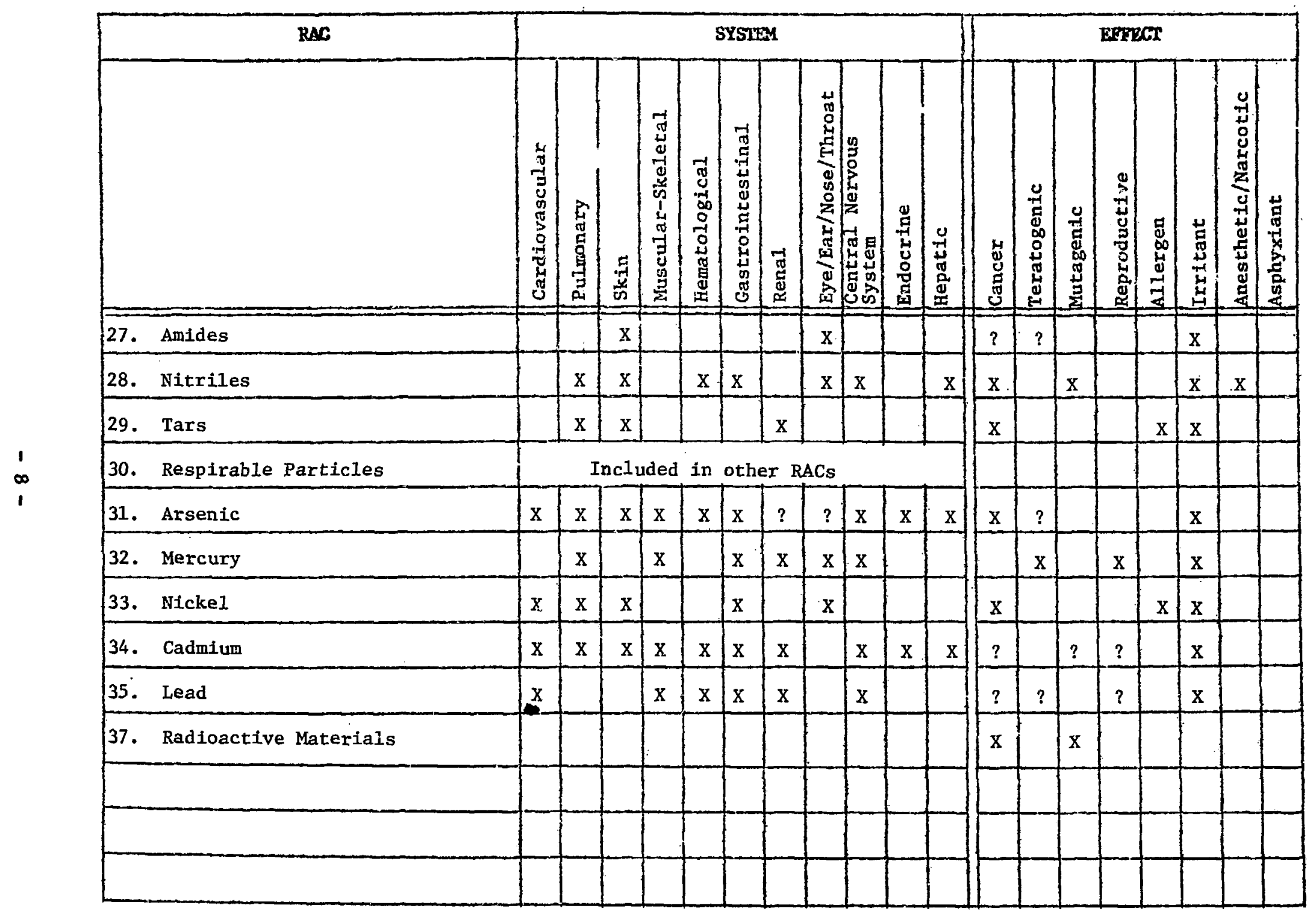


CHAPTER 3

REVIEW OF INDIVIDUAL RISK-ASSESSMENT CATEGORIES 


\section{RAC \#1 - CARBON MONOXIDE}

Overview

Carbon monoxide ( $\mathrm{CO}$ ) is produced by the incomplete combustion of hydrocarbons; it is a constituent of flue gas from coal, oil, and natural gas furnaces and of automoblle exhaust. It is a conetituent of low- and medium-Btu synthetic gas.

\section{Acute Effects}

Effects of $C O$ in humans at high levels are well known (3). These levels are occasionally experienced in occupational settirgs, in homes with unvented heaters, and in automobiles, buses, or trucks, with faulty exhaust systems. At these levels, Co acts principally by forming a complex with the hemoglobin molecule (carboxyhemoglobin), reducing the oxygen-carrying capacity of the blood as well as reducing the rate of dissociation of oxyhemoglobin to tissue. Because of its sensitivity to lack of oxygen, the brain is the most critical organ affected. Dose-response functions are wel1-defined based on occupational epidemiology and clinical experiments.

At lower concentrations ( $550 \mathrm{ppm})$, quantitative dose-response functions are more uncertain, although evidence of effects was sufficiently compelling to justify a National Ambient Air Quality Standard of $10 \mathrm{ppm}$ (10 $\mu \mathrm{g} / \mathrm{m}^{3}$ ) for an 8-hour averaging period. Effects have been repeated on vigilance, vision function and perception, and psychomotor performance. These may be mechanisms behind suggestions of increased motor vehicle injury anj fatality rates during high co periods alone or in combination with co levels from faulty exhaust systems (2).

Chronic Effects

Effects of low-level $c 0$ in amblent air have been extensively reviewed (1). Cardlovascular abnormalities have been reported in assoclation with Co exposure. Some epidemiologic studies have suggested increased mortality from myocardial infarction associated with high amblent co concentrations, although similar studies have shown no effect. Effects of co on pulmonary function have also been reported.

Low ( $<50 \mathrm{ppm}$ ) concentrations of $\mathrm{CO}$ may put principal risk on particularly sensitive groups: fetuses, persons with cardiovascular or CNS defects, sickle cell anemla, the young and the elderly, those taking 
certain drugs, and those at high altitude. At high altitude the concentration of oxygen in alr is lower (e.g., 18\% less in Denver than at sea leve1). Thus, similar concentrations of $\mathrm{CO}$ will have greater impact at high altitude. The effect of $C O$ and altitude seem to be additive, although Co hypoxia and hypoxic hypoxia are not equivalent.

co concentrations in the air are relatively easy to measure, and actual human exposure can be estimated by direct or indirect measurements of carboxyhemoglobin levels in blood (4-6).

A TLN of $50 \mathrm{ppm}$ and an STEL of $400 \mathrm{ppm}$ have been set for CO. NIOSH recommends a 35-ppm TWA and a $200 \mathrm{ppm}$ STEL to protect workers with chronic heart disease.

\section{References}

1. Environmental Protection Agency. 1979. "Effects of Low-Level Carbon Monoxide on Humans," Chapter 11 in Air Quality Criteria for Carbon Monoxide, EPA-600/8-79-022. U.S. Environmenta1 Protection Agency.

2. Goldsmith, J.R. and S.A. Landaw. 1968. Carbon monoxide and human health. Sclence 14: 1352-59.

3. Gosselin, R.E., H.C. Hodge, R.P. Smith, and M.N. Gleason, Clinclal toxicology of commercial products, pp. 86-92, The Williams \& Wilkins Co., Baltimore, MD, 1979.

4. Radford, E.N. and T.A. Drizd. 1982. Blood carbon nonoxide levels in persons 3-74 years of age: United States, 1976-1980. Advance Data from Vital and Health Statistics, No. 76. DHHS Publication No. (PHS) 82-1250. Nacional Center for Health Statistics, Hyattsille, MD.

5. Stewart, R.D., E.D. Beretta, L.R. Platte, E.B. Stewart, J.H. Kalbfleisch, B.V. Yserloo, and A.A. Rimis. 1974. Carboxyhemoglobin levels in American biood donors. J. AMA 229: 1187-95.

6. Stewart, R.D., C.L. Hake, A. Wu, T.A. Stewart, and J.H. Kalbfleisch. 1976. Carboxyhemoglobin trend in Chicago blood donors, 1970-1974 Arch. Environ. Health 21: 280-85. 


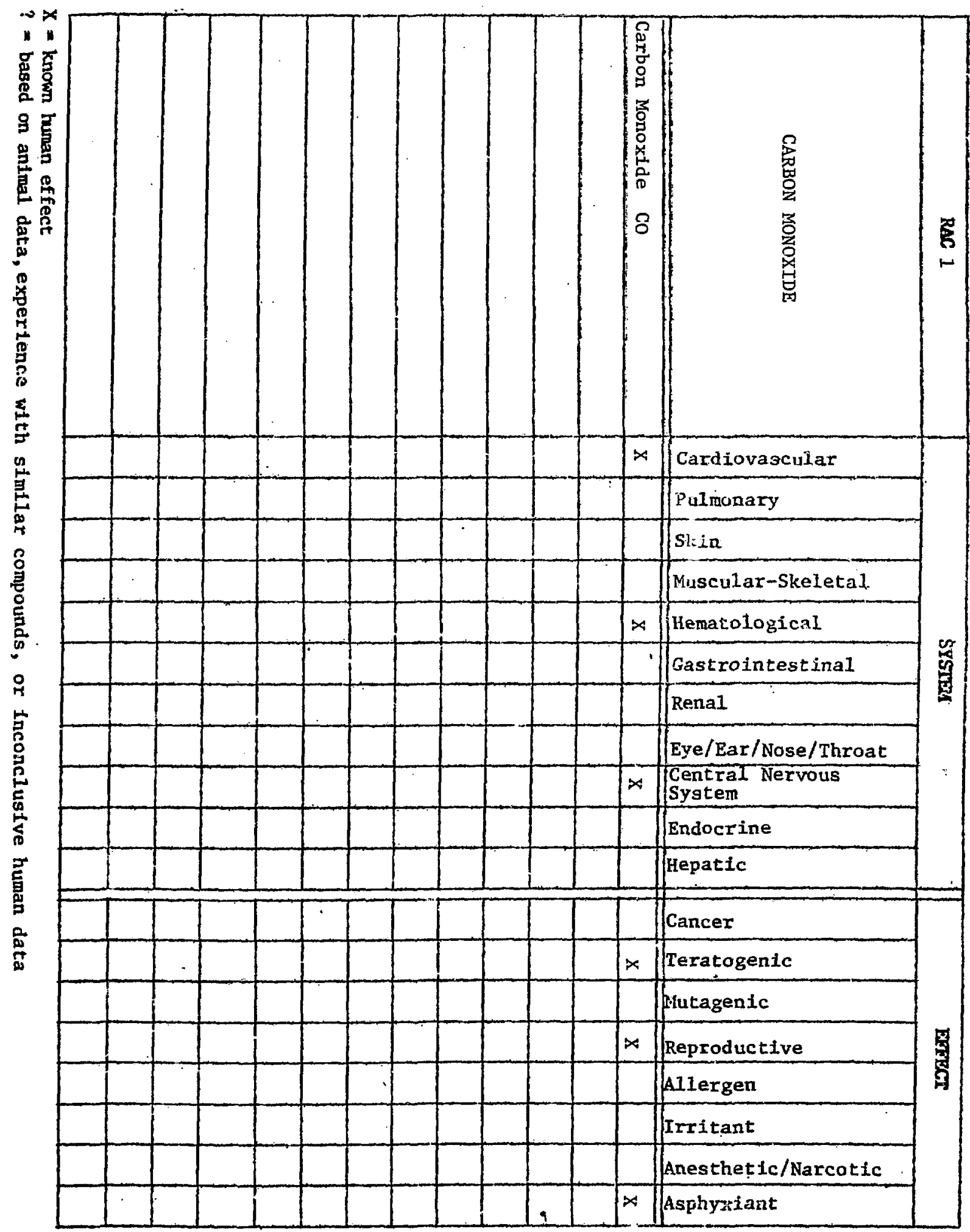


RAC \#2 - SULFUR DIOXIDE $\left(\mathrm{SO}_{2}\right)$

Overview

Sulfur dioxide is formed when materials contalining sulfur are burned (soft coal; high sulfur oil, etc.) and is thus an important air pollutant (1). It is used in smelting operations, paper manufacturing, as a bleaching, disinfecting, and fumigating agent, as a reducing agent, and as a food additive and preservative (1).

Acute Effects

Sulfur dioxide rapidly forms sulfurous actd on contact with moist mucous membrane, thereby explaining its prominent blologic effect of severe mucous membrane irritation. In concentrations above $20 \mathrm{ppm}$, marked irritant effects such as choking and sneezing occur. Exposures of 50 to $100 \mathrm{ppm}$ cause irritation of the nose and throat, resulting in rhinorrhea and cough; and may lead to reflex bronchoconstriction and an increase in bronchial mucous secretion with increased pulmonary resistance to air flow. These changes may be clinically manifested as high pitched rales and a tendency to prolongation of the expiratory phase of respiration. In human experimental studies, subjects inhaling $\mathrm{SO}_{2}$ through the mouth exhibited varying degrees of bronchoconstriction, as measured by increased pulmonary flow resistance $(9,10)$.

Exposures to 400 to $500 \mathrm{ppm}$ are life threatening when inhaled in a confined space and will probably result in asphyxia. In exposures that are high but not sufficient to cause asphyxia, a chenical bronchopneumonia may develop which can be fatal.

Sulfur dioxide gas is irritating to eyes and may produce burning discomfort and 1acrimation, but actual eye injury from exposure is rare (7). However liquid $\mathrm{SO}_{2}$ from pressurized containers has caused severe corneal burns (8). In brief exposures of 1 ppm, no effects were seen; 5 ppm caused a $40 \%$ increase in pulmonary flow resistance; and 13 ppm caused a $73 \%$ increase in pulmonary flow resistance ( 8 ).

Chronic Exposure

Chronic exposure to $\mathrm{SO}_{2}$ is widespread in 1ndustry. Most exposures have occurred with chemical mixtures containing $\mathrm{SO}_{2}$. Symptoms associated 
with low chronic exposures are: resplratory tract irritation leading to cough, epistaxis, chest constriction, and hemoptysis. In addition, nasopharyngitis, alteration in the senses of smell and taste, and increased sensitivity to other irritants may occur from chrontc occupational exposures $(2,10)$. Some sensitive individuals have developed occupational asthma after prolonged $\mathrm{SO}_{2}$ exposure (2).

Some epidemiological studies have found that in areas of increased $\mathrm{SO}_{2}$ and $\mathrm{NO}_{2}$ pollution, decreased ventilatory function was observed in children and adults. There ts also evidence that children living in areas with high atmospheric $\mathrm{SO}_{2}$ and $\mathrm{NO}_{2}$ pollution have tncreased incidence of pulmonary problems $(5,6)$.

$\mathrm{SO}_{2}$ in itself is not known to be a carcinogen, but Lee and Fromeni have suggested that $\mathrm{SO}_{2}$ may be a respiratory tumor promotor when combined with high arsenic exposures (3). Laskin et al. found an increased incidence of squamous cell carcinoma when $\mathrm{SO}_{2}$ at chronic exposure levels of 3.5-10 ppm were combined with inhaled benzo[a]pyrene (1).

A TLV of $2 \mathrm{ppm}$ and an STEL of $5 \mathrm{pm}$ have been set for $\mathrm{SO}_{2}$.

References

1. ACGIH. Documentation of the Threshold Limit Values, 4th Edition, 1980 , P. 375.

2. Fish, James E. 1982. Occupational asthma: A spectrum of acute resplratory disorders. J. Occup. Med. 24: 379-86.

3. Lee and Fromeni. 1969. Arsenic and respiratory cancer in man. An occupational study. J. Nat. Cancer Inst. 46: 1045-52.

4. Linn, W.S., D.A. Shamoo, C.E. Spier, L.M. Valencla, U.T. Anzar, T.G. Venet, and J.D. Hackney. 1982. Respiratory effects of 0.75 ppm sulfur dioxide in exercising asthmatics: Influence of upperrespirat ory defenses. Env. Res. 30: 340-8.

5. Mostard1, R.A., D.L. Ely, N.R. Woebkenber, B. Richardson, and M.T. Jarrett. 1981. The Univeraity of Akron study on air pollution and human health effects I. Methodology, baseline data, and aerometrics. (Toxline abstraction). Arch. Environ. Health. 36: 243-9. 
6. Mostard1, R.A., N.R. Woebkenberg, D.L. Ely, M. Conlon, and G. Atwood. 1981. The University of Akron study on afr pollution and human health effects II. Effects on acute respiratory 111ness. (Toxilne abstraction). Arch. Environ. Health. 36: 250-5.

7. National Library of Medicine. Toxicology Data Bank (computer search 1982).

8. Proctor, N.H. and J.P. Hughes. 1978, Chemlcal hazards of the workplace. p. 451 . J.B. Lippincott Company, PA.

9. Sheppaxd, D., J. Epste1n, R.A. Bethe1, J.A. Nadel, and H.A. Boushey. 1982. Tolerance to sulfur dioxide-induced bronchoconstriction in subjects with asthma. Env. Res. 30: 412-19.

10. U.S. Department of Health, Education, and Welfare. Narional Institute for Occupational Safety and Health. Occupational Exposure to Sulfur Dioxide, 1974, Center for Disease Control, Cincinnat1, OH. 


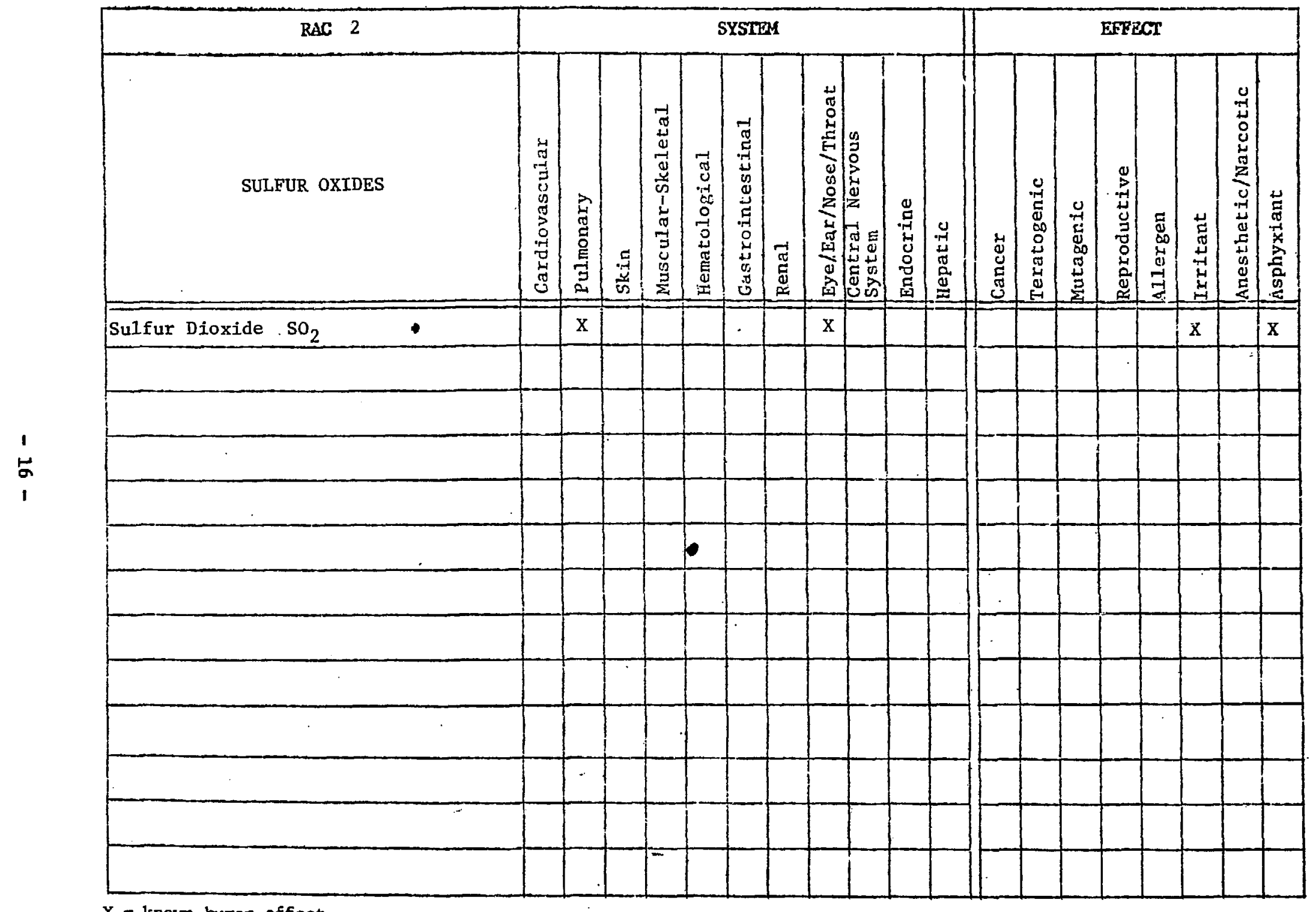

$X=$ known human effect

? = tased on animal data, experience with sfmilar compounds, or Inconclusive human data 
RAC \#3 - NITROGEN OXIDES

The term nitrogen oxides $\left(\mathrm{NO}_{x}\right)$ refers to a family of compounds which typically include: nitric oxide (NO) and nitrogen dioxide $\left(\mathrm{NO}_{2}\right)$, the two most important pollutants in the lower atmosphere; nitrous oxide $\left(\mathrm{N}_{2} 0\right)$ which occurs naturally in unpolluted air; symmetrical nitrogen trioxide $\left(\mathrm{NO}_{3}\right)$; unsymmetrical nitrogen trioxide $(0-0-\mathrm{N}-0)$; dinitrogen trioxide $\left(\mathrm{N}_{2} \mathrm{O}_{3}\right)$, dinitrogen tetroxide $\left(\mathrm{N}_{2} \mathrm{O}_{4}\right)$, and dinitrogen pentoxide $\left(\mathrm{N}_{2} \mathrm{O}_{5}\right)(10)$. NO and $\mathrm{NO}_{2}$ are the principal anthropogenically produced oxides of nitrogen and will be addressed in this $\mathrm{RAC}$. $\mathrm{NO}_{2}$, the more irritating and toxic compound, will be given the most attention.

Overview

Most of the $\mathrm{NO}_{x}$ produced is intially in the form of No which is quickly oxldized to $\mathrm{NO}_{2}$. NO, a colorless and odorless gas, is favored during high temperature combustion and is formed by interaction of the nitrogen content of fuel with amblent nitrogen and oxygen.

Nitrogen dioxide is a reddish-brown gas, formed by the action of nitric acid on reducing agents, by the combustion of nitrogenous organic material, and by the oxidation in air or oxygen oz nitric oxide. Some sources of industrial emissions of $\mathrm{NO}_{2}$ are: reaction between nitric oxide and organic materlals; metal cleaning processes; electric arc welding; electroplating, engraving, and photographic operations; dynamite blasting; diesel exhaust; and other combustion processes. High concentrations of $\mathrm{NO}_{2}$ are frequentiy present in silos where ensilage is stored. Exposure can occur both in and out of doors. The highest and most variable outdoor $\mathrm{NO}_{2}$ levels are known to be in urban areas because of traffic congestion and industrial activity. Indoor sources such as gas appliances (cooking, kerosene space heaters, dryers, etc.) contribute significantly to high exposures. Cigarette smoke also contains $\mathrm{NO}$ and $\mathrm{NO}_{2}$ and can actively or passively be a significant source of exposure. 


\section{Acute Effects}

Very high exposures to $\mathrm{NO}_{2}$ (about $300 \mathrm{ppm}$ ) occurring during Industrial accidents can cause wapld death (10). Exposure to concentrations in the 150- to 200-ppm range causes severe resplratory distress, and death is likely after 2 to 3 weeks, always by bronchitis fibrosa obliterans. Exposures to concentrations of 25 to 100 ppm cause reversible bronchiolitis, bronchitis, or bronchlal pneumonia, usually followed by complete recovery.

Episodic or peaiking concentrations of $\mathrm{NO}_{2}$ (possibly augmented by NO), have been shown to cause immediate and short-term irritaiton to sensitive subgroups of the population $\varepsilon^{n}=\mathrm{h}$ as asthmatics and individuals recovering from acute respiratory infections. Cinfical studies of the short-term effects of $\mathrm{NO}_{2}$ on human volunteers have been conducted on asthmatics, bronchitics, and healthy subjects. Functional impairment was not observed In healthy subjects or patients with bronchitis at or below $1.5 \mathrm{ppm} \mathrm{NO}_{2}$. These studies have generally shown that the sensitivity of asthmatics to irritants such as other alr'poilutants or cold alr can be heightened by short-term concentrations of $0.5 \mathrm{ppm} \mathrm{NO} 2$ or higher (7). Recovery from these effects tends to be rapid, and it is not known whather repeated exposures of this kind have any cumulative effects or predispose the lungs to permanent damage. In one controversial study, heightened sensitivity (airway reactivity) or irritation to a bronchioconstrictive aerosol has been shown for some asthmatic patients exposed to $\mathrm{NO}_{2}$ concentrations as low as $0.1 \mathrm{ppm}$ (11). One study reported healthy adults to ke unaffected by acute exposure of up to $5 \mathrm{ppn}$ (1A), whereas another study found sensitivity in healthy adults to be heightened by concentrations as low as the current outdoor ambient standard of $0.05 \mathrm{ppm} \mathrm{NO}_{2}$ (14).

Chrontc Effects

Chronic exposure to lower concentrations of $\mathrm{NO}_{2}$ has been associated with increased occurrence of acute respiratory infections in infants and children. Some scientists have hypothesized that repeated low-level exposures are also associated with chronic lung disease and increased "aging" of the lung in adolescence and adulthood $(2,3,5)$. 
Epidemiological studies of populations of en. 'ren exposed to $\mathrm{NO}_{2}$, primarily indoor air pollution, conflrm laboratory findings of reduced resistance to respiratory infection in exposed animals (8, 9, 13). Children exposed to additional quantities of $\mathrm{NO}_{2}$ (and possibly NO) fror gas combustion in stoves - in particular, children under the age of two -show significantly greater incldence of acute respiratory illness and changes in lung function than their counterparts living in homes with electric stoves. More recently, investigators have expressed less certainty concerning association between indoor exposire to $\mathrm{NO}_{2}$ from gas stoves and increased respiratory 111ness in children (G). Recent evidence from the Harvard six-clty study strengthen these later findings. The EPA estimates that repeated exposures to $1-\mathrm{hr}$ average $\mathrm{NO}_{2}$ peaks of 0.15 to 0.30 ppm may be a health problem for children under the age of two (4). Similar but less pronounced resuj.ts have been obtained for adult males (6).

In addition to 1 ts having direct health impacts, $\mathrm{NO}_{2}$ also affects sensory perception (4). It can be smelled at a concentration of $0.11 \mathrm{ppm}$, but odor detection is rapidly Impaired. Impairment of dark adaptation of the eyes has been demonstrated at concentrations as low as 0.07 to $0.08 \mathrm{ppm}$ (10). These concentrations are well within the normal range in ambient air.

Populations at special risk from $\mathrm{NO}_{2}$ exposure include children and persons with existing lung dysfunction or hay fever. Chlldren in homes with gas stoves appear to be at unusually high risk. In adcition, animal studies showing increased systemlc, hematological, and hormonal alterations after exposure to $\mathrm{NO}_{2}$ suggest that persons with cirrhosis of the liver or other liver, hormonal, and blood disorders and persons undergoing certain types of drug therapies might be at special risk (4).

Although neither $\mathrm{NO}_{2}$ nor NO has bean shown to be carcinogenic, some recent ev+usnce suggests that $\mathrm{NO}_{2}$, elther singly, in comoination with NO, or together with other ambient air pollutants, may facilitate cancer cell metastasis (12). 
A TLV of $3 \mathrm{ppm}$ and an STEL of $5 \mathrm{ppm}$ has been set for $\mathrm{NO}_{2}$ (1). A T... of $25 \mathrm{ppm}$ and an STEL of $35 \mathrm{ppm}$ has been set for NO. The National Ambient Alr quality standard (NAAQS) for $\mathrm{NO}_{2}$ (primary and secondary) has been set at $100 \mathrm{\mu g} / \mathrm{m}^{3}$ annual arithmetic mean.

References

1. ACGIH. Documentation of the Threshold Limit Values, 4th Edition, 1980.

1A. Beil, M. and W.T. Ulmer, 1976. Effect of $\mathrm{NO}_{2}$ in workroom concentrations on respiratory mechanics and bronchial sensitivity to acetylcholine in normal persons. Int. Arch. Occup. Environ. Health 38: 31 .

2. Burrows, B., J. Knudson, and M.D. Lebowitz. 1977. The relationshlp of childhood respiratory illness to adult obstructive atrway disease. Am. Rev. Respir. Dis. 115(5): 751-60.

3. Burrows, B. and L.M. Taussig. 1980. As the tree is bent, the tree Inclines (perhaps). Am. Rev. Respir. Dis. 122(6): 813-16.

4. EPA. 1979. Alr quality criterla for nitrogen oxides. External review draft. Environmental Criteria and Assessment Office, Research Trlangle Park, NC.

5. Holland, W.W., P. Barley, and J.M. Bland. 1978. Long-term consequences of respiratory disease in infancy. J. Epidemiology Community Health 32: 256-9.

6. Kelier, M.D., R.R. Lanese, R.I. Mitchell, and R.W. Cote. 1979. Respiratory illness in households using gas and electricity for cooking. I. Survey of Incidence. Environ. Res. 19: 495.

7. Kerr, H.D., T.J. Kulla, M.L. McIlhany, and P. Swldersky. 1979. Effect of nitrogen dioxide on pulmonary function in human subjects: An environmental chamber study. Environ. Res. 19: 392.

8. Mella, R.J.W., C.duv. Florey, D.S. Altman, and A.V. Swan. 1977. Association between gas cooking and respiratory disease in children. Brit. Med. J. 2: 149 .

9. Mella, R.J.W., C.duV . Florey, R.W. Morris, B.D. Goldsteln, H.H. John, D. Clark, I.B. Craighead, and J.C. Mackenlay. 1982. Childhood respiratory 111ness and the home environment. II. Association between respiratory 11lness and nitrogen dioxide, temperature and relative humidity. Intern. J. of Epidemiology 11(2): 64-9.

10. National Academy of Sciences. Medical and blological effects of environmental pollutants: nitrogen oxides. NAS, Washington, DC. 
11. Orehek, J. J.P. Massar1, P. Gayrand, C. Grimand, and J. Charpin. 1976. Effect of short-term, low-level nitrogen dioxide exposure on bronchial sensitivity of asthmatic patients. J. Clin. Invest. 57: 307.

12. Richters, A. and V. Richters, 1983. A new relationship between air pollutant and inhalation and cancer. Arch. Env. Health 83: 2.

13. Speizer, F.E., B. Ferris Jr., Y.M.M. Bishop, and J. Spengler. 1980. Respiratory disease rates and pulmonary function in children associated with $\mathrm{NO}_{2}$ exposure. Am. Rev. Respir. Dis. 121: 3 .

14. VonNeiding, G. and H.M. Wagner. 1979. Effects of $\mathrm{NO}_{2}$ on chronic bronchitis. Environ. Health Perspec. 29: 137. 


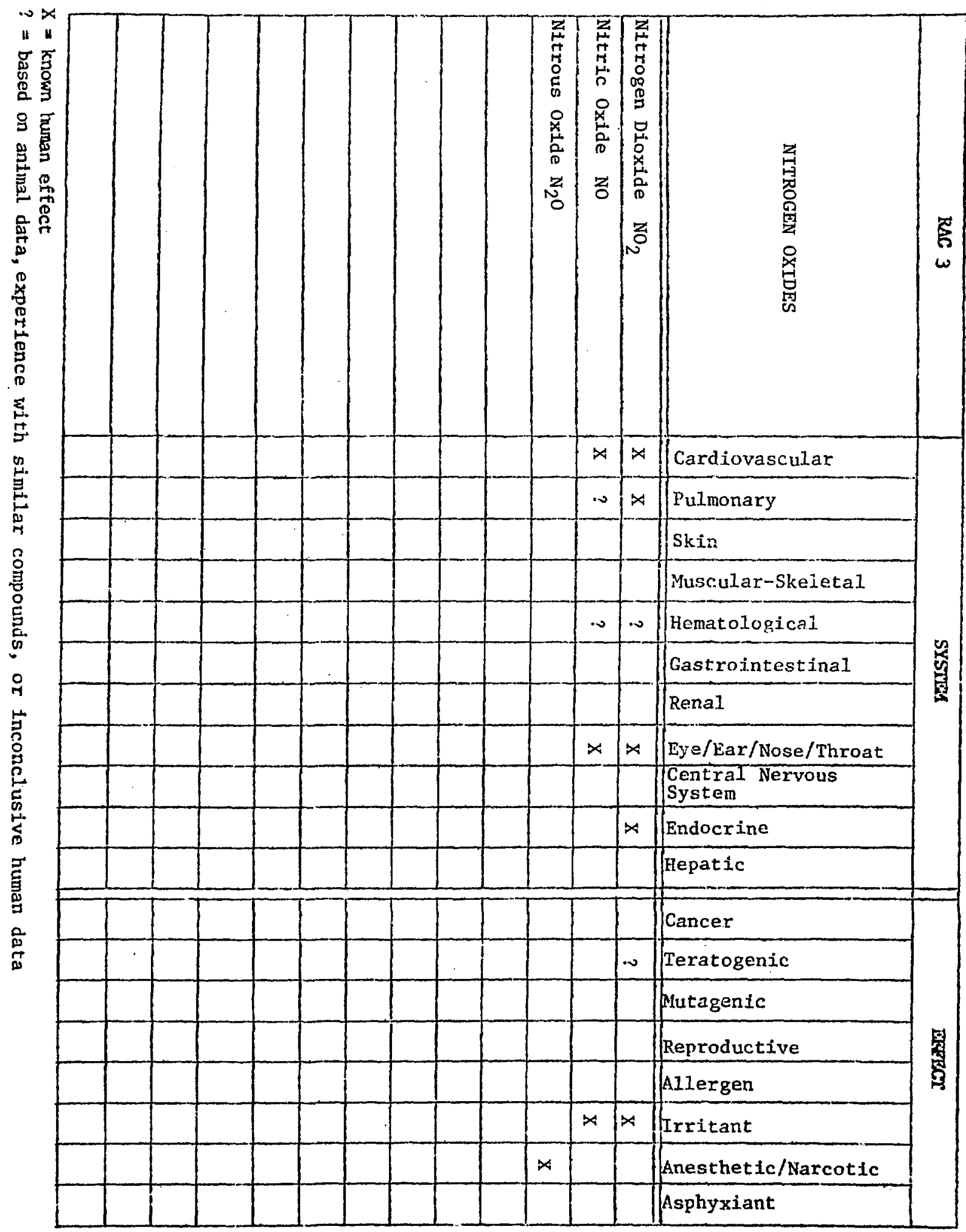


RAC $\$ 4$ - ACID GASES

The two compounds reviewed in this RAC are hydrogen sulfide and hydrogen cyanide.

Hydrogen Sulfide $\left(\mathrm{H}_{2} \mathrm{~S}\right)$

Overview. Hydrogen sulfide is a constituent of petroleum, natural gas, sewer gas, and soil. It is also a by-product of viscose rayon production and certaln leather tanning processes. It is widely used as a chemical reagent in the manufacture of heavy water. Hydrogen sulfide is also a source of elemental sulfur (5).

Acute Effects. In low concentrations (50 to $200 \mathrm{ppm}$ ) hydrogen sulfide is primarily a respiratory and eye irritant (1, p. 225). Prolonged exposures above $250 \mathrm{ppm}$ are likely to result in pulmonary edema, and exposures of 500 to $1000 \mathrm{ppm}$ may cause severe respiratory distress. Concentrations above $1000 \mathrm{ppm}$ are usually fatal within minutes owing to respiratory paralysis $(1,4)$. Even, though $\mathrm{H}_{2} \mathrm{~S}$ has, a recognizable disagreeable odor, olfactory paralysis occurs at levels above $150 \mathrm{ppm}$. Therefore the sense of smell may not be a good indicator of the presence of high atmospheric levels of $\mathrm{H}_{2} \mathrm{~S}(4)$.

Subjects exposed to low levels of $\mathrm{H}_{2} \mathrm{~S}$ have reported various Central Nervous System (CNS) symptoms such as headache, nausea (with occasional vomiting and diarrhea), dizziness, confusion, and weakness of the extremities. If exposure continues, unconciousness will eventually result (7-9). Survivors of acute toxic episodes sometimes show neurologic sequelae such as amnesia, tremor, neuroasthenia, disturbances of equilibrium, and, in rare instances, brain stem damage.

Exposures to levels above 50 ppm can produce pain in the eyes, conjunctivitis, lacrimation, and photophobia. In prolonged exposures keratoconjunctivitis ("gas eye") may occur. This is a cormon occurrence among tunnel, caisson, and sewer workers. It manifests itself several hours or days after exposure as a scratchy irritating sensation with tearing or burning of the eye. In more serious exposures, vesiculation of the corneal epithelium may occur $(4,8)$. 
Direct contact with the skin may produce erythema and pain. $\mathrm{H}_{2} \mathrm{~S}$ can also penetrate the skin and cause toxic symptoms in those exposed to low concentrations over long periods of time.

Chronic Effects. In a study by Bernardini et al. (2), workers exposed to $\mathrm{H}_{2} \mathrm{~S}$ exhibited a high incldence of upper airway inflammations. Gastrointestinal complaints were common, and erosion of dental crowns was observed (2). Other effects of chronic exposures include headache, eye symptoms (irritation, tearing), digestive disturbances, sleep disturbances, cardiac arrhythmias, and general disabilities (7-9).

A TLV of $10 \mathrm{ppm}$ and an STEL of $15 \mathrm{pPm}$ have been set for $\mathrm{H}_{2} \mathrm{~S}$ based on the finding that eye irritation has been reported at $20 \mathrm{ppm}$ (1).

Hydrogen Cyanide (HCN)

Overview. Hydrogen cyanide is used as a chemical reagent in the manufacture of synthetic fibers, plastics, cyanide salts, and nitrates. It may be produced during the refining of petroleum, electroplating, metallurgy, and photographic development (1). Hydrogen cyanide is used as a fumigant and traces of HCN are found in tobacco and various foods (1).

Acute Effects. In acute doses above $100 \mathrm{ppm}$, cyanide acts as a protoplasmic poison combining with methemoglobin to form cyanmethemoglobin, causing death through asphyxiation. Suspension of tissue oxidation lasts only while cyanide is present in the system, and its effects are reversible upon removal.

Various physiologic responses to $\mathrm{HCN}$ concentrations include the following $(1,3$, and 6$)$ :

$\begin{array}{ll}0.1-0.9 \mathrm{ppm} & \text { no effect } \\ 0.2-5.0 \mathrm{ppm} & \text { odor threshold } \\ 10 \mathrm{ppm} & \text { threshold limit value } \\ 4.5-18 \mathrm{ppm} & \text { headache and vertigo } \\ 18-36 \mathrm{ppm} & \text { slight symptoms after several hours } \\ 45-54 \mathrm{ppm} & \text { tolerated } 1 / 2 \text { to } 1 \text { hour without effect } \\ 110-135 \mathrm{ppm} & \text { fatal } 1 / 2 \text { to } 1 \text { hour after exposure or 11fe } \\ & \text { threatening }\end{array}$


$135 \mathrm{ppm}$

fatal within 30 minutes

$181 \mathrm{ppm}$

fatal within 10 minutes

270 ppm

Imediately fatal

Ingested, the oral lethal dose is probably less than $5 \mathrm{mg} / \mathrm{kg}$ body weight. Less than 7 drops can constitute a facal dose for a 70-kg person (3).

Chronic Effects. Workers exposed to HCN in the electroplating industry have complained of dermatitis and irritation of the nose, occasionaily leading to obstruction, bleeding, and perforation of the nasal septum. Reports of chronic Intoxication to HCN exist, but they are limited and based on subjective symptoms such as headache, weakness, changes in taste and smell, throat irritation, vomiting, dyspnea, lachrymation, abdominal colic, precordial pain, and nervousness. Enlargement of the thyroid gland has been observed by a few investigators in workers using cyanide salts. However, many Investigators deny any HCN chronic effects and reports of chronic cyanide polsoning are rare (7-9).

A TLV of $10 \mathrm{ppm}$ has been set for hydrogen cyanide.

\section{References}

1. ACGIH. 1980. Documentation of the threshold 1imit values. Fourth Edition. American Conference of Governmental Industrial Hygienists Inc., OH.

2. Bernardini, P., T. Langlano, F. Vinci, A. Gogglamani, and G. Albertino. 1980. Hydrogen sulfide occupational disease. (Toxline abstraction). G. Ital. Med. Lav. 2: 233-8.

3. EPA. 1981. Hydrogen Cyanide Health Effects. Prepared for the Environmental Protection Agency by the Midwest Research Institute, Kansas City, MO.

4. Gosselin, R.E., H.C. Hodge, R.P. Smith, and M.N. Gleason. 1979. Clinical toxicology of commercial products. The Williams \& Wilkins Co., MD, pp. 86-92.

5. Kirk, R.E. 1978. Kirk-Othmex Encyclopedia of chemical :echnology. Third Edition. John Wiley \& Sons, NY.

6. National Library of Medicine. Toxicology Data Bank (computer search 1982). 
7. Patty, F.A. 1982. Patty's industrlal hyglene and toxicology, 2A, 2B, 2C. Third Revised Edition. John Wiley \& Sons, NY.

8. Proctor, N.H. and J.P. Hughes. 1978. Chemical hazards of the workplace. J.B. Lippincott Company, PA.

9. Sax, N.I. 1975. Dangerous properties of industrial materials. Fourth Edition. Van Nostrand ReInhold Company, NY. 


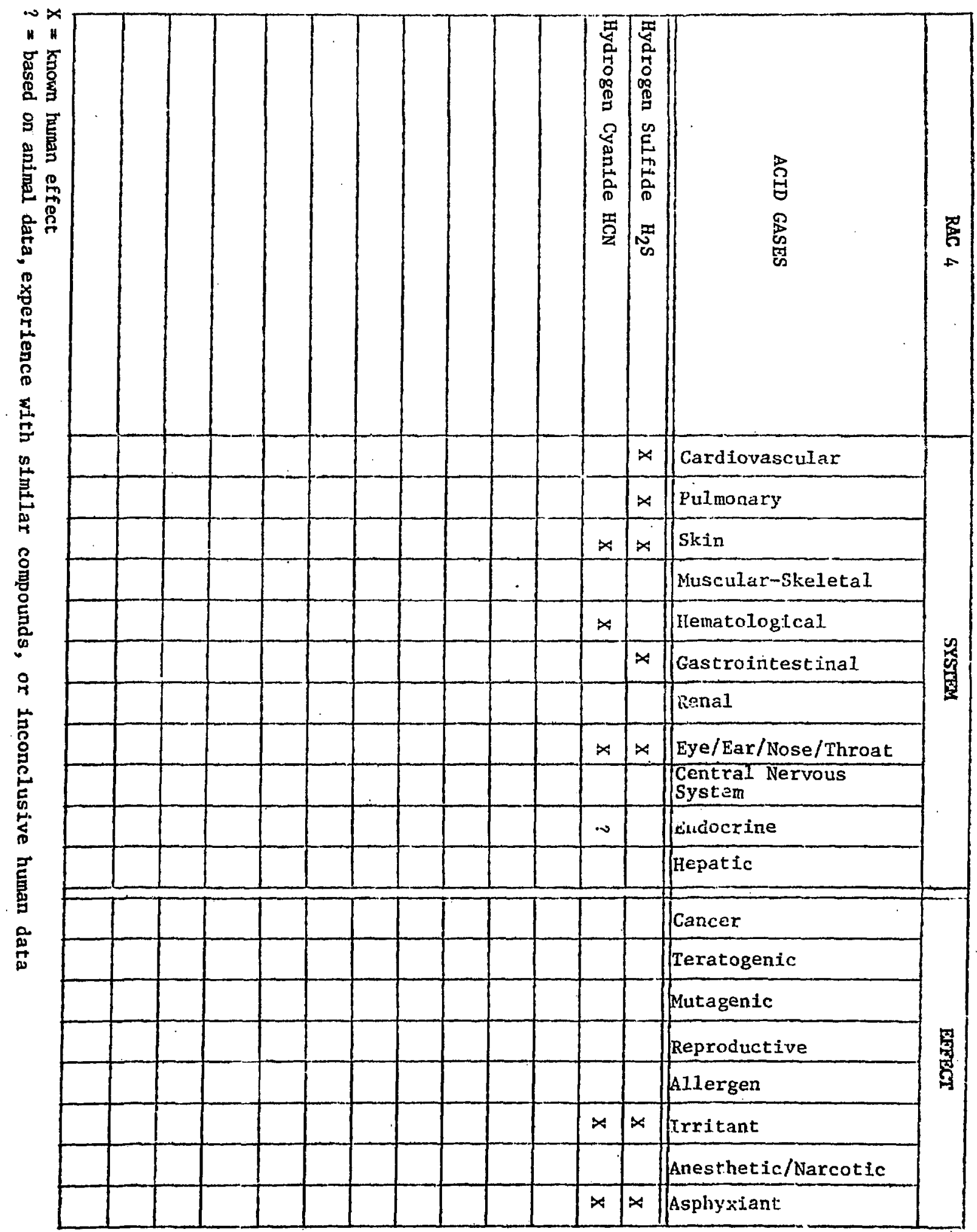




\section{RAC *5 - AIKAIIINE GASES}

Ammonia is the only gas considered under RAC $* 5$. Ammonia is a colorless gas that is irritating to eyes, respiratory tract, and skin. Exposure to high air concentrations $(2500$ to $6500 \mathrm{ppm})$ can produce fatal respiratory effects, while in an occupational setting, 4 to $29 \mathrm{ppm}$ produced "barely noticeable" irritation (5, p. 101). Carson et al. (1) conclude that $0.32 \mathrm{mg} / \mathrm{m}^{3}$ is the lowest concentration at which effects have been observed in human experimental exposure. These effects include decreased eye sensitivity to light and changed cortical activity. They report experiments in which some people could perceive odor at slightly higher levels $\left(0.45 \mathrm{mg} / \mathrm{m}^{3}\right)$.

Ingestion of ammonia solutions produce effects characteristic of corrosive alkalls and even small amounts (a few $\mathrm{ml}$ ) have been recorded as a fatal oral dose, although a few hundreds of $\mathrm{ml}$ of 5 to $10 \%$ solution have been tolerated (2).

Gosselin (2, p. 20) claims ammonia does not produce signs of systemic intoxication and has no significant cumulative effect. Biologic defects can cause accumulation of ammonia leading to ammonia toxicity (4). Some cumulative effects have been reported, however. Ferguson et al. (3) observed dose-dependent changes in respiratory function in a six-week experiment with concentrations of 18 to $72 \mathrm{mg} / \mathrm{m}^{3}$. A number of epidemiological studies have reported adverse effects of chronic exposure to low alrborne concentrations of ammonia (e.g., hyperemia of the conjunctiva and eyelids, headache, $108 s$ of appetite, chronic fatigue, and complaints of varlous respiratory disorders). Most studies, however, were of populations with concurrent exposure to other irritating air pollutants (e.g., nitrogen dioxide), had poor ammonia exposure estimates, and lacked adequate control populations or even adequate characterization of the population studied (4, Pp. 7-25).

Ambient air concentrations of ammonia are much lower than those at whicin any effects have been observed. Rural ground-level concentrations exhibit strong seasonal variations due to bacterial activity but range from 7 to $20 \mathrm{\mu g} / \mathrm{m}^{3}$ (10 to $30 \mathrm{ppb}$ ). Urban amonia concentrations are higher, 10 to $60 \mu \mathrm{g} / \mathrm{m}^{3}$ in the U.S. and over $100 \mu \mathrm{g} / \mathrm{m}^{3}$ in some European cities (4). 
Currently available evidence is inadequate even to conclude that there are human health effects of small Incremental exposures to amonta at these low ambient levels.

References

1. Carson, B.L., C.M. Beall, H.V. E1lis III, and L.H. Baker. 1981. Amonia health effects (IPA 460/3-81-027). Midwest Research Institute, Kansas City, Mo.

2. Gosselin, R.E., H.C. Hodge, R.P. Smith, and M.N. Gleason. 1979. Clincial toxicology of commercial products. The Williams o Wilkins Co., MD.

3. Ferguson, W.S., W.C. Koch, L.B. Webster, and J.R. Gould. 1977. Human physiological response and adaption to ammonia. J. Occup. Med. 19: 319-26. As reported in Carson et al., 1981, p. 6.

4. NAS Subcommittee on Ammonia, Committee on Medical and Biologic Effects of Environmenta1 Pollutants. 1977. Ammonia (EPA-600/1-77-054). National Academy of Sciences, Washington, DC.

5. Proctor, N.H. and J.P. Hughes. 1978. Chemical hazards of the workplace. J.B. Lippincott Company, PA. 


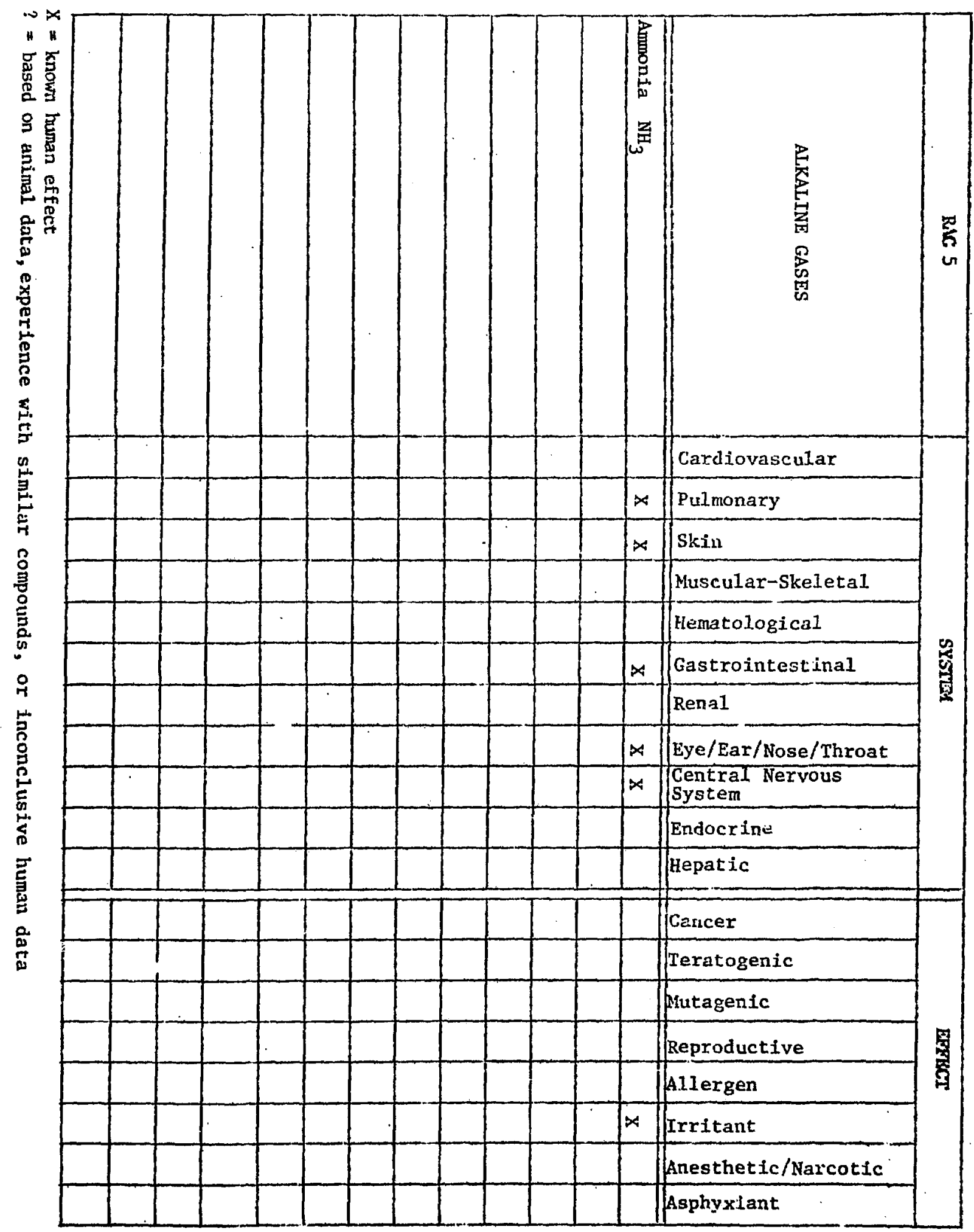


RAC \#6 - HYDROCARBON GASES

Hydrocarbon gases include aliphatic hydrocarbons with the carbon chain ranging from $C_{1}$ to $c_{4}$. They are divided Into alkanes (carbon chains with no double bonds), alkenes (one or more double bonds), and alkynes (triple bonds). Allphatic hydrocarbons are all colorless flammable gases.

No adverse health effects were found for this group of compounds in subjects exposed to low atmospheric levels of hydrocarbon gases. High concentrations of hydrocarbon gases can dilute the oxygen in the air to levels which will not support life, thereby causing asphyxia. In RAC \#6, the following compounds were reviewed.

Alkanes (Saturated Hydrocerbons)

Alkanes occur as constituents of natural gas. Beginning with propane through octane-saturated hydrocarbons show increasingly strong narcotic properties.

Methane $\mathrm{CH}_{4}$

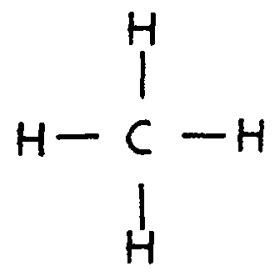

Methane is widely distributed in nature. American natural gas is composed of 65 to $95 \%$ of methane.

Methane is found in coal deposits and is released during mining operations. It is highly flammable and can form explosive mixtures in underground mining operations. Methane gas produced by the decomposition of organic matter is called "marsh gas" when it is produced during the decay of vegetation in stagnant waters. Methane is the principal constituent of natural gas. Relatively small amounts of methane are produced as a by-product of the petroleum process. Its largest use is in the production of ammonia, methanol, and acetylene.

Methane in high concentrations is a simple asphyxiant. 
Ethane (Bimethyl; Dimethy 1 ) $\mathrm{CH}_{3}-\mathrm{CH}_{3}$<smiles>CC</smiles>

Ethane is also a constituent of natural gas (about 0.8 to $9 \%$ ). Its most important commercial use is in the production of ethylene. It has been used as a feedstock for the production of vinyl chloride (3, p. 909).

Ethane can be tolerated in relatively high concentrations of inspired air without producing systemic effects. If concentrations are high enough to dilute or exclude oxygen, however, asphyxia will result.

Propane (D1methy1 Methane) $\mathrm{CH}_{3}-\mathrm{CH}_{2}-\mathrm{CH}_{3}$<smiles>CCC</smiles>

Propane is used in the production of ethylene, and as fuel gas (usually liquefied in pressurized vessels) sometimes mixed with butane. Propane is also used in organic syntheses and as a refrigerant.

Brief exposure to $10,000 \mathrm{ppm}$ causes no symptoms in man. Odor is not detectable below 20,000 ppm. A concentration of $100,000 \mathrm{ppm}$ (10\%) will produce slight dizziness $(5,6)$. At very high concentrations, propane is an asphyxiant $(1,2)$.

Butane $\mathrm{C}_{4} \mathrm{H}_{10}$<smiles>CC</smiles>

Butane has two isomeric forms: n-butane $\mathrm{CH}_{3}-\mathrm{CH}_{2}-\mathrm{CH}_{2}-\mathrm{CH}_{3}$ and isobutane $\left(\mathrm{CH}_{3}\right)_{3} \mathrm{CH}$. It occurs in petroleum and in natural gas. It is a component of high octane liquid fuels. It is used as a food additive and as a propellant for aerosols. 
Butane, 1ike other homologs in the straight chain hydrocarbons, is relatively nontoxic. Butane has simple asphyxiant, irritant, and anesthetic properties at high concentrations, No known adverse health effects have been demonstrated from low level exposures. Subjects exposed to $10,000 \mathrm{ppm}$ ( $1 \%$ concentrations) reported feeling drowsy, but no evidence of other systemic effects were noted $(1, p .51)$.

Because of their extreme flamability, butanes necessitate handling and storage precautions. A TLV of $800 \mathrm{ppm}$ has been recommended for butane. Alkenes (Hydrocarbons With Double Bond)

Ethylene (Ethene) $\mathrm{CH}_{2}=\mathrm{CH}_{2}$<smiles>C=C</smiles>

Ethylene is a colorless flammable gas. It is a compound in illuminating gas, and a by-product of coke oven gas. In the chemical Industry ethylene is a "feedstock" for a varlety of petrochemical products, such as olefins. In agriculture it has been used as a ripening agent for fruits and vegetables and as a herbicide for witchweed ( $3, p .423)$.

Ethylene is nonirritating to the eyes and respiratory system. It quickly diffuses when released into the atmosphere. At very low concentrations, $2.7 \%$, a flammable mixture is formed ( 3, p. 422).

No adverse long-term health effects have been reported from the temporary inhalation of low levels of ethylene gas. At high levels, it is a simple asphyxiant. Skin contact with liquid ethylene may cause frostbite (4).

Propylene (Propene) $\mathrm{CH}_{2} \approx \mathrm{CH}-\mathrm{CH}_{3}$<smiles>C=CC</smiles>

Propylene is a flammable gas obtained from petroleum oils during gasoline refining. It can also be obtained by dehydrogenation of propane. 
Propylene is used in polymerized form as polypropylene, a thermal plastic material, and as a raw material in the manufacture of other chemicals.

Propylene is a simple asphyxiant. High corcentrations cause unconsclousness.

Butylene (Butene) $\mathrm{C}_{4} \mathrm{H}_{8}$<smiles>C=CCC</smiles><smiles>C/C=C\C</smiles>

Butylene occurs in two isomeric forms as 1-butene ( $\alpha$-butene) $\mathrm{CH}_{3}-\mathrm{CH}_{2}-\mathrm{CH}=\mathrm{CH}_{2}$ and 2-butene ( $\beta$-butene) $\mathrm{CH}_{3}-\mathrm{CH}_{-}=\mathrm{CH}-\mathrm{CH}_{3}$. Both form/3 are gases and occur in coal gas and in petroleum oll.

No known adverse health effects have been reported in the literature from low level exposures to 1-butene and 2-butene. In high concentrations they act as weak anesthetics and asphyxiants. Because of flammability hazards, the maximum permissible workroom atmosphere concentration for elther compound is $4000 \mathrm{ppm}$ (4).

Isobutylene (Isobutene; 2-Methyl Propane) $\mathrm{CH}_{2}=\mathrm{C}\left(\mathrm{CH}_{3}\right)_{2}$<smiles>C=CCC</smiles>

Isobutylene is a highly flammable gas which forms an explosive mixture when mixed with air and oxygen. It is obtained from refinery streams. It is primarily used to produce butylene polymers. In high concentrations isobutylene is a weak anesthetic and an asphyxiant.

Alkynes (Hydrocarbons With Triple Bond)

Acetylene (Ethyne) $\mathrm{CH} \equiv \mathrm{CH}$

$$
\mathrm{H}-\mathrm{C} \equiv \mathrm{C}-\mathrm{H}
$$


Acetylene is a highly flammable gas manufactured from calcium carbide and water. It is used as an illuminant, in oxyacetylene welding and cutting metals, and in the manufacture of acetaldehyde.

Acetylene in high concentrations acts as an asphyxiant. Patty reports that subjects inhaling $100,000 \mathrm{ppm}$ ( $10 \%$ concentration) showed slight intoxicant effects. Marked intoxicution has been reported at $200,000 \mathrm{ppm}$ (20\% concentration), incoordination at $300,000 \mathrm{ppm}$ ( $30 \%$ concentration), and unconsclousness after a 5-minute exposure to 350,000 ppm (35\% concentration). Symptoms of acetylene gas exposure are readily reversible once the person is removed from the contaminated atmosphere.

Dizziness, headache, and mild gastric symptoms have been reported by subjects exposed to acetylene vapors, but these symptoms are thought to be due to the impurities found in comercial acetylene $(4,7)$.

Propyne (Methy1 Acetylene) $\mathrm{CH}_{3} \mathrm{C}=\mathrm{CH}$<smiles>C#C</smiles>

Propyne is a colorless gas with a sweet odor.

Experiments on animals indicate that methyl acetylene has a low toxicity. A TLV of $1000 \mathrm{ppm}$ has been suggested (1).

References

1. ACGIH. 1980. Documentation of the threshold 1imit values. Fourth Edition. American Conference of Governmental Industrial Hygienists Inc., $\mathrm{OH}$.

2. Hag, M.Z. and A.Z. Hameli. 1980. A death involving asphyxiation from propane inhalation. J. Forensic Sc1. 25: 25-8.

3. Kirk, R.E. 1978. Kirk-Othmer Encyclopedia of chemical technology, Volume 1, Third Edition. John Wiley \& Sons, NY.

4. Nationat Library of Medicine. Toxicology Data Bank (computer search 1982).

5. Patty, F.A. 1982. Patty's industrial hyglene and toxicology, Volumes 2A, 2B, and 2C. Third Revised Edition. John Wiley \& Sons, NY.

6. Proctor, N.H. and J.P. Hughes. 1978. Chemical hazards of the workplace. J.B. Lippincott Company, PA.

7. Sax, N.I. 1975. Dangerous propertles of industrial materials. Fourth Edition. V an Nostrand Reinhold Company, NY. 


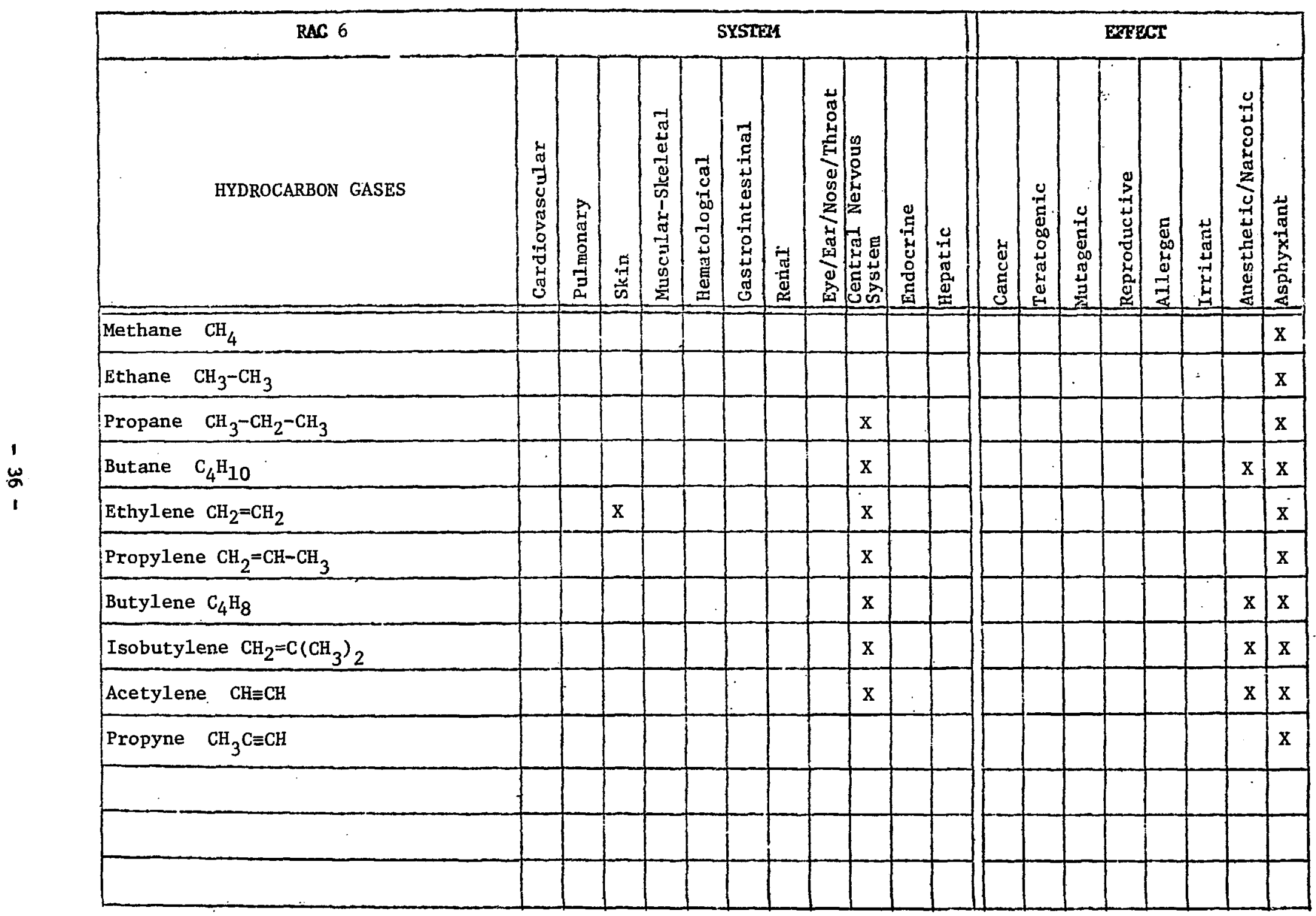

$X=$ known twiman effect

? = based on animal data, experience with similar compounds, or inconclusive human data 
RAC \#7 - FORMALDEHYDE

Formaldehyde (HCHO) is a colorless gas with a pungent odor highly irritating to the eyes, nose, and upper respiratory tract. Recent concern with formaldehyde stems from symptoms reported by people exposed to outgassing of formaldehyde from urea-formaldehyde foam insulation and phenol-formaldehyde resins in particleboard or plywood.

Extensive reviews were carried out on the health effects of formaldehyde by the National Academy of Sciences Comittee on Aldehydes (13) and by the Midwest Research Institute (5) in 1981. This report relies primarily on those reviews. There is a substantial amount of human 1iterature on Irritant and respiratory effects of formaldehyde. Although no quantitative dose-response function for such effects is in use, sufficient information is avallable for its development if needed. Several studies have been initiated, but insufficient human daca are currently avallable on carcinogenic or reproductive effects for the development of dose-response functions.

Formaldehyde is a skin irritant and skin sensitizer. Allergic contact dermatitis from contact with formaldehyde resin or formaldehyde dust is relatively common (1). In general, no other effects have been reported in humans below alrborne concentrations of $0.05 \mathrm{ppm}$. Beginning at this level, changes in laboratory tests of neurophysiologic effects (EEG alterations and changes in the sensitivity of the eye to adapt to light) have been observed. Some people can percelve the odor of formaldehyde at this concentration, and there are reports of eye irritation at $0.05 \mathrm{ppm}$, but, in general, odor perception and nose, throat, and bronchial irritation begin at about $1 \mathrm{ppm}$. It has been estimated that 10 to $20 \%$ of the population is sensitive to concentrations of formaldehyde below $1 \mathrm{ppm}$ and bronchial asthma has been reported after prolonged exposure to the "vapors of formaldehyde. Severe pulmonary reactions (pneumonta, pulmonary edema) occur at concentrations exceeding $50 \mathrm{ppm}$. The severity of the effect seems to be dose related (13). Evaluation of pulmonary function by spirometry and nitrogen washout suggests that exposure to formaldehyde causes bronchoconstriction (3). Inhalation exposure of workers to phenol, formaldehyde, and melamine adhestves resulted in a significant increase in high-density lipid cholestero1 (14). 
Ambient outdoor concentrations of formaldehyde are usually less than $0.05 \mathrm{ppm}$ and rarely exceed $0.1 \mathrm{ppm}$. Over 11 million people $11 \mathrm{ve}$ in homes with either urea-formaldehyde foam insulation or particleboard made with urea-formaldehyde resins. The concentrations of formaldehyde most commonly reported in such homes range from 0.1 to $0.2 \mathrm{ppin}$ (13). Thus, additional exposure to people with such backgrounds might increase irritant and respiratory effects.

The National Academy of Sciences Committee on Aldehydes reported no evidence of formaldehyde causing cancer or reproductive effects in man, but production of nasal cancer in mammals and reproductive effects in nonmammalian systems have raised such concerns $(2,13)$.

Studies on human cells in vitro demonstrated that formaldehyde induced DNA single-strand breaks in human fibroblasts and in bronchial cells $(6,7,9)$. Growing human fibroblasts exposed to $2 \mathrm{mM}$ formaldehyde for 15 minutes showed quantitative and quantative effects comparable to those produced. $7 \mathrm{x}$-ray dose of $100 \mathrm{rad}$ (11). Formaldehyde-induced mutations and chromosomal damage were observed in human lymphoblasts and lymphocytes $(8,12)$. Mutations were also recognized in Salmonella typhimurium in a forward mutation assay (8-oxaguanine resistance) but not in the standard Ames test (4). Some epidemiological studies have linked formaldehyde exposure to cancers of skin, larynx, oral cavity, nasal cavity, liver, and lung, but there seems to be general agreement with the International Agency for Research on Cancer that "... epidemiological studies provide inadequate evidence to assess the carcinogenicity of formaldehyde in man." (10).

References

1. Agathos, M. and H.A. Bernecker. 1982. Hand dermatitis in medical personnel. (Toxline abstract). Derm. Beruf. UmWelt. 30: 43-7.

2. Albert, R.E., A.R. Sellakumar, S. Laskin, M. Kuschner, N. Nelson, and C.A. Snyder. 1982. Gaseous formaldehyde and hydrogen chloride induction of nasal cancer in the rat. JNCI 68: 597-603.

3. Alexandersson, R., G. Hedenstierna, and B. Kolmodin-Hedman. 1982. Exposure to formaldehyde: Effects on pulmonary function. Arch. Environ. Health 37: 279-84.

4. Boreiko, C.J. D.B. Couch, and J.A. Swenberg. 1982. Mutagenic and carcinogenic effects of formaldehyde. (Toxline abstract) Environ. Sci. Res. 25: 353-67. 
5. Carson, B.L., C.M. Beall, H.V. Ellis, III, J.L. MCCann, L. Baker, B.L. Herndon, and E.M. Horn. 1981. Formaldehyde health effects (EPA 460/3-81-033), Midwest Research Institute, Kansas City, Mo.

6. Fornace, A.J., Jr., J.F. Lechner, R.C. Grafstrom, and C.C. Harris. 1982. DNA repair in human bronchial epithelial cells. (Toxline abstract). Carcinogenes 1s (London) 3: 1373-7.

7. Fornace, A.J., Jr. 1982. Detection of DNA single-strand breaks produced during the repair of ddamage by DNA-protein cross-1inking agents. (Toxline abstract). Cancer Res. 42: 145-9.

8. Goldmacher, V.S. and W.G. Thilly. 1983. Formaldehyde is matagenic for cultured human cells. (Toxline abstract). Mutat. Res. 116: 417-22.

9. Grafstrom, R.C., A.J. Fornace Jr., H. Autrup, J.F. Lechner, and C.C. Harris. 1983. Formaldehyde damage to DNA and inhtbition of DNA repair in human bronchial cells. (Toxline abstract). Sclence 220: 216-18.

10. Hileman, B. 1982. Formaldehyde. Envizon. Sci. Technol. 16: $543 \mathrm{~A}-7 \mathrm{~A}$.

11. Levy, S., S. Nocentint, and C. Billardon, 1983. Induction of cytogenetic effects in human fibroblast cultures after exposure to formaldehyde or xrays. (Toxline abstract). Mutat. Res. 119: 309-17.

12. Miretskaya, L.M. and P.Y. Shvartsılan. 1982. Study of chromosomal damage to human 1ymphocytes due to formaldehyde. (Toxline abstract). Tsitologiya 24: $1,056-60$.

13. National Academy of Sclences Committee on Aldehydes. 198i. Formaldehyde and other aldehydes (EPA 600/6-82-002). National Academy Press, Washington, DC.

14. Turay, J., I. Beseda, and A. Biresova. 1981. Effect of inhalation exposure to phenol, formaldehyde, and melamine adhestves on HDL cholesterol levels in humans. (Toxline abstract). Cas. Lek. Cesk. 120: 729-32. 


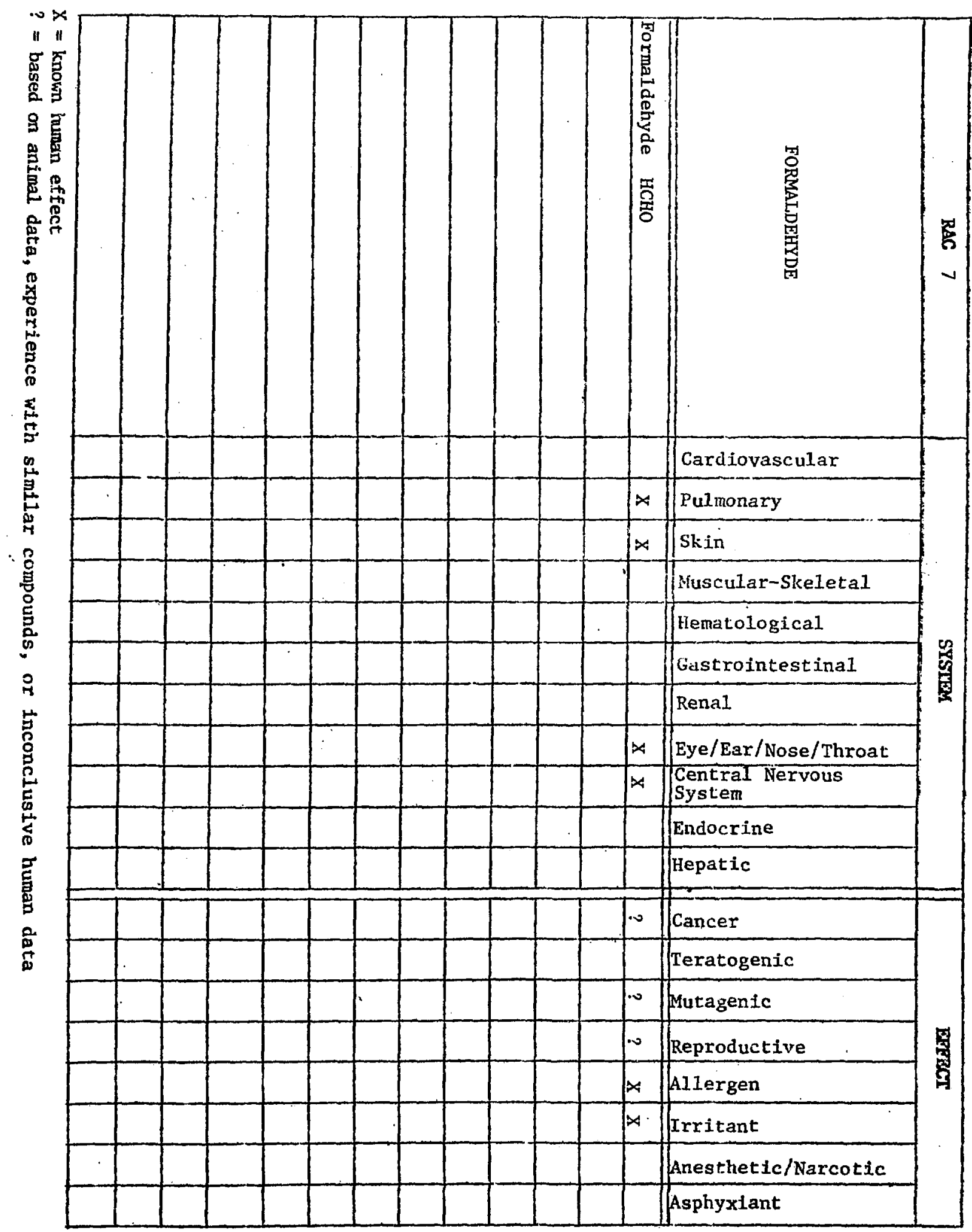


RAC \#8 - VOLATILE ORGANOCHLORINES

Volatile organochlorines listed in RAC \#8 include chloro derivatives of methane, ethane, and ethylene. Except for vinyl chloride, all compounds in this group are used as industrial solvents. Most of them are widely used as degreasing agents in Industries and as solvents in dry cleaning.

Organochlorines are in general volatile, and the major health effects are due to inhalation. They are readily absorbed, with the 11ver and kidneys being the main target organs.

In low chronic exposures, many have been implicated in central nervous system, kidney, and liver damage. They are all central nervous system depressants, causing anesthesia and death if exposures are high enough.

Chloro Derivatives of Methane

Methylene Chloride $\mathrm{CH}_{2} \mathrm{Cl}_{2}$ (Dichloromethane)<smiles>ClC(Cl)Cl</smiles>

Methylene chloride is a colorless volatile liquid with a distinctive sweet odor. It is widely used in industry as a solvent and a degreaser, and in commercial perparations of paint removers readily available for home use. It is considered one of the least toxic of the chlorinated methanes. It accumulates slowly in adipose tissue and has a half-1ife elimination from the body of 6 hours (16, pp. 1-2).

Acute Effects. Since methylene chloride is metabolized in the liver to form carboxyhemoglobin ( $\mathrm{COHb}$ ), many of the acute health effects observed are due to the lowering of the oxygen content in the blood leading to neurological and cardiovascular simptoms similar to carbon monoxide toxicity. In a controlled human exposure study, a performance decrement in a tracking monitoring task was observed at $200 \mathrm{ppm}$; depression of the flicker fusion threshold and of vigilance performance was observed at 300 ppm (60). At prolonged exposures of $500 \mathrm{ppm}$, COHb levels could be reached 
where noticeable symptoms would develop. At 800 to 1,200 ppm, early CNS effects such as lightheadedness and dizziness may occur. At levels of 2300 ppm and above, symptomatology such as lightheadedness, dizziness, nausez, headache, tingling and numbness of the extremities, and impairment of mental alertness and coordination would develop. Ingested, a fatal dose for a $68-\mathrm{kg}$ person ranges from $1 / 3$ to 1 pint (35). Damage to the nervous system has been reported following acute exposure (16).

In 11quid form, methylene chloride is mildly irritating to the skin and painful and irritating if splashed into the eyes $(2,4)$.

Chronic Effects. Clinical laboratory evaluation of employees occupationally exposed to methylene chloride demonstrated an increase in red cell counts, hemoglobin, and hematocrit among women but not among men exposed to approximately $475 \mathrm{ppm}$, which suggested a compensatory hematopoietic effect. A dose-related increase in serum bilirubin occurred both in men and women. However, no corresponding pattern of dose-related or hemolysis was found for other serum and blood constituents $(46,47)$.

No other deleterious long-term effects upon human health or performance were found in workers exposed to levels within recommended industrial criteria (5), but it is possible for exposed workers to develop increased $\mathrm{COHb}$ levels especially if they smoke or if there are other sources of $\mathrm{CO}$ in the atmosphere. It is also possible that chronic exposure to high doses of methylene chloride may be hepato and renal toxic, but no cases were reported of liver or kidney effects from chronic or acute exposures. Since methylene chloride readily crosses the placenta, it could have effects on the developing fetus.

In studies on DNA. damage by haloalkanes in human lymphocytes in vitro, dichloromethane, chloroform, and tetrachloride gave low or negative results (50).

A TLV of $100 \mathrm{ppm}$ is recomended if thére is no other occupational exposure to $\mathrm{CO}$ in the workplace (2). The STEL of $500 \mathrm{ppm}$ has been set based on data that no undesirable levels of COHb are likely to occur at this short-term exposure if there are no other scurces of $\mathrm{CO}$. These recommendations have to be adjusted for concurrent co exposures (2). 


\section{Chloroform (Trichloromethane) $\mathrm{CHCl}_{3}$}

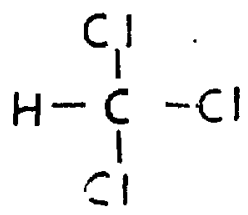

Chloroform is a clear, nonflammable, volatile, sweet-smelling liquid used as a raw material in refrigerant and resin production and as an extractant and industrial solvent. At one time it was used in the dry cleaning industry and it was widely used in the past as an anesthetic agent (2).

Acute Effects. Doses atove 1000 ppm cause CNS symptoms such as dizziness, fatigue, and headache (4). As exposures increase symptoms become more severe, and at levels around 10,000 ppm clinical anesthesia results. Above these levels cardiovascular depression may occur leading to death from ventricular fibrillation (35).

Ingestion of liquid chloroform causes severe burning in the mouth, throat, and chest, and abdominal pain and vomiting. Depending on the amount swallowed, loss of consciousness and liver injury may occur (35). Repeated or prolonged skin contact may result in local tissue irritation and inflammation $(4,51)$.

Chronic Effects. The most serious effects of repeated exposures to chloroform are liver and kidney damage (3). The chance of liver injury assoclated with cloroform exposure is significantly increased in alcoholics and persons with nutritional deficiencies (35). In addition, repeated low level exposures (beiow $100 \mathrm{ppm}$ ) may cause a variety of central nervous system symptoms (lassitude, mental dullness) and GI symptoms (digestive disturbances $)(2,35,51)$.

The mechanism involved in chloroform toxicity is not totally clear. Laboratory studies on isolated hepatocytes suggest two phases in chloroform toxicity: 1) chloroform metabolism, and 2) 11pid peroxidation (31). It was also suggested that phosgene $\left(\mathrm{COCl}_{2}\right)$ is the toxic intermedista in chloroform metabolism (56). Acute chloroform injury to the kidisy is 
supposedly caused by a toxic metabolite which is most likely produced within the kidney (36). Chloroform added to incubated human plasma enhances the generation of proteolytic activity attributable to plasmin (25). Studies on trihalomethanes as initiators and promoters of carcinogenesis did not demonstrate.tumor-initiating activity of chloroform; a tumor-promoting activity indicated by these results requires further confirmation (49).

From animal experiments, chloroform is suspected of being carcinogenic (52) and embryotoxic (2), but no studies were found documenting these effects on humans.

There have been few reports of occupational polsoning from chloroform, primarily because its use as an industrial solvent is limited (2, p. 90). Because of recent reports on the carcinogentcity and embiyotoxictity of chloroform, a TLV of $10 \mathrm{ppm}$ has been set. This is one fifth of the concentration at which organ injury was observed $(2, \mathrm{p} .91)$.

Carbon Tetrachloride (Tetract loromethane) $\mathrm{CCl}_{4}$<smiles>ClC(Cl)(Cl)Cl</smiles>

Carbon tetrachloride is a heavy mobile liquid with a sweet odor (2), widely used at one time as a solvent and a degreasing agent, but because of its high toxicity it has generally been replaced by one of the less toxic volatile organochlorines. Low levels of $\mathrm{CCl}_{4}$ have been found in water samples, and some extremely high levels have been found in urban air and in drinking water samples (5).

Carbon tetrachloride is readily absorbed into the system by ingestion and Inhalation, and, to a lesser degree, by skin penetration. The chief target organs are the 1iver, and kidneys. 
Acute Effects. Like most of the other volatile organochlorines, carbon tetrachloride is a central nervous system depressant, causing narcosis and death at high exposures. Ingegted carbon tetrachloride causes a burning sensation in the mouth, esophagus, and stomach followed by gastric symptoms (initially diarrhea and later constipation). If the dose 1s, large enough, liver symptoms such as jaundice and liver enlargement may occur, Central nervous system symptoms such as dizziness, confusion, unconsclousness, and coma may occur depending on the amount ingested (17, $26,48,51)$.

Skin contact produces pain with erythema, hyperemia, and wheal formation, followed by vesication (44).

Chronic Effects. At low level chronic exposures (45 to $100 \mathrm{ppm}$ ), subjects exhibited symptoms such as gastrointestinal upset, with nausea and vomiting, and central nervous symptoms such as headache, drowsiness, and excessive fatigue. At exposures between 100 and $300 \mathrm{ppm}$, workers have demonstrated apathy, mental confusion, and welght loss (12, p. 704). Liver function abnormalities have been found in subjects chronically exposed to carbon tetrachloride, even in the absence of clinical symptoms, and chronic exposure has also been responsible for liver and kidney damage (2, p. 75 ). Since alcohol increases the toxicity of carbon tetrachloride, alcoholics are more likely to suffer liver damage at lower exposures $(2,5)$.

Carbon tetrachloride has produced hepatic cancers in animals, but human data on carcinogenicity are preliminary and based on 1solated case reports $(52, p .73)$.

Carbon tetrachloride belongs to a group of chemicals which were nonmutagenic to Salmonella typhimurium, but produced morphological transformations in Syrian hamster embryo cells (4). Incubated with rat liver microsomes, $\mathrm{CCl}_{4}$ was metabolized to potentially toxic metabolites (39).

On the basis of animal experiments which showed fatty infiltration of the liver at $10 \mathrm{ppm}$ and the potentiation of carbon tetrachloride toxicity by alcohol and other Industrial substances, a TLV of 5 ppr has been recormended. An STEL of $20 \mathrm{ppm}$ was recommended to avold fatigue and central nervous system symptoms ( $2, \mathrm{p}, 75)$. 
Chloro Derivatives of Ethane

Methy1 Chloroform (1,1,1-Trichloroethane) $\mathrm{CH}_{3}-\mathrm{CCl}_{3}$<smiles>CC(Cl)(Cl)Cl</smiles>

Methy? chloroform is a volatile clear 1iquid, considered among the least toxic of the industrial chlorinated solvents (35, p. 730). Since methyl chloroform readily evaporates into the atmosphere, its major route of absorption is through inhalation of the vapor $(14,24)$. It is estimated that for an 8-hr TWA exposure of $3.50 \mathrm{ppm}\left(1890 \mathrm{ng} / \mathrm{m}^{3}\right)$ about $2 \mathrm{~g}$ will be absorbed into the body of a 70-kg man (14). Once inhaled, it is widely distributed into all organ systems, metabolized by the liver, and eliminated via the lungs, with its metabolites excreted in the urine (14). In very high doses methyl chloroform is capable of causing death due to anesthesia and/or cardiac sensitization $(2,24,34)$.

Acute effects for short-term exposures (14, pp. 1-3):

$14,000-15,000 \mathrm{ppm}$ capable of causing death due to anesthesia and/or cardiac sensitization (2)

$>5000 \mathrm{ppm}$ onset of narcosis

1900-2650 ppm lightheadedness, throat irritation

$1000 \mathrm{ppm}$ disturbance of equilibrium

350-500 ppm

$100 \mathrm{ppm}$ slight changes in perception, obvious odor

Skin exposure to the liquid form can cause irritation, pain, and blisters. Eye exposure can produce irritation, but should not cause serious injury $(35, \mathrm{p} .731,48,51)$.

Chronic Effects. At high levels of chronic exposures (above TWA limits) cellular damage and liver function abnormalities are possible. Blood clotting changes have been reported (45, p. 9). Central nervous system symptoms such as headache, depression, dizziness, feeling of Inebriation, Impaired perception and reaction time, generalized weakness, ringing of the ears, unsteady gait, burning and/or prickling sensation of hands and/or feet have been reported $(6,7)$. Also gastrointestinal symptoms such as nausea, vomiting, and diarrhea have occurred. 
Commercially available nethyl chloroform may have a veak mutagenic and carcinogenic effect, as observed in laboratory experimentation (14, pp. 1-3 to 1-4), but this may be due to impurities that may be found in $1,1,1$-trichlorethane such as vinylidene chloride and other stabilizers (30).

No adverse effects have been reported with concentrations likely to be encountered in the workplace. A TLV of $350 \mathrm{ppm}$ has been set to prevent anesthetic effects and objectionable odor, and an STEL of 450 ppm. 1 s recommended to protect against anesthesia.

1,1,2-Trichloroethane (Vinyl Trichloride) $\mathrm{CH}_{2} \mathrm{Cl}-\mathrm{CHCi}_{2}$

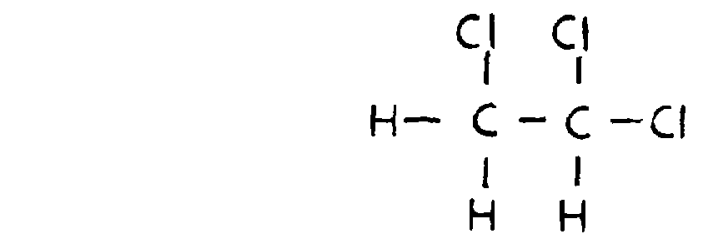

$1,1,2-\operatorname{Tr} 1 \mathrm{chloroethane}$ is a colorless nonflammable 11qui: with a sweet odor. Because of its high toxicity, it has only limited use in industry, mainly as a solvent for fats, resins, etc. (2, p. 406), and as a chemical intermediate in the production of vinylidene chloride.

Exposure to 1,1,2 trichloroethane occurs mainly through inhalation of the vapors.

Acute Effects. In hłgh doses, 1,1,2-trichloroethane depresses the central nervous system, causing narcosis and death from respiratory arrest. In lower concentrations, it is irritating to the eyes and nose (2, p. 406). It has a defatting action on the skin and can cause local skin irritation with possible blistering and burning.

Chronic Effects. 1,1,2-Trichloroethane is assumed to be toxic to the liver and kidneys on the basis of animal experimentation (43). Because of its limited use in industry, there are no known cases of human intoxication or chronic systemic effects from industrial exposures $(48,51,54)$.

A TLV of $10 \mathrm{ppm}$ and an STEL of $20 \mathrm{ppm}$ has been set based on the toxicological resemblence to tetrachloroethane and by analogy with the TLV for chloroform (2, p. 406). 


\section{Chloro Derivatives of Ethylene}

\section{Vinyl Chloride (Chloroethene) $\mathrm{CH}_{2}=\mathrm{CHC1}$}<smiles>C=CCl</smiles>

Vinyl chloride monomer (VCM) is a colorless highly flammable gas with an ether-1ike odor, which becomes a liquid when pressurized. The chief use of vinyl chloride in industry is as a raw material (i.e., monomer) in the manufacture of polyvinyl chloride (PVC) (2, p. 427). In the public sector, small quantities of vinyl chloride may be ingestad through water supplies and in food supplies from the migration of unconnected (unpolymerized) monomer PVC pipelines or food packaging, respectively (5).

Since it is a gas at room temperature, the most common route of exposure is through inhalation (2, p. 42B). It is rapidly absorbed through the lungs and widely distributed through lipid-rich tissue.

Acute Effects. In high doses (8,000 to $10,000 \mathrm{ppm})$, VCM acts as a Central Nervous System depressant. After initial exposure to an atmosphere of high vinyl chloride concentration a feeling of euphoria sets in, followed by slow reaction time and giddiness (resembling alcohol intoxication); narcosis may follow (42). After leaving this environment, a state of somnolence may persist for one or two days $(2$, p. 429 , and 42 , p. 55).

Skin contact with the liquefied gas can produce frostbite (2, p. 427).

Chronic Effects. "Occupational Acroosteolysis" (Vinyl Chloride Disease), is found among workers in the PVC production industry. It is characterized by Reynauds syndrome, hardening of the skin (scleroderma), and lesions of the bone $(2,8,28,37)$. Workers with these symptoms also show clinical symptoms of circulatory, disturbances, thrombocytopenia, splenomegaly, and liver changes (42, pp. 6-7). 
Radiologic pulmonary changes have been reported in workers exposed to vinyl chloride!, and the prevalence of these changes has increased with length of exposiure. Exposed workers have also shown a lowering in respiratory volume and vital capacity (42, p. 55) and changes in blood pressure over a 10-year period. Suclu et al. (42, p. 67) found an increase of average systolic pressure of $20 \mathrm{~mm} \mathrm{Hg}$ and an increase in the diastolic presure of $5 \mathrm{~mm} \mathrm{Hg.}$

A number of digestive symptoms have been reported by chronically exposed workers, such as anorexia, vomiting, and epigastric pains. In a cohort of Swedish PVC workers, Molina et al., have suggested an increased risk of death from myocardial infarction (40). There is also strong evidence of liver damage in workers chronically exposed to vinyl chloride fumes. Numerous epidemiological studies have demonstrated a significant excess of hepatic cancer (anglosarcoma) among exposed workers (11, 21, 27, $41,58)$.

In addition, studies have also suggested that vinyl chloride exposure may be associated with other cancers (respiratory system cancer, brain cancer, lymphomas, and leukemia) $(22,23,33,38,59)$.

An increase in birth defects (malformations of the central nervous system and genital organs, cleft lip and palate, club foot) has been reported in the offspring of persons in neighborhoods surrounding vinyl chloride polynerization plants. In addition, chromosomal abnormalities and increases in spontaneous abortions among wives of exposed workers have been reported ( 9 , pp. A32-4, 29).

A TLV of $5 \mathrm{ppm}$ has been set for vinyl chloride. NIOSH has recomended an 8-hr TWA of $1 \mathrm{ppm}$, with a celling limit of $5 \mathrm{ppm}$.

1,2-Dichloroethylene (1,2 Dichloroethene, Acetylene Dichloride) $\mathrm{ClCH}=\mathrm{CHC1}$<smiles>ClC=CCl</smiles>

1,2-Dichloroethylene is listed as a synfuel. 


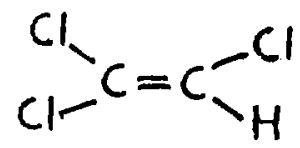

Trichloroethylene is a colorless sweet-smelling volatile liquid (35, p. 745) widely used in industry and dry cleaning establishments as a solvent and degreasing agent.

Principal industrial exposures are by inhalation of the vapor. It is readily absoried into the body through the lungs. It is estimated that 80 to $95 \%$ of trichlorethylene used in the U.S. evaporates into the atmosphere (16A).

Another source of exposure is ingestion. Trichloroethylene has been measured in water supplies and in the food chain. Ingested, it readily enters the portal system and is metabolized by the liver.

Acute Effects. Exposures of $1000 \mathrm{ppm}$ may affect visual perception and motor skills. Exposures above $1500 \mathrm{ppm}$ have anesthetic effects and may cause cardiac arrhythmias (2, p. 407). Metabolism of trichloroethylene is enhanced by alcohol, barbiturates, disulfirami, and warfarin causing toxic symptoms at lower exposures (16A, pp. 1-3). Direct skin contact with the liquid solvent can cause irritation, burns, and rashes (16A, pp. 5-19). Exposure to the vapor has been known to cause dermatitis (16A, pp. 5-16).

Chronic Effects. Long-term exposures to levels of 50 to $500 \mathrm{ppm}$ have caused central nervous system symptoms such as dizziness, headache, fatigue, nausea, and fainting spells. Behavioral and psychological effects, especially ta the ability to perform menial mental tasks have been reported by some subjects at exposures to $100 \mathrm{ppm}$ and above $(6,7,55)$.

Since the liver and kidney are major target organs of trichlorethylene, liver enlargement, abnormal liver function, fatty liver, and kidney damage have been attributed to chronic increased exposures.

There is some evidence that trichloroethylene is a teratogen and mutagen, but reports are limited to scattered observations in the literature of an increased incldence of miscarriages, stillbirths, and 
neonatal respiratory and neuromuscular problems among offspring of exposed women. Present avallable data on mutagenictiy and teratogenicity of trichloroethylene are inconclusive (16A, pp. 1-5).

A number of animal studies have shown trichloroethylene to be a renal and liver carcinogen (16A, pp. 1-11), but no direct human evidence has been found.

A TLV of $50 \mathrm{ppm}$ and an STEL of $150 \mathrm{ppm}$ have been set to protect workers against toxic effects (2, p. 407).

Tetrachloroethylene (Tetrachloroethene, Perchloroethylene [Perc]) $\mathrm{Cl}_{2} \mathrm{C}=\mathrm{CCl}_{2}$<smiles>ClC(Cl)=C(Cl)Cl</smiles>

Perchloroethylene is a colorless moderately volatile nonflammable liquid with an odor like ether. It is a solvent for a varlety of organic compounds and is widely used in the dry cleaning industry.

Exposure to perchloroethylene is primarily through inhalation, since it readily evaporates into the atmosphere. It is rapidiy taken up by adipose tissue and has an estimated half life of approximateley 70 hours in adipose tissue (18, pp. 5-3). It may take several weeks for perchloroethylene to be completely eliminated from the body.

Acute Effects. Acute exposures, $4000 \mathrm{ppm}$ and above, may be fatal causing central nervous system dysfunction and death through narcosis (35). In controlled human studies, subjects exposed to $100 \mathrm{ppm}$ for up to 7 hours demonstrated depression and behavioral alterations (18, pp. 1-6). As doses increase, central nervous system effects become more marked.

Exposures above $100 \mathrm{ppm}$ have caused eye irritation and sinus congestion (2). Direct contact with liquid perchloroethylene may cause skin burns, blistering, and erythema (2, p. 325). 
Chronic Effects. Acute and chronic exposures have the potential of causing liver and kidney damage, since perchloroethylene accumulates in lipid-rich tissue and takes several weeks to be eliminated from the body through the kidneys. Many observers have reported abnormal liver findings in subjects chronically exposed (cirrhosis, toxic hepatitis, 1iver cell necrosis) $(2,18,57)$.

Neurophysiological and psychological changes have been reported in workers chronically exposed (6), as well as other chronic CNS symptoms such as dizziness, headache, nausea, and fatigue (18). Workers have complained of ear, nose, and throat (ENT) irritation from chronic exposure (18, pp. 6-10) and there has been at least one documented case of a young worker with no evidence of heart disease who developed a history of PCs (Premature Ventricular Contractions) upon exposure to perchloroethylene, which subsided after he was removed from the source of exposure (1).

According to toxicology data bank there have been some scattered reports of workers exposed to perchloroethylene who exhibited a connective tissue disorder similar to vinyl chloride disease, but not enough data were found to substantlate these findings.

Traces of perchloroethylene have been found in breast milk, and Bagnell and Ellenberger cited a case of an Infant with an enlarged liver and obstructive jaundice (the mother was exposed to perchloroethylene) whose liver function tests returned to normal after breast feeding was stopped (18, pp. 6-3 and 7-1).

Preliminary studies on yeast cultures have indicated that perchloroethylene might be a mutagen $(18,19,20,32)$, but no conclusive human evidence supporting the mutagenicity of perchloroethylene has been found.

A TLV of $50 \mathrm{ppm}$ has been set to prevent neurological symptoms and eye Irritation (2, p. 325).

References

1. Abedin, Z., R.C. Cook, Jr., and R.M. Milberg. 1980. Cardlac toxicity of perchloroethylene (a dry cleaning agent) (Toxline Abstract). South Med. J. 73: $1,081-3$.

2. ACGIH. 1980. Documentation of the threshoid limit values. Fourth Edition. American Conference of Governmental Industrial Hygienists Inc., $\mathrm{OH}$. 
3. Ahmadezadeh, M. , C.H. Kuo, and J.B. Hook. 1981. Nephrotoxicity and hepatotoxicity of chloroform in mice: Effect of deuterium substitution. (Toxline Abstract). J. Toxicol. Environ. Health 8 (ISS $1-2): \quad 105-11$.

4. Amacher, D.E. and I. Zelljadt. 1983. The morphological transformation of Syrian hamster embryo cells by chemicals reportedly nonmutagenic to Salmonella typhimurium (Toxline Abstract). Carcinogenesis (London) 4: 291-5.

5. Ambient Water Quality Criteria. Criteria and Standards Division, office of Water Planning and Standards, U.S. Environmental Protection Agency, Washington, DC.

6. American Journal of Industrial Medicine, Vol. 1 , Number 1,1980 , Seppalainen, Lindstrom, and Martelin. Neurophyslological and Psychological Pict:re of Solvent Polsoning, pps. 31-42.

7. American Journal of Industrial Medicine, Vol. 1, Number 1, 1980, Lindstrom. Changes in Psychological Performances of Solvent Exposed

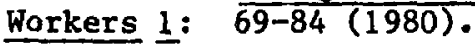

8. Black, C.M., K.I. Welsh, A.E。 Wolker, R.M. Bernstein, L.J. Catoggio, A.R. McGregor, and J.K. Jones. 1983. Genetic susceptibility to scleroderma-like syndrome induced by vinyl chloride (Toxline Abstract). Lancet 1: 53-5.

9. Clement Assoclates, Inc. 1981. Chemical Hazards to Human Reproduction. Councll on Environmental Quality, U.S. Department of Commerce, Washington, DC.

10. Cherry, N., H. Venables, H.A. Waldron, and G.G. Walls. 1981. Some observations on workers exposed to methylene chloride. (Toxline Abstract). Br. J. Ind. Med. 38: 351-5.

11. Cooper, W.C. 1981. Epidemiologic study of vinyl chloride workers: Mortality through December 31, 1972. Environ. Health Perspect. 41: $101-6$.

12. Drinking Water and Health, National Research Council. National Academy of Sciences, Washingt on, DC, 1977.

13. Emmerich, K.H. and K. Norpoth. 1981. Malignant tumors after chronic exposure to vinyl chloride. J. Cancer Res. Clin. Oncol. 192: 1-12.

14. EPA. 1982. Health Assessment DRAFT Document for $1,1,1-$ Trichloroethane (Methyl Chloroform). EPA-600/8-82-003. Environmental Protection Agency, Washington, DC.

15. EPA. Ambient Water Quality Criteria, Chlorinated Ethanes. Office of Water Planning and Standards, Criteria and Standards Division, U.S. Environmental Protection Agency, Washington, DC. 
16. EPA. 1982. Health Assessment Document for Dichloromethane (Methylene Chloride). EPA 600/8-82-004. Office of Health and Environmental Assessment, Washington, DC.

16A. EPA. 1982. Health Assessment Document for Trichloroethylene. EPA600/8-82-006. Office of Health and Environmental Assessment, Washington, DC.

17. EPA. Carbon Tetrachloride. Ambient Water Quality Criteria. Criteria and Standards Division, office of Water Planning and Standards, Washington, DC.

18. EPA. 1982. Draft Health Assessment Document for Tetrachloroethylene (Perchloroethylene). EPA-600/8-82-005. Environmental Protection Agency, Washington, DC.

19. Fabricant, J.D. and J.H. Chalmers. 1980. Evidence of the mutagenicity of ethylene dichloride and structurally related compounds. (Toxline Abstract). Banbury Report 5: 309-29.

20. Fabricant, J.D. and M.S. Legator. 1981. Mutagenicity studies of vinyl chloride. (Toxline Abstract). Environ. Health Perspect. 41: 189-93.

21. Falappa, P., N. Magnavita, A. Bergamaschi, and N. Colavita. 1982. Angiographic study of digital arteries in workers exposed to viny1 chloride. (Toxline Abstract). $\mathrm{Br}$.J. Ind. Med. 39: 169-72.

22. Fedotova, I.V. 1983. Incidence of malignant tumors among workers engaged in the manufacture of vinyl chloride and poly(vinyl chloride). (Toxline Abstract). Gig. Tr. Prof. Zabol. 4: 30-2.

23. Filatova, V.S., V.A. Antonyuzhenko, V.B. Smulevich, I.V. Fedotova, N.A. Kryzhanovskaya, T.V. Bochkareva, L.A. Goryacheva, and M.A. Bul'Bulyan. 1982. Blastomogenic hazard of vinyl chloride (clinicohyglenic and epidemiologic study). (Toxilne Abstract). Gig. Tr. Prof. Zabol. 1: 28-31.

24. Gerace, R.V. 1981. Near fatal Intoxication by 1,1,1,trichlorethane. (Toxline Abstract). Ann. Emerg. Med. 10: 533-4.

25. Gordon, E.M., O.D. Ratnoff, and G.H. Goldsmith, Jr. 1980 . Chloroform-induced fibrinolysis. Its dependence on Hageman factor, plasma prekallikrein, and high molecular welghty kininogen. (Toxline Abstract). J. Lab. C1in. Med. 95: 507-14.

26. Gosselin, R.E., H.C. Hodge, R.P. Smith, and M.N. Gleason. 1979 . Clinclal toxicology of commercial products. The Williams \& Wilkins Co., MD, pp. 86-92. 
27. Greiser, E., W. Rein1, and H. Weber. 1982. VIny1 ch1orlde exposure and mortality of German chemical Industry workers compared to the mortality of unexposed chemical industry workers and PVC workers. (Toxline Abstract). Zentralbl. Arbeitsmed., Arbeitsschutz, Prophyl. Ergon. 32: 44-62.

28. Hahn, E., D. Aderka, H. Suprun, and B. Shtamler. 1979. Occupational acroosteolysis in vinyl chloride workers in Israel. (Toxline Abstract). Isr. J. Med. Sc1. 15: 218-22.

29. Haas, J.F., and D. Schottenfeld. 1979. Risks to the offspring from parental occupational exposures. (Toxline Abstract). J. Occup. Med. 21: $607-13$.

30. Henschler, D., D. Reichert, and M. Metzler. 1980. Identification of potential carcinogens in technical grade 1,1,1-trichloroethane. (Toxline Abstract). Int. Arch. Occup. Environ. Health 47: 263-8.

31. Hogberg, J., T. Ekstrom, I. Anundi, and A. Kristoferson. 1980. Metabolism of toxic substances in 1solated hepatocytes. (Toxline Abstract). Toxicology 17: 113-8.

32. Ikeda, M., A. Kolzum1, T. Watanabe, A. Endo, and K. Sato. 1980. Cytogenetic and cytokinetic investigations on lymphocytes from workers occupationally exposed to tetrachloroethylene. (Toxline Abstract). Toxicol. Lett (AMST) 5: 251-6.

33. Infante, P.F. 1981. Observations of the site-specific carcinogenicity of vinyl chloride to humans. (Toxline Abstract). Environ. Health Perspect. 41: 89-94.

34. Jones, R.D. and D.P. Winter. 1983. Two case reports of deaths on Industrial premises attributed to 1,1,1-trichloroethane. Arch. of Env. Health 38: 59-61.

35. Kirk, R.E. 1978. Kirk-0thmer Encyclopedia of chemical technology. Third Edition, John Wiley \& Sons, NY.

36. Kluwe, W.M. and J.B. Hook. 1980. Metabolic activation of nephrotoxic haloalkanes. (Toxline Abstract). Fed. Proc. 39: 3,129-33.

37. Koischwjtz, D., H.J. Marsteller, K. Lackner, G. Brecht, and T. Brecht. 1980. Changes in the arteries in the hand and fingers due to vinyl chlorlde exposure (author's transl.) (Toxline Abstract). ROEFO 132: $62-8$.

38. Lllis. R. 1981. Review of pulmonary effects of poly(vinyl chloride) and vinyl chloride exposure. Environ. Health Perspect. 41: 167-9. 
39. Mico, B.A., R.V. Branchflower, L.R. Pohl, A.T. Pudzianowski, and G.H. Loew. 1982. Oxidation of carbon tetrachloride, bromotrichloromethane, and carbon tetrabromide by rat 11ver microsomes to electrophilic halogens. (Toxline Abstract). Life Sc1. 30: 131-7.

40. Molina, G., B. Holmberg, S. Elofsson, L. Holmlund, R. Moosing, and P. Westerholm. 1981. Mortality and cancer rates among workers in the Svedish PVC processing Industry. (Toxline Abstract). Environ. Health Perspect 41: 145-51.

41. Mortality experfence of workers in a vinyl chloride monomer product plant. J. Occup. Med. 21: 195-203.

42. NAS. 1975. Toxicity of Vinyl Chloride-Polyvinyl Chloride. Volume 246. Annals of the New York Academy of Sciences.

43. National Cancer Inst1tute. 1978. Bioassay of 1,1,2-Trichloroethane for Possible Carcinogenicity. CAS No. 79-00-5, NCI-CG-TR-74. Technical Report Serles, No. 74. U.S. Department of Health, Education, and Welfare.

44. National Library of Medicine. Toxicology Data Bank. (computer search 1982).

45. NIOSH, 1978. Chloroethanes: Review of Toxicity. IN: Current Intelligence Bulletin 27. U.S. Department of Health, Education, and Welfare.

46. Ott, M.G., L.K. Skory, B.B. Holder, J.M. Bronson, and P.R. Williams. 1983. Health evaluation of employees occupationally exposed to methylene chloride. Clinical laboratory evaluation. (Toxline Abstract). Scand. J. Work, Environ. Health 9: 17-25.

47. Ott, M.G., L.K. Skory, B.B. Holder, J.M. Bronson, and P.R. Williams. 1983. Health evaluation of employees occupationaliy exposed to methylene chloride. Metabolism data and oxygen half-saturation pressures. (Toxline Abstract). Scand. J. Work, Environ. Health 9: $31-8$.

48. Patty, F.A. 1982. Patty's industrial hygiene and toxicology, volumes 2A, 2B, and 2C. Third Revised Edition. John Wiley \& Sons, NY.

49. Pereira, M.A., L.H. LIn, J.M. Lippitt, and S.L. Herren. 1982. Trihalomethanes as inftiators and promoters of carcinogenesis. (Toxline Abstract). Environ. Health Perspect., Volume 46.

50. Perocco, P. and G. Prodi. 1981. DNA damage by haloalkanes in human lymphocytes culture in vitro. Cancer Lett. Volume 13, 213-18.

51. Proctor, N.H. and J.P. Hughes. 1978. Chemical hazards of the workplace. J.B. Lippincott Company, PA. 
52. Public Health Service. 1981. Second annual report on carcinogens. U.S. Department of Public Health and Human Services.

53. Savolainen, K., V. Rlihimak1, A. Laine, and J. Kekonf. 1982. Shortterm exposure $n_{i}$ human subjects to m-xylene and $1,1,1-t r i c h l o r o-$ ethane. (Toxline Abstract). Arch. Toxicol. (Suppl.) 5: 96-9.

54. Sax, N.I. 1975. Dangero's properties of Industrial materials. Fourth Edition. V an Nostrand Reinhold Company, NY.

55. Seppalainen, A.M., K. Lindstrom, and T. Martelin. 1980. Neurophyslological and psychological picture of solvent poisoning. (Toxline Abstract). Am. J. of Ind. Med. 1: 31-42.

56. Stevens, J.L. and M.W. Anders. 1981. Effect of cysteine, diethyl maleate, and phenobarbital treatments on the hepatotoxicity of [1H] chloroform. (Toxline Abstract). Chem. Biol. Interact 1981 37: 207-17.

57. Takeuch1, Y., N. Hisanaga, M. Iwata, S. Oguri, T. Tauch1, and T. Tanaka. 1981. An occupational health survey of dry cleaning workers. (Toxline abstract). Jpn. J. Ind. Health 23: 407-18.

58. Vlanna, N.J., J. Brady, and P. Harper. 1981. Angiosarcoms of the liver: A signal lesion of vinyl chloride exposure. Environ. Health. Perspect. 41: 207-10.

59. Wagoner, J.K., P.F. Infante, and R.B. Apfeldorf, 1980. Toxicity of vinyl chloride and polyvinyl chloride as seen through epidemiologic observations. (Toxline abstract). J. Toxicol. Environ. Health 6: $1,101-7$.

60. Winneke, G. 1981. The neurotoxicity of dichloromethane. (Toxline Abstract). Neurobehav. Toxicol. Teratol. 3: 391-5. 


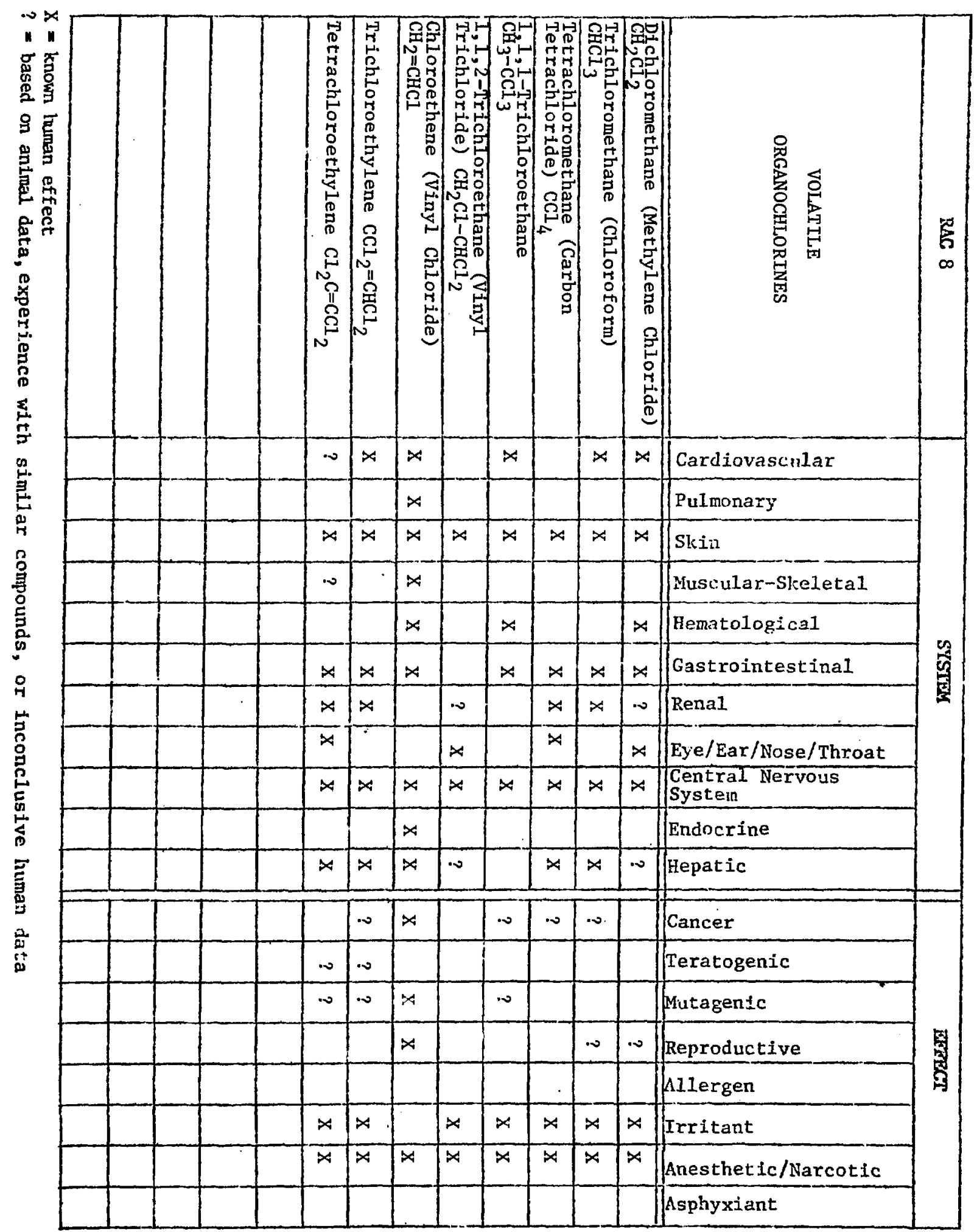


Formic Acid (Methanolc Acid) $\mathrm{HCOOH}$

$$
\mathrm{H}-\mathrm{C} \geqslant \mathrm{OH}
$$

Formic acid is a colorless foul-smelling caustic liquid widely used by the textile and paper industries in dyeing and finishing processes. It is a powerful dehydrating agent and burns readily when ignited.

Its primary effect is as an irritant to mucous membrane. In its liquid form it produces blisters upon contact with the skin and if not immediately washed off will cause ulceration and necrosis. Vapors of formic acid are intensely irritating to the membranes of the eyes, nose, and mouth, and can lead to corrosion of the mouth, throat, and esophagus $(4,5,6)$. Chronic absorption of formic acid has been reported to cause albuminuria and hematuria (3, p. 546; 7).

TLV 2 ppm; STEL 10 ppm (1)

Acetic Acid (Ethanoic Actd) $\mathrm{CH}_{3} \mathrm{COOH}$<smiles>CC(=O)O</smiles>

Acetic acid is a clear colorless liquid with a pungent odor (1) used in the manufacture of plastics, pharmaceuticals, dyes, insecticides, photographic chemicals, natural latex coagulants, and textile printing. It is also used in the production of acetic anhydride, cellulose acetate and vinyl acetate monomer, acetic esters, and chloroacetic acid (1). Diluted, it is the common household vinegar.

At 10 to $50 \mathrm{ppm}$ the vapors of acetic acid can be irritating to the eye and respiratory tract. At 50 ppm lacrimation, irritation of the eyes, nose, and throat will occur in most persons. If exposures are prolonged, 
pharyngeal edema and bronchitis may develop. Levels of 800 to $1200 \mathrm{ppr}$ are intolerable after 3 minutes (4). There have been various reports of workers exposed to chronic, long-terp levels of 60 to $200 \mathrm{ppm}$ with complaints of chronic conjunctivitis, bronchitis, pharyngltis, tooth erosion, various abdominel complaints, (digestive disturbances and constipation), and skin 1rritations $(1,2,7)$.

In the liquid form, acetic acid is strongly corrosive to the skin, eye nose, and mouth. Its action is insidious since there is no immediate burning sensation and blistering may take 30 minutes to 4 hours to develop. Workers have reported cracking and dryness of the palms of their hands In working with acetic acid, and blackening and hyperkeratosis of the skin has been reported with chronic exposures $(5,6)$.

Ingested, glacial acetic acld can perforate the esophagus.

IL $10 \mathrm{ppm}$; STEL $15 \mathrm{ppm}$ (1).

\section{References}

1. ACGIH. 1980. Documentation of the threshold 1imit values. Fourth Edition. American Conference of Governmental Industrial Hygienists Inc., $\mathrm{OH}$.

2. Kf:k-0thmer. 1978. Encyclopedia of chemical technology, Volume 1. Third Edition. John Wiley \& Sons, NY.

3. The Merck Index. 1976. An encyclopedia of chemicals and druge. Ninth edition. Merck \& Co., Inc., Rahway, NJ.

4. Patty, F.A. 1982. Patty's Industrlal hyglene and toxicology, Volumes 2A, 2B, and 2C. pps. 4,909-10. ThIrd Revised Edition. John Wiley \& Sons, NY.

5. Proctor, N.H. and J.P. Hughes. 1978. Chemical hazards of the workplace. P. 80 . J.B. Lippincott Company, $\overline{\mathrm{PA}}$.

6. Sax, N.I. 1975. Dangerous properties of Industrial materlals. Fourth Edition. Van Nostrand Reinhold Company, NY.

7. Toxicology Data Bank. National L1'rary of Mediclne. (Computer Search 1982). 


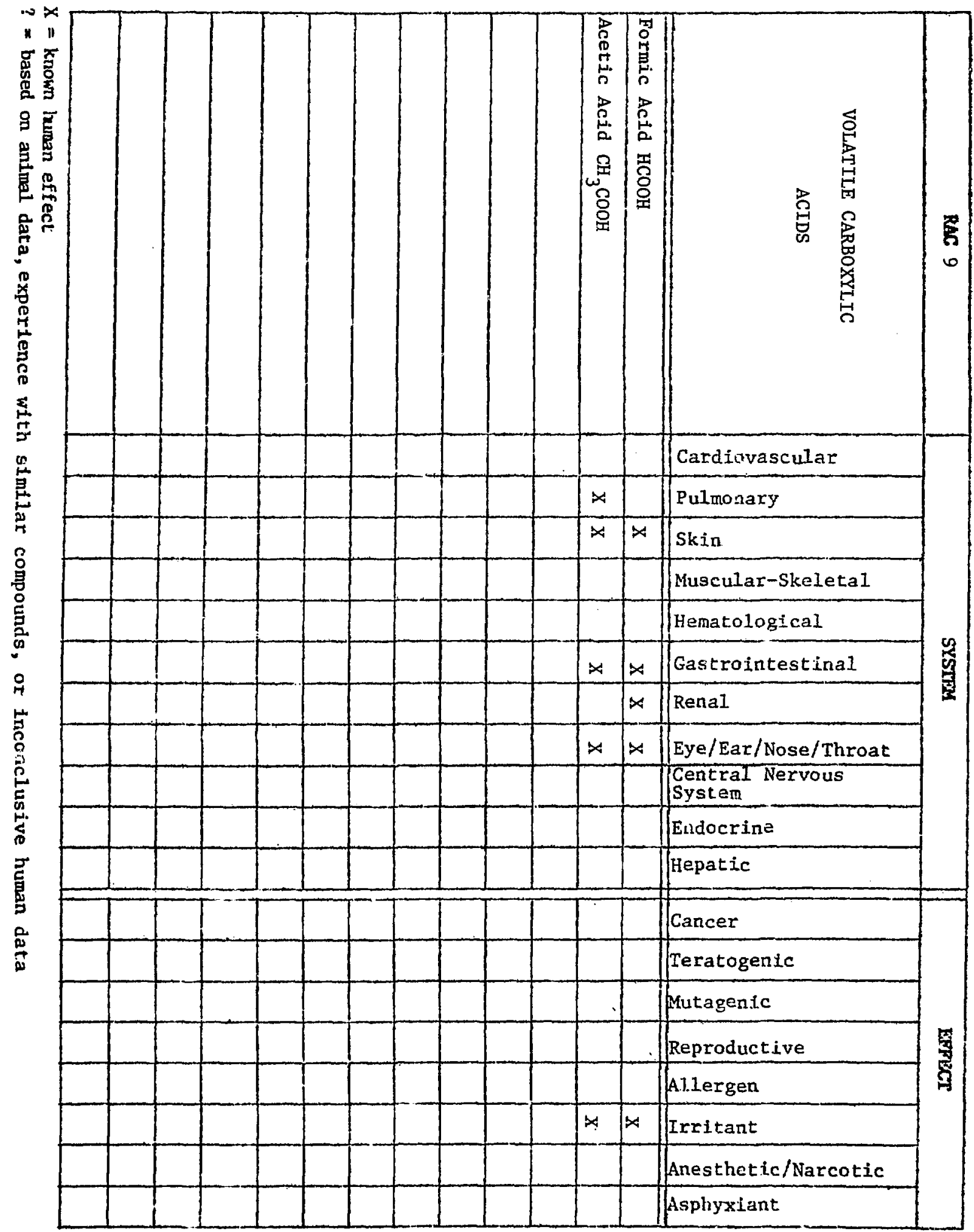


Listed in RAC $\# 10$, volatile 0 and is heterocyclics are derived from a five-membered heterocycle ring with either an oxygen or sulfur atom as a member of an aromatic ring.

Oxygen Heterocyclics

Furan (1,4-Epoxy-1,3-Butadiene; Furfuran) $\mathrm{C}_{4} \mathrm{H}_{4} \mathrm{O}$<smiles></smiles>

Furan is a colorless highly flammable liquid, with a strong ethereal odor. It occurs in olls obtained by the distillation of pine wood resin. Furan is utilized in the production of other industrial chemicals (pharmaceuticals, herbicides, stabilizers, and fine chemicals).

Furan is a highly volatile liquid. Since it can be absorbed through skin, direct contact should be avoided. It is a constituent of tobacco smoke, and its toxicity (and metabolism) in the lung has recently attracted more attention in research (2). No record of injury due to occupational exposures to furan has been found (3).

Tetrahydrofuran (THF, 1,4-Epoxybutane, Diethylene Oxide, Tetramethylene Oxide) $\mathrm{C}_{4} \mathrm{H}_{8} \mathrm{O}$.

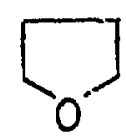

THF is a colorless liquid with an ethereal odor. It is a solvent for natural and synthetic resins, particularly vinyls. It is also a chemical intermediate and monomer.

Experiments with animals show skin irritation, increased pulse rate, and evidence of kidney damage in cats and rabbits after exposures of 3,400 to $17,000 \mathrm{ppm}(1,4)$. No documentation of human data was found. 
Dioxane (1,4-Diethylene Dioxide) $\mathrm{O}\left(\mathrm{CH}_{2} \mathrm{CH}_{2}\right)_{2} \mathrm{O}$<smiles>C1COCCO1</smiles>

Dioxane is a colorless flammable liquid, with an etiereal odor. It is used as a solvent for a wide range of organic products. A major use has been as a stabilizer in chlorinated solvents.

Animals studies show the toxicity of dioxane, particularly if it is introduced intraperitoneally. Nasal and liver tumors were reported in rats ingesting 7,000 to $18,000 \mathrm{ppm}$ of dioxane in drinking water for 14 to 23 months.

Human studies are relatively scarce. There are reports of five workers in an artificial silk factory who died of kidney damage and liver necrosis after approximately two months' exposure to dioxane. other workers suffered from nausea, vomiting, and irritation of eyes and respiratory passages. Death has been reported in a worker after one week on a job where the average concentration of dioxane vapor was 470 ppm. There was a possibility of skin absorption. Damage to the kidneys, liver, and brain were seen on autopsy. ther workers similarly exposed were unaffected. Studies on other plants with average vapor concentrations $1.07,0.9$, and $6.5 \mathrm{ppm}$, and the corresponding maximum values $7.2,2.0$, and $23.6 \mathrm{ppm}$, respectively, showed lack of unusual cancer incidence or mortality. In one of these studies, both liver and kidney functions tests were abnormally high for a few workers (1).

There is a controversy as to the recommended standard of dioxane. NIOSH (1976) suggested 1 ppm and ACGIH (1) suggested 25 ppm.

Sulfur Heterocyclics

Thiophene (Thiophuran; Thiofurfuran; Thiotetrole; Diuinylene Sulfide) $\mathrm{C}_{4} \mathrm{H}_{4} \mathrm{~S}$<smiles>c1ccsc1</smiles> 
Thlophene is a liquid with slight aromatic odor resembling that of benzene. It is found in coal tar, in coal gas, and in technical benzene. It is used in the manufacture of resins, dyes, and pharmaceuticals.

Thiophene is dangerous when heated to decomposition since it emits highly toxic fumes of sulfur oxides (4).

No human data on exposure to thiophene have been found.

Methyl Thiophene $\mathrm{C}_{4} \mathrm{H}_{3} \mathrm{CH}_{3} \mathrm{~S}$

2-Methy1 thiophene ( $\alpha$-thiophene)<smiles>Cc1cccs1</smiles>

3-Methy1 thiophene ( $\beta$-thiophene)<smiles>Cc1ccsc1</smiles>

No human data on methyl thlophenes have been found.

References

1. ACGIH. 1980. Documentation of the threshold 1imit values. Fourth Edition. American Conference of Governmental Industrial Hygienists Inc., OH.

2. Kirk-0thmer. 1978. Encyclopedia of chemical technology, Volume 1. Third Edition. John wiley \& Sons, NY.

3. RTEC - Registry of Toxic Effects of Chemicals, National Library of Medicine (Computer search 1982).

4. Sax, N.I. 1975. Dangerous properties of industrial materials. Fourth Edition. Van Nostrand Reinhold Company, NY. 


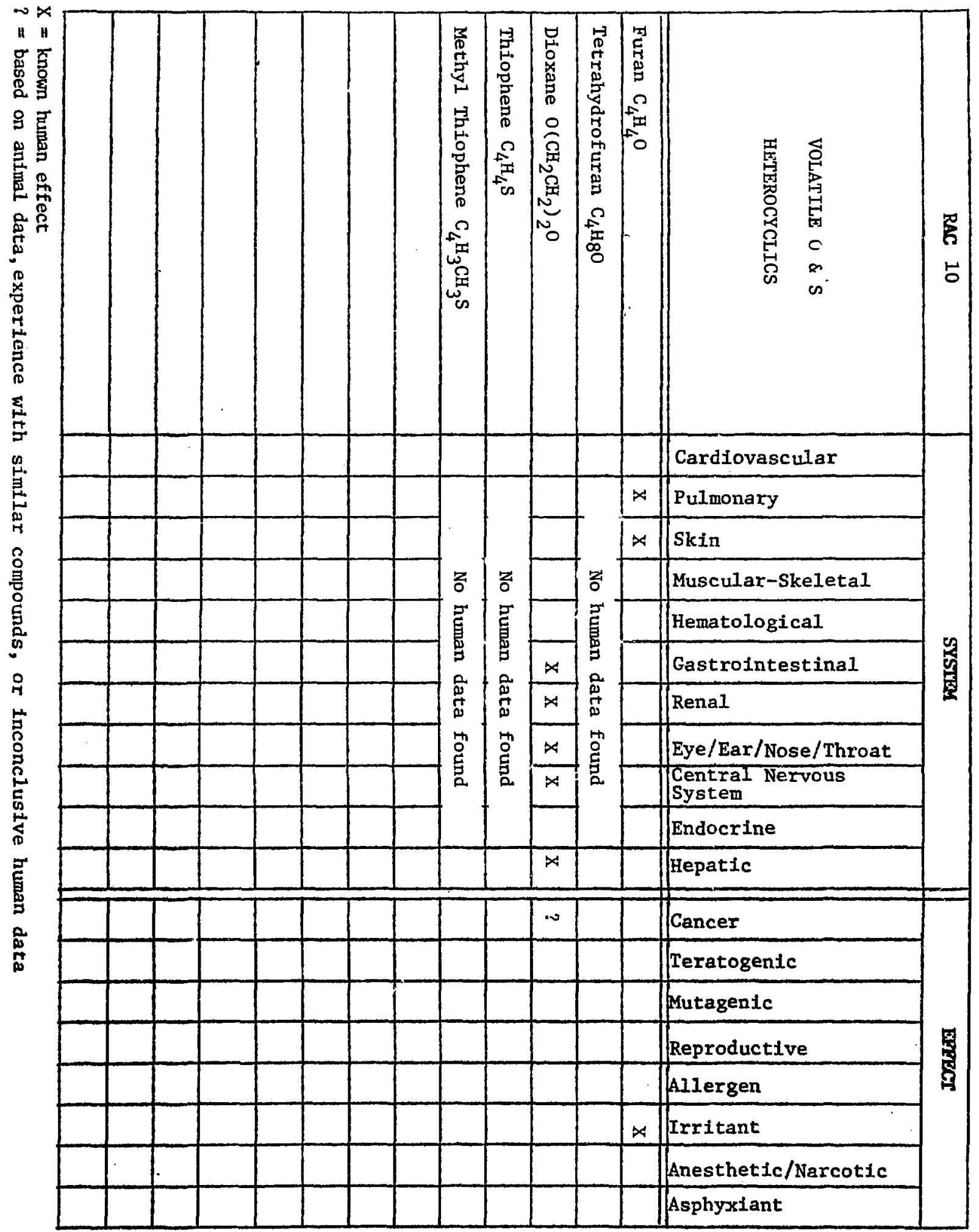


Nitrogen heterocyclics contain nitrogen as a member of an aromatic or aliphatic carbon ring. RAC \#11 includes 1) aromatic $N$ heterocyclics (piridine and three isomers of methyl piridine), and 2) aliphatic $N$ heterocyclics (ethylenimine, pyrrolidine, and piperidine).

Aromatic N Heterocyclics

Pyridine $\mathrm{C}_{5} \mathrm{H}_{5} \mathrm{~N}$

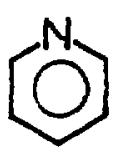

Pyridine is a flammable colorless iquid with a disagreeable odor detectable below $1.0 \mathrm{ppm}$. It is used to denature alcohol and as a solvent in the paint and rubber industrie's. It is also used in the manufacture of pharmaceuticals, dyes, pesticides, polycarbonate resins, and water-repellent finishes fo: textiles.

Ingested, pyridine affects the central nervous system. Smaller doses stimulate bone marrow to increase production of blood platelets. Large doses act as a heart poison. The dose 0.83 to $2.46 \mathrm{ml}$ of pyridine used for treatment of eptlepsy appeared to be toxic, with one death from liver and kidney damage. The vapor of pyridine affects mucuus membrane causing nasal and eye irritation. Inhalation causes chronic poisoning centering in the liver, kidney, and bone marrow $(1,10)$.

Exposures of 6 to $12 \mathrm{ppm}$ produced chronic poisoning with mild symptoms of central nervous system injury. Transient symptoms of overexposure are nausea, headache, insomnia, nervousness, mental depression, and low back or abdominal discomfort with urinary frequency. These symptoms have been reported in workers exposed at levels from 15 to $330 \mathrm{ppm}(1,2,6,7,9)$.

Prolonged or repeated skin contact causes irritation.

Reports of Injurious effects of pyridine are rare despite its widespread industrial use. 
<smiles>Cc1ccccn1</smiles>

2-methyl pyridine ( $\alpha$-picoline)<smiles>Cc1cccnc1</smiles>

3-methyl pyridine ( $\beta$-picoline)<smiles>Cc1ccncc1</smiles>

4-methyl pyridine ( $\gamma$-picoline)

Methyl pyridines are colorless liquids with strong odors. They are found in coal tar and in bone oil. 2- and 3-methyl pyridines are used as intermediates in dye and resin industries; 4-methyl pyridine is used in the manufacture of isonicotinic acid and derivatives, and in waterproofing agents for fabrics.

Clinical signs of intoxication used by 2- and 3-methyl pyridines include weight loss, diarrhea, weakness, ataxia, and unconsclousness ( 8 , 10).

Studies on mutagenic activity of aromatic nitrogen compounds indicate that the alkylation of pyridine did not produce a mutagen (3). 
Aliphatic $N$ Heterocyclics

Ethylenimine (Ethylene imine, Aziridine, Azacyclopropane, Dimethylenimine) $\left(\mathrm{CH}_{2}\right)_{2} \mathrm{NH}$

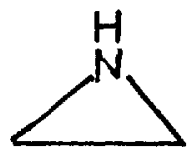

Ethylentmine is a clear extremely flammable caustic liquid with an intense odor of ammonia. It is used in a variety of industrial applications (usually as a polymer) such as paper and textile chemicals; adhesives; binders; petroleum refining chemicals, fuels, and lubricants; coating resins; varnishes; lacquers; agricultural, cosmetic, and photographic chemicals; etc.

Ethylenimine is highly toxic by skin contact, ingestion, and inhalation. Direct contact may cause eye and skin irritation, and a slowly healing dermatitis ( 1 ). The vapors may cause severe irritation of the eyes and throat, and produce inflammation of the respiratory tract, lung edema and hemorrhage, and kidney damage. A decrease in white blood cell count and depression of all formed blood elements have been observed, and thus polyaziridine has been used as a cancer chemotherapeutic agent $(1,4,6)$.

Numerous experiments on animals indicate carcinogenic activity of ethylenimine. The mutagenic activity in lower organisms (Drosophila, Neurospora, Saccharomyces) has been recognized $(1,6)$.

In spite of the serious na', e of anfmal findings, industrial experience has been good. An $=$. -demiologic study of 144 ethylenimine workers, some of whom had 40 years' experience, revealed no evidence of an increased risk of cancer among thes e workers (1).

FDA and OSHA list ethylenemine as a carcinogen $(4,5)$.

Pyrrolidine (Tetrahydropyrrole) $\mathrm{C}_{4} \mathrm{H}_{8} \mathrm{NH}$

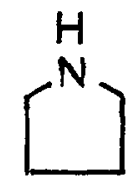


Pyrrolidine is an almost colorless liquid with an unpleasant ammonialike odor. It is found in tobacco and carrot leaves. It is one of predominant amines found in tobacco and cigarette smoke condensate (10). Carcinogen N-nitrosopyrrolidine is formed in frled bacon from proline via pyrrolidine (10).

Pyrrolidine, a strong base, is an irritant to skin and mucous membranes. When heated to decomposition, it emits highly toxic fumes of NO2*

Piperidine (hexahydropyridine) $\mathrm{C}_{5} \mathrm{H} 10 \mathrm{NH}$<smiles>C1CCNCC1</smiles>

Piperidine is a highly irritating liquid with a characteristic odor. It may cause death or permanent infury after very short exposure to small amounts.

References

1. ACGIH. 1980. Documentation of the threshold limit values. Fourth Edition. American Conference of Governmental Industrial Hyg jenists Inc. $\mathrm{OH}$.

2. Gosselin, R.E., H.C. Hodge, R.P. Smith, and M.N. Gleason. 1979. clinical toxicology of commerclal products. The Williams \& Wilkins Co., MD, Pp. 86-92.

3. Ho, C.H., B.R. Clark, M.R. Guerin, B.D. Barkenbus, T.K. Rao, and J.L. Epler. 1981. Analytical and biological analyses of test materials from the synthetic fuel technologies: 4. Studies of chemical structure-mutagentc activity relationships of aromatic nitrogen compounds relevant to synthetic fuels. (Toxline Abstract). 'Mutat. Res. 85: 335-46.

4. K1rk-0thmer. 1978. Encyclopedia of chemical technology, Volume 1. Third Edition. John Wiley \& Sons, NY.

5. The Merck Index. 1976. An encyclopedia of chemicals and drugs. Ninth edition. Merck \& Co., Inc., Rahway, NJ.

6. Patty, F.A. 1982. Patty's Industrlal hyglene and toxicology, Volumes 2A, 2B, and 2C. Third Revised Edition. John Wiley \& Sons, NY.

7. Proctor, N.H. and J.P. Hughes. 1978. Chemical hazards of the workplace. J.B. Lippincott Company, PA. 
8. RTEC - Registry of Toxic Effects of Chemfcals, National Library of Medicine (Computer search 1982).

9. Sax, N.I. 1975. Danger properties of industrial materials. Fourth Edition. V an Nost rand Relnhold Company, NY.

10. Toxicology Data Bank, National Library of Medicine. (Computer search 1982). 


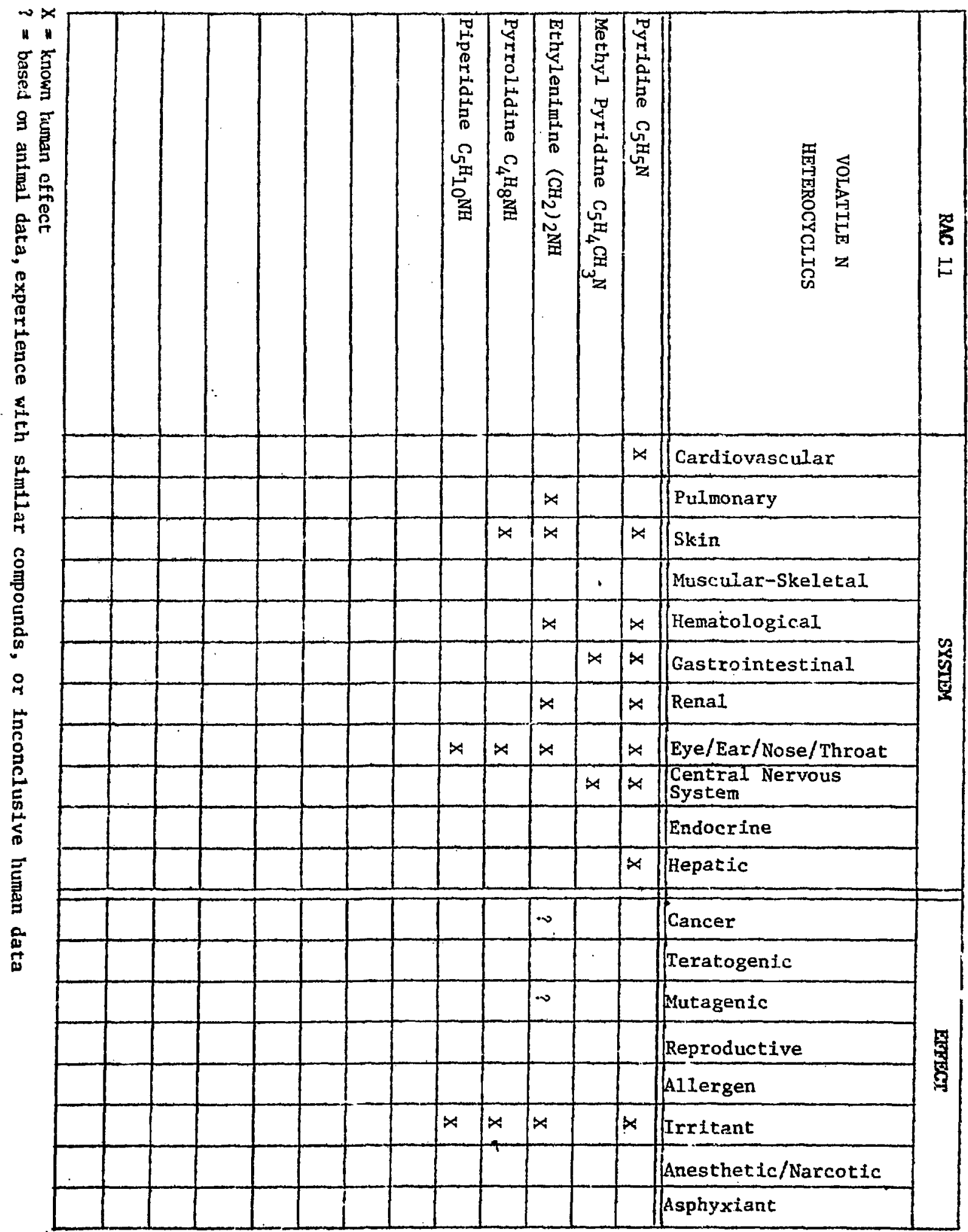


Benzene (Benzol, Phene) $\mathrm{C}_{6} \mathrm{H}_{6}$

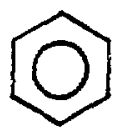

Benzene is a colorless volatile liquid aromatic hydrocarbon with a specific odor. Ninety-four percent is produced by distillation of perroleum and $6 \%$ by the coking process in steel infls.

Benzene is used in the synthesis of polymers, detergents, and pesticides, as an intermediate in clinical and pharmaceutical industries; in the preparation of chloronitrate solvents; in the rubber industry; in cements and adhesives; as components of inks in printing; in thinners; and as a degreasing and cleaning agent. Benzene has been added to gasoline (2\% in USA, 4 to $5 \%$ in Europe) to replace lead tetraethyl. It is ubiquitous in the workplace, and with its vapor pressure of $74.6 \mathrm{~mm} \mathrm{Hg}$ at $20^{\circ} \mathrm{C}$, it easily escapes into the environment. The present U.S. standards for occupational exposure during an 8-hr day, 40-hr week time weighted average (TWA) is $10 \mathrm{ppm}\left(32 \mathrm{mg} / \mathrm{m}^{3}\right.$ ) with a celling value (15 min) of $25 \mathrm{ppm}$ and an allowable peak value of $50 \mathrm{ppm}$ (1).

The amblent benzene in air varies from 0.1 to $14 \mathrm{ppb}$. Dietary intake may be as high as $250 \mu \mathrm{g} / \mathrm{day}$.

Toxicity. Toxic effects of benzene have been known since the turn of the century. Inhaled benzene is absorbed rapidly in the lung. The benzene concentration in blood reaches about $70 \%$ of the air content in 30 minutes. About $40 \%$ of inhaled benzene is exhaled unchanged. Since it is highly soluble in lipids, it accumulates in fat-containing organs. The highest levels are found in bone marrow, fat, and nervous tissues. Complex metabolic pathways of benzene include formation of benzene oxide, phenol, hydrozinol, and catachol which are biologically active and may account for a large part of its toxicity $(1,7,14,15,17)$.

Phenol excreted in urine is the end product of benzene metabolism. The methods evaluating the exposure to benzene and its distinction from the 
exposure to other organic solvents (toluene, xylene, styrene, etc.) are based on the analysis of urinary samples $(4,6)$. The measurement of phenol/creatinine ratio in urine is considered a highly sensitive method to evaluate the atmospheric concentration of benzene (14A). Increased concentration of phenol in urine occurs parallel to the decrease of thrombocytes and leucocytes in blood $(11,12)$.

Acute Toxicity. The primary acute toxic effect of benzene is on the central nervous system and is seen initially at exposures above $250 \mathrm{ppm}$. Exposure to massive concentrations, around $2.5 \%$ by volume in air (about $25,000 \mathrm{ppm}$ ) is fatal within winutes. The prominent signs are central nervous system depression and convulsions, with death usually following as a consequence of cardiovascular collapse.

Fatalities have occurred after benzene inhalation in closed spaces such as tanks. Severe nonfatal cases exhibit similar signs, but recovery occurs after a period of unconsciousness. Milder exposures (4000 ppm) produce euphoria followed by giddiness, headache, nausea, staggering gait, and finally unconsciousness if exposure continues. Inhalation of lower concentrations (250 to $500 \mathrm{ppm}$ ) produces vertigo, drowsiness, headache and nausea, symptoms which clear rapidly once exposure ceases. Deaths from cardiac sensitization and cardiac arrhythmias have also been reported after benzene exposure to unknown concentrations $(1,7,15 \mathrm{~A}, 17)$.

Exposures above $50 \mathrm{ppm}$ for extended periods may produce changes in the bone marrow, which result in decreased levels of platelets, red blood cells, or white blood cells (pancytopenta). Eenzene-induced pancytopenia is characterized by a relatively frequerc occuirence of bone marrow hyperplasia. A milder form, unicytopenia, includes cases of anemia, granulocytopenia, or thrombocytopenia. In its most severe form, damage to the bone marrow results in aplastic anemia. About $13 \%$ of these cases of benzene-induced aplastic anemia are fatal. The signs of chronic benzene poisoning can appear any time following a few weeks to several years of exposure. Typical symptoms are rather nonspecific: severe fatigue, headache, dizziness, nausea, vertigo, stomach pain, loss of appetite, or feeling cold $(7,13,17,18,20)$. Neurological abnormalities were reported in four out of six pancytopenic patients with chronic benzene poisoning (3, 5). 
Prolonged or repeated skin contact may produce a dry, scaly dermatitis, erythema, and blistering.

Carcinogenic Effects - Leukemia. While aplastic anemia is a major complication of benzene toxicity, acute leukemias of the marrow-formed blood elements are the most severe manifestations of benzene toxicity.

The evidence for benzene-induced leukemia is largely from epidemiological studies $(7,18,20)$. Increased incidence of leukemia was observed in some industries (shoemakers, certain rubber products, etc.) where benzene in high concentration mixed with other solvents was handled indoors and in unventilated areas $(2,3,13 \mathrm{~A})$. In all well-documented cases of benzene-related leukemia, victims developed a previously detectable decrease in blood levels of one or more of the cell 1ines.

The implications of these observations for the relationship between benzene sxposure and leukemia are twofold: 1) chronic exposure to high concentrations of benzene appear to be required, and 2) decreases in blood concentrations of platelets, leukocytes, and/or red blood cells may be an important early warning of leukemia risk in workers exposed to benzene (13, 14).

Cellular Mechanism. The mechanism by which benzene produces its hematologic and carcinogenic effects in humans is still unknown. Commonly observed chromosomal abnormalities in occupationally exposed individuals, in experimental animals, and in human cells cultured in vitro suggest an effect on the function of stem cell nuclei (13, 15B, 15). Pancytopenia may represent either a destruction of bone marrow stem cells, a failure of these cells to differentiate, or a destruction of more mature precursors of hematopoietic cells. Muconaldehyde has been recognized as a potential toxic intermediate of benzene metabolism. When incubated with human peripheral blood cultures, muconaldehyde inhibited erythroid stem cell production (13). Macrocytosis represents the most frequently reported abnormality of red cells. Evidence of decreased platelet function was also demonstrated in numerous investigations $(7,13,20)$.

Experimental exposure of cultured human lymphocytes to different toxic compounds showed that benzene inhlbited [3H] thymidine uptake in the absence of $\mathrm{NADH}-$ generating system ( $\mathrm{S} 9 \mathrm{mix}$ ) but had no effect on cell 
viability. These observations suggest that a cytotoxic action of benzene is not immediately followed by cellular death (16).

Goldstein (13) points out that the evidence of altered lymphocytic function in humans is indirect, consisting mainly of studies suggesting aberrant imuisne function. An effect of benzene on lymphocytes implies that the target of benzene hematotoxicity is not simply the myeloproliferative stem cell. It raises the possibility that benzene leukemogenesis is a result of altered immune function. Such supposition is based on the current theoretical concept of the role of Immune survelliance in carcinogenesis. Furcher studies are indicated in order to evaluate the role of 1ymphocytes in benzene hematotoxicity, to establish whether the effect is specific for $B$ or $T$ lymphocytes, and to evaluate the possible interaction of benzene with supressor lymphocytes (13, 17). Casale (8) suggested that the aplastic anemia may represent a stem-cell defect, a hostile microenvironment, or an autoimmune phenomenon; immunosuppression and bone marrow transplantation are considered as particularly promising therapies. Increased formation of immunoglobin and alterations in lymphocyte nuclei have been recognized as early signs of an enhanced immune reactivity following chronic exposure to benzene (9). Flow cytofluorometry has also been applied for the evaluation of early proliferative change in bone marrow from persons exposed to benzene (13A).

Incldence. The literature reporting benzene hematotoxicity includes single-case reports and series of case reports of individuals with a relatively unique benzene exposure experience. Since the mild symptoms are often not reported by the patient, or not associated with the exposure to benzene, the total incidence of benzene-induced pancytopenia is unknown (20). There are very few studies of the longltudinal assessment of groups of workers previously exposed to benzene. The long-term study which evaluated 147 persons exposed to benzene in a shoe factory showed that 10; persons had abnormal blood count. Nine years after cessation of the exposure to benzene, 125 of these workers were reexamined. The mean leucocyte count was Improved; however, the mean erythrocyte and platelet counts remained significantly less than the control level (13). A follow-up study lasting 18 years reported 10 deaths within a cohort of 60 workers occupationally exposed to benzene. Four deaths were due to 
malignancies, but no leukemia was observed. Workers with olight initial hematologic disorders related to benzene exposure returned to nornal (13B). In a chemical plant where benzene was used in large quantitiea, a cohort of 259 males employed at any time between 1947 and 1960 was followed through Decenber 31, 1977. Fifty-elght deaths were identified, four resulting from lymphoreticular cancers, when 1.1 would have been expected. Three of the deaths were due to leukemia and one was caused by multiple myeloma. In addition, one of the leukemias had multiple myeloma 11sted on the death certificate. These findings raise the possibility that besides leukemia, multiple myeloma could also be linked to benzene exposure (10). Additional follow-up studles of large groups of benzene-exposed individuals are Indicated (13).

References

1. ACGIH. 1980. Documentation of the threshold 11mit values. Fourth Edition. American Conference of Governmental Industrlal Hygienists Inc., $\mathrm{OH}$.

2. Aksoy, M., S. Erden, and G. Dincol. 1974. Leukemla in shoe-workers exposed chronically to benzene. Blood 44 .

3. Aksoy, M. 1980. Different types of malignancies due to occupational exposure to benzene: A review of recent observations in Turke $\%$ (Toxline Abstract). Environ. Res. 23: 181-90.

4. Andrzejewski, S., M. Paradowski, E. Lis, and E. Rojewska. 1981. Analysis of the methods of evaluation of occupational exposure to benzene and phenol of petrochemical industry workers. (Toxline Abstract). Med. Pr. 32: 91-8.

5. Baslo, A. and M. Aksoy. 1982. Neurological abnormalities in chronic benzene polsoning: A study of 6 patients with aplastic anemia and 2 with preleukenia. (Toxline Abstract). Environ. Res. 27: 457-65.

6. Braier, L., A. Levy, K. Dror, and A. Pardo. 1981. Benzene in blood and phenol in urine in monitoring benzene exposure in industry. Am. J. Ind. Med. 2: 119-23.

7. Brief, R.S., J. Lynch, T. Bernat, and R.A. Scala. 1980. Benzene in the workplace. (Toxline Abstract). Am. Ind. Hyg. Assoc. J. 9: 61623.

8. Casale, T.B. 1982. Aplastic anemla: The disease and its management. (Toxline Abstract). Postgrad. Med. 71: 59-70. 
9. Chircu, V., M. Ionescu, and T.C. Zgoan. 1981. Early changes of lymphocyta RNA and serum immunoglobulins following chrunic exposure to benzene. (Toxline Abstract). Med. Interne. 19: 373-8.

10. Decoufl'e, P., W.A. Blattner, and A. Blair. 1983. Mortallty among chemical workers exposed to benzene and other agents. (Toxline Abstract). Environ. Res. 30: 16-25.

11. Eikmann, T., W. Mueller, and D. Prajsnar. 1980. Phenol excretion and hematological values as parameters for a benzene burden. Comparative study of the adult population of two provinclal towns. (Toxline Abstract). Wis8. Umwe1t. 4: 183-9.

12. Eikmann, T., D. Stinner, and D. Prajsnar. 1981. Haematological data relating to phenol excretion in urine with chronic benzene exposure. I. Epldemiological studies of adults (author's trans1.). (Toxline Abstract). Zentralb1. Bakteriol. Mikrobiol. Hyg. 174: 57-76.

13. Goldstein, B.D. 1980. Benzene toxicity a critical evaluation. American Petroleum Institute, S. Laskin and B.D. Goldstein (Eds.), Washington, DC.

13A. Irons, R.D. 1981. Benzene-induced myelotoxicity: application of flow cytofluorometry for the evaluation of early proliferative change In bone marrow. Environ. Health Perspect. 39: 39-49.

13B. Grossenbacher, J. and M. Iob. 1982. (Longitudinal study of the long-term effects of occupational exposure to benzene). Schwelz Med. Wochenschr. 112: $1,858-9$.

14. Kirk-0thmer. 1978. Encyclopedia of chemical technology. Third Edition. John Wiley \& Sons, NY.

14A. Melc, E. and M. Melo. 1980 Phenol and phenol/creatinine in urine. Index of industrial exposure to benzene. Rev. Bras. Patol. Clin. 16: 115-19.

15. Morimoto, K. and S. Wolff. 1980. Increase of sister chromatid exchanges and perturbations of cell division kinetics in human lymphocytes by benzene metabolites. (Toxline Abstract). Cancer Res. 40: $1,189-93$.

15A. National Academy of Sciences. 1977. Drinking Water and Health. pp. 688-91. The National Research Counctl.

15B. Orsi, E.V., W.J. Zois, and 0.F. Baturay. 1983. Human cell cultures response to simulated and natural levels of air pollution. NATOC Conf. Ser., (Ser.) 1; Volume 58, ISS In Vitro Toxic. Test. Environ. Agents: Curr. Future Possibilities, Part B., pp. 85-98. 
16. Pexocco, P., S. Bolognes1, and W. Alberghini. 1983. Toxic activity of seventeen industrial solvents and halogenated compounds on human lymphocyteg cultured in vitro. (Toxline Abstract). Toxicol. Lett. 16: $\quad 69 \sim 75$.

17. Snyder, R. and Y.Y. Kocsis. 1975. Current Concepts of Chrontc Benzene Toxicity. CRC Critical Reviews in Toxicology, 1975. pp. 265-87.

18. Snyder, R., E.W. Lee, J.J. Kocsis, and M. Whitmer. 1977. Minireview. Bone marrow depressant and leukemogenic actions of benzene. Life Sc1. 21: 1709-22.

20. White, M.D., P.F. Infante, and B. Walker, Jr. 1980. Occupational exposure to benzene: A review of carcinogenic and related health effects following the U.S. Supreme Court dectsion. Am. J. Indus. Med. 1: 233-43. 


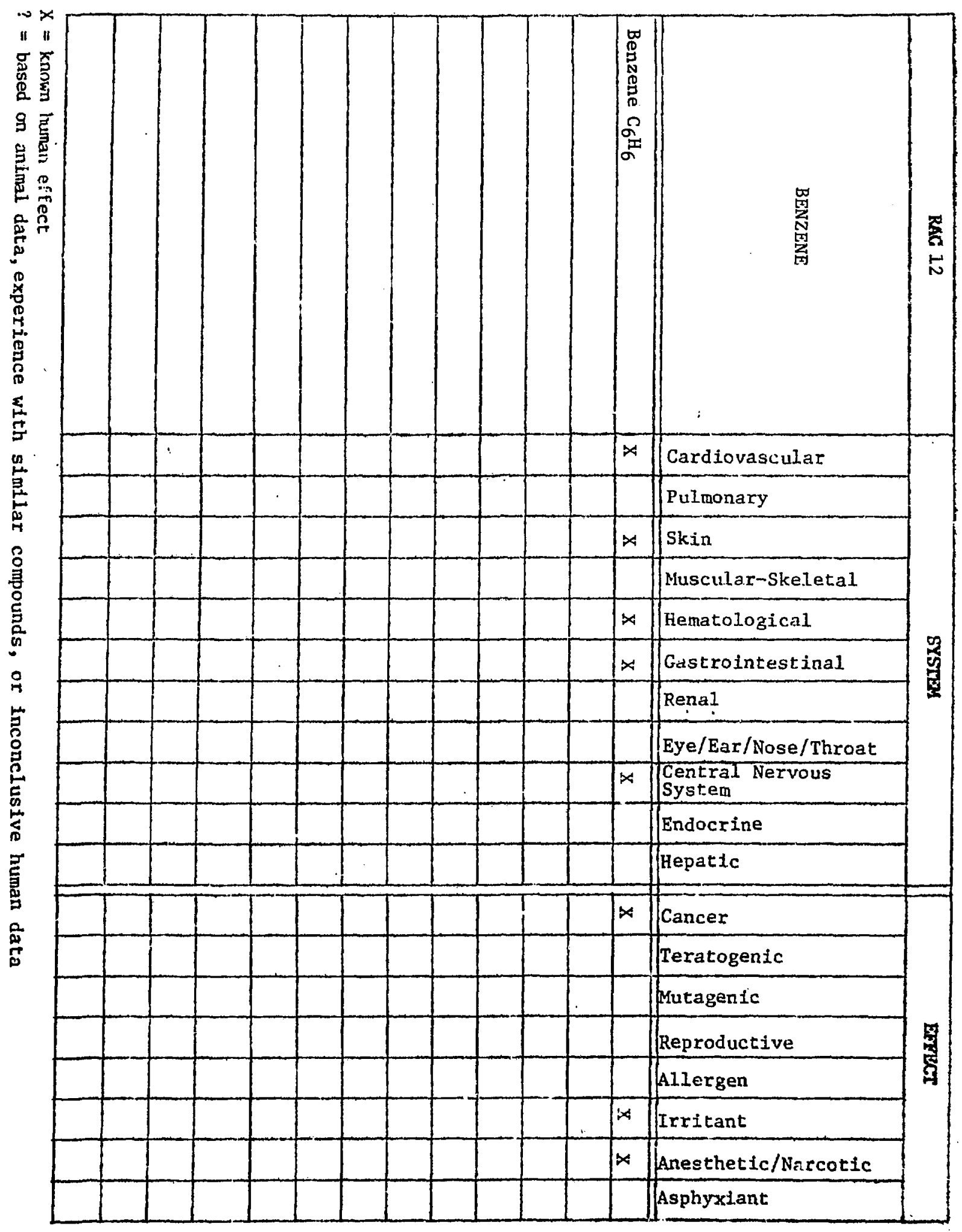




\section{RAC *13 - ALIPHATIC/ALICYCLIC HYDROCARBONS}

Aliphatic hydrocarbons discussed in RAC \#13 include: (alkanes) $\left(\mathrm{C}_{\mathrm{n}} \mathrm{H}(2 \mathrm{n}+2)\right.$ ) with straight carbon chains: (a) $\mathrm{C}_{5}$ to $\mathrm{C}_{8}$; (b) $\mathrm{C}_{9}$ to $\mathrm{C}_{12}$; and (c) their isomers.

Alfcyclic hydrocarbons are represented by methylcyclopentane. Alkanes With $\mathrm{C}_{5}$ to $\mathrm{C}_{8}$ Carbon Chains (pentane, hexane, heptane, and octane)

Alkanes are colorless liquids with a light petroleum odor, produced almost exclusively from petroleum. They are used in a varlety of industrial applications: as solvents in glues, in varnishes, in the extraction of oils from varlous seeds, and in the formulation of gasoline.

Commerclal alkanes contain mixtures of hydrocarbons. Analysis of commerclal pentane showed $76 \%$ n-pentane, $21 \%$ isopentane, and small quantities of butane and hexane. Commerclal hexane is mostly a mixture of hexane isomers with roughly one third n-hexane, and small amounte of cyclopentane and cyclohexane, and of pentane and heptane 1somers. Commercial heptane is largely composed of isomers of heptane $(1,7,24)$.

Since exposure of workers to only one alkane is infrequent, NIOSH has recommended TWA concentration $350 \mathrm{mg} / \mathrm{m}^{3}$ as the occupational limit for pentane, hexane, heptane, octane, and total alkaises (mixture) (14).

Generally alkanes Erom pentane ( $\left.C_{5}\right)$ through octane ( 8 ) show increasingly strong narcotic properties. Early symptoms of exposure to alkane vapors include headache, burning sensation on the face, abdominal cramps, and vertigo. The physiologic response in humans to alkanes increases markedly with increasing numbers of carbon atoms $(7,14,23)$.

Similarly, the alkane concentrations required to produce a physiologic response decreases as the number of carbon atoms in the compound increases. A 10-min exposure to pentane at $5000 \mathrm{ppm}$ or to hexane at $2000 \mathrm{ppm}$ caused no symptoms of intoxication, but a $10-\mathrm{min}$ exposure to hexane at $5000 \mathrm{ppm}$ caused marked vertigo. Heptane caused moderate vertigo after 4-min exposures at $3500 \mathrm{ppm}$, and marked vertigo after $4-\mathrm{min}$ exposures at $5000 \mathrm{ppm}(5,7)$.

Several reports show that exposure of workers to n-hexane causes polyneuropathy and polyneuritis $(1,20,21)$. In most cases, however, no measurements of solvent vapor concentration was reported. Sax suggested 
that occupational neuropathy cesulted from exposures as low as $500 \mathrm{ppm}$ and below (21). Recently Iida (10) reported outbreaks of polyneuropathy and neurotoxicity in sandal factory workers exposed to $50 \mathrm{ppm}$ of $\mathrm{n}$-hexane. The need for lowering the TLV level for n-hexane and cyclohexane in shoe factories was suggested by Mutti et al. $(12,13)$ who also considered the possibility of the synergistic effects of the two hydrocarbon solvents. Potentiation of hexacarbon neurotoxicity by methyl-ethyl-ketone has been recognized in other studies $(1 \mathrm{~A}, 11)$. The evidence seems fairly convincing that the neurotoxic effect of $n$-hexane is not possessed by other hexane 1somers; however, other alkanes, especially heptane, may also be neurotoxic (4).

There have been some recent studies on the neurotoxicity and metabolism of hexane. The recognition that 2,5-hexanedione was the principal n-hexane metabolite found in the urine of shoe-factory workers exposed to commercial hexane was consistent with the idea that this compound was responsible for the development of neuropathy $(17-19)$. In experimental conditions 2,5-hexanedione and other gamma-diketones reacted with primary amines forming pyrrole adducts ( $\dot{6})$. These authors suggested that the pyrrole formation is the probable mode of in vivo tissue binding of 2,5-hexanedione.

Clinical and morphological studies of cases of neuropathy due to $\mathrm{n}$-hexane reveal alterations of both myelin sheaths and axons (22). Study of $\mathrm{H}$-reflex behavior in $\mathrm{n}$-hexane neuropathy gives evidence of spinal involvement in these patients (2); others also suggest the neurotoxic effect of $n$-hexane on the central nervous system (13). Studies on the respiratory uptake and elimination of n-hexane during physical exercise show considerable differences in inspired hexane at different levels of exercise (25). Although the exact mechanism of hexacarbon neurotoxicity has not yet been identified, an interference with neuronal axoplasmic flow seems most likely.

No studies correlating environmental concentrations of pentane, hexane, heptane, with observed toxic effects have been found, except for those relating industrial exposures to $n$-hexane with the development of polyneuropathy. Nor were any long-term epidemiologic studies of low-level occupational exposures to alkanes found. 
Octane has been reported as a compound producing giddiness, vertigo, headache, and anesthetic stupor or apneic anoxia. Also, epileptiform selzures were observed months after acute eplsodes. Pathological examination of tissue from fatal cases showed widespread microhemorrhage (23).

Effects of liquid alkanes on the skin were studied on five volunteers under laboratory conditions. One-hour skin contact produced irritation, and swelling. Blisters appeared after longer exposure $(16,20,21)$. Increased numbers of carbons in the alkane chain were correlated with the increased intensity of symptoms and with the increased length of time needed for the disappearance of pain after removal of alkanes (B).

Morphea-like skin lesions have been recognized in patients with systemic scleroderma who were engaged in occupations exposing them to organic solvents for a long time before the symptoms appeared (26).

No studies showing carcinogenic, mutagenic, or teratogenic potential of alkanes $\left(C_{5}-C_{8}\right)$ have been found.

Alkanes W1th $\mathrm{C}_{9}$ to $\mathrm{C}_{12}$ Carbon Cha1ns (nonane, decane, undecane, and dodecane)

Nonane and decane in high concentrations are central nervous system depressants. They are considered relatively nontoxic. The 5-nonanone showed the same degree of neurotoxicity as n-hexane and methyl-n-buty1ketone. The neurotoxicities of these three compounds were limited by virtue of their metabolism to a gamma-diketone (15). No epidemiological studies on the effects of $\mathrm{C}_{9}-\mathrm{C}_{12}$ alkanes have been found.

Undecane and dodecane. No human data were found. Animal studies suggest that dodecane may act as a potentiator of the skin carcinogen benzo[a]pyrene.

Hexane Isomers $\mathrm{C}_{6} \mathrm{H}_{14}$

2-Methylpentane. The toxic effect has not been sufficiently Investigated, although irritation of mucous membranes and a low oral toxicity are suspected. There is no evidence of neurotoxicity $(16,23)$.

3-Methylpentane. The toxicity is presumably parallel to that of 2-methylpentane, but no data on human reaction have been found. 


\section{2,2-Dimethylbutane. No data found.}

2,3-Dimethylbutane has been found in glue solvents which cause polyneuropathy; there are, however, no data indicating what component of the solvent was the causative agent.

\section{Alicyclic Hydrocarbons}

Methylcyclopentane (Methylpentamethylene) $\mathrm{C}_{6} \mathrm{H}_{12}$. Methylcyclopentane was a component of glue solvents which produced polyneuropathy, but the effects of separate components of glue solvent have not been determined.

The concentration of n-hexane and its isomers, acetone, and methylcyclopentane, was measured in the environmental air in a shoe factory and in the alveolar air ind biood of workers. Lung uptake and alveolar and bloc: concentration were correlated with environmental concentration of methylcyclopencane, 2-methylpentane, and 3-methlypentane (3).

\section{References}

1. ACGIH. 1980. Documentation of the threshold 1imit values. Fourth Edition. American Conference of Governmental Industrial Hygienists Inc., $\mathrm{OH}$.

1A. Altenkirch, H., H.M. Wagner, G. Stoltenburg-Didinger, and R. Steppat. 1982. Potentiation of hexacarbon-neurotoxicity by methyl-ethyl-ketone (MEK) and other substances: Clinical and experimental aspects. (Toxline Abstract). Neurobehav. Toxicol. Teratol. 4: 623-7.

2. Bravaccio, F., A. Ammendola, L. Barruffo, and S. Carlomagno. 1981. H-reflex behavior in glue (n-hexane) neuropathy. (Toxline Abstract). clin. Toxicol. 18: 1,369-75.

3. Brugnone, F., L. Perbellini, L. Grigolini, and P. Apostoli. 1979. Solvent exposure in a shoe upper factory; II Methylcyclopentane, 2-methylpentane, and 3-methylpentane concentration in alveolar and in environmental air and in blood. (Toxline Abstract). Int. Arch. occup. Environ. Health 42: 355-64.

4. Chauplannaz, G., B. Bady, N. Kopp, R. Levrat, and M. Trillet. 1982. [Peripheral neuropathy due to n-hexane in a drug addict (author's trans1.)]. (Toxline Abstract). Rev. Neurol. (Paris) 138: 249-51.

5. Cour1, D. and M. Milks. 1982. Toxictty and metabolism of the neurotoxic hexacarbons n-hexane, 2-hexanone, and 2,5-hexanedione. (Toxline Abstract). Annu. Rev. Pharmacol. Toxico1. 22: 145-66. 
6. DeCaprio, A.P., F.J. 0lajos, and P. Weber. 1982. Covalent binding of a neurotoxic $n$-hexane metabolite: conversion of primary amines to substituted pyrrole adducts by 2,5-hexanedione. (Toxline Abstract). Toxicol. Appl. Pharmacol. 65: 440-50.

7. EPA. 1977. Multimedia Environmental Goals for Environmental Assessment. Volume I. EPA-600/7-77-136a, Indust ria? Environmental Research Laboratory, Washington, D.C.

8. Gosselin, R.E., H.C. Hodge, R.P. Smith, and M.N. Gleason. 1979. Clinical toxicology of commercial products. The Williams \& Wilkins Co., MD, Pp. 86-92.

10. Iada, M. 1982. Neurophysiological studies of $\mathrm{n}$-hexane polyneuropathy in the sandal factory. (Toxline Abstract). Electroencephalogr. Clin. Neurophysio. [Supp1.] 36: 671-81.

11. Lagueny, A., J. Julien, J.M. Vallat, X. Ferrer, P. Deliac, and M.M. Deliac. 1982. [Electrophyslological study of 2 cases of polyneuritis Induced by a combination of n-hexane-methyl-ethyl ketone]. (Toxilne Abstract). Rev. Electroencephalogr. Neurophysiol. C1in. 12: 158-66.

12. Mutt1, A., F. Ferr1, G. Lommi, S. Lotta, S. Lucertini, and I. Franchini. 1982. N-hexane-induced changes in nerve conduction velocities and somatosensory evoked potentials. (Toxline Abstract). Int. Arch. Occup. Environ. Health 51: 45-54.

13. Mutt1, A., A. Cavatorta, , G. Lommi, S. Lotta, and I. Franchini. 1982. Neurophysiological effects of long-term exposure to hydrocarbon mixtures. (Toxline Abstract). Arch. Toxicol., Suppl. 5: 120-4.

14. NIOSH. Criteria for a Recommended Standard.... Occupational Exposure to Alkares (C5-C.8). U.S. Department of Health, Education, and Welfare, Public Health Services, Center for Disease Control.

15. O'Donoghue, J.L., W.J. Krasavage, G.D. Divincenzo, and D.A. Ziegler. 1982. Commercial grade methyl heptyl ketone (5-methy1-2-octanone) neurotoxictity: Contribution of 5-nonanone. (Toxline Abstract). Oxicol. App1. Pharmacol. 62: 307-16.

16. Patty, F.A. 1982. Patiy's industrial hygiene and toxicology, Volumes 2A, 2B, and 2C. Third Revised Edition. John Wiley \& Sons, NY.

17. Perbellini, L., F. Brugnone, and E. Gaffur1. 1981. Neurotoxic metabolites of "commercial" hexane; in the urine of shoe factory workers. (Toxline Abstract). Clin. Toxicol. 18: 1377-85.

18. Perbellini, L., F. Brugnone, R. Silvestri, and E. Gaffuri. 1981. Measurement of the urinary metabolites of n-hexane, cyclohexane and their 1somers by gas chromatography. (Toxline Abstract). Int. Arch. Occup. Environ. Health 48: 99-106. 
19. Perbellin1, L., M.C. Amantin1, F. Brugnone, and N. Frontal1. 1982. Urinary excretion of n-hexane metabolites. A comparative study in rat, rabbit, and monkey. (Toxline Abstract). Arch. Toxicol. 50: 203-15.

20. Proctor, N.H. and J.P. Hughes. 1978. Chemical hazards of the workplace. J.B. Lippincott Company, PA.

21. Sax, N.I. 1975. Dangerous properties of 1ndustrlal matertals. Fourth Edition. $V$ an Nostrand Reinhold Company, NY.

22. Scels1, R., P. Pogg1, L. Fera, and G. Gonella. 1981. Industrial neuropathy due to n-hexane. Clinical and morphological findings in three cases. (Toxline Abstract). Clin. Toxicol. 18: 1387-93.

23. Toxicology Data Bank. National Library of Medicinf (Computer search, 1982.)

24. The Merck Index. 1976. An encyclopedia of chemicals and drugs. Ninth edition. Merck \& Co., Inc., Rahway, NJ.

25. Veulemans, H., E. Van Vlem, H. Janssens, R. Masschelein, and A. Leplat. 1982. Experimental human exposure to $n$-hexane. Study of the respiratory uptake and elimination, and of $n$-hexane concentrations in peripheral venous blood. (Toxline Abstract). Int. Arch. Occup. Environ. Health 49: 251-63.

26. Yamakage, A. and H. Ishikawa. 1982. Generalized morphea-like scleroderma occurring in people exposed to organic solvents. (Toxline Abstract). Dermatologica (Base1) 165: 186-93. 


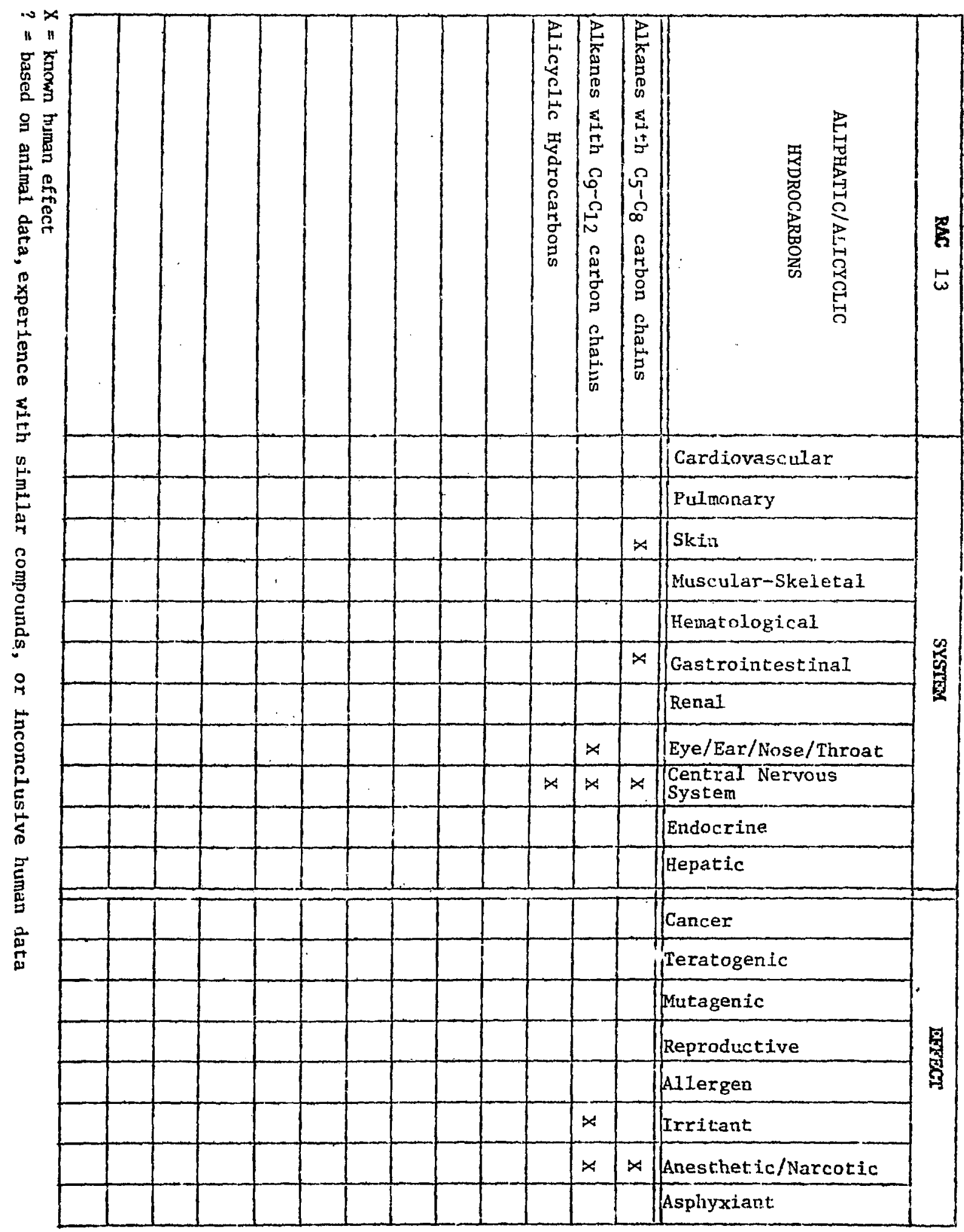




\section{RAC \#14 - MONO/DIAROMATIC HYDROCARBONS (EXCLUDING BENZENE)}

Mono- and diaromatic hydrocarbons are Gitivatives of benzene. Monoaromatic Hydrocarbons

Monoaromatic hydrocarbons are single ring aromatic hydrocarbons with one or more substitutions.

Alkyl Benzenes (toluene, xylene, ethyl benzene, cumene, styrene, and methyl styrene) are single benzene ring compounds, with aliphatic side chains attached. Thry are colorliss ilquids with a relatively low boiling point and a characteristic odor of aroratic hydrocarbons. Human exposure to concentrations up to $200 \mathrm{ppm}$ produce mila to moderate symptoms of fatigue, headache, and eye and throat irritation. Concentrations above $200 \mathrm{ppm}$ produce gastrolntestinal symptoms, injuries to the heart, liver, and kidneys, pulmonary injurles, and neurological disturbances. Concentrations reachlng about $800 \mathrm{ppm}$ and/or long-term exposures may be fatal.

Indene and Indan are single benzene ring compounds with a cyclopentane ring attached. The toxic effects of indene and Indan have not been studied in humans. Experiments on antmals suggest possible Inhalation toxicity.

Diaromatic Hydrocarbons

Diaromatic hydcocarbons include hydrocarbons composed of two benzene rings (biphenyl, naphthalene) and their methy1-derivatives (methyl naphthalenes). Dfaromatic hydrocarbons appear as crystalline halves or scales dith strong specifled odor. Exposure to the fumes affects the gastrolntestinal, pulmonary, and nervous systems. Severe Intoxication may be produced by ingestion.

Monoaromatic Hydrocarbons

\section{Alky1 Benzenes}

Toluene (Methyl Benzene, Phenyl Methane, Toluol) $\mathrm{C}_{6} \mathrm{H}_{5} \mathrm{CH}_{3}$. Toluene is a clear liquid with benzene-like odor. The major source (96\%) is from petroleum. About $70 \%$ of produced toluene is converted into benzene. Another $15 \%$ is used in the production of chemlcals, and the remainder is used as a solvent for palnts and as a component of gasoline.<smiles>Cc1ccccc1</smiles> 
Exposure to toluene produces neurotoxic effects. Experímental 8-hr exposures to essentially pure toluene at concentrations up to 200 ppm produced mild to mocicrate fatigue, slight headache, and mild eye and throat Irritation. Increased concentrations of toluene up to $400 \mathrm{ppm}$ intensified the above symptoms and produced muscular weakness, impaired coordination, and moderate dilation of pupils. Exposures at 400 to $800 \mathrm{ppm}$ produced narcotic effects leading to mental confusion, considerable incoordination, lack of self-control, änd staggering gait. Similar effects were observed in 100 workers exposed to toluene concentrations ranging from 50 to $200 \mathrm{ppm}$, 200 to $500 \mathrm{ppm}$, and 500 to $1500 \mathrm{ppm}(1,40,42,52,59)$. An increased risk of neuropsychlatric diseases has been recently reported in epidemiological studies in Finland (29A).

Most reports of occupational exposures to toluene lack information about either the purity of toluene or the accurate atmospheric concentration of toluene and other solvent vapors at work sites (1).

Acute low-level exposure to organic solvent vapors may result in prenarcotic states of central nervous system depression. Progressive Increase of reaction time was observed at toluene exposures of $300 \mathrm{ppm} / 30$ minutes (65).

Inhalation of high doses (glue sniffing) produces encephalopathy and may lead to permanent neurological damage (7), cerebellar degeneration (29), cerebral cortical atrophy (53), optic neuropathy and the loss of hearing (15), or sudden death from cardiac arrhythmia (1). Clinical findinge on 25 adults hospitalized for problems related to paint sniffing showed neuropsychiatric disorders (altered mental status, cerebellar abnormalities, and peripheral neuropathy) in 10 patients, muscle weakness in 9 patients, and gastrointestinal complaints in 6 patiants. Laboratory data showed a ciecrease in potassium and phosphorus and an increase in chlorine and carion dioxide in the blood serum (55). Renal acidosis and multiple metabolic abnormalities were recognized in a group of 16 patients hospitalized for paint sniffing (62). Hypokalemic periodic paralysis was also reported in dermic exposure to toluene (8). Toluene skin contact can cause irritation.

Reports on the effects of toluene on the hematopoletic system are not clear since the benzene content of the toluene was not reported. Some studies on chromosome aberrations report that the exposure to toluene does 
not affect sister chromatid exchange $(23,30)$. However, cytogenatic analyses of perlpheral leucocytes from 20 male workers exposed only to toluene for wore than 16 years showed ylelds of chromatd breaks, chromatid exchanges and gaps significantly higher than in a group of 24 unexposed workers (7). Cytoenzymat1c studies of neutrophils in workers show that the exposure to solvents contalning benzene, toluene, and xylene produces increased activity of acid phosphatase and beta-glucuronidase, dacreased activity of peroxidase and decrease in giycogen reserves (32, 33$)$. Metabolic end product toluene is hippuric actd excreted in the urine. The correiation between exposure to toluene and excreted hippuric acid is commonly observed $(2,4,22,28,31,57,58,60,61)$. However, the Intake of benzolc acid in foodstuffs (ralsins, coffee, certain fruits and vegetables, preservatives, and medicine) can cause a 3-fold increase in the excretion of hippuric acid and in particular cases a 10-fold increase in the normal excretion $(64,66)$. Thus the food intake should be considered in the evaluation of tolitene exposure when measuring hippuric acid excretion. A number of studies are devoted to the Improvement of laboratory methods evaluating the excretion of hippuric acid $(9,11,25,34,36-39,43,47$, 56).

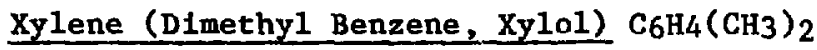<smiles>Cc1ccccc1C</smiles>

Xylene is a clear flammable liquid with an aromatlc hydrocarbon odor. Commercially avallable xylene is a mixture of three 1somers (ortho, meta, and para). Xylene is used extensively as a solvent in paints. All isomers are used in making drugs, dyes, and insecticldes, and in the preparation of phthallc acids. Xylene is also present in gasoline.

Toxic effects of xylene are sluilar to or higher than toluene. Workers exposed to xylene complained of headache, fatigue, lassltude, Irritability, and gastrointestinal disturbances. Neurological disturbances, and injury to the heart, liver, kidneys, and nervous system were also observed. Xylene and toluene are probably greater irritants than benzene to the eyes and mucous membranes of the resplratory tract (1). Eplleptiform selzures were 
reported in a patient after a brief exposure to xylene vapor and in a patient who had sniffed glue $(1,5,27)$. The death from aplastic anemia of a lithographer who used xylene for several years has also been reported (1). In most cases of blood disease associated with xylene, the presence of benzene as an impurity was not ruled out.

The product of $x y l e n e$ metabolism is methylhippuric acid excreted in urine. Its distinction from the urinary hippuric acid by new methods allows the evaluation of xylene and toluene exposures (37-39). Controversial results were reported on the effect of xylene and alcohol on the central nervous system. Xylene efther enhanced $(48,49)$ or counteracted (54) the effect of alcohol. In one study, ingestion of ethanol before exposure to xylene produced an 1.5- to 2.0-fold increase in the blood xylene level and about a $50 \%$ decline in the excretion of urinary methylhippuric acid, thus suggesting that ethanol decreased the metabolic clearance of xylene (46).

Acute impairment of body balance directly related to the xylene uptake was correlated with xylene concentration in the blood. Rilhimaki (46) considers that brain tissue will reach xylene equilibrium within a few minutes and brain xylene concentration probably closely follows blood xylene levels. Inhalation exposure of male volunteers to $\mathrm{m}-\mathrm{xylene}(200 \mathrm{pm})$ for 4 hours at 6-day intervals over a six-week period induced only slight changes in psychophysiological functions (body sway and reaction time) (48-51). Postexposure excretion of xylene from most tissues except adipose tissue takes place rapidiy. The uptake of xylene by adipose tissue is greatly enhanced by physical exercise $(17,45)$.

Xylene has a defatting action on the skin and contact can cause erythema and blistering (19A).

Ethyl Benzene $\mathrm{C}_{6} \mathrm{H}_{5} \mathrm{C}_{2} \mathrm{H}_{5}$<smiles>CCc1ccccc1</smiles>

Ethyl benzene is a colorless, flammable liquid with an aromatic odor. It is used as a solvent and as an intermediate in the production of styrene. 
Ethyl benzene toxicity produces sinin and less narkedly mucous membrane irritation. Skin reddening, exfoliation, and blistering observed in rats suggested that ethyl benzene is the most severe irritant of the benzene series.

Human exposure to $200 \mathrm{ppm}$ produces transient eye irritation. Increased concentration up to $2000 \mathrm{ppm}$ produces immediate and severe eye irritation and lacrimation accompanied by moderate nasal irritation. Vapor concentrations at $5000 \mathrm{ppm}$ cause intolerable 1rritation (1).

Aspiration of a small amount of ethyl benzene can cause severe pulmonary injury. TDB reported the possiblity of toxic hepatitis, leukopenta, and lymphocytosis from prolonged exposure. The acute toxicity is low ( $10,000 \mathrm{ppm}$ is fatal for guinea pigs in a few minutes). Studies on simultaneous exposures to ethylbenzene and xylenes indicate a competitive reaction mechanism between these compounds and suggest possible carcinogenic properties of epoxides formed as intermediates (4).

Cumene (Isopropylbenzene, 2-Phenylpropane, 1-Methyl Ethyl Benzene) $\mathrm{C}_{6} \mathrm{H}_{5} \mathrm{CH}\left(\mathrm{CH}_{3}\right)_{2}$

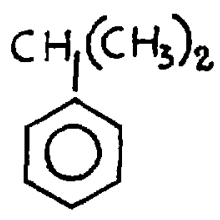

Cumene is a colorless liquid manufactured exclusively from propylene and benzene. It is used in the production of acetone, phenol, and methylstyrene, and as a solvent.

Cumene is a potent narcotic but the hazards of use are minimized by virtue of its relatively high bolling point and hence low vapor pressure. Cumere is considered a primary skin and eye irritant. It is absorbed by the skin more rapldly than toluene, xylene, or ethylbenzene. The small quantity of cumene absorbed in blood is exhaled unchanged, but the major portion is metabolized in the liver and excreted in the urine as conjugated alcohols or acids (1).

The suggested TLV of $50 \mathrm{ppm}$ and STEL of $75 \mathrm{ppm}$ are recommended on the basis solely of animal studies. East Germany and USSR recommendations $(1972 / 73)$ are $10 \mathrm{ppm}$. 
Styrene (Phenyl Ethylene, Ethenylbenzene, Vinyl Benzene) $\mathrm{C}_{6} \mathrm{H}_{5} \mathrm{CH}=\mathrm{CH}_{2}$

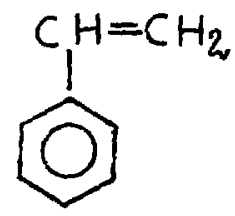

Styrene monomer is a colorless ofly liquid with an aromatic odor. It is commonly used in making polystyrene plastics, protective coatings, styrenated polyesters, copolymer resins, as a solvent, and as a chemical intermediate.

"Styrene sickness" (lightheadedness, drowsiness, nausea, and dizziness) has been reported after exposures at 200 to $700 \mathrm{ppm}$ (1).

The accumulation of acute toxic quantities is unlikely since odor threshold is $0.1 \mathrm{mg} / 1 \mathrm{iter}$, and is objectionable at $200 \mathrm{ppm}$. Increased accumulations produce neurological impairment and strong irritation of eyes and nasal mucous membrane. Concentrations of $800 \mathrm{ppm}$ produce immediate eye and throat irritations, nasal mucous secretion, drowsiness, and vertigo. After three hours' exposure, slight muscular weakness occurs accompanied by inertia and depression (40).

Metabolic end products of styrene are phenylglyoxylic acid and mandelic acid which are excreted in urine. The measurements of these acids in urine serves as biological monitors for the evaluation of exposure to styrene (10, $13,14,16,18,19,21,64)$. The metabolites are rapidly removed from the body after cessation of exposure $(44,67)$.

ACGIH quotes a study by Dutkfewicz and Tyras which found that a brief contact of the hands with styrene, or one hour contact with styrene-saturated water resulted in absorption as great as 8 hours' inhalation of $12 \mathrm{ppm}$. However, mandelic acid excretion was much less than after lung absorption.

Styrene has been observed to cross the placental barrier and to produce defects in the central nervous system of offspring, although it is not clear if other solvents were involved. Reported chromosomal alterations are controversial. Andersson et al. (3), and Watanabe et al. (63) concluded that chromosome aberrations are not correlated with exposure to styrene. A distinct dose-dependent increase in sister-chromatid exchanges has been 
found in human whole-blood lymphocyte cultures treated with styrene, its methyl substituted derivatives, and with styrene oxides (35). The authors conclude that styrene and methyl styrenes were apparently converted into reactive metabolites in the above culture.

Lymphocytes from 38 individuals occupationally exposed to styrene $(1-40$ ppm) showed a significant increase in the mean level of N-acetoxy-2acetylaminofluorene-induce. unscheduled DNA synthesis (UDS) but no significant effect of W-induced UDS (41). Lymphocyte cultures in vftro exposed to styrene (100 wM) in the same study confirmed the above findings. The authors conclude that styrene exposure apparently does not Inhibit DNA repair synthesis, but rather it predisposes lymphocytes to an increased risk for DNA damage Induction from subsequent genotoxic exposures. Anemis and morphofunctional alterations of erythrocytes were reported by Gribova et al. (20) and by Khristevaand Mirchev (26).

\section{$\alpha$-Methyl Styrene (2-Phenyl Propene) $\mathrm{C}_{6} \mathrm{H}_{5} \mathrm{C}\left(\mathrm{CH}_{3}\right)=\mathrm{CH}_{2}$}<smiles>C=C(C)c1ccccc1</smiles>

$\alpha$-Methyl styrene is a polymerizable liquid monomer.

Human subjects exposed to a concentration $200 \mathrm{ppm}$ of $r_{\text {-methyl styrene }}$ reported definite unpleasant odor and slight eye irritation after two minutes of exposure. No adverse effect was found in animal studies (40, 42).

Severe or prolonged exposure may cause depression of the central nervous system. Prolonged skin contact causes dermatitis.

\section{Allylbenzene (3-Phenylpropene) $\mathrm{C}_{6} \mathrm{H}_{5} \mathrm{CH}_{2} \mathrm{CH}=\mathrm{CH}_{2}$}<smiles>C=CCc1ccccc1</smiles>

Allylbenzene is a liquid synthetic fuel. No human data have been found. 
Indene and Indan

Indene $\left(\mathrm{C}_{9} \mathrm{H}_{8}\right)$

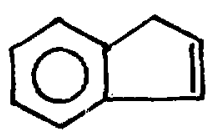

Indene is a colorless liquid. Its chief use is in the preparation of cumarone-indene resins. Inhalation of indene ts expected (by analogy of related monoaromatic hydrocarbons) to cause irritation of mucous membranes, but no quantitacive studies on human inhalation of indene vapors have been reported. Prolonged or repeated skin contact. with liquid indene has a defatting action on the skin and may lead to dermatitis. Studies on animals suggest possible inhalation toxicity (1).

Indan $\mathrm{C}_{9} \mathrm{H}_{10}$

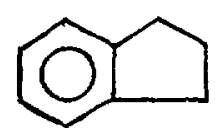

No human data found.

Diaromatic Hydrocarbons

Bipheny1 (Dipheny1, Phenylbenzene) $\mathrm{C}_{6} \mathrm{H}_{5} \mathrm{C}_{6} \mathrm{H}_{5}$

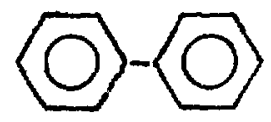

Biphenyl exists as white scales with a pleasant pecullar odor. Crystalline forms are also known. Because of its thermal stability, biphenyl is used as a heat-transfer agent, elther alone or mixed with diphenyl oxide. It is also used as a fungistat in the shipping of oranges and In organic syntheses.

Biphenyl is not particularly toxic by ingestion. Mild to moderate eye irritation was reported by workers exposed to the fume of an unknown concentration. 
A few cases of occupational biphenyl poisoning have been reported. Translent nausea, vomiting, and bronchitis were reported in workers exposed to biphenyl vapors during paper impregnation. Poor hygienic condition in another factory (concentration of biphenyl from 4.4 to $128 \mathrm{mg} / \mathrm{m}^{3}$ ) resulted in polsoning characterized by peripheral nerve injury and liver damage. One case of death resulted from acute liver atrophy. In still another plant, electroencephalic and electromyographic abnormalities were observed (1).

No threshold for safe worker exposure can be estimated from the currently avallable data. Studies on animals suggest a TLV of $0.2 \mathrm{ppm}$ an STEL of $0.6 \mathrm{ppw}$ until evidence indicating the need for a change is avallable.

\section{Naphthalene $\left(\mathrm{C}_{1} \mathrm{OH}_{8}\right)$}

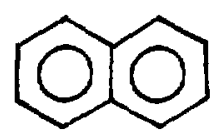

Naphthalene occurs commonly as white crystalline flakes which have a strong coal tar odor. Naphthalene is used in the household as a moth repellent; scientifically it is used in scintillation counters. Naphthalene represents raw materlal used for the manufacture of several derivatives. It is also used in the production of dyes, explosives, lubricants, tanning agents, and emulsion breakers.

Skin contact with naphthalene produces severe dermatitis. Inhalation of naphthalene vapors may cause headache, nausea, and sweating. Injuries of the cornea and optical neurltis, kidney damage, dysuria, and hematuria have been reported. Blankets contalning naphthalene have been known to cause acute hemolysis in infants, in some cases fatal (1).

Inhalation may produce hemolytic symptoms in persons with the red cell glucose-6-phosphate dehydrogenase deflciency. Hemolysis is accompanfed by anemia, leucocytosis, fever, hemoglobinuria, renal insufficiency, faundice, and disturbances in liver function. Symptoms often begin on the third day after ingestion. Bone marrow may appear hyperplastic. Death can occur from respiratory failure. The lethal doses are 2-3 $\mathrm{g}$ (children) and 5 to $15 \mathrm{~g}$ (adult). 
Ingestion of naphthalene causes abdominal cramps, vomiting, and diarrhea; listlessness and confusion and coma with convulsions may follow in severe poisonings. Irritation of the urinary bladder is presumably due to the excretory products of naphthalene metabolism.

\section{Methylnaphthalene $\mathrm{C}_{10} \mathrm{H}_{7} \mathrm{CH}_{3}$}<smiles>Cc1cccc2ccccc12</smiles>

$\boldsymbol{\alpha}$<smiles>Cc1ccc2ccccc2c1</smiles>

$\beta$

Methy1- and dimethylnaphthalenes occur in coke-oven tar and in certain petroleum fractions. Separation of Individual isomers seliom is attempted In the USA. The mixtures are used as solvents for pesticides, sulfur, various aromatic compounds, and in dyeing of synthetic fibers (27A). Limited animal experiments suggest high toxicity. No human data found.

\section{References}

1. ACGIH. 1980. Documentation of the threshold 1imit values. Fourth Edition. American Conference of Governmental Industrial Hyglenists Inc., $\mathrm{OH}$.

2. Alessio, L., P. Odone, G. Rivolta, R. Soma, and G. Confortini. 1981. Behavior of urinary hippuric acid in in occupationally exposed subjects and In workers with moderate exposure to toluene. (Toxline Abstract). Med. Lav. 72: 38-45.

3. Andersson, H.C., E.A. Tranberg, A.H. Uggla, and G. Zetterberg. 1980. Chromosomal aberrations and sister-chromatid exchanges in 1ymphocytes of men occupationally exposed to styrene in a plastic-boat factory. (Toxline Abstract). Mutat. Res. 73: 387-402.

4. Angerer, J. 1979. Metabolism of toluene in man. Int. Arch. Occup. Environ. Health 43: 63-8.

5. Arthur, L.J. and D.A. Curnock. 1982. Xylene-induced epilepsy following innocent glue sniffing (letter). (Toxline Abstract). Br. Med. J. (C11n. Res). 284: 1787 . 
6. Askergren, A., L.G. Allgen, and J. Bergstrom. 1981. Studies on kidney function in subjects exposed to organic solvents. II. The effect of desmopressin in a concentration test and the effect of exposure to organic sclvents on renal concentrating ablilty. (Toxline Abstract). Act a. Med. Scand. 209: 485-8.

7. Bauchinger, M., E. Schmid, J. Dresp, J. Kolin-Gerresheim, R. Hauf, and E. Suhr. 1982. Chromosome changes in lymphocytes after occupational exposure to toluene. (Toxline Abstract). Mutat. Res. 102: 439-45.

8. Bennett, R.H. and Forman, H.R. 1980. Hypokealemic periodic paralysis in chronic toluene exposure. (Toxline Abstract). Arch. Neuro1. 37: 673.

9. Bientek, G., E. Palys, and T. Wliczok. 1982. TLC separation of hippuric, mandelic, and phenylglyoxylic acids from urine after mixed exposure to toluene and styrene. (Toxline Abstract). Br. J. Ind. Med. 39: 187-90.

10. Caperos, J.R., B. Humbert, and P.0. Droz. 1979. Styrene exposure: II. Percentage studies of absorption, excretion, and metabolism by human subjects. (Toxline Abstract). Int. Arch. Occup. Environ. Health 42: $223-230$.

11. Catflifna, P. and Chamoux, A. 1980. Study of urinary excretion of hippuric acid in workers exposed to low amounts of toluene in the air. Discussion a'sout the value of this blological index of exposure. (Toxline Abstract). Arch. Mal. Prof. Med. Trav. Secur. Soc. 41: 141-6.

12. Checkoway, H. and T.M. Williams. 1982. A hematology survey of workers at a styrene-butadiene synthet1c rubber manufacturing plant. (Toxline Abstract). Am. Ind. Hyg. Assoc. J. 43: 164-9.

13. Cherry, N., B. Rodgers, H. Veanbles, H.A. Waldron, and G.G. Wells. 1981. Acute behavioral effects of styrene exposure: A further analysis. (Tox1Ine Abstract). Br. J. Ind. Med. 38: 346-50.

14. Cranda11, M.S. 1981. Worker exposure to styrene monomer in the reliforced plastic boat-making industry. (loxline Abstract). Am. Ind. Hyg. Assoc. J. 42: 499-502.

15. Ehyal, A. and F.R. Fremmon, 1983. Progressive optic neuropathy and sensorineural hearing $108 s$ due to chronic glue sniffing. (Toxline Abstract). J. Neurol. Neurosurg. Psychlatry 46: 349-51.

16. Ella, V.J., L.A. Anderson, T.J. MacDonald, A. Carson, C.R. Buncer, and S.M. Brooks. 1980. Determination of urinary mandelic acld and phenylglyoxylic acid in styrene exposed workers and a control population. (Toxline Abstract). Am. Ind. Hyg. Assoc. J. 41: 922-6. 
17. Engstrom, J. and $V$. Rilhiwak1. 1979. Distrijution of m-xylene to subcutaneous adipose tissue in short-term experimental human exposure. (Toxline Abstract). Scand. J. Work Environ. Health 5: 126-34.

18. Fields, R.L. and S.W. Horstman. 1979. Biomonitoring of Industrial styrene exposures. (Toxline Abstract). Am. Ind. Hyg. Assoc. J. 40: 451-9.

19. Flek, J. and V. Sedivec. 1980. Simultaneous gas chromatographic determination of urinary mandelic acid and phenylglyoxylic acid using diazomethane derivat $1 \%$ ton. (Toxline Abstract). Int. Arch. Occup. Environ. Health 45: $181-0$.

19A. Gosselin, R.E., H.C. Hodge, R.P. Smith, and M.N. Gleason. 1979. Clinical toxicology of commercial products. The Williams \& Wilkins Co., MD, pp. 86-92.

20. Gribova, I.A., I.A. Guseinov, N.P. Pavlyuchenko, N.S. Sorokina, and V.V. Sokolov. 1980. Effect of toxic factors on morphofunctional changes of erythrocytes. (Toxline Abstract). Gig. Sanit. 6: 74-6.

21. Guillemin, M.P. and D. Bauer. 1979. Human exposure to styrene: 3. Elimination kinetics of urinary mandelic acid and phenylglyoxylic acid after single experimental exposure. (Toxline Abstract). Int. Arch. Occup. Environ. Health 44: 249-63.

22. Gutewort, T., J. Gartzke, and R. Pannler. 1981. The rate of excretion of hippuric acid in urine in evaluating occupational exposure to toluene. (Toxline Abstract). Z Gesamte Hyg. Grenzgeb 27: 57-63.

23. Haglund, U., I. Lindberg, and L. Zech. 1980. Chromosome aberrations and sister chromatid exchanges in Swedish paint industry workers. Scand. J. Work. Environ. Health 6: 291-8.

24. Hansen, S.H. and M. Dossing. 1982. Determination of uriaary hippuric acid and o-cresol, as indices of toluene exposure, by liquid chromatography on dynamically modifled silica. (Toxline Abstract). J. Chromatogr. 229: 141-8.

25. Hasegawa, K., X. Seiji, S. Shiofima, A. Kolzumi, and M. Ikeda. 1979. Comparative evaluation of colorimetry, gas liquid chromatography and high performance liquid chromatography for the determination of urinary hippuric acid. (Toxline Abstract). Ind. Health 17: 215-22.

26. Khrlsteva, V. and N. Mirchev. 1981. Changes in the peripheral blood of workers employed in several chemical industries. (Toxline Abstract). Khig. Zdraveopaz 24: 36-41.

27. KIng, M.D., R.E. Day, T.S. Oliver, M. Lush, and J.M. Watson. 1981. Solvent encephalopathy. (Toxline Abstract). Br. Med. J. (Clin. Res.) 283: $663-5$. 
28. Kuo, T.L., J.M. Fong, and S.W. How. 1980. Urinary excretion of hippuric acid as a blological parameter of exposure to toluene. (Toxline Abstract). J. Foromsan Med. As8oc. 79: 686-93.

29. Lachapelle, J., F. Duplantis, S. Rousseau, J. Bolleau, and I.E. Roy. 1982. Cerebellar degeneration due to toluene toxiclty. (Toxline Abstract). Unton Med. Cen. 111: 132-3.

29A. Lindstrom, K. 1982. Behavioral effects of long-term exposure to organic solvents. (Toxline Abstract). Acta Neurol. Scan. (Supp1.) 92: $131-41$.

30. Maki-Paakkanen, J., K. Husgafve1-Pursialnen, P.L. Kallomaki, J. Tuominen, and M. Sorsa. 1980. Toluene exposed workers and chromosóme aberrations. (Toxline Abstract). J. Toxico1. Environ。 Health 6 : 775-82.

31. Metes, L., V. Coldea, and C. Szanto. 1981. Effects of occupational exposure to toluene in a group of workmen from the woodprosessing industry. (Toxline Abstract). Rev. IG Bacterlol V1rusol Parazitol Epidemiol. Pneumoftiziol. Ser. IG 30: 55-60.

32. Moszczynsk1, P. 1980. Cytoenzymatic studies on neutrophils in workers having contact with organic solvents containing benzene, toluene, and xylene. (Tox1lne Abstract). Folla Hemato1. 107: 747-56.

33. Moszczyusk1, P. 1983. The effect of working environment contaminated with organic solvents on the activity of acid phosphatase in 1ymphocytes. (Tox1 ine Abstract). Med. Interne 21: 37-42.

34. N11numa, Y., T. Saka1, S. Yanagihara, S. Nakahira, Y. Kunug1, and K. Ushio. 1982. Simultaneous determinations of urinary hippuric and methylhippuric acids in solvent-workers by high-performance liquid chromatography, (Toxline Abstract). Sangyo Igaku 24: 322-3.

35. Norppa, H. and H. Vainio. 1983. Induction of sister-chromatid exchanges by atyrene analogs in cultured human lymphocytes. (Toxline Abstract). Mutat. Res. 116: 379-87.

36. Ogata, M. and T. Hobara. 1979. A new direct method for colorimetric determination of hippuric acid and methylhippuric acid as indines of toluene and m-xylene, and Its application to workers using chinner. (Toxline Abstract). Ind. Health 17: 61-72.

37. Ogata, M. and T. Hobara, 1980. A new direct method for colorimetric determination of hippuric acid and methylhippuric acid as indices of toluene and m-xylene, and its application to workers using thinner. (Toxline Abstract). Ind. Health 17: 61-72.

38. Ogata, M., Y. Yamazaki, R. Sugihara, Y. Shimada, and T. Meguro. 1980. Quantitation of urinary o-xylene metabolites of rats and humans by high performance liquid chromatography. (Toxline Abstract). Int. Arch. Occup. Environ. Health 46: 127-40. 
39. Ogata, M. 1981. Quantitative determination of urinary metabolites in subjects exposed to organic solvents. (Toxline Abstract). Acta Med. Okayma 35: 385-94.

40. Patty, F.A. 1982. Patty's industrlal hygiene and toxicology, Volumes 2A, 2B, and 2C. Third Revised Edition. John Wiley \& Sons, NY.

41. Pero, R.W., T. Bryngelsson, B. Hogstedt, and B. Akesson. 1982. Occupational and in vitro exposure to styrene assessed by unscheduled DNA synthesis in resting human lymphocytes. (Toxline Abstract). Carcinogenesis (Lond). 3: 681-6.

42. Proctor, N.H. and J.P. Hughes. 1978. Chemical hazards of the workplace. J.B. Lippincott Company, PA.

43. Radzikowska-Kintz1, H. and Jakubowsk1, M. 1981. Interna1 standardization in the head space analysis of organic solvents in blood. (Toxline Abstract). Int. Arch. Occup. Environ. Health 49: $115-24$.

44. Ramsey, J.C. J.D. Young, R.J. Karbowsk1, M.B. Chenoweth, L.P. McCarty, and H.H. Braun. 1980. Pharmacokinetles of inhaled styrene in human volunteers. (Toxline Abstract). Toxico1. Apply. Pharmaco1. 53: 5463.

45. RIihlmak1, V. and K. Savolainen. 1980. Human exposure to m-xylene. Kinetics and acute effects on the central nervous system. (Toxline Abstract). Ann. Occup. Hyg. 23: 411-22.

46. Rithimak1, V., K. Savolainen, P. Pfaff11, K. Pekar1, H.W. Sippel, and A. Laine. 1982. Metabolic interaction between mxylene and ethanol. (Toxline Abstract). Arch. Toxicol. 49: 253-63.

47. Sato, M., O. Mighloka, S. Kamlyama, K. Hasegawa, and H. Ikeda. 1980. Comparative evaluation of the paper chromatographic and high performance liquid chromatographic methods for the determination of urinary hippuric-acid. (Toxline Abstract). Ind. Health 18: 211-4.

48. Savolainen, K., V. Rilhimak1, A. Laine, and J. Kekonf. 1981. Shortterm exposure of human subjects to m-xylene and 1,1,1-trichloroethane. (Toxline Abstract). Int. Arch. Occup. Environ. Health 49: 89-98.

49. Savolainen, K. and V. RAlhimaki. 1981. Xylene and alcohol involvement of the human equilibrium system. (Toxline Abstract). Acta Pharmacol. Toxicol 49: 447-51.

50. Savolainen, K., V. RAlhiraki, A. Laine, and J. Kekonl. 1982. Shortterm exposure of human subject to m-xylene and 1,1,1-trichlorethane. (Toxline Abstract). Arch. Toxicol (Suppl.) 5: 96-9. 
51. Savolainen, K., Y. Rilhimakt, and A. Laine. 1982. Biphasic effects of Inhaled solvents on human equilibrlum. (Toxline Abstract). Acta Pharamacol. Toxicol. 51: 237-42.

52. Sax, N.I. 1975. Dangerous properties of industrial materials. Fourth Edition. Van Nostrand ReInhold Company, NY.

53. Schikler, K.N., K. Seitz, J.F. Rfce, and T. Strader. 1982. Solvent abuse assoclated cortical atrophy. (Toxline Abstract). J.Adolesc. Health Care 3: 37-9.

54. Seppalainen, A.M., K. Savolainen, and T. Kovala. 1980. Effects of xylene and alcohol on human visual evoked potentials. (Toxline Abstract). Dev. Toxico1. Environ. Sc1. 8: 83-6.

55. Streicher, H.Z. et al. 1981. Syndromes of toluene sniffing in adults. (Toxline Abstract). Ann. Intern. Med. 94: 758-62.

56. Sugihara, R. 1979. High-performance 11quid chromatographic studies of tolvene and xylene poisoning. I. Workers' exposure to toluene and xylenes estimated from metabolites in their urine in a shipyard. (Tox11ne Abstract). Okayama Igakka1 Zasssh1 91: 1427-32.

57. Tabuch1, T., M. Hayash1, and I. Hara. 1981. Relationship between time weighted average concentration of organic solvents and their urinary metabolites. On the case of workers handling toluene and xylene. (Toxline Abstract). Osaka-furitsu Koshu Eisei Kenkyusho Kenkyu Hokoku, Rodo E1se1 Hen 19: 23-32.

58. Tahit1, H., S. Karka1nen, K. Pyykko, E. Rintala, M. Kataja, and H. Vapatalo. 1981. Chronic occupational exposure to toluene. (Toxline Abstract). Int. Arch. Occup. Environ. Health 48: 61-70.

59. U.S. Department of HEW, PHS, NIOSH. Occupational exposure to toluene.

60. Veulemans, H., E. Van Vlem, H. Jakssens, and R. Masschelein. 1979. Exposure to toluene and urinary hippuric acid excretion in a group of helionotagravure printing workers. (Toxline Abstract). Int. Arch. Occup. Environ. Health 44: 99-107.

61. Veulemans, H. and R. Masscheleln, 1979. Urinary hippuric acid excretion as a measure of individusi solvent uptake. (Toxline Abstract). Int. Arch. Occup. Environ. Health 43: 53-62.

62. Volghts, A. and C.E. Kaufman, Jr. 1983. Acldosis and other metabolic abnormalities assoclated with paint sniffing. (Toxline Abstract). South Med. J. 76: 443-7.

63. Watanabe, T. A. Endo, K. Sato, T. Ohtsuki, M. Miyasaka, A. Koizumi, and M. Ikeda. 1981. Mutagenic potential of styrene in man. (Toxline Abstract). Ind. Health 19: $37-46$. 
64. Hieczorek, H., E. Gesicka, and A. Stawska. 1981. Evaluation of the interrelation between the mandelic acid concentration in urine and the styrene concentration in air under conditions of occupational exposure. (Toxline Abstract). Przeg1. Lek. 38: 681-4.

65. Winneke, G. 1982. Acute behavioral effects of exposure to some organic solvents-psychophyslological aspects. (Toxline Abstract). Acta Neuro1. Scan. (Suppi.) 92: 117-29.

66. Yoshida, Y., A. Harada, K. Kono, S. Toyota, M. Watanabe, and Y. Shibuya. 1979. Gas and 1lquid chromatographtc determination of urinary hippuric actd as an index of toluene exposure. (Toxline Abstract). Bul1. Osaka Med. Sch. 24: 68-78.

67. Zechiesche, H., K. Gossler, K.H. Schaller, G. Triebig, D. Weltle, and J. Angerer. 1979. Blochemical methods for monttoring persons exposed to styrene. (Toxline Abstract). Berufskr. Keram. Glas-Ind. 28: 73. 


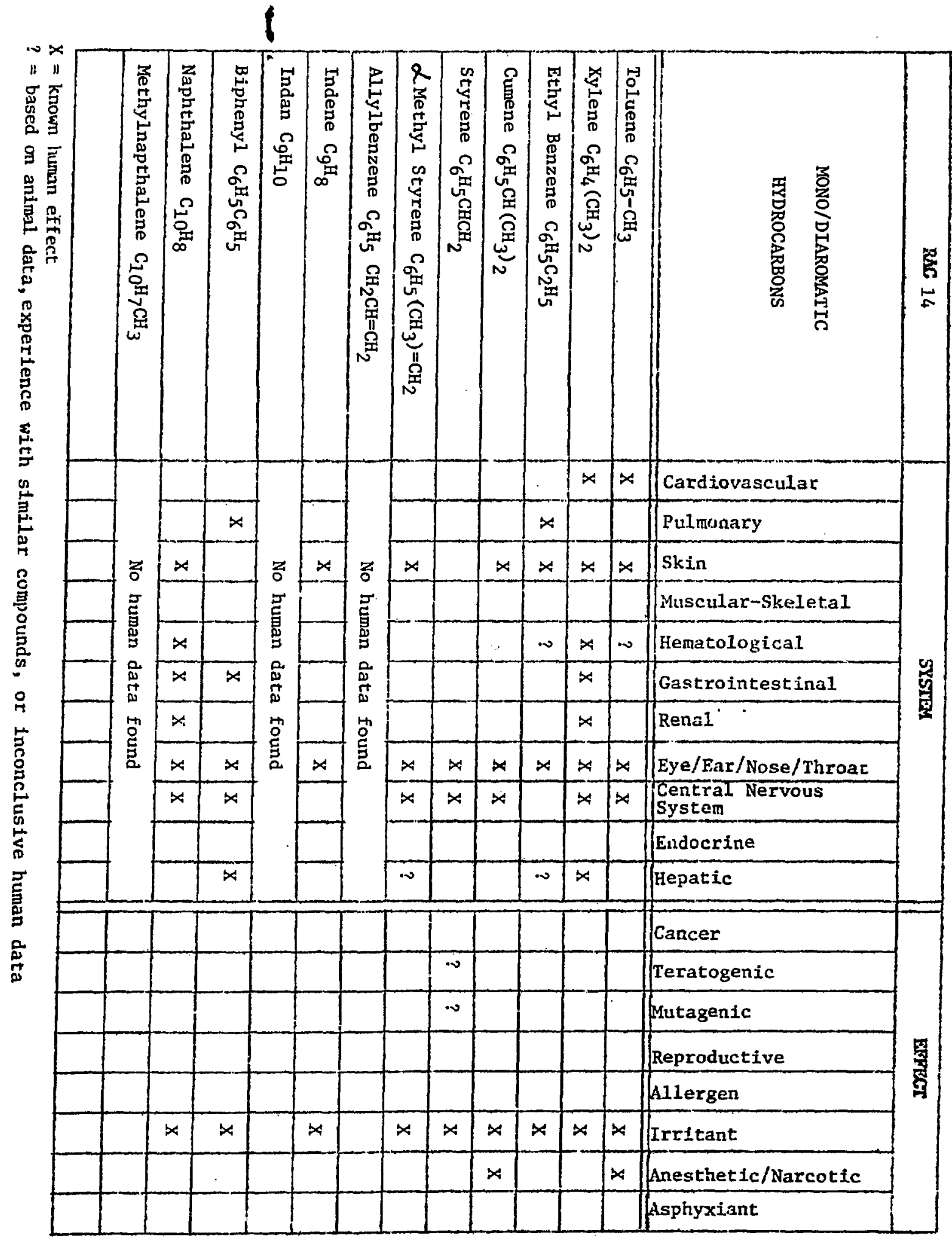


RAC \#15 - POLYCYCLIC AROMATIC HYDROCARBONS

\section{Overview}

Polycyclic aromatic hydrocarbons ( $P A H$ ) are a group of hydrocarbon compounds with three or more benzene rings. They are present in coal and are formet during the combustion of hydrocarbon fuels.

Polycyclic aromatic hydrocarbons reviewed in RAC \#15 include 51 compounds. These are grouped Into six subcategories.

1. Tricyclic hydrocarbons

2. Tetracyclic hydrocarbons (benzo-derivatives of tricyclics)

3. Pentacyclic hydrocarbons (dibenzo-derivatives of tricyclics and benzo-pyrenes)

4. Hexacyclic hydrocarbons (dibenzo-derlvatives of pyrene, benzo-perilene, and dibenzo-naphthacenes)

5. Fluorene, fluoroanthene and its benzo-derivatives

6. Methyl and dimethyl derivatives of polycyclic hydrocarbons

Tricyc1ic Hydrocarbons $\left(\mathrm{C}_{14} \mathrm{H}_{10}\right)$

Anthracene

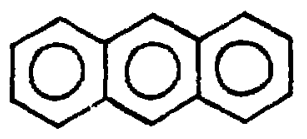

Anthracene is obtained from coal tar and used mainly in the manufacture of dyes. Coal tar fumes contain mainly anthracene and phenanthrene (44).

Anthracene causes acute and chronic dermatitis, and phototoxic and photoallergic action on the skin. Exposure to anthracene has produced skin cancers on the arms and the scrotum, reported in the earliest studies of chimney sweeps.

Internal absorption of coal tar fraction can cause headache and nausea. Prolonged exposure can lead to gastrointestinal inflammation (48D).

Eye contact with anthracene can cause photophobia, and edema of the eyelids, but symptoms disappear after cessation of contact. 


\section{Phenanthracene (Phenanthrene)}

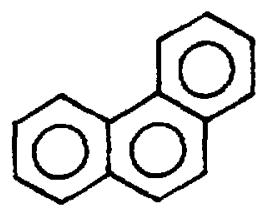

Phenanthracene is a constituent of waste industrial water, afrborne tobacco smoke, and car exhaust.

It is a mild aliergen and mild human dermal photosensitizer.

Weak dermal neoplastic properties were reported in animal studies (49B).

Tetracyc11c Hydrocarbons

Benz[a]anthracene (BaA; 1,2-Benzanthracene, 2,3-Benzophenanthracene, Naphanthracene, Tetraphene) $\mathrm{C}_{18} \mathrm{H}_{12}$<smiles>c1ccc2cc3c(ccc4ccccc43)cc2c1</smiles>

Benz[a]anthracene is a constituent of clgarette smoke, car exhaust, soot, coal gas, and electric plant emissions. Microgram quantities are found in barbecued and smoked food and in roasted coffee.

It is an animal carcinogen (58A, 68). Many carcinogenic PAHs are derived from the BaA skeleton (48D).

Chrysene (1,2-Benzophenanthrene, Benzo[a]phenanthrene, 1,2,5,6,Dibenzonaphthalene) $\mathrm{C}_{18} \mathrm{H}_{12}$<smiles>c1ccc2c(c1)ccc1c3ccccc3ccc21</smiles>

Chrysene is a weak skin carcinogen in animals. It is toxic by oral, dermal, eye, and inhalation routes (49A). 
Benzo[c]phenanthrene $(3,4-B e n z[0]$ phenanthrene, 3,4-Benzphenantinrene) $\mathrm{C}_{18 \mathrm{H}_{12}}$

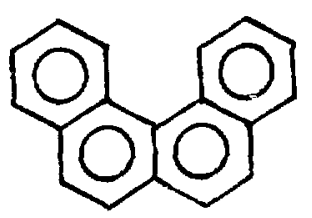

Benzo[c]phenanthrene is considered to be a relatively weak animal carcinogen present in the atmosphere (49).

Pyrene (Benzo $[d, e, f]$ phenanthrene) $\mathrm{C}_{16^{\mathrm{H}}}{ }^{\mathrm{H}} \mathrm{O}$<smiles>c1cc2ccc3cccc4ccc(c1)c2c34</smiles>

Animal carcinogen.

Pentacyclic Hydrocarbons

Dibenz[a,c]anthracene $\quad(1,2,3,4-D i b e n z a n t h r e c e n e, \quad$ Naphtho-2, 3:9,10 Phenanthrene, Benzo[b]triphenylene) $\mathrm{C}_{22} \mathrm{H}_{14}$<smiles>c1ccc2cc3c4ccccc4c4ccccc4c3cc2c1</smiles>

Dibenz $[\mathrm{a}, \mathrm{h}]$ anthracene $(1,2: 5,6$-Dibenzanthracene; $\mathrm{DB}(\mathrm{a}, \mathrm{h}) \mathrm{A}) \mathrm{C}_{22} \mathrm{H}_{14}$

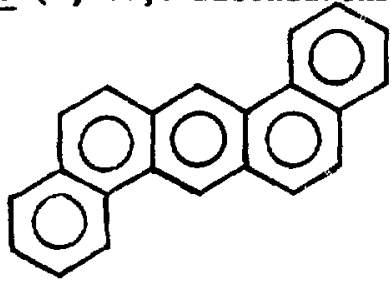

Highest concentrations are reported in soot (64 to $\left.705 \mathrm{mg} / 1000 \mathrm{~m}^{3}\right)$ and in coal tar (230 $\mathrm{ng} / \mathrm{kg})$. Animal carcinogen and tumorigen. 
Dibenz $[a, j]$ anthracene $(1,2: 7,8-D i$ benzanthracene, Dinaphthanoanthracene) $\mathrm{C}_{22} \mathrm{H}_{14}$<smiles>c1ccc2c(c1)ccc1cc3ccc4ccccc4c3cc12</smiles>

Benzo[c]chrysene $\left(1,2: 5,6\right.$-Dibenzophenanthrene) $\mathrm{C}_{22} \mathrm{H}_{14}$<smiles>c1ccc2c(c1)ccc1c2ccc2ccc3ccccc3c21</smiles>

Benzo[8]chrysene $\left(1,2: 3,4\right.$-Dibenzophenanthrene) $\mathrm{C}_{22^{\mathrm{H}}} \mathrm{H}_{14}$<smiles>c1ccc2c(c1)ccc1c3ccccc3c3ccccc3c21</smiles>

Benzo[e]pyrene $(1,2-B e n z o p y r e n e) \mathrm{C}_{20} \mathrm{H}_{12}$

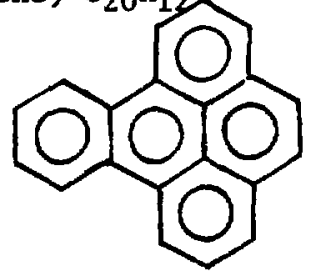

Benzo[a]pyrene (BaP; 3,4-Benzopyrene) $\mathrm{C}_{20} \mathrm{H}_{12}$<smiles>c1cc2ccc3ccc4ccc5c6cccc(c(c1)c23)c6c45</smiles>

Usually found in the air surrounding urban and industrial areas and occasionally in water samples, benzo[a]pyrene is recognized as a powerful animal carcinogen and is strongly suspected as a human carcinogen. Heavy BaP exposure has been corr lated with increase in lung cancer incidence, but fumes from emissions al ;o contain other compounds which may influence 
lung cancer directly, or may produce a synergistic effect with BaP. Originating from fossil fuel and other organic combustion processes, BaP is largely adsorbed on firc air particulates and hence is a widespread atmospheric pollutant. Since $B a P$ is readily identifiable, it is frequently used as an index of PAH compounds.

Hexacyc1ic Hydrocarbons

Benzo $[g, h, 1]$ perylene ("tiger butter") $\mathrm{C}_{22}{ }^{\mathrm{H}} 12$<smiles></smiles>

Dibenzo[a,h]pyrene (Dibenzo[b,d,e,f]chrysene; 1,2:6,7-Dibenzopyrene; $3,4,8,9-D i$ benzopyrene) $\mathrm{C}_{22} \mathrm{H}_{14}$<smiles></smiles>

Listed as suspected human carcinogen on the basis of animal studies. Dibenzo[a,1]pyrene (Dibenzo[d,e,f,p]chrysene) $\mathrm{C}_{24} \mathrm{H}_{14}$

Animal carcinogen.<smiles>C1=Cc2ccc3cc4ccccc4c4c(c5ccccc5c4c23)=C1</smiles> 
Dibenzo[a, 1$]$ pyrene (Benzo[r,s,t]pentaphene; DB(a,i)P; $1,2,7,8-$ Dibenzopyrene; 3,4:9,10-Dibenzopyrene) $\mathrm{C}_{24} \mathrm{H}_{14}$

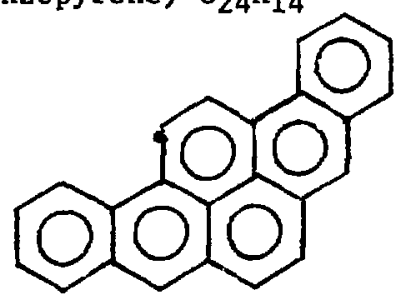

Animal carcinogen.

Dibenzo[a,e]pyrene ( $1,2: 4,5$-Dibenzopyrene; Naphtho $[1,2,3,4-d, e, f]$ chrysene; $\mathrm{DB}(\mathrm{ae}) \mathrm{P}) \mathrm{C}_{24} \mathrm{H}_{14}$

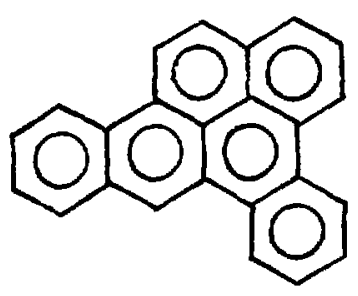

Naphtho( $8,1,2-c, d, e)$ naphthacene (Naphtho-2,3, a-Pyrene) $\mathrm{C}_{22} \mathrm{H}_{14}$<smiles></smiles>

Dibenzo $[a, c]$ naphthacene $(1,2: 3,4-D i$ benzonaphthacene; $1,2: 3,4-$ Dibenzotetracene) $\mathrm{C}_{24} \mathrm{H}_{16}$

Fluorene

Fluorene $\mathrm{C}_{13} \mathrm{H}_{10} \mathrm{O}$<smiles>c1ccc2c(c1)Cc1ccccc1-2</smiles> 
Benzo(d,e,f)fluorene (4,5-Methylenephananthracene, 4,5-Phenanthrylene Methaue) $\mathrm{C}_{15} \mathrm{H}_{10}$

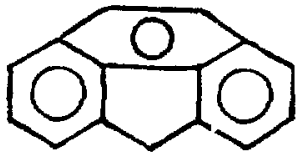

Strong carcinogen when applied to mouse skin.

Fluoroanthene and its Benzo-Derivatives

Fluoroanthene $\left(1,2-\right.$ Benzacenaphthene, Idry1) $C_{16^{\mathrm{H}}}{ }_{10}$

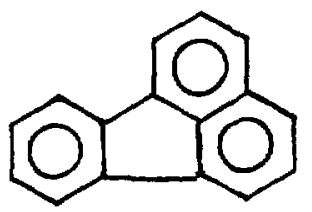

Limited animal studies show no toxicity.

Benzo(b) fluoroanthene (3,4-Benzofluoroanthene, Benz(e)acephenanthrylene) $\mathrm{C}_{20} \mathrm{H}_{12}$

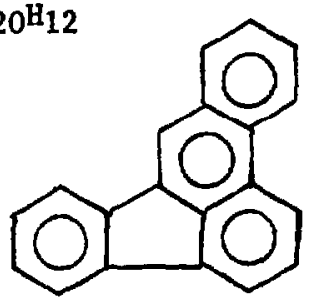

Benzo( $j$ fluoroanthene $\left(10,11\right.$-Benzofluoroanthene) $\mathrm{C}_{20} \mathrm{H}_{12}$

Benzo(k)fluoroanthene<smiles>c1ccc2c(c1)-c1cccc3cccc-2c13</smiles><smiles>c1ccc2cc3c(cc2c1)-c1cccc2cccc-3c12</smiles> 
Methy1 aud Dimethy1 Derivatives of Polycyclic Hydrocarbons

Trisuglic Derivatives $\mathrm{C}_{15^{\mathrm{H}}} \mathrm{H}_{12}$

1 - Methyilanthracene

2 - Mathylanthracen-

9 - Methylanthracene

Methylphenanthrene

1,4 - Dimethylphenanthrene

1,8 - Dimethylphenanthrene

2,7 - Dimethylphenanthrene

3,6 - Dimethylphenanthrene

4,5 - Dimethylphenanthrene

9,10 - Dimethylphenanthrent

Tetracyclic Dertvattves

1 - Methylchrysene $\mathrm{C}_{19} \mathrm{H}_{14}$

2 - Methylchrysene $\mathrm{C}_{19 \mathrm{H}_{14}}$

6 - Methylchrysene $\mathrm{C}_{1 \mathrm{gh}_{14}}$

siethylpyrene

Pentacyclic Derivatives

Methylbenzo[e]pyrene

1 - Methylbenzo[a]pyrene $\mathrm{C}_{21} \mathrm{H}_{14}$

6 - Methylbenzo[a] pyrene

10 - Methylbenzo[a]pyrene

11 - Methylbenzo[a] pyrene

12 - Methylbenzo[a]pyrene

Fluorene Derivatives

1 - Methylfluorene

2 - Methylfluorene

3 - Methylfluorene

4 - Methylfluorene

9 - Methylf luorene

It has generally been concluded that PAHs are important agents in assoclations of human cancer with cigarette smoking and exposure to soot, 
raw shale oils, roofing tar and coke oven, gas retort, and coal 1iquefaction emissions. These conclusions are generally based on epidemiological studies of the total exposure to a complex mixture (38). Animal studies and in vitro mutagenesis test systems have also played an Important role in interpretation. (Refer also to RACs 29 and 30.)

Health effects of PAH were extensively reviewed in the National Academy of science complttee reports in 1972 and 1976. While there has been considerable new laboratory work since that time and limited new epidemiological data, basic clinical and epidemlological understanding of health effects of PAH is unchanged.

Quantitative Dose Response

Two basic sources of quantitative dose-response information have been studies of public exposure and studies of occupational exposure. Exposure indices used have been benzola]pyrene (BaP) and total benzene soluble particulate matter. The latter may include non-PAli compounds. Myers et a1. (48B) are more explicit than most authors by stating their estimates are "For continuous Inhalation of alr with a mixture of combustion products contalning 1 ng of benz-a-pyrene (BaP) per w3." Public exposure Includes corvelation analysis of lung cancer and ambient BaP concentrations (48C) and more general urban pollution studies and clgarette smoking using BaP as an index of exposure (17A). These estimates are summarized in Table 1.

The earliest quantitative dose-response function was based on studies of Britlsh gas retort workers $(17 \mathrm{~B}, 39 \mathrm{~A}, 50 \mathrm{~A})$. A number of quantitative dose-response functions have been derived from data generated in the Long-Term Steelworkers Mortality Study at the University of Pittsburgh Graduate School of Public Health (53). The estimates are given in Table 2 Indexed by BaP.

A comparison of Tables 1 and 2 shows that estimates derfved from genera1 population studies are about 10 times higher than those derived from occupational studies. The occupational studies are of much better deftncd populations and are generaily more rellable studies. Both the occupational and general public studies may be incompatible with a linear dose-response relationship implied by the coefficlents in the tables. The 
Table 1. General Population Studies

\begin{tabular}{lc}
\hline Study & $\begin{array}{c}\text { Annual Fatal ca/million } \\
\text { person-ng BaP } / \mathrm{m}^{3}\end{array}$ \\
\hline NAS (48C) & 17 \\
Cuddihy et al. (17A) & $14-40$ \\
Myers et a1. (48B) & $10-40$ \\
Ozkaynak et al. (49A) & $0-40$ \\
\hline
\end{tabular}

Table 2. Occupational Population Studies

\begin{tabular}{lc}
\hline \multicolumn{1}{c}{ Study } & $\begin{array}{c}\text { Annual Fatal ca/militon } \\
\text { person-ng Bap/m }\end{array}$ \\
\hline Pike et a]. (50A) & 4 \\
Land (1976) & $2 . \mathrm{m}^{*}$ \\
Cudd thy (17A) & 0.8 \\
EPA CAG (19A) & 2.3 \\
Morris and Thode (48A) & $0.5 *$ \\
Batte1le Northwest (1982) & $0.9 *$ \\
Brown (9A) & $0.02 *$ \\
\hline *Indicates transformed from original form (original usually 11fetime \\
cancers per coal tar pitch volatiles exposure). \\
\hline
\end{tabular}

overall range of available estimates is best expressed by ozkaynak et al. (49A) as 0 to 40 annual fatal cancers per million person-ng Bap per cubic meter.

In one study in which a quantitative risk estimate was used to predict " cancers in a population assoclated with organic air pollutants (50A), cancer cases were later followed epidemlologically (50A). It was concluded that occupational exposure could account for all the excess cancer mortality. This suggests less credit should be given to higher risk estimates and that zero is a possible estimate for exposures at low amblent exposures. 


\section{Metabol1sm}

Polycyclic aromatic hydrocarbons belong to a group of carcinogens which are not chemically reactive with cellular components of living organisms. They must be converted metabolically into compounds which are capable of reacting directly with the macromolecules of the cell $(48 \mathrm{C}, 35)$.

Benzo[a]pyrene is therefore a procarcinogen which is metabolized by animal and human cells intc derivatives, proximate and ultimate carcinogens. A variety of metabolites was found in different types of tissues $(9,16)$.

The primary enzyme system responsible for the metabolism of polycyclic hydrocarbons is localized in the microsomal fraction of living cells. This enzyme system called "aryl hydrocarbon hydrolaze" is responsible for the conversion of benzo[a]pyrene into cytotoxic metabolites and for their binding to cellular DNA or protein.

The metabolism and carcinogenicity of BaP have been studied in animals In vivo and in cultures in vitro of organs, cells, and cell-free fractions. The parallelism between organ's response in animals in vivo and In vitro have been demoistrated (48C). Human data are obtained from organs, ce11s, and microsomal fractions cultured in vitro. Quantitation of BaP metabolites, their binding to cellular DNA, and the production of mutagenetic effects are evaluated after exposure of cultures to BaP.

Comparisons of human and animal tissues indicate basically similar effects of BaP, although some differences in the proportions of metabolites or mutations induced by BaP have been reported $(7,9,12,22,30,32-34,45,46$, $48,50,56)$.

The differences between different types of human tissues in their reactions to carcinogens have also been recognized. The urinary bladder seems to be the most sensitive to carcinogenic effect of BaP with the following sequence of skin, bronchus, esophagus, and colon $(5,6,59,64)$. The binding of BaP metabolites in epithelial cells is more prominent than the binding in flbroblasts (4). The main metabolic pattern of BaP was different in epithelial cells and in fibroblasts $(9,62)$. 
Cultured in vitro cells and tissues taken from different persons show great individual variations in the metabolism of $\mathrm{BaP}$, as reported in breast cells (23), esophagus (25), neoplastic lung tissue (15,43) and microsomal fractions from lung neoplasm (63) and liver cells (19). Prominent varlations in placental $\mathrm{BaP}$ metabolism of cigarette smokers were reported (24). Binding of BaP to DNA in cultured human endometrial tissues was substantially higher in premenopausal than postmenopausal women $(18,42)$. These findings correlate with studies suggesing that carcinogentc factors such as cigarette smoke, polycyclic and polyhalogenated hydrocarbons induce special enzymes which activate estrogens and nonsteroid antiestrogens to act as initiators and/or promoters of neoplasia in estrogen-dependent organs (67).

A genetic factor is also involved in the individual differences in the resistance to carcinoger. Comparison of BaP metabolism in human hair follicles showed that monozygotic twins display smaller differences than heterozygotic twins and that great individual differences occur within pairs of unrelated persons (32).

The formation of DNA adducts in the cell can be stimulated by other factors such as lipoproteins which show high levels of binding of $B a P$ and its metabolites $(11,17,54,60,61)$.

On the other hand, A retinolds (vitamin $A$ and its precursors) reduce the carcinogenic effect of BaP and its metabolites by inhibition of the neosynthesis of enzymes which metabolize BaP $(39,55,58,60)$. Prominerit inhibitory effect and suppression of neoplasms was also achieved by the addition of seven synthetic phenolic compounds to the diet of mice which had BaP-induced neoplasia. Three naturally occurring phenolic derivatives of cinnamic acids had similar inhibitory effects (69). The inhibition of BaY metabolism in iuman liver microsomes has also been achieved by the addition of naturally occurring flavonoids. Twelve flavonoids, all possessing the hydroxyl groups, showed the inhibitory effects. However, three flavonolds that lacked hydroxyl groups caused the many-fold stimulation of BaP and of aflatoxin B1 metabolism (10). Cultured human skin fibroblasts orfginating from donors with glucose-6-phosphate deficlency were more resistant to BaP than normal human skin fibroblasts $(21,51)$. Altered glucose metabolism resulting in a decrease of NADPH/NADP 
ratio inhibited benzo[a]pyrene whose activation proceeds through the NADPHdependent enzyme formation $(21,51)$.

The tests of mutagenic activity of different compounds are comonly carried out on Salmonella typhimurium (the Ame's test). It has been reported, however, that chemicals nonmutagenic to $\underline{s}$. typhimurium can induce morphologic transformations in Syrian hamster embryo cells (2). Mutagenic effect of BaP on Salmonella has been enhanced by the addition of other chemicals $(27,29,41,47,52,57,65)$. Human hepatoma cells treated with benz(a)anthracene ylelded an increased frequency of sister chromatid exchanges (SCEs) when exposed to benzo[a]pyrene (1). Also, an enhanced metabolic activity of BaP in cultured normal and neoplastic human cells was induced by the pretreatment of the culture with other chemicals $(13,14,20$, $29,31,33,37,57)$. The pretreatment of bronchial eptthelial cells with benz(a)anthracene enhanced metabolic activity of Bap in mice but not in human cells, thus indicating that animal model systems for $\mathrm{PAH}$ carcinogenesis in man have to be selected on the basis of comparable metabolite patterns (34). Metabolic activity of Bap can also be enhanced by such factors as Herpes simplex virus $(4,36)$, by the automobile exhaust products $(8,28,40,41)$, and by other airborne particles $(3,66)$.

Polycyclic aromatic hydrocarbons occur as a mixture of airborne particles. Herlan and Mayer (26), reviewing the difficulties involved in determining exact structures of polycyclics in environmental samples, asked if it was ingenuous to maintain the principle of analyzing individual compounds.

\section{References}

1. Abe, S., N. Nemoto, and M. Sasak1. 1983. Sister chromatid exchange induction by indirect mutagens/carcinogens, aryl hydrocarbon hydroxylase activity and benzo[a]pyrene metabolism in cultured human hepat oma cells. (Toxline Abstract). Mutat. Res. 109: 83-90.

2. Amacher, D.E. and I. Zelljadt. 1983. The morphological transformation of Syrian hamster embryo cells by chemicals reportedly nonmutagenic to Salmonella typhimurium. (Toxline Abstract). Carcinogenesis (London) 4: 291-5.

3. Arashidani, K., M. Fukunaga, M. Yoshikawa, Y. Kodama, and $Y$. Mizuguchi. 1982. Mutagenic activities of benzene extract of airborne part1culates. (Toxline Abstract). J. UOEH 4: 451-8. 
4. Arrand, J.E. and A.M. Murray. 1982. Benzopyrene groups bind preferentially to the DNA of active chromatin in human lung cells. (Toxline Abstract). Nucleic Acids Res. 10: 1547-55.

5. Autrup, H., R.C. Grafstrom, B. Christensen, and J. Kieler. 1981. Metabolism of chemical carcinogens by cultured human and rat bladder epithelial cells. (Toxline Abstraci). Carcinogenesis (London) 2: 763-8.

6. Autrup, H. and R.C. Grafstrom. 1982. Comparison of carcinogen metabolism in different organs and species. (Toxline Abstract). Dav. Biochem. 23: 643-8.

7. Autrup, H., R.D. Schwartz, J.M. Essigmann, L. Smith, B.F. Trump, and C.C. Harris. 1980. Metabolism of aflatoxin B1, benzo[a]pyrene, and 1,2-dimethylhydrazine by cultured rat and human colon. (Toxline Abstract). Teratogenesis Carcino. Mutagen. 1: 3-13.

8. Barfknecht, T.R., R.A. Hites, E.L. Cavaliers, and W.G. Thilly. 1982. Human cell mutagenicity of polycyclic aromatic hydrocarbon components of diesel emissions. (Toxline Abstract). Dev. Toxicol. Environ. Sci. 10: 277-94.

9. Bartley, J., J.C. Bartholomew, and M.R. Stampfer. 1982. Metabolism of benzo(a)pyrene by human epithelial and fibroblastic cells: Metabolite patterns and DNA adduct formation. (Toxline Abstract). J. Cell Biochem. 18: 135-48.

9A. Brown, C.D. 1982. Analysis of the level of health risk posed by emission of volatile organic compounds released during continuous operation of a commercial scale coal gasification facility. In: BNL 51542, Health and Environmental Risk Analysis Program Workshop: Potential Publir Health Impacts of Airborne Organic Combustion Products, Brookhaven Nat lonal Laboratory, Upton, NY, August 17 and 18 , 1981.

10. Buening, M.K., R.L. Chang, M-T. Huang, J.G. Fortner, A.W. Wood, and A.H. Conney. 1981. Activation and Inhibition of benzo(a)pyrene and aflatoxin Bl metabolism in human liver microsomes by naturally occurring flavonoids. (Toxline Abstract). Cancer Res. 41: 67-72.

11. Busbee, D.L., P.W. Rankin, D.M. Payne, and D.W. Jasheway. 1982. Binding of benzo[a]pyrene and intracellular transport of a bound electrophilic benzo[a]pyrene metabolite by lipoproteins. (Toxline Abstract). Carcinogenes1s 3: 1,107-12.

12. Casto, B.C. 1983. Comparison of the sensitivity of rodent and human cells to chemical carcinogens using viral transformation, DNA damage, and cytotoxicity assays. (Toxline Abstract). Basic Life Sci. 24: 429-49. 
13. Cavalieri, E., A. Munhall, E. Rogan, S. Salmasi, and K. Pat11. 1983. Syncarcinogenic effect of the environmental pollutants cyclopenteno [cd]pyrene and benzo[a]pyrene in mouse skin. (Toxline Abstract). Carcinogenesis 4: $393-7$.

14. Chang, M.J.W., N.P. Singh, A. Turturro, and R.W. Hart. 1982. Interaction of benzo[a]pyrene and chrysolite. Polynucl. Aromat. Hydrocarbons: Phys. Biol. Chem., Int. Symp., 6th; $167-76$.

15. Cohen, G.M., K. Mehta, and M. Meredith-Brown. 1979. Large interindividual variations in metabolism of benzo(a)pyrene by peripheral lung tissue from lung cancer patients. (Toxline Abstract). Int. J. Cancer 24: 129-33.

16. Cohen, G.M., R.C. Grafstrom, E.M. Gibby, L. Smith, H. Autrup, and C.C. Harris. 1983. Metabolism of benzo[a]pyrene and 1-naphthol in cultured human tumorous and nontumorous colon. (Toxline Abstract). Cancer Res. 43: 1312-15.

17. Craven, P.A. and F.R. Derubert1s. 1980. Fatty acid induced drug and carcinogen metabolism in rat and human colonic mucosa: A possible link to association of high dietary fat intake and colonic carcinogenesis. (Toxline Abstract). Biochem. Blophys. Res. Commun. 94: $1044-51$.

17A. Cuddihy, R.G., F.A. Seller, W.C. Griffith, B.R. Scott, and R.0. McClellan. 1980. Potential health and environmental effects of diesel light duty vehicles. Lovelace Biomedical and Environmental Research Institute, Inhalation Toxicology Research Institute Report LMF-82.

17B. Doll, R., M.P. Vessey, R.W.R. Beasley, A.R. Buckley, E.C. Fear, R.E.W. Fisher, E.J, Gammon, W. Gunn, G.0. Hughes, K. Lee, and B. Norman-Smith. 1972. Mortality of gasworkers - final report of a prospective study. Brit J. Industr. Med. 29: 394-406.

18. Dorman, B.H. V.M. Genta, M.J. Mass, and D.G. Kaufman. 1981. Benzo(a) pyrene binding to DNA in organ cultures of human endometrium. Cancer Res. 41: 2718-22.

19. Ekstroem, G., C. V on Bahr, H. Glaumann, and M. Ingelman-Sundberg. 1982. Interindividual variation in benzo-(a)-pyrene metabolism and composition of isoenzymes of cytochrome $P-450$ as revealed by sodium dodecyl sulfate-gel electrophoresis of human liver microsomal fractions. (Toxline Abstract). Acta Pharmacol. Toxicol. 50: 251-60.

19A. EPA. 1979. Final risk assessment on coke oven exposure. Carcinogen Assessment Group, Environmental Protection Agency.

20. Fang, W.F. and h.W. Strobel. 1982. Effects of cyclophosphamide and polycyclic aromatic hydrocarbons on cell growth and mixed-funtion oxidase activity in a human colon tumor cell line. Cancer Res. 42: 3676-81. 
21. Fao, F., L. Pirisi, R. Pascale, S. Zanett1, L. Daino, and V. La Spina. 1982. Modulatory effects of glucose-6-phosphate dehydrogenase deficiency on the carcinogen activation by "in vitro" growing human fibroblasts. (Toxline Abstract). Deve. Cancer Res. 7: 549-57.

22. Gou1d, M.N., L.E. Cathers, and C.J. Moore. 1982. Human breast cel1mediated mutagenesis of mammalian cells by polycyclic aromatic hydrocarbons. (Toxline Abstract). Cancer Res. 42: 4619-24.

23. Grover, P.L., A.D. Macnicoll, P. Sims, G.C. Easty, and A.M. Neville. 1980. Polycyclic hydrocarbon activation and metabolism in epithelial cell aggregates prepared from human mammary tissue. Int. J. Cancer 26: $467-76$.

24. Gurtoo, H.L., C.J. Williams, K. Gottlieb, A.I. Mulhern, L. Caballes, J.B. Vaught, A.J. Harinello, and S.K. Bansal. 1983. Population distribution of placental benzo(a)pyrene metabolism in smokers. (Toxline Abstract). Int. J. Cancer 31: 29-37.

25. Harris, C.C., H. Autrup, G.D. Stoner, B.F. Trump, E. Hillman, P.W. Schafer, and A.M. Jeffrey, 1979. Metabolism of benzo(a)pyrene, N-nitrosodimethylamine and N-nitrosopyrrolidine and identification of the major carcinogen-DNA adducts formed in cultured human esophagus. (Toxline Abstract). Cancer Res, 39: 4401-6.

26. Herlan, A. and J. Mayer. 1982. Polycyclic aromatics in airborne dusts and emissions: Profiles, the problem of determining origin and the role of analytics. (Toxline Abstract). Zentralb1. Bakteriol. Mikrobiol. Hyg. Abt. 1 orig. B. Hyg. Umwelthyg. Krankenhaushyg. Arbeitshyg. Praev. Med. 176: 206-48.

27. Hermann. M. 1981. Synergistic effects of individual polycyclic aromatic hydrocarbons on the mutagenicity of their mixtures. (Toxline Abstract). Mutat. Res. 90: 399-409.

28. Howard, A.G. and G.A. Mi1ls. 1983. Jdentification of polynuclear aromatic hydrocarbons in diesel particulate emissions. Int. J. Environ. Anal. Chem. 14: 43-53.

29. Hughes, T.J., T.J. Wolff, D. Nlchols, C. Sparacino, and A.R. Kolber. 1983. Synergism and antagonism in complex environmental mixtures: l masking of latent mutagenicity by chemical fractionation. (Toxline Abstract). NATO Conf. Ser., [Ser.] 1; Vo1. 5B, In Vitro Toxic. Te... Environ. Agents: Curr. Future Possibilities, Pt. B: 115-44.

30. Hsu, I.C., C.C. Harris, M. Yamaguch1, B.F. Trump, and P.W. Schafer. 1979. Induction of ouabain-resistant mutation and sister chromatid exchanges in Chinese hamster cells with chemical carcinogens mediated by human pulmonary macrophages. (Toxline Abstract). J. Clin.Invest. 64: 1245-52. 
31. Huh, N., N. Nemoto, and T. Utakoj1. 1982. Metabolic activation of benzo[a]pyrene, aflatoxin Bl, and dimethylnitrosamine by a human hepatoma cell line. (Toxline Abstract). Mutat. Res. 94: 339-48.

32. Hukkelhoven, M.W.A.C., A.J.M. Vermorken, E. Vromans, and H. Bloemenda1. 1982a. Human hair follicles, a convenlent tissue for genetic studies on carcirogen metabolism. (Toxline Abstract). Clin. Genet. 21: 53-8.

33. Hukkelhoven, M.W.A.C., E. Vromans, A.J.M. Vermorken, and H. Bloemendal. 1982b. Differences in benzo(a)pyrene metabolism between cultured human and murine bronchial cells after pretreatment with benz(a)anthracene. (Toxline Abstract). Toxicol. lett (AMST) 12: 41-6.

34. Hukkelhoven, M.W.A., E. V romans, A.J.M. Vermorken, and H. Bloemendal. 1982c. Formation of dihydrodiol metabolites of benzo[a]pyrene in cultured human and murine skin cells. (Toxline Abstract). Anticancer Res. 2: $89-94$.

35. Ide, F., T. Ishikawa, M. Takag1, S. Umemura, and S. Takayama. 1982. Unscheduled DNA synthesis in human oral mucosa treated with chemical carcinogens in short-term organ culture. (Toxline Abstract). J. Nat1. Cancer Inst. 69: 557-63.

36. Johnson, F.B. 1982. Chemical interactions with Herpes simplex type 2 virus: Enhancement of transformation by selected chemical carcinogens and procarcinogens. (Toxline Abstract). Carcinogenesis (London) 3 : 1235-40.

37. Kandaswam1, C. and P.J. O'Brien. 1982. The effect of asbestos on the bioactivation of polynuclear aromatic hydrocarbons. Nat1. Res. Counc. Canc., [Rep.] NRCC, Workshop Comb. Eff. Xenobiot 1cs, 207-36.

38. Karstadt, M. and R. Bobal. 1982. Avallability of epidemlologic data on humans exposed to animal carcinogens. (Toxline Abstract). Teratog. Carcinog. Mutagen. 2: 151-67.

39. Koh1, F.V. and H.W. Ruediger. 1979. In vitro studies in human cell ciltures on tumor prophylaxis by vitamin A. (Toxline Abstract). J. Cancer Res. Cl1n. Oncol. 93: 149-60.

39A. Lawther, P.J., B.T. Commins, and R.E. Waller. 1965. A study of the concentrations of polycyclic aromatic hydrocarbons in gas works retort houses. Brit. J. Ind. Med 22: 13-20.

40. Lockard, J.M., P. Kaur, C. Lee-Stephens, P.S. Sabharwal, M.A. Pereira, L. McMillan, and J. Mattox. 1982. Induction of sister-chromatid exchanges in human lymphocytes by extracts of particulate emissions from a diesel engine. (Toxline Abstract). Mutat. Res. 104: 355-60. 
41. Madsen, E.S., P.A. Nielsen, and J.C. Pedersen. 1982. The distribution and origin of mutagens in alrborne particulates, detected by the Salmonella typhimurium microsome assay in relation to levels of lead, vanadium, and polycyclic aromatic hydrocarbons. (Toxline Abstract). Sc1. Total Environ. 24: 13-26.

42. Mass, M.J., N.T. Rodgers, and D.G. Kauman. 1981. Benzo(a)pyrene metabolism in organ cultures of human endometrium. (Toxline Abstract). Chem-B1ol. Interact. 33: 195-206.

43. Mehta, R., M. Meredith-Brown, and G.M. Cohen. 1979. Metabolism and covalen binding of benzo(a)pyrene in human peripheral lung. (Toxline Abstract). Chem-Biol. Interact. 28: 345-58.

44. Mellinger, P.J., B.W. Hilson, D.D. Mahlum, L.E. Sever, and A.R. 0lson. 1982. Health and environmental effects document for direct coal liquefaction - 1981. PNL-4230, Pasific Northwest ilaboratory, Richland, WA.

45. Milo, G.E. 1981. Chemical carcinogen (hydrazine, polynuclear hydrocarbon and/or synthetic jet fuel components) induced cacinogenesis of human cells, In vitro. Reporr; ISS AFOSR-TR-81-0719; Order No. AD-A107721, $127 \mathrm{pp}$.

46. Milo, G.E., J.W. O1dham, R. Zimmerman, G.G. Hatch, and S.A. Weisbrode. 1981. Characterization of human cells transformed by chemical and physical carcinogens in vitro. (Toxline Abstract). In vitro 17: 719-29.

47. Monarca, S., R. Pasquini, G.S. Sforzolini, V. V1ola, and F. Fagiolf. 1982. Application of the Salmonella mutagenicity assay and determination of polycyclic aromatic hydrocarbons in workplaces exposed to petroleum pitch and petroleum coke. (Toxline Abstract). Int. Arch. Occup. Environ. Health 49: 223-40.

48. Moore, B.P., R.M. Hicks, M.A. Knowles, and S. Redgrave. 1982. Metabolism and binding of benzo(a)pyrene and 2-acetylaminofluorene by short-term organ cultures of human and rat bladder. (Toxline Abstract). Cancer Res. 42: 642-8.

48A. Morris, S.C. and H.C. Thode, Jr. Estimating the risk of chronic occupational disease per person-year worked. IN: J. Van Ryzin and D. Barletta Proceedings of the 1982 Statistical Symposium (BNL 51535), Brookhaven National Laboratory, 1982 .

48B. Myers, D.K., N.E. Gentner, J.R. Johnson, and R.E.J. Mitc'a1. 1981 . Carcinogentc potential of varlous energy sources. In: IAEA Proc. of a Symposium Nashville 22-26 June 1981 Health Impacts of Different Sources of Energy. 
48C. NAS. 1972. Particulate polycyclic organic matter. Comittee on Blologic Effects of Atmospheric Pollutants, Washington, DC.

48D. National Library of Medicine. Toxicology Data Bank. (Computer search 1982).

49. Patak1, J. and R.G. Harvey. 1982. Benzo(c)phenanthrene and its oxidized metabolites. (Toxline Abstract). J. Org. Chem. 47: 20-2.

49A. Ozkaynak, H., A.J. Warren, T.D. Tosteson, J.S. Evans, G.D. Thurston, and S.D. Colome. 1982. Analysis of health effects resulting from population exposures to amblent particulate matter, health and environmental effects document. Harvard University Energy and Environmental Pollcy Center, Cambridge, MA.

49B. Patty, F.A. 1982. Patty's Industrlal hyglene and toxicology, volumes 2A, 2B, and 2C. pps. 4,909-10. Third Revised Edition. John Wiley \& Sons, NY.

50. Pelkonen, O. and H. Saarn1, 1990. Unusual patterns of benzo(a)pyrene metabolites and DNA benzo(a)pyrene adducts produced by human placental microsomes in vitro. (Toxline Abstract). Chem-Biol. Interact. 30: 287-96.

50A. Pike, M.C., R.J. Gordon, B.E. Henderson, H.R. Menck, and J. Soottoo. 1975. Alr Pollution. IN: Persons at High Risk of Cancer. J.F. Fraumen1, Jr. (ed.), Academic Press, NeW York, 225-40.

51. Plrls1, L.; R. Pascale, L. Dainc, S. Frassetto, V. LaSplna, S. Zanett1, L. Gaspa, G.M. Ledda, R. Garcea, and F. Feo. 1982. Effect of glucose-6-phosphate' dehydrogenase deficiency on 'the benz(a)pyrene toxicity for in vitro cultured human skin fibroblaets. (Toxline Abstract). Res. Commun. Chem. Pathol. Pharmacol. 38: 301-11.

52. Rao, T.K., J.A. Young, C.E. Weeks, T.J. Slaga, and J.L. Epler. 1979. Effect of the co-carcinogen benzo(a)pyrene on microsome-mediated chemical mutagenesis in Salmonella typhimurium. (Toxline Abstract). Environ. Mutagen. 1: 105-12.

53. Redmond, C.K., A. Clocco, J.W. Lloyd, and H.W. Rush. 1972. Long-term mortality study of steelworkers, VI. Mortality from malignant neoplasms among coke oven workers. J. Occup. Med. 14: 621.

54. Remsen, J.F. and R.B. Shireman. 1981. Effect of low-density 1ipoprotein on the incorporation of benzo(a)pyrene by cultured cells. Cancer Res. 41: $2179-85$.

55. Rocch1, P., G. Arfelint, A. Capuccl, M.P. Grilli, and G. Prodi. 1983. Effect of vitamin A palmitate on mutagenesis induced by polycyclic aromatic hydrocarbons in human cells. (Toxline Abatract). Carcinogenesis 4: 245-7. 
56. Sabadie, N., C. Malaveille, A.M. Camus, and H. Bartsch. 1980. Comparison of the hydroxylation of benzo(a)pyrene with the metabolism of vinyl chloride, N-nttrosomorpholine and N-nitroso-N'methylplperazine to mutagens by timan and rat liver microsomal fractions. (Toxline Abstract). Cancer Res. 40: 119-20.

57. Salamone, M.F., J.A. Heddle, J. Gingerich, and M. Yatz. 1982. On the complexities of risk estimates, metabolic activation, and chenical mixtures. (Toxline Abstract). Prog. Mutat. Res. 3: 179-85.

58. Santamarla, L., A. Blancht, A. Arnabold1, L. Andreont, and P. Bermond. 1982. Chemoprevention of skin cancer by carotenoids. (Toxline Abstract). Med. Btol. Environ. 10: 359-64.

58A. Second Annual Report on Carcinogens. 1981. National Toxicology Program, Public Information Office, Research Triangle Park, NC.

59. Selk1rk, J.K., A. Nikbakht, and G.D. Stoner. 1983. Comparative metabolism and macromolecular binding of benzo[a]pyrene in explant cultures of human bladder, skin, bronchus and, esophagus from elght 1ndividuals. (Toxline Abstract). Cancer Lett. (Shannon, Irel.) 18: 11-19.

60. Shu, H.P. and A.V. Nichols. 1979. Benzo(a)pyrene uptake by human plasma lipoproteins in vitro. (Toxline Abstract). Cancer Res. 39: $1,224-30$.

61. Shu, H.P. and A.V. Nichols. 1981. Uptake of 1ipophilic carcinogens by plasma lipoproteins: Structure-activity studies. (Toxline Abstract). Biochim. Biophys. Acta 665: 376-84.

62. Stampfer, M.R., J.C. Bartholomew, H.S. Smith, and J.C. Bartley. 1981. Metabolism of benzo[a]pyrene by human mammary epithelial cells: Toxicity and DNA adduct formation. Proc. Natl. Acad. Scl. U.S.A. 78: $6,251-5$.

63. Sipal, Z., T. Ahlenius, A. Bergstrand, L. Rodriquez, and S.W. Jakobsson. 1979. Oxidative blotransformation of benzo(a)pyrene by human lung microsomal fractions prepared from surgical specimens. (Toxline Abstract). Xenobiotica 9: 633-45.

64. Stoner, G.D., F.B. Danle1, K.M. Schenck, H.A.J. Schut, P.J. Goldblatt, and D.W. Sandwisch. 1982. Metabolism and DNA binding of benzo(a)pyrene in cultured human bladder and bronchus. (Toxline Abstract). Carcinogenesis (London) 3: 195-202. 
65. Thakker, D.R., W. Levin, M. Buening, H. Yagi, R.E. Lehr, A.W. Wood, A.H. Conney, and D.M. Jerina. 1981. Species-specific enhancement by 7,8-benzoflavone of hepatic microsomal metabolism of benzo(e)pyrene 9,10-dihydrodiol to bay region diol epoxides. (Toxline Abstract). Cancer Res. 41: 1389-96.

66. Tok1wa, H., S. Kitamor1, K. Takahash1, and Y. Ohnish1. 1980. Mutagenic and chemical assay of extracts of airborne particulates. (Toxline Abstract). Mutat. Res. 77: 99-108.

67. Tsibris, J.C.M. 1979. Carcinogen activation by human uterine enzymes. Cell sorter analysis of carcinogen metabolites in human tissues. Ann. Clin. Lab. Sc1. 9: 236-42.

68. Tyrer, H.W., L.A. Adams, S.M. Tiffany, J.P. O'Connell, and E.T. Cantre11. 1979. (Toxline Abstract). Cell sorter analysis of carcincgen metabolites in human tissues. J. Histochem. Cytochem. 27: 508-11.

69. Wattenberg, L.W., J.B. Coccla, and L.K.T. Lam. 1980 Inhibitory effects of phenolic compounds on benzo(a)pyrene-induced neoplasia. (Toxline Abstract). Cancer Res. 40: 2820-3. 


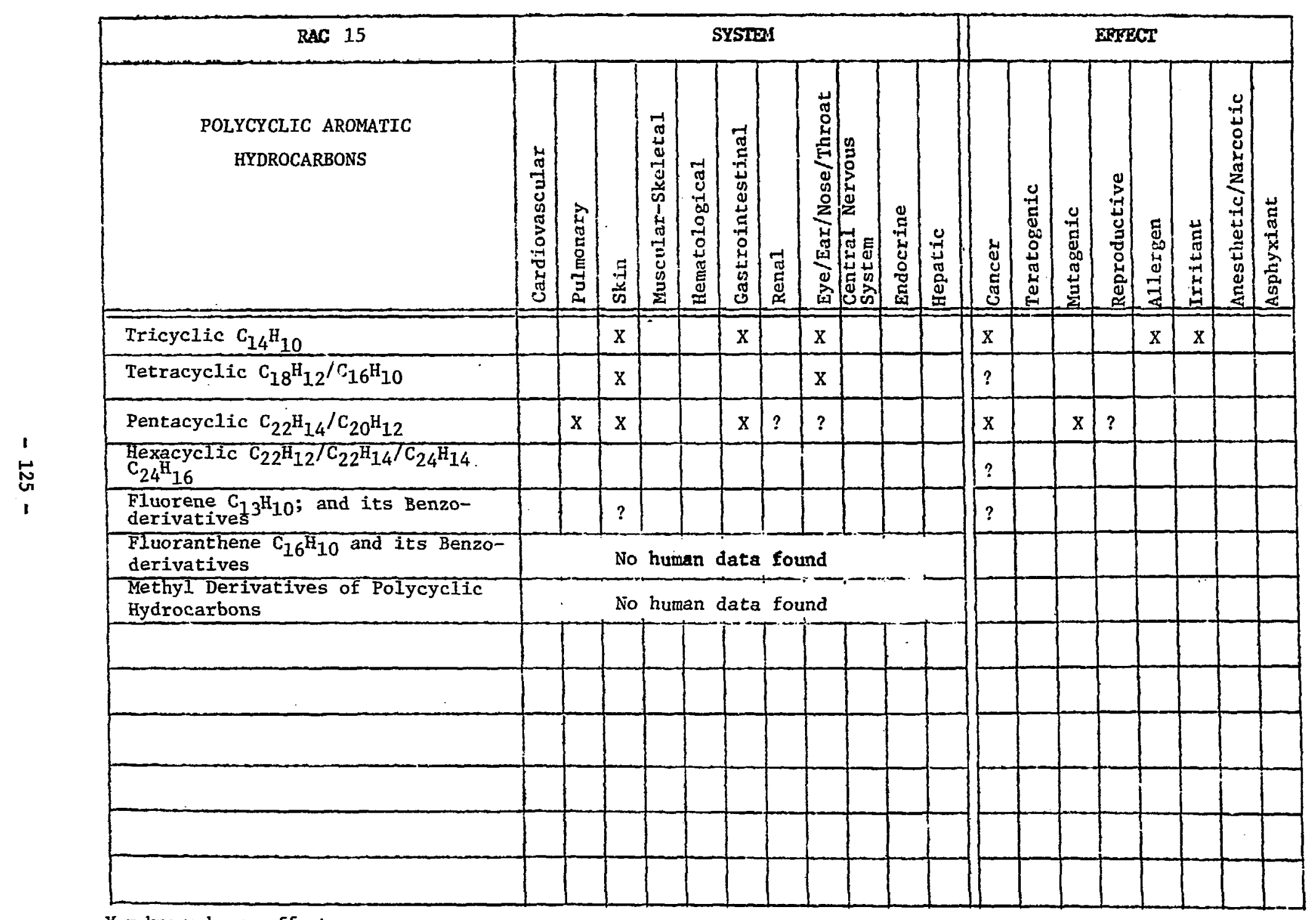

$X=$ known human effect

$?$ = based on animal data, experfence with similar compounds, or Inconclusive human data 
The four compounds reviewed in this category are:

Methylamine (Aminomethane) $\mathrm{CH}_{3} \mathrm{NH}_{2}$

Dimethylamine $\left(\mathrm{CH}_{3}\right)_{2} \mathrm{NH}$<smiles>CN</smiles>

Trimethylamine $\left(\mathrm{CH}_{3}\right)_{3} \mathrm{~N}$<smiles>CNC</smiles>

Ethylamine $\mathrm{C}_{2} \mathrm{H}_{5} \mathrm{NH}_{2}$<smiles>CN(C)C</smiles><smiles>CCN</smiles>

Aliphatic amines are the alkyl derivatives of ammonia. They are organic solvents with an ammonia-like odor. With the exception of ethylamine, they are gases under ordinary conditions (room temperature) and become colorless liquids when cooled or compressed. Ethylamine remains a gas when pressurized $(1-8)$.

In workers exposed to these compounds, varying concentrations have been found in the urine. Other than being strong eye, 1ip, skin, and upper respiratory tract irritants, no other adverse health effects were found for this group of compounds $(1-8)$.

A TLV of $10 \mathrm{ppm}$ has been set for all four compounds covered in this group, to prevent eye and mucous irritation and severe tisaue damage that might occur at higher doses (based on antmal studies) (1). 
1. ACGIH. 1980. Documentation of the threshold 11mit values. Fourth Edition. pps. 174, 415, and 145. American Conference of Governmental Industrial Hygienists Inc., $\mathrm{OH}$.

2. Bittersoh1, G. and H. Heberer. 1980. Results of workplace air and worker urine analyses in persons occupationally exposed to aliphatic amines. (Toxline Abstract). 2. Gesamte Hyg. Ihre Grenzgeb. 26: 258-9.

3. Kirk-0thmer. 1978. Encyclopedia of chemical technology. Third Edition. John Wiley \& Sons, NY.

4. National Library of Medicine. Toxicology Data Bank. (Computer search 1982).

5. Patty, F.A. 1982. Patty's industrial hygiene and toxicology, Volunes 2A, 2B, and 2C. pps. 3,145-7. Third Reyised Edition. John Wiley \& Sons, NY.

6. Proctor, N.H. and J.P. Hughes. 1978. Chemical hazards of the workplace. pps. 249, 223, and 330. J.B. Lippincott Company, PA.

7. RTEC - Registry of Toxic Effects of Chemicals, National Library of Medicine (Computer Search 1982).

8. Sax, N.I. 1975. Dangerous properties of industrial materials. pps. $764,726,1,202$, and 670. Fourth Edition. Van Nostrand Reinhold Company, NY. 


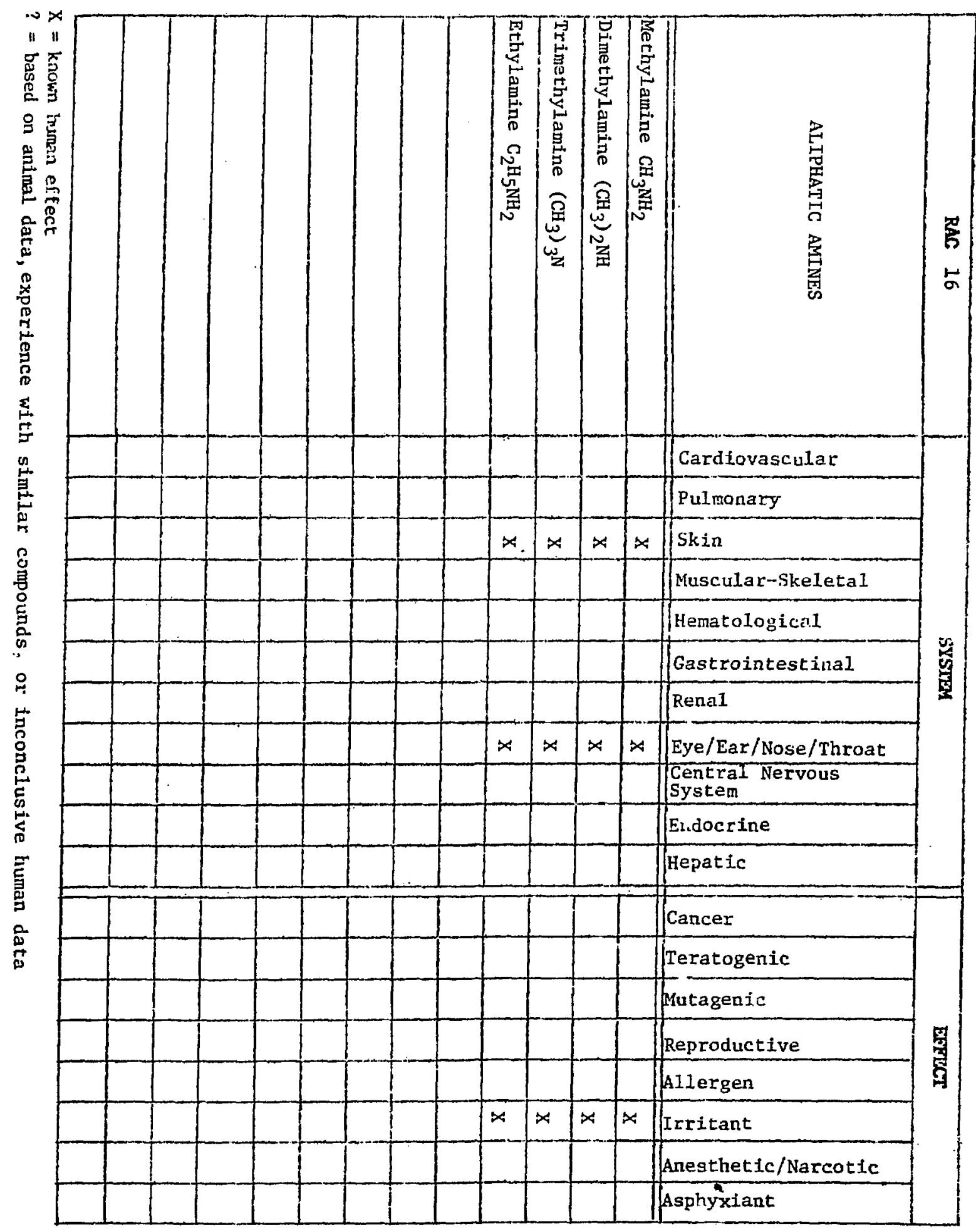




\section{RAC \#17 - AROMATIC AMINES (EXCLUDING N-HETEROCYCLICS)}

Aromatic amines are compounds in which the aromatic ring is attached to nftrogen. Aromatic amines listed in RAC $\|_{17}$ include phenyl and biphenyl amines (aniline and xenylamine), biphenyl diamines (hydrazobenzene and benzidine), and naphthylamines ( $\alpha-$ and $\beta-$ ).

Aniline (Aminobenzene; Phenyl Amine) $\mathrm{C}_{2} \mathrm{H}_{5} \mathrm{NH}_{2}$

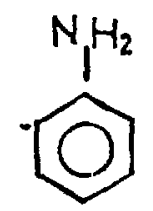

Aniline is an ofly liquid with a characteristic odor detectable at 1 ppm. Antline is used chiefly in the chemical industry for the production of polymers, dyes, rubber accelerators and antloxidants, drugs (such as sulfa drugs), photographic chemicals, isocyanates, herbicides, and fungicides.

Severe intoxication with aniline may occur after skin contact or ingestion. Skin absorption of anlline vapor was evaluated as approximateiy equal to absorption from inhalation (1). No significant difference appeared between the mean rate of skin absorption of liquid aniline and that with $3 \%$ content of water (2). Studied in vitro, permeabllity of different areas of human skin to aniline varied, however, up to 100-fold (4).

Acute intoxication results in cyanosis, caused by the conversion of hemoglobin to methemoglobin. As the methemoglobin content rises above a certain level, death ensues from anoxia $(1,3,8)$. Methemoglobinemia and hemolytic anemia have been reported in two patients using phenazopyridine. The probable role of antline, a major metabolite of phenazopyridine, was discussed (6).

Chronic poisoning can occur after repeated exposures to low concentrations. Early symptoms are pallor, secondary anemia, and fatigue. Such cases recover when properly treated and completely removed from further exposure (8).

In human blood lymphocytes, aniline did not induce an increase of sister chromatid exchange $\underline{\text { In}}$ vitro, but such an increase was induced by p-aminophenol, one of the aniline metabolites in the body (14). 
Xenylamine (4-Aminodiphenyl, 4-Diphenylamine) $\mathrm{C}_{6} \mathrm{H}_{5} \mathrm{NHC}_{6} \mathrm{H}_{5}$

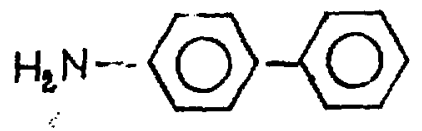

Xenylamine is composed of colorless crystals. It is no longer produced on a compercial scale because of its demcistrated carcinogenicity. It appears to be one of the most potent known bladder carcinogens.

Epidemlologic studies conducted between 1935 and 1969 by Melick and co-workers confirmed a high incidence of bladder tumors among exposed workers. The tumors appeared 5 to 19 years after initial exposure, which ranged in duration from 1 to 10 years. No dose relationship was given ( 1 , 5,12 ).

Hydrazobenzene (1,2-Dipheny1hydraz1ne) $\mathrm{C}_{6} \mathrm{H}_{5}(\mathrm{NH})_{2} \mathrm{C}_{6} \mathrm{H}_{5}$

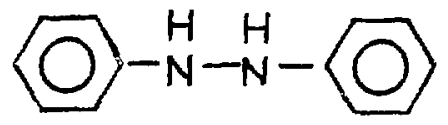

Hydrazobenzene is a precursor of benzidine and therefore a potential carcinogen. Carcinogenicity of hydrazobenzene was found in antmal studies. It is listed as human carcinogen (12). No human data have been found. Benzidine (4, 4'-Diaminobipheny1) $\mathrm{NH}_{2} \mathrm{C}_{6} \mathrm{H}_{4}-\mathrm{C}_{6} \mathrm{H}_{4} \mathrm{NH}_{2}$<smiles>Nc1ccc(-c2ccc(N)cc2)cc1</smiles>

Benzidine is a white or slightly reddish crystalline material which darkens on exposure to light and air. Its major industrial use is in the preparation of dyes. It is also used in laboratorles as a reagent or indicator in forensic and clinical medicine, and for the detection of hydrogen peroxide in milk. There is some use in security yitnting, in the detection of HCN and sulfate, and for determination of nicotine.

Benzidine is a well-recognized carcinogen. There are a large number of reports of bladder cancer in humans caused by benzidine in the industrial 
environment. Both inhalation and skin absorption are significant portals of entry for benzidine into the human body. Ingestion of benzidine has occurred in industries producing vapors, aerosols, fumes, and dust. A long-term study of workers in the manufacture of benzidine by Zavon et a1. (17) demonstrated that 13 of 25 exposed men developed bladder tumors, 11 of which were malignant. In three cases, malignant tumors metastasized to the kIdney, and metastases to the neck and abdomen were also recognized. The perlods of exposure to benzidine ranged from 8 to 28 years (average 13.61). Tumorigenic action of benzidine shows long latency. In the above study, tumors appeared 9 to 29 years (average 16.62) after the first exposure. Benzidine-based dyes containing benzidine attached to other substituents by diazo linkages are also highly carcinogenic, since they are metabolized to carcinogen-benzidine.

Epidemiologic studies $(15,16)$, indicate an association between employment in the dye industry and urinary bladder cancer in humans. However, the average latent perfod from the first and last exposure was 26.4 and 14.0 years, respectively. Thus, lifetime urine cytology surveillance is strongly recommended for all exposed workers (16).

Bladder tumors have also been reported among Japanese s1lk painters who were believed to have ingested small amounts of benzidine dyes on a regular basts over many years ( 8 ).

Regulations concerning the handling of known carcinogens have been imposed in most industrial nations. U.S. regulations caused virtually all the dye companies to discontinue the use of benzidine compounds. All countries which list benzidine as an industrial health hazard consider it a carclnogen. None has adopted a limit for concentration in workroom alr (1, 8).

1-Naphthylamine ( $\alpha$-Naphththylamine, 1-Aminonaphthalene) $\mathrm{C}_{10} \mathrm{H}_{7} \mathrm{NH}_{2}$

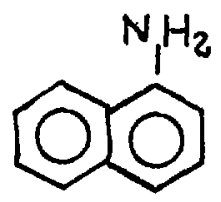

1-Naphthylamine occurs as needles or a crystalline mass becoming red on exposure to air. It has an unpleasant odor. $\alpha$-Naphthylamine has been 
declared by the FDA as a carcinogen. IARC Monographs report 93 cases of bladder tumors attributed to $\alpha$-naphthylamine. The latent period was 5 to over 50 years with the average time about 18 years (10).

Epidemiologic studies of a large cohort of workers in industries manufacturing benzidine and $\alpha$-naphthylamine in Japan revealed that primary cancers of the genitourinary organs were often followed by subsequent primary cancers of the liver, gall bladder, bile duct, large intestine, and lung (9).

Since commercial 1-naphthylamine contains 4 to $10 \%$ impurities of 2-naphthylamine, it is unclear whether or not bladder cancer reported in the occupational exposure was due to the impurity. There are no human data available on exposure to pure 1-naphthylamine (5).

Studies on dogs given various mixtures of 1- and 2-naphthylamines claimed no carcinogenic effect of 1-naphthylamine (13).

2-Naphthylamine ( $\beta$-Naphthylamine, 2-Aminonaphthalene) $\mathrm{C}_{10} \mathrm{H}_{7} \mathrm{NH}_{2}$

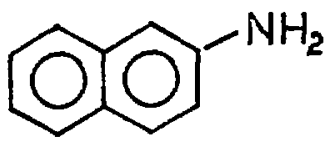

2-Naphthylamine forms white or reddish crystals. It is rarely used for industrial research purposes and has no commercial value. 2-Naphthylamine was widely used in dyestuif, and rubber, and in research in the past years, but it has been banned beciuse of its very high carcinogenicity. It is considered the most dangerous carcinogen among aromatic amines. Acute exposures can cause methemoglobinemia or hemorrhagic cystit.is. Contact with 2-naphthylamine should be avoided. A worker handling this substance should be fully protected with impervious clothing and self-contained breathing equipment. In addition, the hands, feet, and eyes should be covered. No exposure by any route should be permitted (1).

The average latent period of carcinogenic activity is 16 years. Recent long-term studies of Yamaguchl et al. (16) state that it may be 26.4 years or more.

The use of the Coil Planet Centrifuge system in studies of the effects of aromatic nitro and amino compounds on rabbit red blood cells (RBC) showed 
the increase in methemoglobin, appearance of Heinz bodies, and an increased osmotic fragility of RBC. The use of the Coll Planet Centrifuge method is suggested in examining workers exposed to aromatic and nitro amino compounds (11).

A method was developed for the removal of carcinogenic aromatic amines from industrial aqueous effluents. It includes the treatment of aqueous solutions containing the carcinogens with horseradish peroxidase and hydrogen peroxide (7).

\section{References}

1. ACGIH. 1980. Documentation of the threshold limft values. Fourth Edition. American Conference of Governmental Industrial Hygienists Inc., $\mathrm{OH}$.

2. Baranowska-Dutkiewicz, B. 1982. Skin absorption of aniline from aqueous solutions in man. (Toxline Abstract). Toxicol. Lett., 10: 367-72.

3. Gosselin, R.E., H.C. Hodge, R.P. Smith, and M.N. Gleason. 1979. clinical toxicology of comerctal products. The Williams wilkins Co., SD, PP. 86-92.

4. Gostinski1, V.D. and G.B. Krasnopeviseva. 1980. Some toxicokinetic characteristics of chemicals absorbed through the skin. Toxline Abstract). Gig. Tr. Prof. Zabol. 6: 42-4.

5. International Agency for Research on Cancer. 1979. IARC monographs on the Evaluation of Carcinogenic Risk of Chemicals to Man. World Health Organization.

6. Jeffrey, W.H., A.P. Zellcoff, and W.R. Hardy. 1982. Acquired methemoglobinemia and hemolytic anemia after usual doses of phenazopyridine. (Toxline Abstract). Durg. Intel1. C11n. Pharm. 16: $157-9$.

7. KIlbanov, A.M. and E.D. Morr1s. 1981. Horseradish peroxidase (EC $1.11 .1 .7)$ for the removal of carcinogenic aromatic amines from water. (Toxline Abstract). Enzyme Microb. Techno1. 3: 119-22.

8. Kirk-0thmer. 1978. Encyclopedia of chemical technology. Third Edition. John Wiley \& Sons, NY.

9. Morinaga, K., A. Oshima, and I. Hara. 1982. MuIt1.ple primary cancers following exposure to benzidine and beta-naphtiylamine. (Toxline Abstract). Am. J. Ind. Med. 3: 243-6.

10. National Library of Medicine. Toxicology Data Bank. (Computer search 1982). 
11. Nishida, N., I. Nakamura, Y. Kudo, and M. Kagami. 1982. Effects of aromatic nitro and aromatic amino compounds on the osmotic fragility of red cells. (Toxline Abstract). JPN J. Ind. Health 24: 172-80.

12. Public Health Service. 1981. Second annual report on carcinogens. U.S. Department of Public Health and Human Services.

13. Purchase, I.F., A.E. Kalinowsk1, J. Ishmae I, J. W1lson, and C.W. Gore. 1981. Lifetime carcinogenicity study of 1 - and 2-naphthylamine in dogs. (Toxline Abstract). Br. J. Cancer 44: 892-901.

14. Takeh1sa, S. and N. Kanaya. 1982. SCE induction in human lymphocytes by combined treatment with anliline and norharman. (Toxline Abstract). Mutat. Res. 101: 165-72.

15. U.S. Department of Health and Human Services. 1980. Benzidine-, o-Tolidine- and $c$-Dlanisidine-Based Dyes. Occupational Safety and Health Administration (OSHA) and National Institute for Occupational Safety and Health (NIOSH).

16. Yamaguchi, N., H. Tazak1, T. Okubo, and T. Toyama. 1982. Perlodic i. cytology surveillance of bladder tumor incidence in dyestuff w. .rs. Am. J. Indus. Med. 3: 139-48.

17. Zavon, M.R., U. Hoegg, and E. Bingham. 1973. Benzidine exposure as a cause of bladder tumors. Arch. Environ. Hea1th 27. 


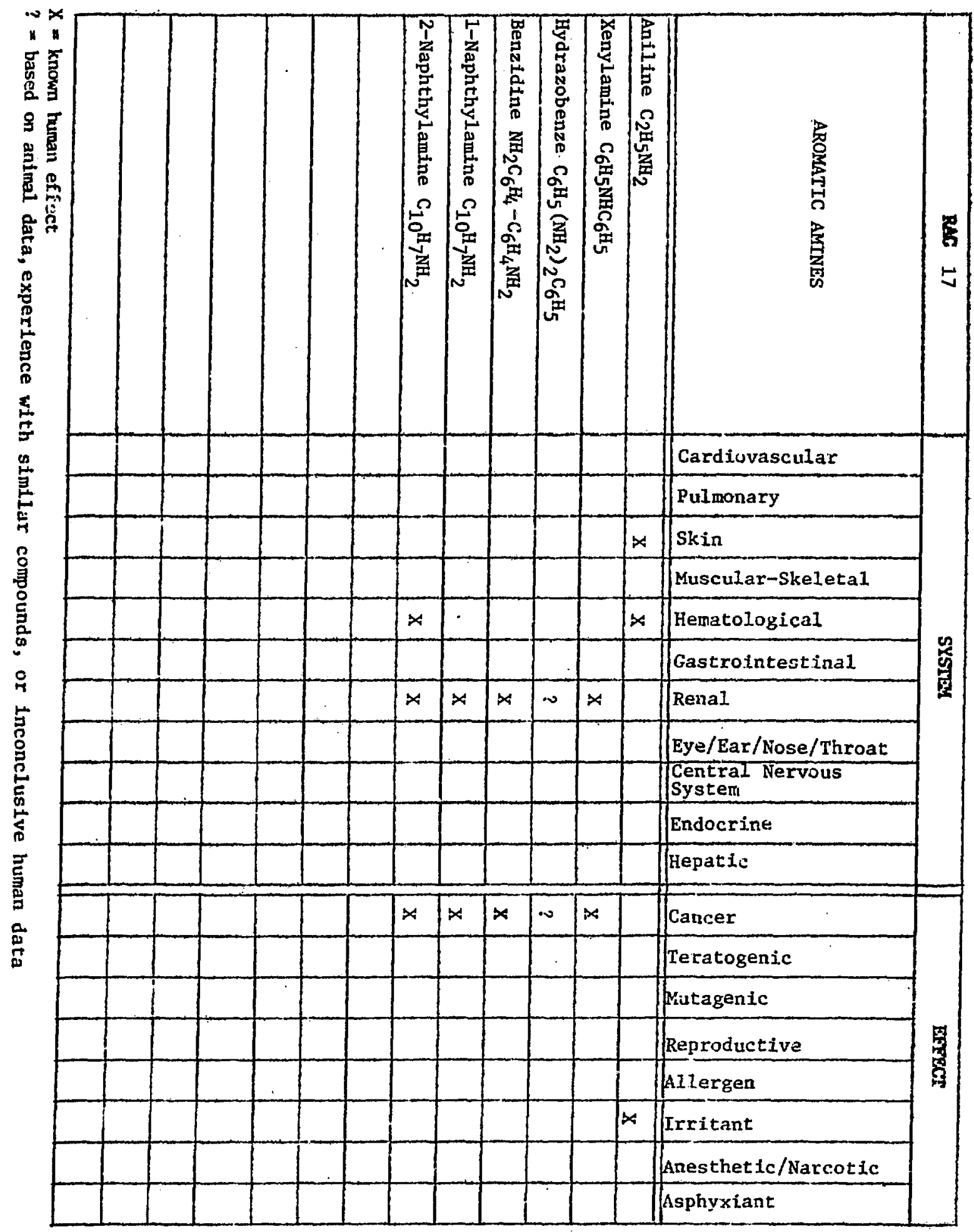


The three compounds reviewed in this category are:

Quinoline $\left(\mathrm{C}_{9}-\mathrm{H} 7 \mathrm{~N}\right)$<smiles>c1ccc2ncccc2c1</smiles>

Acridine $\left(\mathrm{C}_{13}-\mathrm{Hg}-\mathrm{N}\right)$<smiles>c1ccc2nc3ccccc3cc2c1</smiles>

Benz(c)acridine $\left(\mathrm{C}_{17}-\mathrm{H}_{11}-\mathrm{N}\right)$<smiles></smiles>

Quinoline, acridine and benz(c)acridine occur in small amounts in coal tar (5). The primary effects of exposure to these compounds were skin and mucous membrane irritation $(2,6)$. No industrial injuries related to exposures were found, but a notation in Toxicology Data Bank (taken from the Encyclopedia of Occupational Health and Safety, 1971, p. 1,136) states "Clinical signs of toxiclty to 'Quinoline' include lethargy, respiratory distress, and prostration leading to coma." In addition, quinoline is classified as an animal mutagen and tumorigen (3). Recently acridine has been detected in the urine of patients whose skin has been painted with a paste containing 1-6g of coal-tar (a dermatologic therapeutic agent). This observation was the first proof of the absorption of coal-tar component through the skin (1). 
Since th1s group of compounds is found in coal tar (a known carcinogen), the role they play (if any) in the carcinogenic properties of conl. tar is unknown at this time, but they are included in the NIOSH 11st of surpected carcinogens.(4)

References

1. Cernikova, M., H. Hubsky, and J. Horacek, 1983. Detection of acridine in human urine after topical coal-tar treatment. I. Chromatogr. 273: 202-6.

2. Kirk-0thmer. 1978. Encyclopedia of chemical technology. Third Edition. John Wiley and Sons, NY.

3. National Library of Medicine. Toxicology Data Bank. (Computer search 1982).

4. NIOSH. 1976. Suspected Carcinogens, 2nd Edition. National Institute for Occupational Safety and Health, U.S. Department of Health, Education, and Welfare, Cincinnat, $\mathrm{OH}$.

5. The Merck Index. 1976. An encyclopedia of chemicals and drugs. Ninth edition. Merck \& Co., Inc., Rahway, NJ.

6. Sax, N.I. 1975. Dangerous properties of Industrial materials. Fourth Edition. Van Nostrand Reinhold Company, NY. 


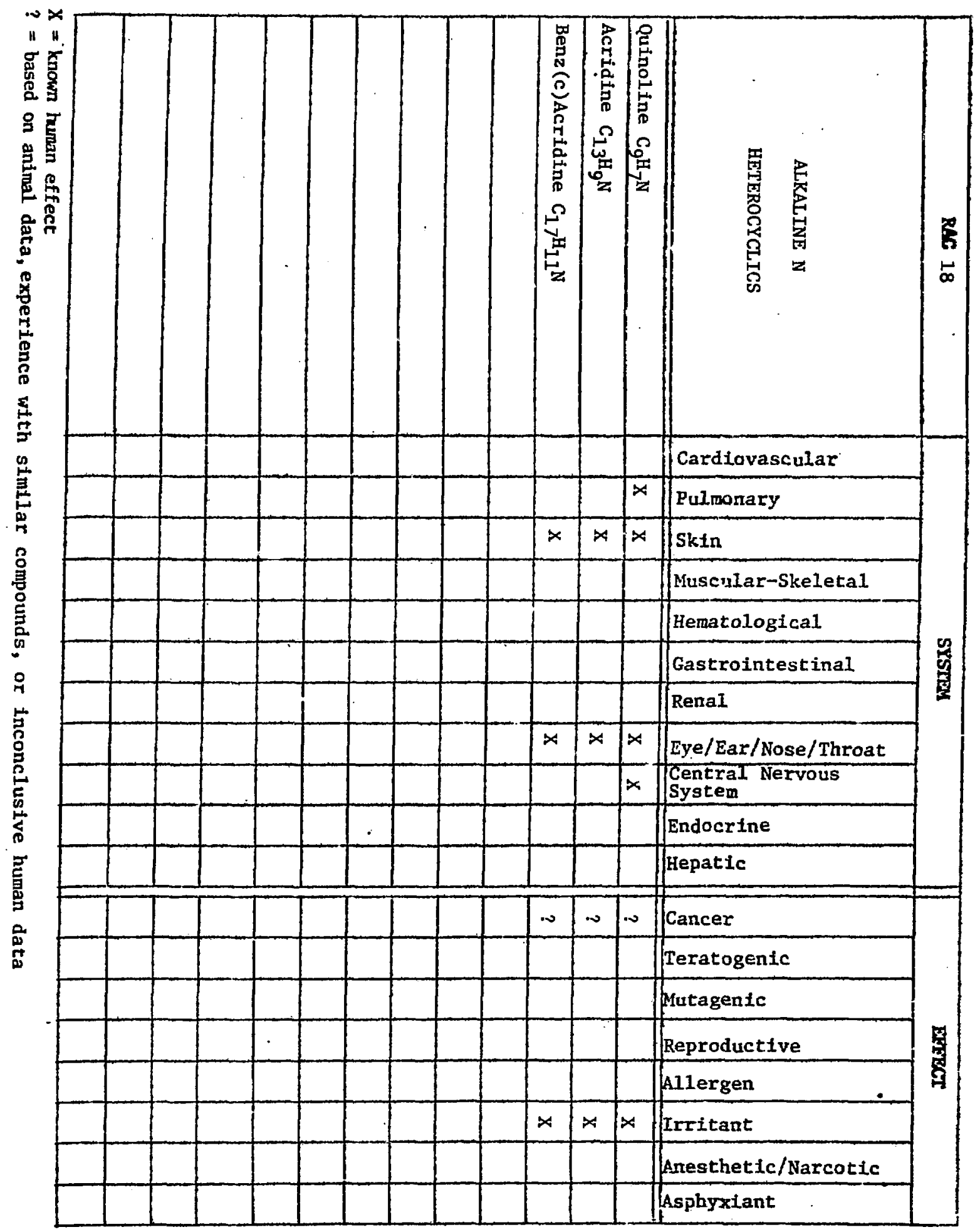


RAC $\$ 19$ - NEIJTRAL $N, 0$, S HETEROCYCLICS

(EXCLUDING "VOLATILES")

Nitrogen, oxygen, and sulfur heterocyclics are characterized by the $N$, 0 , or $S$ atoms as members of aromatic rings. Neutral heterocyclics selected for RAC \#19 include the following:

Nitrogen Heterocyclics

Indole (1-Benzolblpyrrole; 2,3-Benzopyrrole, 1-Aza Indene; 1-Benzazole) $\mathrm{C}_{8} \mathrm{H}_{6} \mathrm{NH}$<smiles>c1ccc2[nH]ccc2c1</smiles>

Indole forms leaflets with an intense fecal odor. It is found in a large number of naturally occurring compounds (e.g., Jasmine and orange blossom ofls). It is of a commercial importance as a component of perfumes. The comercial source of indole is the extraction from coal-tar distillate.

Indole derivatives occur as essential amino acld (tryptofan), as plant growth hormone, and as several groups of important alkaloids. 3-Methylindole is produced with indole during digestion and decomposition of proteins, and hence both occur in the intestines and feces. Recent medicinal and biochemical studies on indole derivatives were focused on serotonin (a metabolite of brain chemistry); psychotomimetic indoles; the tranquilizer reserpine; and the melamin plgments (2).

No data on the effects of indole on human health have been found. Carbazole (9H-Carbazole; 9-Azafluorene; Dibenzopyrrole;

Diphenylemimine) $C_{12} \mathrm{Hg} \mathrm{NH}$

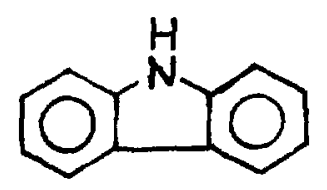


Carbazole occurs as crystals. It is used as a dye intermediate, in making photographic plates sensitive to ultraviolet 1 ight, and as a reagent for lignin, carbohydrates, and formaldehyde.

Carbazole at $0.6,0.3$, and $0.15 \%$ in the diet of mice appeared signiffcantly carcinogentc to the liver and forestomach (4).

Carbazole is listed by Sax (3) as an allergen, but otherwise no data about Its effect on human health have been found.

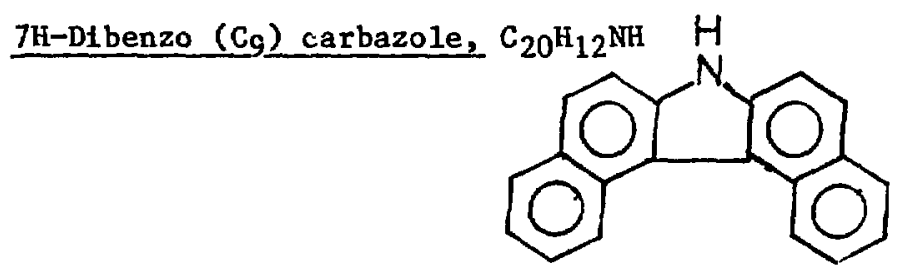

7H-Dibenzo $(\mathrm{Cg})$ carbazole has been found in cigarette tar. It is carcinogenic in humans. No case reports or epidemlological studies on the significance of the exposure of man to $7 \mathrm{H}-\mathrm{dibenzo}\left(\mathrm{C}_{9}\right)$ carbazole have been found (1).

Oxygen Heterocyclic

Benzofuran (Cumarone) $\mathrm{C}_{8} \mathrm{H}_{6} \mathrm{O}$

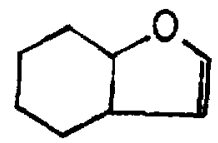

Benzofuran is isolated from coal tar o1ls. It is an oil of aromatic odor, used in the manufacture of cumarone-indene resins.

No data on the effect of benzofuran on human health were found. 
Sulfur Hecerocyclics

2,3-Benzothiophene

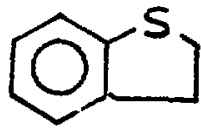

Dibenzothiophene (Diphenylene Sulfide)

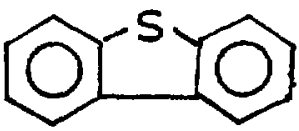

No data on the effect of $S$ heterocyclics on human health were found.

\section{References}

1. International Agency for Research on Cancer. 1979. IARC monographs on the Evaluation of Carcinogentc Risk of Chemicals to Man. World Health Organization.

2. Kirk-0thmer. 1978. Encyclopedia of chemical technology, Volume 1. Third Edition. John wiley \& Sons, NY.

3. Sax, N.I. 1975. Dangerous properties of industrial materials. Fourth Edition. Van Nostrand Reinhold Company, NY.

4. Tsuda, H., A. Hagiwara, M. Shibata, M. Ohshima, and N. Ito. 1982. Carcinogenic effect of carbazole in the liver of (C57BL/6N times. C3H/HeN)F1 mice. (Toxline Abstract). JNCI, J. Nat1. Cancer Inst., Volume 69 6: $1,383-9$. 


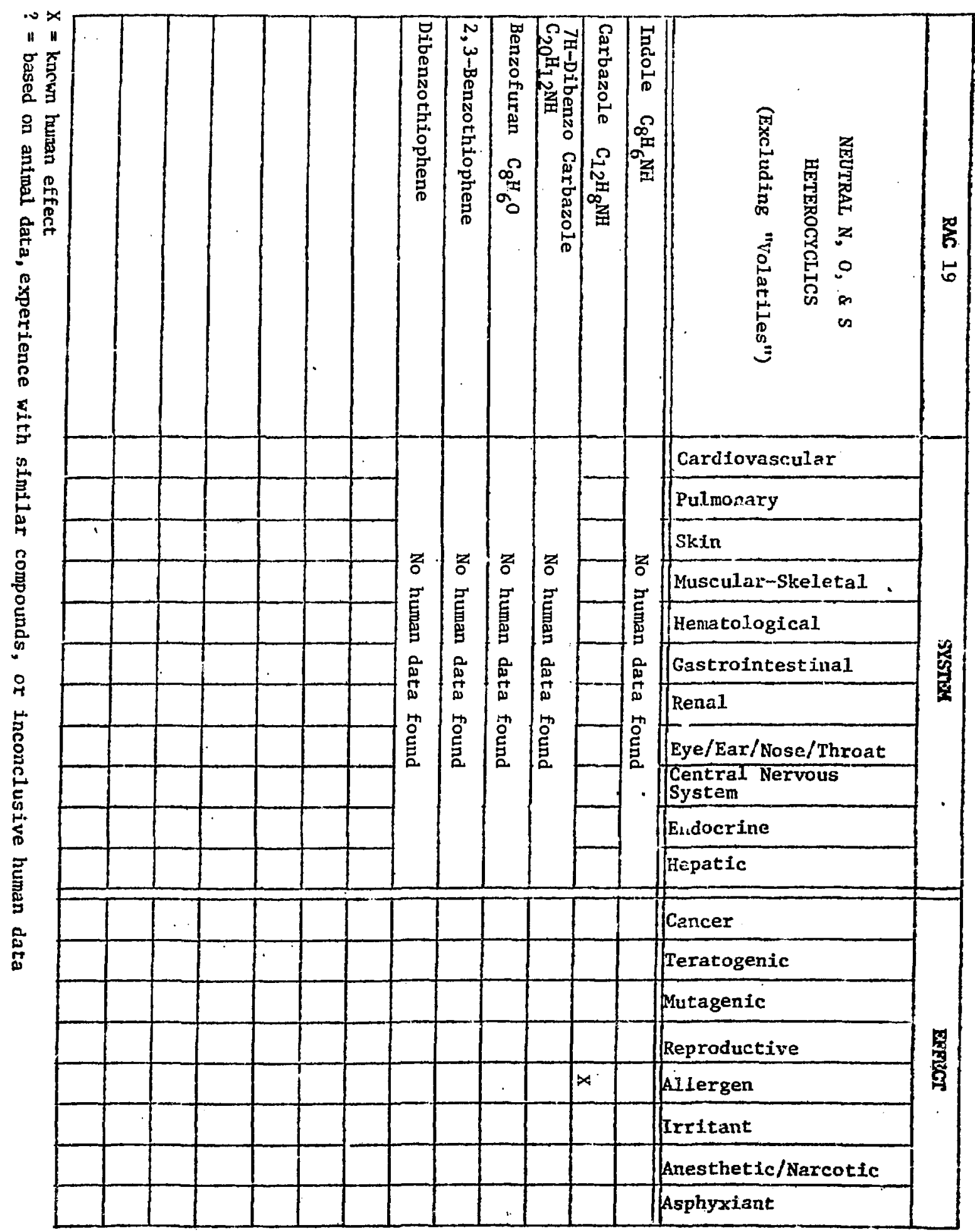


Carboxylic acids contain a carboxyl group<smiles>[R]C(=O)O</smiles>

att:shed to aliphatic or aromatic hydrocarbons. These substances ionize in water to give acidic solutions and can combine to form esters, amides, or anhydrides (2). Carboxylic acids derived from open-chain hydrocarbons with more than $s i x$ carbon atoms are of ten referred to as fatty acids. They can be obtalned from natural sources such as animal tallow and greases, and various vegetable and marine oils. Carboxylic actds are also produced synthetically from petroleum sources (9). Two aliphatic and two aromatic carboxylic actds will be discussed in this category.

Aliphatic Carboxylic Aclds

Butyric Acid (Butanoic Acid) $\mathrm{CH}_{3}\left(\mathrm{CH}_{2}\right)_{2} \mathrm{COOH}$<smiles>CCC(=O)O</smiles>

Butyric acil is a colorless ofly liquid with an unpleasant rancid odor. Butter contains about 4 to $5 \%$ butyric acid. Butyric acid is used in the manufacture of esters, some of which serve as bases in artificial flavoring ingredients of liquers, soda water, syrups, and candies. It Is also used for varnishes and as a decalctfjer of hides (10).

Butyric acid is an eye, skin, and respiratory irritant and requires strict handling precaltions (5). An application of butyric acid to incact human skin may be followed within an hour by moderate burning; within 24 hours, a slight scaling of the epidermis may occur (17). Butyric acid has been noted to have antiseptic properties (1?) and has been suggested for use as an anticancer agent. In the lattex" role, "sodium butyrate was given to

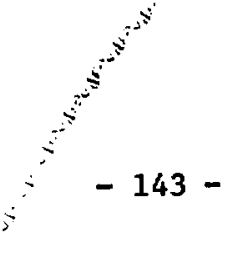


patients with neuroblastoma. Although high doses were given (up to 10 g/day), no clinically detectable toxicity was observed (14).

In vitro studies of normal and Xeroderma pigmentosum human fibroblasts showed that the pretreatment with sodium butyrate produced a decrease in UV-induced DNA replicative synthesis and an increase in DNA repair synthesis (16). Another study showed that sodium butyrate (and severa1 other compounds) were cytotoxic to actively cycling cells of human leukemic lymphoblasts (1). Treatment of human 1ymphoblastold cells with butyrate and 5'-bromo-deoxyuridine caused a substantial increase in Sendai virus-induced interferon synthesis. The effect was highly specific as the majority protein synthesis remained unaffected (15).

Stearic Acid (Octadecanoic Acid) $\mathrm{CH}_{3}\left(\mathrm{CH}_{2}\right)_{16} \mathrm{COOH}$

$$
\mathrm{CH}_{3}-\left(\mathrm{CH}_{2}\right)_{16}-\mathrm{C}_{-}=\mathrm{OH}
$$

Stearic actd occurs as a glyceride in tallow and other animal fats and olls as well as in some vegetable oils (10). Stearic acid is used in candles, phonograph records, insulators, cosmetics, and coatings for bitter remedies (10), and is considered a safe food additive and gum base (13).

Stearlc acid is relatively nontoxic (7) and is a mild skin irritant. An exposure of $75 \mathrm{mg}$ over 3 days causes mildly toxic effects (11). Skin contact with molten stearic acid may cause an itchy dermatitis with dryness of the skin, fissures, and desquamation (17). The probable oral lethal dose for humans is in excess of $2 \mathrm{~g} / \mathrm{kg}$ (more than 1 quart for a 150-1b person), with the greatest danger being from intestinal obstruction (4). Overheated wax may decompose, releasing vapors which can irritate the respiratory system and cause a chemical pneumonitis (4). Patty (2nd ed.) states that despite extensive use in industry there have been no reports of injury.

Aromatic Carboxylic Acids

Benzoic Acid (Benzenecarboxylic Acid, Phenylformic Acid, Dracyclic Acid) $\mathrm{C}_{6} \mathrm{H}_{5} \mathrm{COOH}$<smiles>O=C(O)c1ccccc1</smiles> 
Benzoic acid occurs in nature in free and combined forms (most berries contain 0.05\%). Benzoic acid is used in a wide range of preservation applications because of an effective combination of bactericidal and bacteriostatic action with nontoxicity and tastelessness. It is used is a preservative in sauces, fruit julces, bottle carbonated beverages (9), and pharmaceutical and cosmetic items such as toothpastes, powders, tobacco paste, fragrances, soap, creams, and lotions (12). It is also used in the manufacture of benzoates and benzoyl compounds, production of phenol, and dyes (10), to improve properties of alkyd resin coatings, and as an additive to coolants in automoblle cooling system (9).

Healthy individuals may tolerate $0.5 \mathrm{~g}$ of benzoate per day in concentrations of $0.1 \%$ without 111 effects, and the food content of benzoic acid is regulated by state and federal laws to be no more than $0.1 \%$ sodium benzoate ( 9 ).

Benzolc acid is a mild irritant to skin, eyes, and mucous membranes, including the nose and throat (10). The NIOSH low toxic dose for human skin is $6 \mathrm{mg} / \mathrm{kg}$. The systemic toxicity of benzoic acid is low (9). Large doses have mainly digestive effects such as nausea and vomiting. The amount producing these symptoms may vary in different individuals from 6 to $8 \mathrm{~g}$ to $50 \mathrm{~g}$. The probable oral lethal dose for man is $500 \mathrm{mg} / \mathrm{kg}$ (7).

Perforal urticaria was reported in chlldren in a kindergarten following the intake and accidental perioral application of a mayonnaise salad cream. Stinging tests and closed 20-min patch tests with salad dressing were postive in a large number of healthy adult controls. Sorblc acid and benzolic acids were the components of the salad dressing which gave almost identical results. Nonimmunologic mechanisms appeared responsible for the above transient reactions and no restrictions have been suggested in the use of sorbic and benzoic acids as food preservatives (3). Dyes and food preservatives including benzoates were also recognized as components which Induced food Intolerance and hypersensitivity in 25 children aged 18 months to 12 years (8). No mutagenic activity has been demonstrated for benzolc acid when tested in a number of assays, and it has not been reported as a teratogenic agent (12). 
Phthalic Acid (1,2-Benzenedicarboxylic Ac1d) $\mathrm{C}_{6} \mathrm{H}_{4}(\mathrm{COOH})_{2}$<smiles>O=C(O)c1ccccc1C(=O)O</smiles>

Phthalic acid is a white solid with a characterisic choking odor (11). Most toxicity information is concerned with phthalate esters and phthalic anhydride. Phthalic anhydride is used in the manufacture of plasticizers, alkyl and polyester resin, synthetic fibers, dyes, pigtnents, pharmaceuticals, and insecticides (11).

Phthalic acid is a mild allergen and a mild irritant to the skin, eyes, and mucous membranes. There have been reports of confunctivitis, bloody nasal excretion, atrophy of nasal mucosa, hoarseness, cough, and bronchitis In workers employed in the production of phthalfc acid and anhydride (10A).

References

1. Bell, P.A. and C.N. Jones. 1982. Cytotoxic effects of butyrate and other differentiation inducers on immature lymphoid cells. (Toxline Abstract). Blochem. Biophys. Res. Commun. 104: 1,202-8.

2. Brown, W.H. 1976. Introduction to Organic Chemistry. Willard Grant Press, Boston, 468 pp.

3. Clemmensen, $O$. and N. Hjorth. 1982. Perioral contact urticaria from sorbic acid and benzolc actd in a salad dressing. (Toxline Abstract). Contact Dermatitis 8: 1-6.

4. Drefsback, Robert H. 1980. Handbook of Poisoning 10th ed. Lange Medical Publications, Los Altos, CA, p. 276.

5. Encyclopedia of Occupational Health and Safety, 1971.

6. Goodman. Pharm. Basis Therap., 5th ed. pp. 994 (Toxdata).

7. Gosselin, R.E., H.C. Hodge, R.P. Smith, and M.N. Gleason. 1979. Clinical toxicology of commercial products. The Williams \& Wilkins Co., MD, pp. 86-92.

8. Ibero, M., J.L. Eseverr1, C. Barroso, and J. Botey. 1982. Dyes, preservatives and salicylates in the induction of food intolerance and/or hypersensitivity in children. (Toxline Abstract). Allergol. Immunopathol. (Madr.) 10: 263-8. 
9. Kirk-Othmer. 1978. Encyclopedia of chemical technology. Third Edition. John Wiley \& Sons, NY.

10. Merck Index. 1976. An encyclopedia of chemicals and drugs. Ninth edition. Merck \& Co., Inc., Rahway, NJ.

10A. National Library of Medicine. Toxicology Data Bank. (Computer search 1982).

11. NIOSH/OSHA Encyclopedia of Occupational Health and Safety. 1978.

12. Opdyke, D.L.J. 1979. Monographs on Fragrance Raw Materials. Food and Cosmetics Toxicology 17 (Supplement), 715-722.

13. Patty, F.A. 1982. Patty's industrial hygiene and toxicology, Volumes 2A, 2B, and 2C. Third Revised Edition. John Wiley \& Sons, NY.

14. Prasad, Kedar, N. 1980. Minjureview. Butyric Acid: A Small Fatty Acid With Diverse Blological Functions. Life Sciences 27: 1,351-58.

15. Shuttleworth, J., J. Morser, and D. Burke. 1982. Protein synthesis in human lymphoblastoid cells (Namalwa) after treatment with butyrate and 5'-bromodeoxyuridine. (Toxline Abstract). Blochim. Biophys. Acta 698: $1-10$.

16. Smerdon, M.J., S.Y. Lan, R.E. Calza, and R. Reeves. 1982. Sodium butyrate stimulates DNA repair in UV-irradiated normal and xeroderma pigmentosun human fibroblasts. (Toxline Abstract). J. Biol. Chem. 257: $13,441-7$.

17. Von Oettingen, W.F. 1960. The Aliphatic Acids and Their Esters: Toxicity and Potential Dangers. AMA Archives of Industrial Health 21: 100-13. 


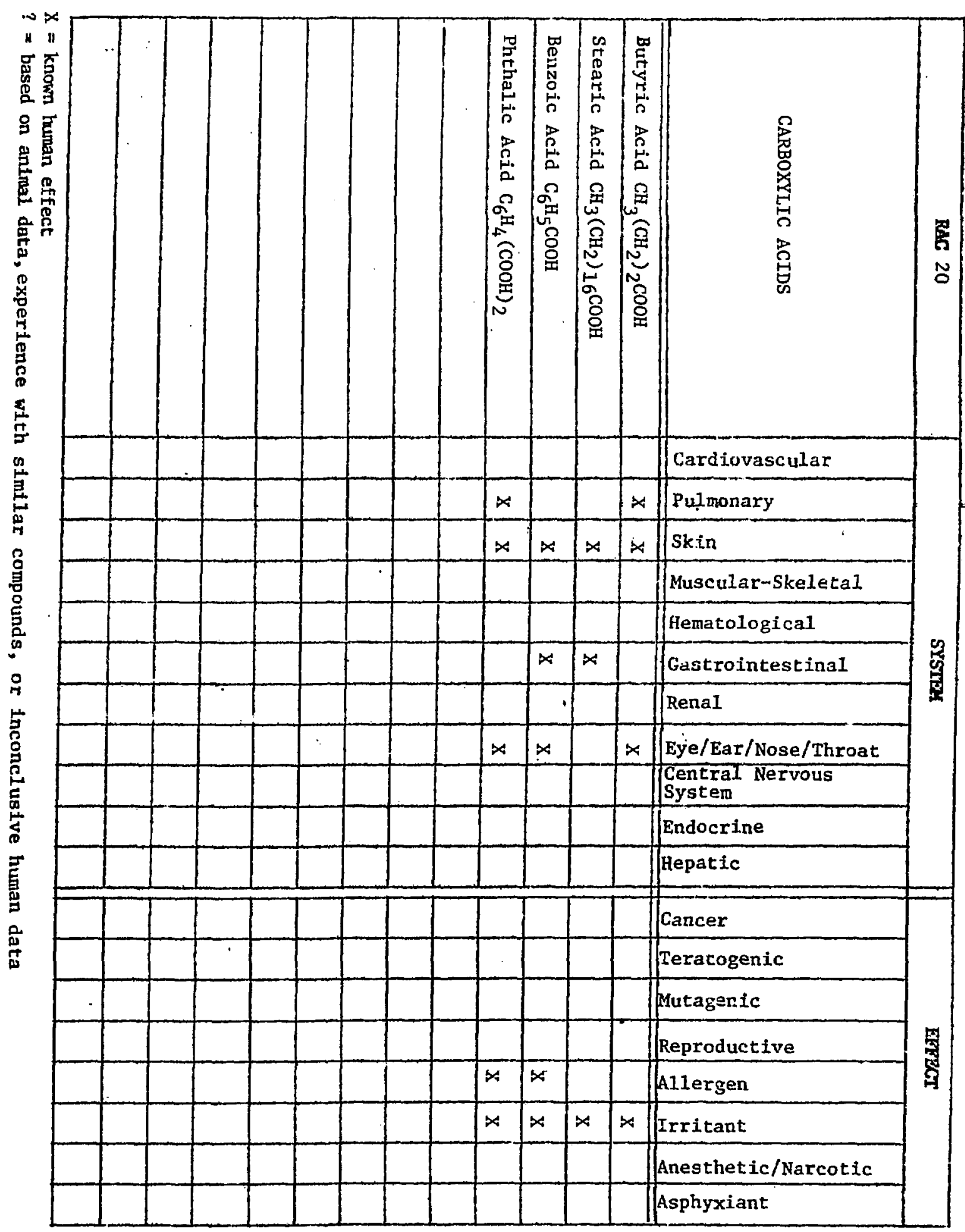


Phenols are derivatives of aromatic hydrocarbons with a hydroxyl group attached directly to an aromatic ring. Phenols discussed in category include: 1) monohydroxy benzenes [phenol $\mathrm{C}_{6} \mathrm{H}_{5} \mathrm{OH}$; cresols (methyl phenols) $\left.\mathrm{C}_{6} \mathrm{H}_{4} \mathrm{CH}_{3} \mathrm{OH}\right]$ and xylenols (dimethyl phenols) $\left(\mathrm{C}_{6} \mathrm{H}_{3}\left[\mathrm{CH}_{3}\right]_{2} \mathrm{OH}\right.$ ), and 2) dihydroxy benzenes $\left(\mathrm{C}_{6} \mathrm{H}_{4}[\mathrm{OH}]_{2}\right.$ ) (catechol, resorcinol, hydroquinone).

Monohydroxy Benzenes

Phenol (Carbolic Acid, Benzenol, Hydroxybenzene) $\mathrm{C}_{6} \mathrm{H}_{5} \mathrm{OH}$

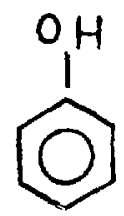

Phenol is a solid at room temperature and is liquefled by mixing with about $8 \%$ water. Its chlef use is in the manufacture of phenolic resins and many other chemicals and drugs. It is also employed as a disinfectant in germicidal paints and as a slimicide. Phenol is produced as a waste product of many industrial activities and, as such, appears in industrial effluents that contaminate aquatic ecosystems.

Phenol is highly toxic by skin absorption, inhalation, and ingestion. However, because of its low volatility, it does not frequently constitute a serious respiratory hazard in industry (1). Formerly, use of phenol as an antiseptic in surgery resulted in numerous subacute and chronic poisonings.

As efther a solution or a vapor, phenol penetrates into the skin rapldly. Phenol vapors are also well absorbed by the lung. Although the onset of phenol poisoning can be abrupt, the dangerous phase of the intoxication is usually complete in 24 hours. A profound central nervous system depression with coma, hypothermia, loss of vasoconstriction, cardiac depression, and respiratory arrest are the most common manifestations of systemic phenol poisoning (6). Changes in heartbeat rate, systolic blood pressure, and the activity of blood cholinesterase were reported in workers exposed to phenol vapors for 6 hours with the concentrations of phenol increased from $3 \mathrm{mg} / \mathrm{m}^{3}$ to $9 \mathrm{mg} / \mathrm{m}^{3}$ (18). Respiratory death of pulmonary 
origin, cardiac death, and renal complications were frequently reported (6). In many of the above cases, the original contact with phenol was cutaneous rather than by mouth.

Phenol has recently been used by plastic irgeons for chemical face peeling. Cardiac complications (with tachycardia being the most frequent), were reported by $13 \%$ of the plastic surgeons reing this procedure (9).

Chronic exposure to phenol has caused brown discoloration of skin and dark plgmentation of ligaments, cartilage, fibrous tissue, skin, and urine (16). Marked corrosion and skin necrosis is produced by $10 \%$ solutions of phenol (6). Schmidt and Maibach (17) reported an Immediate and delayed dermatitis produced by topical phenol exposure. The immediate painful skin necrotic eruption produced by contact with chemicals containing $10 \%$ phenol extends proximally without any further contact with the chemical, leaving skip areas of normal skin. Approximately 3 to 7 months later, spontaneous flares appeared within the area of original contact. Gradual release from an Initially formed phenol-protein complex was thought to be responsible for the progression beyond the contact area and the delayed reaction.

Metabolism. "Phenol is a normal constituent of animal and human tissues and also occurs in the urine, feces, saliva, and sweat. Background levels of phenol arise from microbial metabolic activities, particularly the metabolism of tyrosine and the catabolism of proteins, in the intestines. Escherichia coli is thought to be the main producer of phenol. The production of phenol is a function of the type of diet, with a high protein or meat diet promoting phenol formation. The phenol, so formed, may be conjugated with various acids and may be oxidized, either completely to carbon dioxide or incompletely to quinol (1,4-dihydroxybenzene) and catechol (o-dihydroxybenzene). The production of phenol in the body may be elevated by exposure to chemicals that are metabolized to phenol, such as benzene and phenylsalicylate. In addition, pathological conditions that involve the catabolism of body tissues elevate the leve's of phenol in the body. A rise In free and conjugated phenol was detected in the blood of human beings afflicted with pernicious anemia, gangrene of the lungs, cirrhosis of the liver, and carcinoma of the stomach" (3). 
Patients with chronic renal failure had abnormal function of blood platelets which has been associated with elevated levels of phenol and phenolic acids in serum. In vitro studies showed the inhibition of secondary platelet aggregation by phenol (5). Laboratory studies on binding of phenol and its derivatives to human serum proteins showed that phenol itself was bound least to most proteins as compared to the derivatives (7). A correlation between the toxicity of nitrophenols and their binding property with serum albumin has also been reported (10).

Phenol is now recognized as a general cytoplasmic poison toxic to all cells. However, its metabolic effects are still poorly understood. Gosselin (12) quotes a study showing that a nontoxic dose of ${ }^{14} \mathrm{C}$-labeled phenol in man was excreted in 24 hours, principally as the sulfate (77\%) and as the glucuronide ( $16 \%$ ) with small amounts of sulfate and glucuronide conjugates of hydroquinone. He adds that with larger doses, free (unmetabolized) phenol can presumably be found in the urine. In other studies, the content of urine phenol is used for the evaluation of phenol exposure $(4,11$,$) . The evaluations apparently assume that there was no$ exposure to benzene, since phenol is also the urinary metabolic end product of benzene.

Carcinogenicity. Phenol is a tumor promoter. Its tumor-promoting activity was noted in "S" albino mice pretreated with 9,10-dimethyl-1, 2-benzathracene (DMBA) in acetone followed by weekly skin applications of $20 \%$ phenol. Phenol at $5 \%$ had only a weak tumor-promoting activity. However, $20 \%$ phenol alone (i.e., without prior treatment with DMBA) was weakly carcinogenic; no carcinogenic activity was noted with $5 \%$ phenol alone. Altiough a tumor promoter, phenol is not a cocarcinogen (3). NIOSH (1976), In their recent review of the relevancy of the occupational standard for phenol, has stated that there is no evidence that phenol acts as a specific carcinogen; the one study that did show phenol to have weak carcinogenic properties did not evaluate the effects of the solvent (1.e., acetone) used to dissolve the phenol. 
Cresol (Methyl Phenol, Hydroxytoluene) $\mathrm{CH}_{3} \mathrm{C}_{6} \mathrm{H}_{4} \mathrm{OH}$

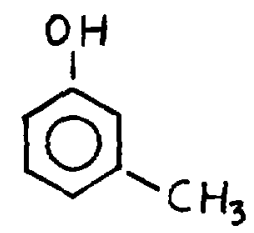

Cresol occurs in three isomerlc forms (ortho, meta, and para). Orthoand meta-cresols are crystalline; para-cresol is liquid. A commercially avallable mixture of three isomers occurs as a colorless, yellowish, or pinkish liquid wtih a phenolic odor. Cresol 1someis are derived from coal tar or petroleum. Cresol is used in making synthetic resins, as a disinfectant, in photographic developers, and in explosives.

Toxicity of cresol is regarded as similar to that of phenol; meta-cresol is less toxic than ortho-cresol, and para-cresol is the most toxic $(1,15)$.

Toxic effects which develop in 20 to 30 minutes after absorption are headache, dizziness, dimness of vision, tinnitus, irregular and rapid respiration, weak pulse, dyspnea, and profound muscular reakness, with occasional mental confusion. On tissue contact, cresol can be absorbed through the skin and produce local and systemlc damages in humans. The skin is considered the primary route of occupational exposure to cresol. Skin contact with cresols has resulted in skin peeling on the hands, facial peripheral neuritis, severe faclal burns, and damage to internal organs, including loss of kidney function and necrosis of the liver and kidneys. Sensitization of the skin and dermatitis developed on the fingers of workers who had been using a solution containing cresol and cresylic acid (14). Fatalities can occur from prolonged skin contact (15).

Appreclable concentrations of cresol vapors are rarely generated in industry, because all three cresol isomers have low vapor pressures. However, a hazardous concentration of vapor may be generated at elevated temperatures, and there have been a few reports in the literature describing effects from inhalation of cresol vapor (14). Workers exposed to airborne cresol at an unspecified concentration developed headaches and nausea. Some workers also developed hypertension, muscular 1rritability, convulsions, and decreased kidney function. 
Out of 10 persons exposed to o-cresol vapor at a concentration of 6 $\mathrm{mg} / \mathrm{m}^{3}, 8$ complatied of dryness of the respiratory mucosa, nasal constriction, irritation of the throat, and the sensation of an unspecified taste (14).

Several cases of cresol ingestion (mostly as sulcidal attempts) have shown cresol to be corrosive to body tissues and to cause toxic effects on the vascular system, 11ver, kidneys, pancreas. In some cases death has followed. Cresol introduced Into the uteri of pregnant women has caused abortion, extensive hemolysis, erosion of blood vessels, damage to the kiney tubules, necrosis of the 11ver, and death (14). Pathologic description of changes Induced by cresol are simtlar to those caused by phenol.

No Investigations of the mutagenic or teratogenic potential of cresol were found. Studies on the role of phenol and its derivatives, including cresol and xylenol, in promoting the formation of both papillomas and carcinomas suggest that the cresol and xylenol isomers may promote the production of benign tumors (14).

Because of the lack of relevant quanticative toxicity data and in view of the closely analogous toxic action to phenol, a TWA of $5 \mathrm{ppm}$ for mixed cresols is recommended by ACGIH (1).

Xy1eno1 (Dimethy1 Pheno1, Dimethy1 Hydroxy Benzene) $\left(\mathrm{CH}_{3}\right)_{2} \mathrm{C}_{6} \mathrm{H}_{3} \mathrm{OH}$

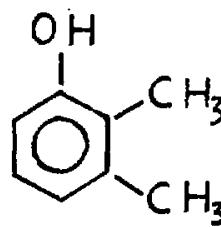

There are 6 isomers of xylenol:

2,3-dimethyl phenol (needles)

2,4-dimethy1 phenol (crystals)

2,5-dimethy1 phenol (crystals)

2,6-dimethyl phenol (needles)

3,4-dimethy1 phenol (needles)

3,5-dimethyl phenol (needles) 
Xjlenols are used in the preparation of coal tars and disinfectants, and in the manufacture of synthetic resins.

No data on human exposure to xylenols were found.

\section{Dihydroxybenzenes $\mathrm{C}_{6} \mathrm{H}_{4}(\mathrm{OH})_{2}$}

Catechol (1,2-Dihydroxybenzene, 1,2-Benzenediol, Pyrocatechol)<smiles>Oc1ccccc1O</smiles>

Resorcinol (1,3-Dihydroxybenzene)<smiles>Oc1cccc(O)c1</smiles>

Hydroquinone (1,4-Dihydroxybenzene, Quinol)<smiles>Oc1ccc(O)cc1</smiles>

Dihydroxybenzenes (DHB) are white crystalline compounds with a faint phenolic odor. The greatest use of dihydroxybenzenes, hydroquinone and catechol particuiarly, is as developers in photography. The second greatest use is in the rubber Industry as tire and rubber adhesives. Another use is as antloxidants in rubber and in the food Industry. Catechol and resorcinol are also used in fur dyeing and leather tanning.

Except for resorcino1, DHBs are more toxic than phenol. Experimental studies on humans and animals have demonstraced low chronic toxicity and rapid excretion of DHBs. They are absorbed from the gastrointestinal tract and readily absorbed through human skin. After absorption of catechol and hydroquinone, one part of the molecule is oxidized to the more toxic compound, quinone, whereas the other part of the molecule confugates with 
hexuronic, sulfuric, and other acids. Resorcinol is excreted in the free state and is conjugated to acids. The symptoms of intoxication by DHBs resemble those induced by phenol poisoning; nausea, dizziness, a sense of suffocation, an increased rate of respiration, vomiting, pallor convulsions, headache, dyspnea, cyanosis, delerium, and coma. Catechol can cause depression of the central nervous system and a rise of blood pressure resulting from peripheral vasoconstriction. Unlike phenol, DHBs do not have a tumor-promoting activity, but catechol is reported to have a cocarcinogenic activity (8).

Cases of dermatitis have resulted from skin contact with hydroquinone, and with other derivatives of phenolic compounds (2). Cases of keratitis and discoloration of the confunctiva have been reported among men exposed to hydroquinone vapor or dust. Persons with poor visual acuity caused by sstigmatism, keratoconus, or preexisting corneal injury should be excluded from repeated unprotected exposure. Hydroquinone induces hyperemia of abdominal organs that are rich in pigments, pathological changes in the liver and kidney, and bronchopneumonia.

Resorcinol may cause irritation to the eyes and induce dermatitis particularly in sensitive individuals. The cutaneous application of resorcinol solution or salves may result in local hyperemia, itching, dermatitis, edema, and the loss of superficial layers of the skin. Resorcinol markedly affects the spleen, and induces tubular injury in the kidney, fatty changes and anemia in the l1ver, fatty changes in the heart, and edems and emphysema in the lungs ( 8 ).

Catechol contact with the skin can cause an eczematous dermatitis. Catechol induces degenerative changes in the tubull of the kidney characterized by red blood cells and fibrin clots in the lumina.

Average dally concentration of $\mathrm{DHB}$ dust should be maintained below the threshold limit value. Operations, e.g., sleving, blending, and packaging, usually require enclosure and local controlled ventilation. Good housekeeping practices and personal contamination control are essential. In the case of hydroquinone, complete eye protection may be useful for short exposure where other controls are not feasible (8).

Catechol and hydroquinone appear as intermediate products of benzene metabolism in man. Morimoto and Wolff (13) studied the effect benzene and 
Its metabolites had on human lymphotcyes cultured in vitro. They found that catechol is a potent compound, which induces sister chromatid exchanges and readily delays cell divisicn, and that hydroquinone is also potent but to a lesser degree than catechol. Benzene 1tself does not affect sister chromatid exchange and cell kinetics. Thus the benzene toxicity is most likely due to the formation of catechol and hydroquinone. Subsequent studies showed that catechol and hydroquinone can be optimally metabolized to produce reactive species, presumably benzo(semi)quinones, under conditions of lower metabolic activity than those necessary for phenol and benzene (13).

\section{References}

1. ACGIH. 1980. Documentation of the threshold 11mit values. Fourth Edition. American Conference of Governmental Industrial Hygienists Inc., $\mathrm{OH}$.

2. Angelini, G., G.A. Vena, and C.I. Meneghini. 1980. Shoe contact dermatitis. Contact Dermatitis 6: 279-83.

3. Babich, H. and D.I. Davis. 1981. Phenol: A review of environmental and health ilsks. Reg. Toxicol. and Pharm. 1: 90-109.

4. Brancato, D.J. 1982. Recognizing potential toxicity of phenol. Vet. Hum. Toxicol. 24: (Toxline Abstract). 29-30.

5. Coan, M.L., K.R. Case, and H.B. Bosmann. 1982. Platelet aggegation: Inhibition of secondary aggregation by phenol. (Toxline Abstract). Res. Commun. Chem. Pathol. Pharmacol. 36: 241-9.

6. Gosselin, R.E., H.C. Hodge, R.P. Smith, and M.N. Gleason. 1979. Clinical toxicology of commercial products. The Williams \& Wilkins Co., MD, Pp. 86-92.

7. Judis, J. 1982. Binding of selected phenol derivatives to human serum proteins. (Toxilne Abstract). J. Pharm. Sc1. 71: 1,145-7.

8. Kirk-0thmer. 1978. Encycıopedia of chemical technology. Third Edition. John Wiley \& Sons, $\mathbb{N Y}$.

9. Iitton, C. and G. Trinidad. 1981. Complications of chemical face peeling as evaluated by questionnaire. (Toxline Abstract). plast. Reconstr. Surg. 67: 738-44. 
10. Luik, A.I. and V.D. Luk'yanciruk. 1982. Parameters of interaction between albumin and nitrophanols of various chemical structures and their toxicity, (Toxline Abstract). Vopr. Med. Khim. 28: 48-51.

11. Lutogniewska, J. 1980. A simple test for an approximate evaluation of occupational exposure to pheno1. 1980. (Toxline Abstract). Med. Pr. 31: $399-401$.

12. Morimoto, K. and S. Wolff. 1980. Increase of sister chromatid exchanges and percurbations of cell division kinetics in human 1ymphocytes by benzene metabolites. Cancer Res. 40: 1189-93.

13. Morimoto, K., S. Wolff, and A. Kolzumi. 1983. Induction of sister-chromatid exchanges in human lymphocites by microsoma! activation of benzene retabolites. (Toxline Abstract). Mutat. Res. 119: $355-60$.

14. NIOSH. Criteria for a recommended standard... Occupational exposure to cresol. U.S. Departwerit of Health, Education, and Welfare, Public Health Service, Center for Disease Control.

15. Proctor, N.H. and J.P. Hughes. 1978. Chemical hazards of the workplace. J.B. Lippincott Company, PA.

16. Sax, N.I. 1975. Dangerous properties of industrial materials. Fourth Edition. Van Nostrand Reinhold Company, NY.

17. Schmidt, R. and H. Maibach. 1981. Immediate and delayed onset "skip area" dermatitis presumed secondary to topical phenol exposure. (Toxline Abstract). Contact Dermatitis 7: 199-202.

18. Sedov, A.V., N.A. Surovtsev, G.L. Mazneva, and O.N. Shevkun. 1980 . Hygienic standardization of phenol in a gaseous medium of insulating agents for Individual protection. (Toxline Abstract). Eig. Santt. 5: $81-2$. 


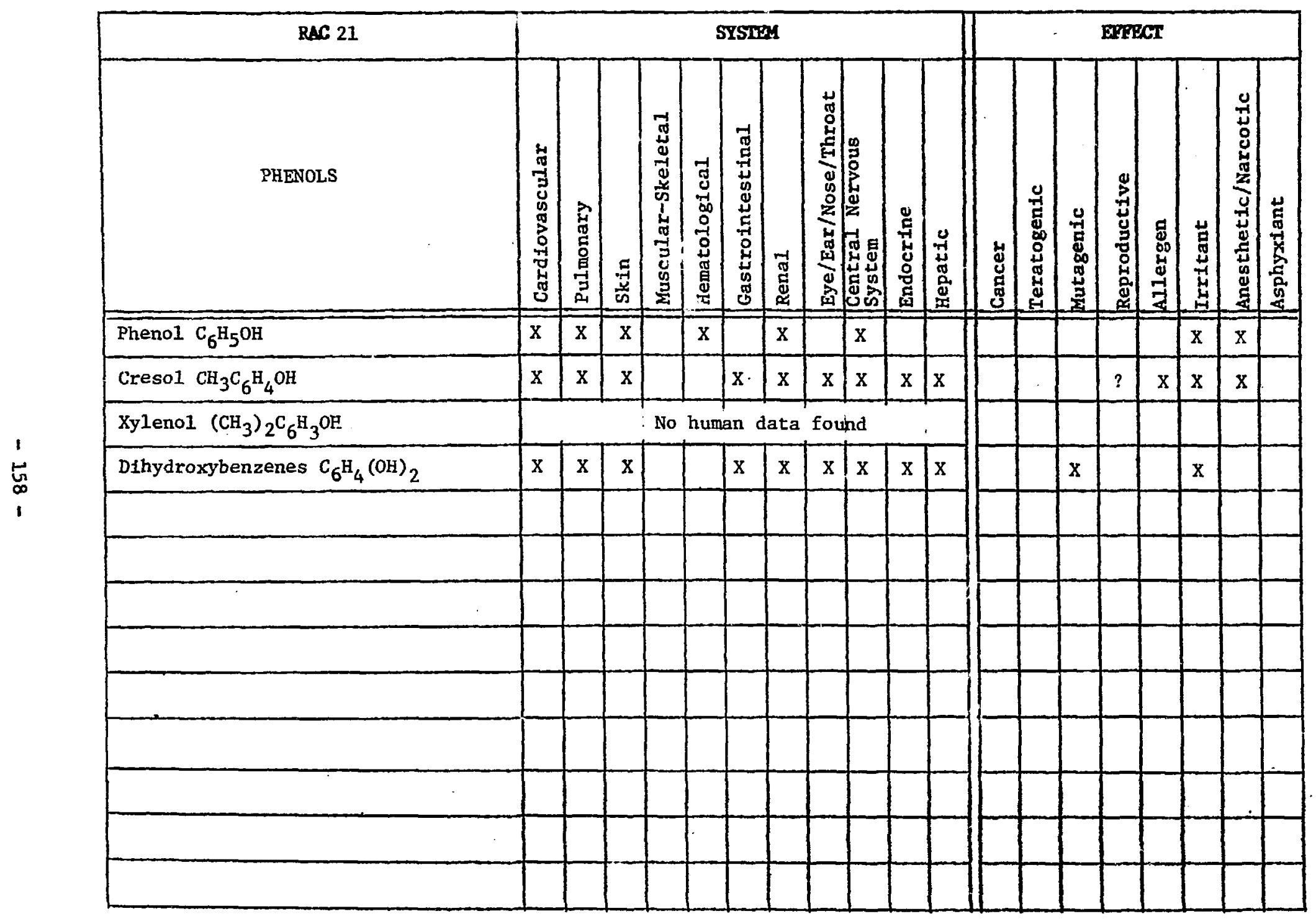

$X=$ known buman effect

? = based on andmal data, experfence with similar compounds, or Inconclusive human data 
RAC \#22 - ALDEHYDES AND KETONES ["CARBONYLS"] (EXClUDING FORMALDEHYDE)

Aldehydes and ketones are characterized by the presence of the carbonyl group $=C=0$. Because of the common carbonyl functional group, the properties of aldehydes and ketones are In many ways similar.

Aldehydes 1isted in RAC $\$ 22$ Include acetaldehyde, acrolein, nonanal, and benzaldehyde; ketones Include acetone and acetophenone.

\section{Aldehydes}

Acetaldehyde (Ethana1, Ethyl Aldehyde, Acet $1 \mathrm{c}$ Aldehyde) $\mathrm{CH}_{3} \mathrm{CHO}$<smiles>CC=O</smiles>

Acetaldehyde is a colorless liquid with a pungent fruity odor. It is used in the manufacture of acetic acid and its derivatives, and in other chemical compounds.

The primary effect of exposure to acetaldehyde in industry is irritation of the eyes and mucous membranes (irritation of the upper respiratory system). Changes in light and auditory sensitivity have also been observed (4).

Some worke:s reported eye irritation at $50 \mathrm{ppm}$ but acclimatation occurred later. Concentrations of $200 \mathrm{ppm}$ produce eye 1rritation and transient conjunctivitis in almost every exposed person (1).

In high concentrations, acetaldehyde produces narcotic effects. Bronchitis, albuminuria, fatty liver, and lung edema have been reported as high dose inhalation effects. Paralysis of respiratory muscle leading to death may also result from high dose inhalation $(1,3,4,9)$. Prolonged exposure causes a decrease of red and white blood cells. Prolonged contact with skin produces erythema, burns, and chronic dermatitis. Acetaldehyde Increased the frequency of sister chromatid exchange in cultured human lymphocytes (2) and significantly inhibited lymphocyte function (7). 
No health hazards of acetaldehyde have been found in industry when recommended standard precautions were followed (3).

\section{Acrolein (Propenal, Acrylaldehyde) $\mathrm{CH}_{2}=\mathrm{CHCHO}$}<smiles>C=CC=O</smiles>

Acrolein is a colorless or yellowish liquid with a disagreeable choking odor. It is used as an intermediate for the synthesis of glycerol, resins, pharmaceuticals, herbicides, and as a tear gas. Acrolein is also utilized Iil protecting liquid fuels against microorganisms.

Acrolein is highly irritating to the eyes, nose, and upper respiratory tract. High concentrations can cause pulmonary edema. Exposures of 1 ppm are immediately detectable, $5.5 \mathrm{ppm}$ produce intense irritation, and $10 \mathrm{ppm}$ and over can be lethal in a short time. Contact with liquid acrolein causes severe corneal injury and burns of the skin. Swallowing produces acute gastrointestinal distress, pulmonary congestion and edema (1, 3-7).

Nonanal (n-Nonaldehyde, Pelergonaldehyde) $\mathrm{C}_{9} \mathrm{H}_{18} \mathrm{O}$

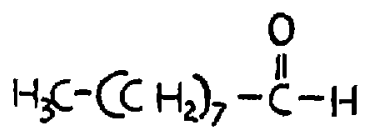

No human health data ware found.

Benzaldehyde (Benzencarbona1, Benzencarboxya1dehyde) $\mathrm{C}_{6} \mathrm{H}_{5} \mathrm{CHO}$<smiles>O=Cc1ccccc1</smiles>

Benzaldehyde is produced by oxidation of toluene as a co-product of benzolc actd. It is used in the food and pharmaceutical industry and in the manufacture of odorants and flavoring chemicals like cinnamaldehyde (3). 
Benzaldehyde is nontoxic but its vapors have a mild narcotic effect, causing depression of the central nervous system. High concentrations can cause convulsions. It can be also irritating to eyes, and skin contact can cause dermatitis $(4,9)$.

\section{Ketones}

\section{Acetone (2-Propane) $\mathrm{CH}_{3} \mathrm{COCH}_{3}$}<smiles>CC(C)=O</smiles>

Acetone is a colorless volatile flammable liquid with an aromatic odor. It is a widely used industrial solvent and chemical intermediate. It is found in paints, varnishes, lacquers, and is used as a solvent for cements in the leather and rubber industries.

Studies on exposures to low concentrations show controversial results. According to ACGIH (1), Nelson et al. reported slight irritation after 3 to 5 minutes' exposure at $300 \mathrm{ppm}$, whereas DiVincenzo found no effect after 2 to 4 hours' exposure at $500 \mathrm{ppm}$ except for an awareness of odor.

Inhalation of acetone at $500 \mathrm{ppm}$ causes eye, nose, and throat irritation. Higher concentrations (1000 ppm) cause dryness of the mouth and throat, dizziness, nausea, uncoordinated movements, loss of coordinated speech, drowsiness, and, in extreme cases, coma $(1,4,5)$.

Direct contact of acetone with skin may cause dermatitis. Acetone readily penetrates the skin, but it is rapidly excreted in urine and breath. Examination of workers engaged in the production of acetone, where concentrations were reported to be $700 \mathrm{ppm}$ for 3 hours/day for 7 to 15 years, demonstrated chronic inflammation of the respiratory tract, stomach, and duodenum, attacks of giddiness, and loss of strength. Kidney and liver damage were also observed $(1,4)$.

The recommended TLV is $750 \mathrm{ppm}$. Recommendations in other countries range from $83 \mathrm{ppm}$ [(Bulgaria, Hungary, Poland (1970)], to $1000 \mathrm{ppm}$ [(Finland and Germany (1976)]. 
Acetophenone (Acety1benzene, Methy1 Pheny1 Ketone, Hypnone) C8H80<smiles>CC(=O)c1ccccc1</smiles>

Acetophenone is a liquid made from benzene and acetylchloride. It forms laminal crystals at low temperatures. It is used in perfumes (orangeblossom-like odor) as a catalyst for polymerization of olefins, and in organic syntheses.

Acetophenone in high concentrations produces a narcotic effect. It can affect pulse rate and cause a slight but continuous decrease of hemoglobin. Contact with skin produces irritation. Acne-like skin lesions have been reported. Contact with eyes causes transient corneal infury $(4,8)$.

\section{References}

1. ACGIH. 1980. Documentation of the threshold limit values. Fourth Edition. American Conference of Governmental Industrial Hygienists Inc., $\mathrm{OH}$.

2. Jansson, T. 1982. The frequency of sister chromatid exchanges in human lymphocytes treated with ethanol and acetaldehyde. (Toxline Abstract). Hereditas (Lund, Swed.) 97: 301-3.

3. Kirk-0thmer. 1978. Encyclopedia of chemical technology, Volume 1. Third Edition. John Wiley \& Sons, NY.

4. National Library of Medicine. Toxicology Data Bank. (Computer search 1982).

5. NIOSH. 1978. Criteria for a recommended standard.... occupational exposure to ketones. U.S. Department of Health, Education, and Welfare, Public Health Service, Center for Disease Control.

6. Patty, F.A. 1982. Patty's industrial hyglene and toxlcology, Volumes $2 A, 2 B$, and $2 C$. Third Revised Edition. John Wiley \& Sons, NY.

7. Roselle, G.A. and C.L. Mendenha11. 1982. Alteration of In vitro human lymphocyte function by ethanol, acetaldehyde and acetate. (Toxline Abstract). J. Clin. Lab. Immunol. 9: 33-7.

8. Sax, N.I. 1975. Dangerous properties of Industrial mater1als. Fourth Edition. Van Nostrand Reinhold Company, NY.

9. The Merck Index. 1976. An encyclopedla of chemicals and drugs. Ninth edition. Merck \& Co., Inc., Rahway, NJ. 


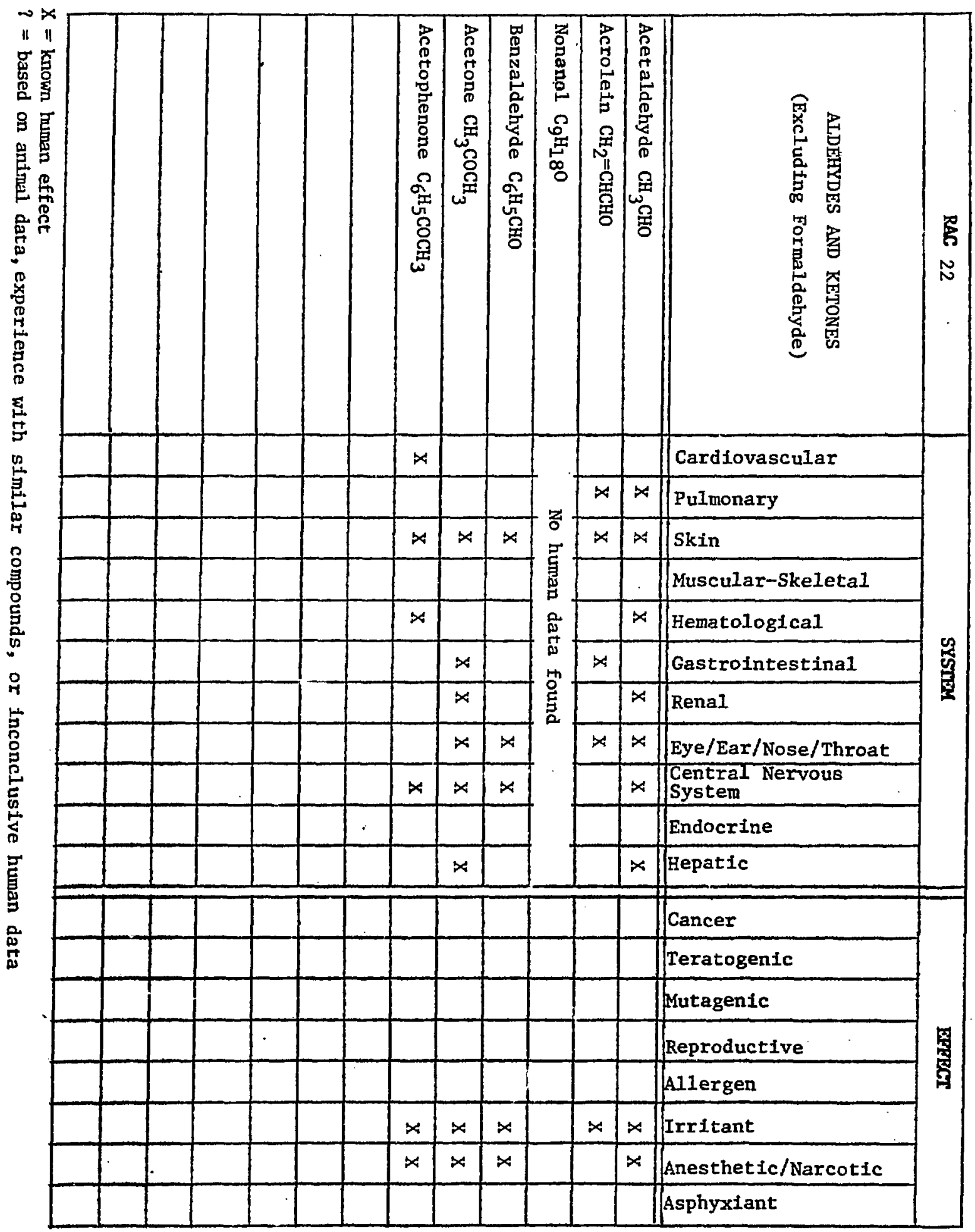


RAC $\$ 23$ - NONHETEROCYCLIC ORGANO SULFUR

Category \#23 includes: 1) thiols and 2) sulfides, disulfides and sulfateu.

Thiols

Formerly called mercaptans, thiols are formed from alcohols in which the oxygen in the hydroxyl (OH) group is replaced by sulfur (SH).

Methyl Mercaptan (Methanethiol, Thiomethyl Alcohol, Mercaptomethane, Methy1 Sulfhydrate) $\mathrm{CH}_{3} \mathrm{SH}$<smiles>CS</smiles>

Methyl mercaptan is a flammable, water soluble gas with a disagreeable odor. It is added to natural gas in order to give it odor. It is used in the synthesis of methionine, and as an intermediate in the production of pesticides, fungicides, jet fuel, and plastics. It is a by-product in the operations of paper and pulp mills.

Reported toxicity of methyl mercaptan is similar to that of hydrogen sulfide. It acts on the respiratory center, producing respiratory paralysis leading to death. Less acute concentrations cause pulmonary edema ( 1 ).

A worker handling tanks used for holding methyl mercaptan was hospitalized because of coma; acute hemolytic anemia and methemoglobulinemia developed (1).

Contact with liquid methyl mercapican is painful and irritating to eyes and skin. The exposure to vapors produces 10 ss of sense of sme11 and 10 ss of consciousness with temporary physlological tmpalrment.

Thiophenol (Phenyl Mercaptan, Mercaptobenzene, Benzenethiol) $C_{6} \mathrm{H}_{5} \mathrm{SH}$

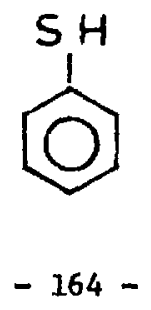


Thiophenol is a colorless liquid with a repulsive garlic-like odor. It is used as a chemical intermediate, solvent, and mosquito larvicide.

It is a definite skin irritant and should be considered moderately toxic. It can cause severe dermatitis, headaches, and dizziness ( 1 ). No human data on subchronic or chronic exposures were found.

Animal data Indicate effects of thlophenol on the central nervous system; some changes in kIdney, lung, and liver were also observed. It is lethal in higher doses.

Sulfides, Disulfides, and Sulfates

Carbonyl Sulfide (Carbon Oxysulfide) $\cos$

$$
O=C=S
$$

Carbonyl sulfide is listed as an irritant by Sax. When heated to decomposition, it may liberate hydrogen sulfide fumes. In high concentrations, it may act as a narcotic.

Diethyl Sulfide $(2,2-T h i o d i e t h a n o l$, Thiodiethylene Glycol $)\left(\mathrm{C}_{2} \mathrm{H}_{5}\right)_{2} \mathrm{~S}$

$$
\mathrm{CH}_{3}-\mathrm{CH}_{2}-\mathrm{S}-\mathrm{CH}_{2}-\mathrm{CH}_{3}
$$

No data available.

Carbon Disulfide (Carbon Bisulfide) $\mathrm{CS}_{2}$

$$
S=C \approx S
$$


Carbon disulfide is a clear, colorless, or faintly yellow liquid. Technical grade $\mathrm{CS}_{2}$ has a strong odor of the hydrogen sulfide with which it is contaminated.

Carbon disulfide is used in the manufacture of viscose rayon, carbon tetrachloride, cellophane films; in rubber and polymer industries; in the preparation of a variety of sulfur compounds; and as a solvent.

Carbon disulfide vapor is absorbed largely through the lung, and toxic quantities can also be absorbed through the skin. The toric effects are mostly on the nervous system. Single exposures may cause narcosis. Intoxication of workers exposed to carbon disulfide produces psychological and behavioral symptoms. Symptoms start with headache, fatigue, Insomnia, rapid changes of mood, and some psychomotor and intellectual impairments. The symptoms can progress to severe emotional and mental disorders and to Parkinson's-1ike syndromes $(1,2,4,12,13,19,22,25,26,31-33,36,42-44)$. Chronic peripheral neuropathy has been reported in workers with previous exposure to $\mathrm{CS}_{2}$, thus Indicating that carbon disulfide can cause permanent axomal neuropathy (8).

Ocular changes (blind spot enlargement, contraction of jeripheral field, corneal anesthesia, impairment of optic nerves, retincpathy) have also been reported $(9,17,28,32,34,39,42)$. Ophthalmoscopic tests indicate microaneurysm, the incidence of which being proportional to the duration and intensity of exposure to carbon disulfide (38).

Exposure to carbon disulfide can accelerate coronary heart disease, hypertension, and atherosclerosis $(3,27,32,37,40)$. Epidemiologic studies of viscose rayon workers indicate a 2.5- to 5-fold increase in risk of death from coronary heart disease as compared with the risk to unexposed workers $(2,11,32,41)$.

However, the tests for total cholesterol, high-density 1ipoprotein cholesterol, triglycerides, blood pressure, and 2 coronary heart disease risk indices of 70 male viscose rayon workers exposed to $\mathrm{Cs}_{2}$ at $35 \mathrm{mg} / \mathrm{m}^{3} \mathrm{did}$ not differ from 70 individually matched controls (10). The authors conclude that apart from a possible toxic effect directly infuced by $\mathrm{CS}_{2}$ on the myocardium, $\mathrm{CS}_{2}$ exposure up to $30 \mathrm{mg} / \mathrm{m}^{3} \mathrm{did}$ not promote atherosclerosis nor increase the risk of coronary heart disease. Metabolic ultrastructural changes have been reported in the myocardium after prolonged exposure to low concentrations of carbon disulfide (17). 
Other reported effects of exposure to carbon disulfide include menstrual disturbances and secretion of carbon disulfide in the mother's milk (5), and a decrease in nonspecific humoral resistance to infectious diseases (18), A community study reported an increased rate of spontaneous abortions in women employed in rayon text 1 le jobs and paper product jobs, as well as in wives of men employed in transport and communication, in rayon textile jobs, and in chemical process jobs (15). Increased adhesiveness of blood platelets reported in workers with mild exposure to carbon alsulfide was reported (39A). The platelet adhesiveness can be reduced by the prophylactic treatment of workers with Cynarex (45).

Carbon disulfide alters the metabolism of lipids $(13,20,31 \mathrm{~A})$ and of carbohydrates resulting in the decrease in glucose tolerance in diabetics $(3,6,10,14,16)$.

The chronic and acute effects of carbon disulfide are ascribed to its high reactivity with nucleophilic cellular components such as amino acids, catecholamines, and steroids. It affects human metabolism by chelate formation with essential metals in enzymic system, and inhibition of vitamin $B_{6}$ activity and catecholamine metabolism $(3 \mathrm{~A}, 7,12)$. Long-term studies on catecholamine metabolism in viscose spinners exposed to carbon disulfide show. that inhelation over $80 \%$ of the work time results in increasing excessive excretion of adrenaline, noradrenaline, dopamine, and dopa. The excretion of noradrenaline reached a plateau within 6 to 10 years, and that of remaining catecholamines within 5 years (21). Studies on serum metals show a decrease in the level of $\mathrm{Zn}$ associated with an increase in urinary $\mathrm{Zn}$ (24) and a decrease in $\mathrm{Ca}$ and $\mathrm{Mg}$ levels in the blood of exposed workers $(29,30)$.

The levels of blood serotonin and of 5-hydroxyindoloacetic acid in the urine of persons exposed occupationally to $\mathrm{CS}_{2}$ varied with 1 ts concentration and the exposure length. The respective blood and urinary tests were suggested as indicators of $\mathrm{CS}_{2}$ poisoning (23). Urinary levels of 2-thio-thiazolidine-4-carboxylic acid (TTCA) in workers exposed to the carbon disulfide in a Belgian viscose plant varied among different individuals doing the same jobs and for the same individuals in the course of the working period, with a marked increase during the exposure. The correlation between individual personal monitoring results and the increase in TTCA levels was found to be statistically significant (35). 
Dimethy1 Sulfate $\left(\mathrm{CH}_{3}\right)_{2} \mathrm{SO}_{4}$

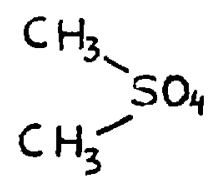

Dimethyl sulfate is a colorless liquid with a faint onion odor. The vapor has no odor and thus has no warning properties. It is used as a methylating agent in the manufacture of many organic chemicals.

Animal studies suggest carcinogenic properties of dimethyl sulfate. clinical and $x$-ray evidence suggest possibilities of an excess of lung cancer among workers exposed to dimethyl sulfate, but epidemiologic data are insufficient (1).

Early (before 1962) cases of dimethyl sulfate polsoning In industrial workers reported in Europe describe headache and giddiness with burning of the eyes as primary symptoms reaching a maximum in 2 to 10 hours. The condition becomes progressively worse with painful photophobla, irritation of the respiratory tract, cough, difficulty in breathing and swallowing, vomiting, diarrhea, and burning micturition. Dysurla persists for 3 to 4 days, and congestion of mucous membranes and laryngeal edema may persist for two weeks. Some impalrment of liver function and reduction in the visual flelds were observed six years later.

Burns of the skin and eyes as the primary acute effects from overexposure to dimethyl sulfate were reported in plants where leakage sites showed close to $0.2 \mathrm{ppm}$. There was, however, no evidence of excess cancer death (1).

\section{References}

1. ACGIH. 1980. Documentation of the threshold limit values. Fourth Edition. American Conference of Governmental Industrial Hygienists Inc., $\mathrm{OH}$.

2. Afendikova, A.P. 1982. Nature of body disturbances in carbon disulfide exposure. (Toxline Abstract). Vrach Delo 2: 111-3. 
3. Balcarova, 0., A. David, J. Valnickova, I. Stepanova, E. Svandova, M. Hromadka, and V. Lambl. 1980. Epidemtological study of ischemic heart disease in workers exposed to carbon disulfide. (Toxline Abstract). Prac. Lek. 32: 338-44.

3A. Bittersoh1, G. 1979. Significance of disciplinary and interdisciplinary cooperation in the evaluation and reduction of chemotoxic risks as an example of cellulose-synthetic fiber industry. (Toxline Abstract). W1ss. Z. - Martin-Luther-Univ. Halle-Wittenberg, Math.Naturwis8. Reihe 28: 38-52.

4. BokIna, A.I., R.V. Merkur'yeva, N.D. Eksler, A.A. Olelnik, and I.I. Pinigina. 1979. Experimental study of the mechanism and indices of harmful effects of certain chemical substances on the central nervous system. (Toxline Abstract). Environ. Health Perspect. 30: 31-8.

5. CaI, S.X. and Y.S. Bao. 1981. Placental transfer and secretion Into mother's milk of carbon disulfide and the effects on maternal function of female viscose rayon workers. (Toxline Abstract). Ind. Health 19: 15-29.

6. Candura, F., G. Franco, T. Malaman1, and A. Plazza. 1979. Altered glucose tolerance in carbon disulfide exposed workers. (Toxline Abstract). Acta Diabetol. Lat. 16: 259-64.

7. Coppock, R.W., W.B. Buck, and R.L. Mabee. 1981. Toxicology of carbon disulfide: A revier. (Toxline Abstract). Vet. Hum. Toxicol. 23: $331-6$.

8. Corsi, G., P. Maestrel11, G. Picott1, S. Manzoni, and P. Negrin. 1983. Chronic peripheral neuropathy in workers with previous expusure to carbon disulphide. (Toxline Abstract). Br. J. Ind. Med. 40: 209-11.

9. Dombakyan, K. 1979. Effect of carbon disulfide on the eye - changes in the action potential of the retina studied by dynamic electroretinography. (Toxline Abstract). Oftgimelogiya (Sofia) 27: 71-4.

10. Franco, G., T. Malamani, A. Plazza, and F. Candura, 1979. Subclinical defect of carbohydrate metabolism in viscose rayon workers exposed to carbon disulfide. (Toxline Abstract). G. Ital. Med. Lav. 1: 75-8.

11. Eranco, G., T. Malamani, L. Germani, and F. Jandura. 1982. Assessment of coronary heart disease risk among viscose rayon workers exposed to carbon disulfide at concentrations of about 30 milligrams per cubic millimeter. (Toxline Abstract). Scand. J. Work Environ. Health 8: 113-20.

12. Gosselin, R.E., H.C. Hodge, R.P. Sutth, and Y.N. Gleason. 1979. Clinical toxicology of commercial products. The Williams \& Wilkins Co., MD, Pp. 86-92. 
13. Graovac-ieposavic, L., R. Banicevic, S. Ozelajlija, V. Delic, and V. Dordevic. 1980. Study on motor nerve conduction velocity, peripheral circulation and lifid metabolism in workers exposed to carbon disulfide. (Toxline Abstract). Proc. Int. Congr. Occup. Health, 19th 1: $521-7$.

14. Harris, M. 1979. Classification and diagnosis of diabetes mellitus and other categories of glucose intolerance. (Toxline Abstract). Diabetes 28: 1039-57.

15. Hemmink1, K. and M.I. Niemi. 1982. Community study of spontaneous abortions: Relation to occupation and air pollution by sulfur dioxide, hydrogen sulfide, and carbon disulfide. (Toxline Abstract). Int. Arch. Occup. Environ. Health 51: 55-63.

16. Karakasevic, B., V. Delic, A. Grujin, I. Graovac-Leposavic, and A. Vidakovic. 1980. Influence of carbon disulfide on enzymes regulating carbohydrate metabolism. (Toxline Abstract). Proc. Int. Congr. occup. Health, 19th 1: 511-4.

17. Kazakova, B., G. Antov, M. Stefanova, and S. Pavlova. 1982. Metabolic and ultrastructural changes in the myocardium after prolonged exposure to low concentrations of carbon disulfide. (Toxline Abstract). Probl. Khig. 7: 81-7.

18. Kiere's, H., B. Kra jewska, and J. Hanke. 1981. Iron metabolism and serum lysozyme as exponents of nonspecific resistance of workers exposed to $\mathrm{CS}_{2}$. (Toxline Abstract). Med. Pr. 32: 337-41.

19. Kirk-0thmer. 1978. Encyclopedia of chemical technology. Third Edition. John Wiley \& Sons, NY.

20. Klein, G., B. Gromadies, A. Buerger, E. Scheunert, and G. Rittner. 1981. Long-term effects of carbon disulfide and halocarbons in general and of perchloroethylene in particular on lipid metabolism. (Toxline Abstract). Z. Gesamte Hyg. Grenzgeb 27: 48-51.

21. Lukhta1, V.A. 1981. State of catecholamine metabolisin at early stages of development of chronic carbon disulfide poisoning. Literature review. (Toxline Abstract). Vrach. Delo. 5: 110-14.

22. Mokri, B., A. Ohnishi, and P.J. Dyck. 1981. Disulfiram neuropathy. (Toxline Abstract). Neurology 31: 730-5.

23. Nedelcheva, K., S. Pavlova, and V. Todorov, 1982. Effect of carbon disulfide exposure on blood serotonin level and excretion of 5-hydroxyindoleacetic acid in the urine. (Toxline Abstract). Suvrem. Med. 33: 9-14. 
24. Niculescu, T., R. Dumftru, and R. Alexandrescu. 1980. Variations in the concentrations of serum zinc and its values in the course of chronic occupational intoxication with carbon disulfide: A preliminary study. (Toxline Abstract). Rev. Ig. Bacteriol. Virusol Parazitol Epidenio1. Pneumoftiziol. Ser. Ig. 29: 209-12.

25. Nikiforova, N.A., V.N. Dumkin, and T.M. Nablev. 1980. Dynamics of the bioelectrical activity of muscles under chronic exposure to carbon disulfide. (Toxline Abstract). Gig. Tr. Prof. Zabol. 9: 17-19.

26. SIOSH Technical Information. 1976. Behavioral and Neurological Effects of Carbon Disulfide. U.S. Department of Health, Education, and Welfare.

27. Nurminen, M., P. Mutanen, M. Tolonen, and S. Hernberg. 1982. Quantitated effects of carbon disulfide exposure, elevated blood pressure and aging on coronary morrality. (Toxline Abstract). Am. J. Epidemiol. 115: 107-18.

28. Palacz, 0. K. Szymanska, and D. Czepita. 1980. Electroretinographic stifies in subjects with chronic exposure to carbon disulfide. I. Evaluation of the state of the visual system considering electroretinographic studies in relation to the duration of exposure to carbon disulfide. (Toxline Abstract). Klin. Oczna 50: 65-7.

29. Pavlova, S. 1980. Calcium, phosphorus, copper, creatinine and ceruloplasmin content in the blood of workers in contact with carbon disulfide. 1980. (Toxline Abstract). Probl. Khig 5: 116-23.

30. Pavlova, S., D. Charukchiev, R. Stefanova, and S. Krusteva. 1980. Some metabolic processes in workers in synthetic fiber production. (Toxline Abstiact). Suvrem. Med. 31: 586-90.

31. Peters, H.A., R.L. Levine, C.G. Matthews, S.L. Sauter, and J.H. Rankin. 1982. Carbon disulfide-induced neuropsychiatric changes in grain storage workers. (Toxl ne Abstract). Am. J. Ind. Med. 3: 373-91.

31A. PImentel, L.C. and A.L. Rossi. 1981. Determination of the serum 11pid profile in workers occupationally exposed to carbon disulfide. (Toxline Abstract). Rev. Farm. Bioquim. Univ. Sao Paulo 17: 152-62.

32. Proctor, N.H. and J.P. Hughes. 1978. Chemical hazards of the workplace. J.B. Lipplncott Company, PA.

33. Rafaila, E. and A. Georgescu. 1980. Evolutive aspects of the chronic occupational intoxication with carbon disulfide. (Toxline Abstract). Rev. Ig. Bacteriol. Virusol Parazitol. Epidemiol. Pneumoftizlol. Ser. Ig. 29: 23-6. 
34. Raitta, C., H. Telr, M. Tolonen, M. Nur: Malstron. 1981. Impafred color discrixi . among viscose rayon workers exposed to carbon disulfide. (To: ... ingtract). J. Occup. Med. 23: 189-92.

35. Rosier, J., M. Vanhoorne, R. Grosjean, E. Van de Walle, G. Billemont, and C. Van Peteghem. 1982. Preliminary evaluation of urinary 2-thio-thiazolidine-4-carboxylic-acid (TTCA) levels as a test for exposure to carbon disulfide. (Toxline Abstract). Int. Arch. Occup. Environ. Health 51: 159-67.

36. Ryzhtova, M.N. and V.N. Kumkin. 1980. Cilnical characteristics of sequelae of chronic occupational neurointoxications. (Toxline Abstract). Gig. Tr. Prof. Zabol. 9: 5-8.

37. Sakura1, H. 1982. A morbidity study of viscose rayon workers exposed to carbon disulfide. (Toxline Abstract). Br. J. Ind. Med.; 39 (1) 39-44.

38. Savi'c, S. 1982. Ophthalmological and angiographic findings in workers exposed to carbon disulfide (author's transl.). (Toxline Abstract). Klin. Monatsb1. Augenhe11kd. 180: 90-1.

39. Sugimoto, K. and S. Goto. 1980. Retinopathy in chronic carbon disulfide exposure. (Toxline Abstract). Neurotoxic. Visual Syst., (Rochester Int. Conf. Environ. Toxic.) 11: 55-71.

39A. Taccola, A., P.L. Cipoll1, M.C. Bossi, F.M. Gobba, and D. Grampella. 1980. Platelet alteration and carbon disulfide poisoning: Adhesiveness. (Toxline Abstract). Boll. Soc. Ital. B1ol. Sper. 56: 409-15.

40. Tereshchenko, Y.A. 1979. Metabolism of tryptamine and serotonin in chronic carbon disulfide poisoning. (Toxline Abstract). Gig. Tr. Prof. Zabol. 11: 39-42.

41. Tolonen, M., M. Nurminen, and S. Hernberg. 1979. 10-Year coronary mortality of workers exposed to carbon disulfide. Scand. J. Hork Environ. Health 5: 109-14.

42. Vanhoorne, M. 1981. Preliminary study of toxicity of carbon dizulfide and hydrogen disulfide in the Belgian viscose industry. (Toxline Abstract). G. Ital. Med. Lav. 3: 57-68.

‘3. Villa, A., M. Tomasini, G.C. Andreini, and L. Quaćrell1. 1981. Effects of prolonged exposure to carbon disulfide on myocardial contractile efficiency. (Toxline Abstract). Med. Lav. 72: 52-60.

44. Wood, R.W. 1981. Neurobehavioral toxicity of carbon disulfide. Neurobehav. Toxicol. Teratol. 3: 397-405.

45. Woyke, M., H. Cwajda, J. W'ojcicki, and K. Ko'smider. 1981. Platelet aggregation in workers chronically exposed to carbon disulfide and subjected to prophylactic treatment with Cynarex. (Toxline Abstract). Med. Pr. 32: 261-4. 


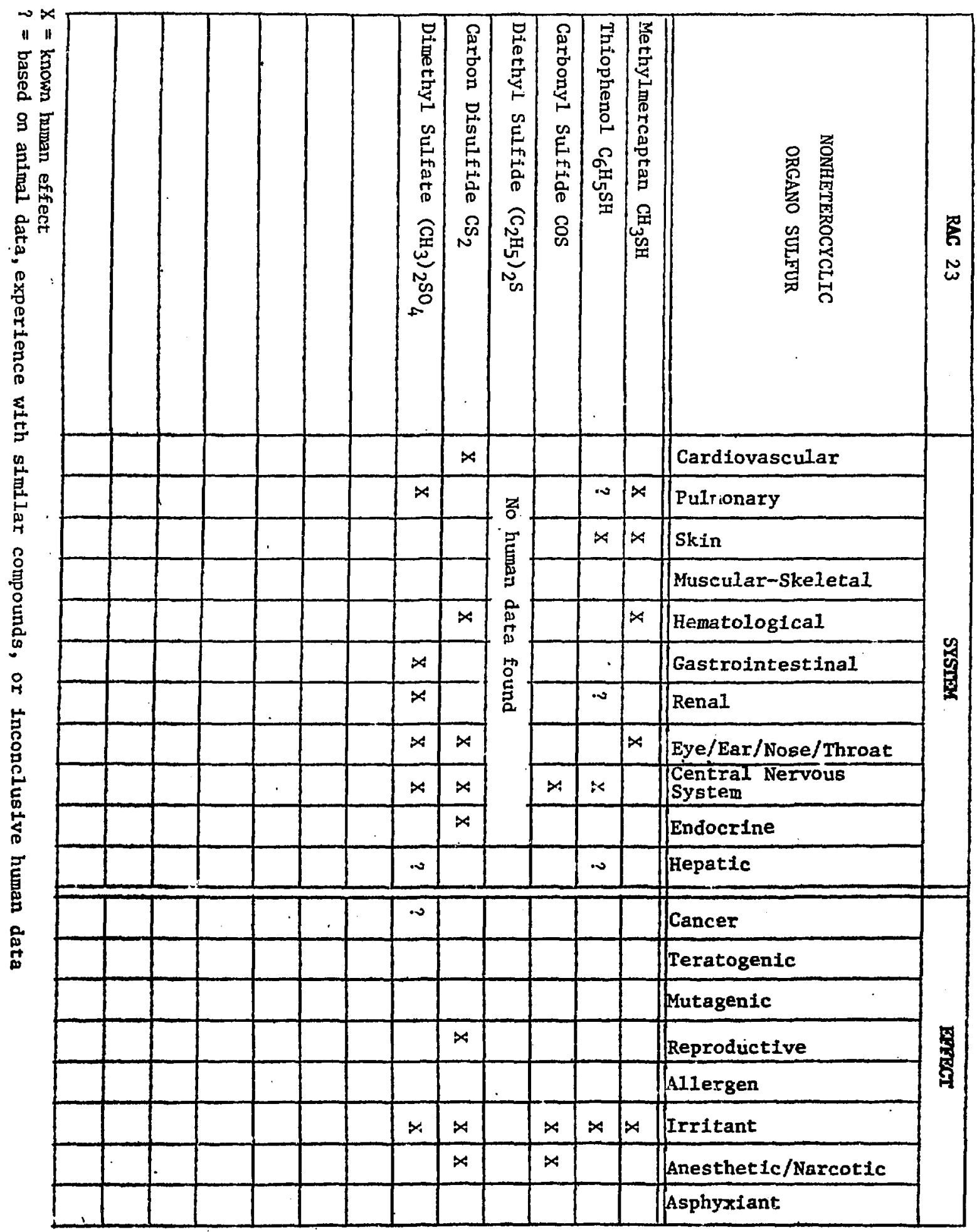


The two compounds covered in this category are methanol and ethanol.

Methano1 $\left(\mathrm{CH}_{3} \mathrm{OH}\right)$

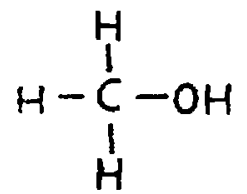

Methanol is a mobile, highly polar liquid. It is miscible with water, ethyl alcohol, ether, and many other organlc solvents (1). Methanol 1s used as a solvent for nitrocellulose, ethyl cellulose, various natural synthetic resins, and in paint removers. It is also used as a denaturant for ethyl alcohol, as an antifreeze, and in the manufacture of formaldehyde and other chemicals (notably methyl derivatives) (1). Methanol is also found in the exhaust of cars equipped with catalytic converters and in cigarette smoke.

Acute Effects. Exposure to vapor levels of 200 to $500 \mathrm{ppm}$ in a confined space may cause headaches and eye irritation. Exposures of 800 to $1200 \mathrm{ppm}$ and above have caused permanent dimlnution of vision. The extent of the visual damage depends on the length and amount of exposure. Very high concentrations, especially in a confined space, will cause the same symptomatology as ingestion of methanol.

Ingested, methanol is highly toxic. As little as 2 tsp. can cause symptoms. The fatal dose in mar ranges between 2 and 8 ounces (9). The immediate symptom of methanol ingestion is inebriation, Indistinguishable from that of ethanol ingestion. Th1s may be followed by an entirely asymptomatic interval. After a latency perlod of 6 to 30 hours (usually 12 to 18 hours), the characteristic symptoms of methanol toxicity appear. These include: headache; weakness; leg cramps; vert1go; nausea and vomiting sometimes with violent abdominal pain; back and leg pain; vision defects; rapld shallow breathing from metabolic acidosis; and weak rapld pulse with hypotension progressing to apathy and coma, or to excitement, mania, and convulsions. If death occurs, it is usually from respiratory fallure. In nonfatal cases, convalescence is often protracter and can be complicated by debilit", permanent eye damage (with possible blindness), kidney damage, and motor dysfunctions $(7,9)$. Since ethyl alcohol inhibits the metabolic 
oxidation of methanol, methanol polsoning is treated by adininistering ethanol in small quantities every 3 to 4 hours, along with bicarbonate to combat acidosis.

Wethanol is readily absorbed through the skin. There have been reports of death, blindness, and other injuries from methanol spilled on clothing or applied to large areas of the skin. Immersing a whole hand in methanol for two minutes results in the absorption of $170 \mathrm{mg}(0.2 \mathrm{ml})(7)$. Gimenez et al. (8), reported cases of 21 children with soaked methanol clothing applied to their bodies as treatment for "collcky abdominal pain" and other "unspecifled symptoms." Early toxic symptoms exhibited by these children were central nervous system depression of variable degrees with alternate perlods of excitation. Eleven of these children developed tonic-clonic convulstons, 8 developed anurla or severe uligurla, and 12 children died from cardlac and/or respiratory arrest despite aggressive treatment. Post mortem of one case revealed marked edema and softening of the brein (8).

Direct contact with the skin can cause erythema, dermatitis, and scaling (16).

Chronic Effects. Since methanol is slowly eliminated from the body, repeated exposures can result in increasing methanol blood concentrations. Chronfc effects from repeated exposures to high levels of methanol vapor Include conjunctivitis, diminished vision, giddiness, headaches, Insomnia, gastric disturbances, and metabolic acidosis (1).

A TLV of $200 \mathrm{ppm}$ and an STEL of $250 \mathrm{ppm}$ have been set for methanol.

Ethanol $\left(\mathrm{C}_{2} \mathrm{H}_{5} \mathrm{OH}\right)$

$$
\mathrm{CH}_{3}-\mathrm{CH}_{2}-\mathrm{OH}
$$

Ethanol is a colorless flamable volatile liquid. It is comonly used as a solvent and in the manufacture of denatured alcohol, and as a raw materlal in plastics, lacquers, polishes, plasticizers, perfumes, and cosmetics. In diluted form it is used in alcoholic beverages and in medications. 
Acute Effeits. Inhalation of $1000 \mathrm{ppm}$ causes slight mucous membrane Irritation and 11ghtheadedness. Exposures of 5,000 to 10,000 ppm cause stupor, sleepiness, headache, irritation of the eyes and mucous membrane of the upper respiratory tract, and a sensation of warmth $(1,13)$. Intoxication from Inhalacion of ethanol vapors is possible, but rare.

Ingested, ethanol is a central nervous system depressant causing varlous states of inebriation, and possibly coma and death, depending upon amounts ingested. A blood concentration of 0.3 to $0.4 \%$ is associated with stupor or coma and $0.5 \%$ blood concentration can be fatal (9). Severe hypoglycemia often follows a bout of heavy drinking (13).

Splash contact with the eye causes immediate stinging and burning with reflex closure of the lids and tearing, transitory injury of the corneal epithelium, and hyperemia of the conjunctiva. A foreign-body-type discomfort may be felt for one or two days, but healing is usually rapid and complete.

Ethanol can be absorbed through the skin. A case of ethanol intoxication was reported in a 15-day-old iufant treated with dressings contalning alcohol (5). No cases of adult intoxication via percutaneous absorption were found.

Ethanol ingestion has been clearly implicated as a major factor in the induction of trauma.

Chronic Effects. Since ethanol is metabolized by the liver, chronic exposure to ethanol causes Ilver impairment. Cirrhosis of the liver is a common finding among persons with a history of chronic alcoholism. Persons exposed to ethanol (via Ingestion or possibly via inhalation) are also more susceptible to the toxic effects of other compounds which are hepatocoxic, such as volatile organochlorines.

Hypertension is a clinical feature often found in heavy alcohol drinkers $(4,17)$. A higher-than-normal incidence of cerebral blood vessel spasms, cardiac depression, arrhythmias, cardiomyopathy, and sudden death 
has been observed in persons who are "binge drinkers" $(2,3)$. Alcoholic consumption will also decrease cerebral blood flow and increase susceptibility to cerebral thrombosis (15A).

Hillbom et al. (11), found decreased fibrinolytic activity, increased factor VIII complex, and shortened bleeding time in a group of healthy volunteers who were given ETOH. The highest levels of these factors were detected 16 hours after ingestion.

On the basis of animal experimentation, Kaufman et al. ( $\vec{i})$, have suggested that ethanol consumption at the time of conception may be the cause of certain types of chromosomal defects commonly observed in human spontaneous abortions. Alcohol consumption by women during pregnancy has beet r ported to cause an increased incidence of first and second trimester abortions, an increased risk of placenta abruptio $(1,14)$, an increased incidence of low birth weights and stillbirths, and an increased risk of birth and developmental defects (10). In addition, offspring of pregnant women who drink during pregnancy (averages of 1 to 2 ounces daily) have a higher incidence of clinical features of abnormal growth (7). Ouellette et: a1. report a $32 \%$ incidence of congenital abnormalities in offspring of women who are heavy drinkers (average of $174 \mathrm{ml}$ absolute alcohol/day), and a 14\% incidence of abnormalities in offspring of women who are moderate drinkers (6). Fetal alcohol syndrome is an entity commonly seen in infants born to alcoholic mothers. These infants experience alcohol withdrawal symptoms and often suffer permanent brain damage.

Chronic drinking in men has been associated with testicular atrophy, azoospermia, and testicular pathology ( 7 ).

Degenerative changes have been found in myelinated and unmyelinated fibers in alcoholics (15A).

A TLV of 1,000 ppm has been set for ethyl alcohol.

\section{References}

1. ACGIH. 1980. Documentation of the Threshold L1mit Values, 4th ed., 1980 (ISBN 0-036712-31-7). American Conference of Governmental Industrial Hygienists, Cincinnat $1, \mathrm{OH}$. 
2. Altura, B.M., B.T. Altura, and A. Carella. 1983. Ethanol produces coronary vasospasm: Evidence for a direct action of ethanol of vascular muscle. (Toxline Absiract). Br. J. Pharmacol. 78: 260-2.

3. Altura, B.M., B.T. Altura, and A. Gebrewold. 1983. Alcohol-1nduced spasms of cerebral blood vessels: Relation to cerebrovascular accidents and sudden death. (Toxline Abstract). Science 220: 331-3.

4. Arkwright, P.D., L.J. Bellin, I. Rouse, B.K. Armstrong, anả R. Vandongen. 1982. Effects of alcohol use and other aspects of lifestyle on blood pressure levels and prevalence of hypertension in a work place. (Toxline Abstract). Circulation 66: 60-6.

5. Autret, E., P. Sanyas, A. Chanteple, F. Gold, and J. Laugier. 1982. [Poisoning by externally-administered ethanol in an infant]. (Toxline Abstract). Arch. Fr. Pediatr. 39: 823-4.

6. CEQ. 1981. Chemical hazards to human reproduction. Prepared by Clement Assoclates, Inc. for the Council on Environmental Quality, Washington, DC.

7. EPA. 1981. Methanol Health Esfects, 1981 (PB82-160797). U.S. Environmental Protection Agency, Washington, DC.

8. Gimenez, E.R., N.E. Vallejo, E. Roy, M. LIs, E.M. Izurleta, S. Rossi, and M. Capuccio. 1968. Percutaneous alcohol intoxication. Clin. Toxicol. 1: $39-48$.

9. Gosselin, R.E., H.C. Hodge, R.P. Sulth, and M.N. Gleason. 1979. Clincial toxicology of commercial products. The Williams \& Wilkins Co., MD.

10. Guay, D.R.P. 1982. Sedative--hypnotics and teratogenesis. (Toxline Abstract). Can. J. Hosp. Pharm. 35: 42-5.

11. Hillbom, M., M. Kaste, and V. Rasi. 1983. Can ethanol intoxication affect hemocoagulation to increase the risk of brain infarction in young adults? (Toxline Abstract). Neurology 33: 381-4.

12. Kaufman, M.H. 1983. Ethanol-Induced chromosomal abnormalities at conception. (Toxline Abstract). Nature (London) 302: 258-60.

13. Kirk-0thmer. 1978. Encyclopedia of chemical technology, Volume 9. Third Edition. John Wiley \& Sons, NY.

14. viarbury, M.C., S. Linn, R. Monson, S. Schoenbaum, P.G. Stubblefield, and K.J. Ryan. 1983. The assoclation of alcohol consumption with outcome of pregnancy. Am. J. Pub. Hlth. 73: 1,165-68. 
15. McLean, D.R., H. Jacobs, and B.W. Melke. 1980. Methanol poisoning: A clinical and pathological study. (Toxline Abstract). Ann. Neurol. 8: $161-7$.

15A. National Library of Medicine. Toxicology Data Bank. (Computer search 198?).

16. NIOSH/OSHA: Occupatonal Health Guidelines for Chemical Hazards, DHHS (NIOSH), Pub. No. 81-123 (1981).

17. Ramsay, L.D. 1982. Clinical features of hypertension in frequent and heavy alcohol drinkers. (Toxline Abstract). Scott. Med. J. 27: 207-11. 


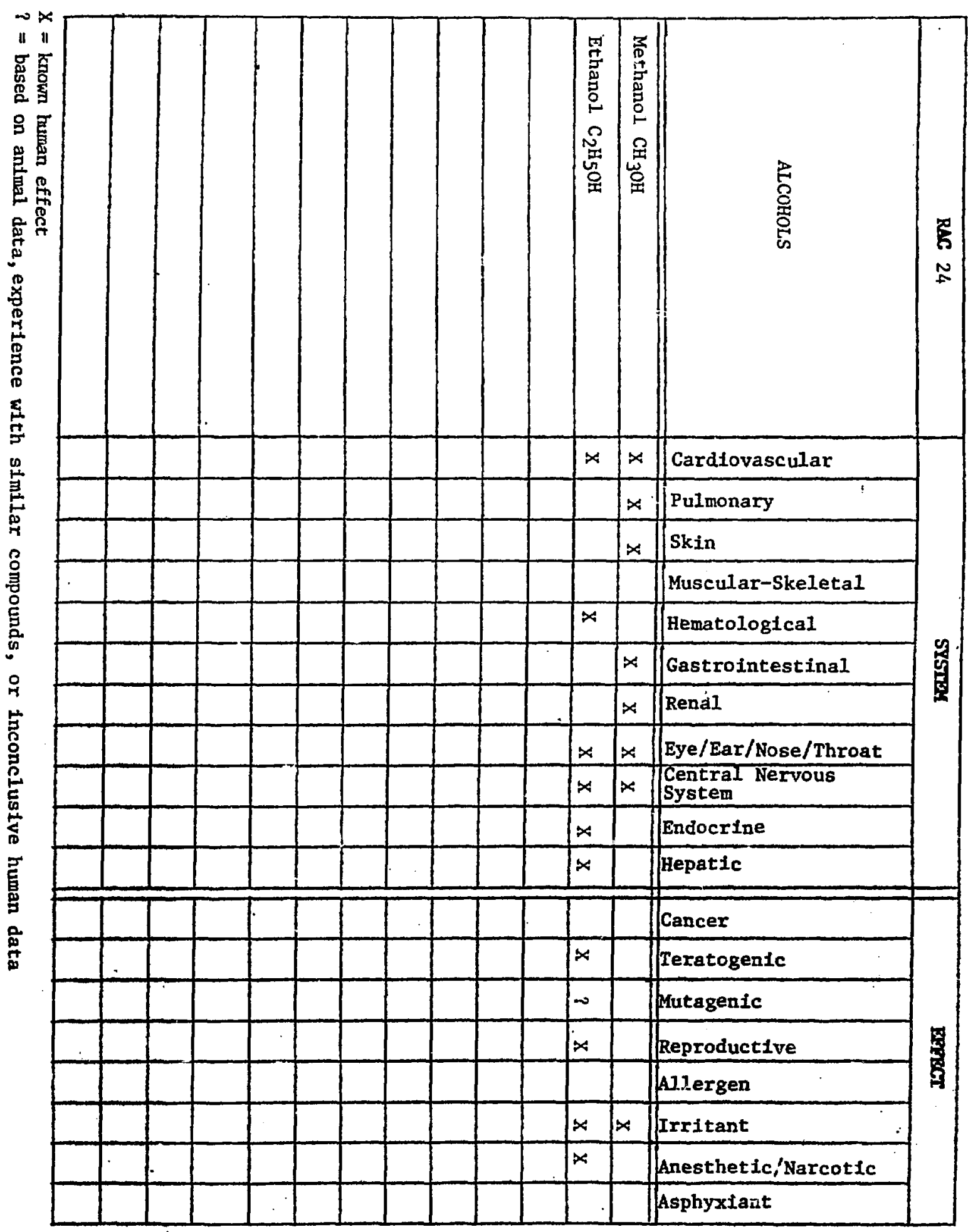


RAC \#25 - NITROAROMATICS

Aromatic nitro compounds contain a nitro $\left(-\mathrm{NO}_{2}\right)$ substituent on the ring.

Monocyclic Nitroaromatics

Nitrobenzene $\mathrm{C}_{6} \mathrm{H}_{5} \mathrm{NO}_{2}$<smiles>O=[N+]([O-])c1ccccc1</smiles>

Nitrobenzene is a colorless-to-pale-yellow olly liquid, with an odor resembling bitter almonds. It is used in the manufacture of aniline and benzidine, in soaps, shoe and metal polishes, and as a solvent.

Nitrobenzene is a highly toxic substance readily absorbed by contact with the skin and by inhalation. Workers exposed for 8 hours to 1 ppm nitrobenzene in the air would absorb $25 \mathrm{mg}$ of nitrobenzene of which, one third would be by skin absorption. The primary effect of nitrobenzene toxicity is the conversion of hemoglobin to methemoglobin, and the appearance of cyanosis when the methemoglobin level reaches $15 \%$. Nitrobenzene affects the central nervous system and produces fatigue, headache, vertigo, vomiting, general weakness, and, in some cases, unconsclousness and coma. The usual latent period before appearance of symptoms is 1 to 4 hours.

Chronic exposure can lead to spleen and 11ver damage, faundice, anemia, and methemoglobinemia $(1,7)$. Both the cyanogenic and anemiogenic potentials of nitrobenzene are listed as considurably greater than those of aniline.

Nitrobenzene was included in a list of 14 aromatic nitro compounds suspected of carcinogenic activity ( 4 ).

Dinitrobenzene (DNB) $\mathrm{C}_{6} \mathrm{H}_{4}\left(\mathrm{NO}_{2}\right)_{2}$<smiles>O=[N+]([O-])c1ccccc1[N+](=O)[O-]</smiles> 
Dinitrobenzene occurs in three isomeric forms (ortho, meta, and para) as white (ortho and para) or yellow (meta) crystals. DNB is used in the manufacture of dyes, as a camphor substitute, in the production of celluloids, and in organic syntheses.

Dinitrobenzene is a higly toxic substance producing methemoglobinemia. Prolonged exposure may lead to liver damage ( 1 ).

Dinitro aromatic derivatives are at least five times more toxic than the corresponding mononitro compounds.

Nitrotoluene $\mathrm{CH}_{3} \mathrm{C}_{6} \mathrm{H}_{4} \mathrm{NO}_{2}$<smiles>Cc1ccccc1[N+](=O)[O-]</smiles>

Nitrotoluene occurs in three isomeric forms. Ortho- and meta-nitrotoluenes are liquids; the para isomer is a yellowish crystalline. All isomers are used in the manufacture of other chemicals such as toluldine, fuchsin, tolidine, and various dyes.

Nitrotoluene has a low toxiclty, especially when compared with nitrobenzene. Poisoning from nitrotoluene is uncommon ( 1 ).

Dinitrotoluene (2,4-Dinitrotoluene; DNT) $\mathrm{CH}_{3} \mathrm{C}_{6} \mathrm{H}_{3}\left(\mathrm{NO}_{2}\right)_{2}$<smiles>Cc1c([N+](=O)[O-])cccc1[N+](=O)[O-]</smiles>

Commercial DNT is a combustible, oily liquid, composed of a mixture of ortho, meta, and para isomers. The pure isomers are yellow crystals. DNT is used in the manufacture of explosives and dyes, and in organic synthesis. The toxic effect of DNT is similar to that of other aromatic nitro compounds. The first and most characteristic symptom ts methemoglobinemia. Animal experiments suggest that DNT is less acutely toxic than dinitrobenzene. According to Gosselin (2), liver injury may be more common 
than cyanosis, especialiy if the diet to deficlent in protein. of several isomeric forms of DNT, the 2,4-dinitrotoluene is more toxic for antmals than other DNT 18omers. The cyanogenfc potentlal of DNTs is evaluated below that of aniline, but their anemlagenic potential is consldered greater (1).

Studies of the metabolism of 2,4-dinitrotoluene by intestinal mlcroorganisms from rat, mouse, and man showed that an ordered sequence of reductive metabolism occurs under anaerobic conditions. The 2- and 4-nitro groups were reduced to amino groups (3). The test on Salmonella typhimurium showed the mutagenic activity of DNT enhanced by a para orientation of nitro groups (11).

Polycyclic Nitroaromatics

1-Nitropyrene (3-Nitropyrenc) $\mathrm{C}_{16} \mathrm{H} \mathrm{NO}_{2}$<smiles>O=[N+]([O-])c1ccc2ccc3cccc4ccc1c2c34</smiles>

1,3-Dinttropyrene $\mathrm{C}_{16} \mathrm{H8}\left(\mathrm{NO}_{2}\right)_{2}$<smiles>O=[N+]([O-])c1cc([N+](=O)[O-])c2ccc3cccc4ccc1c2c43</smiles> 


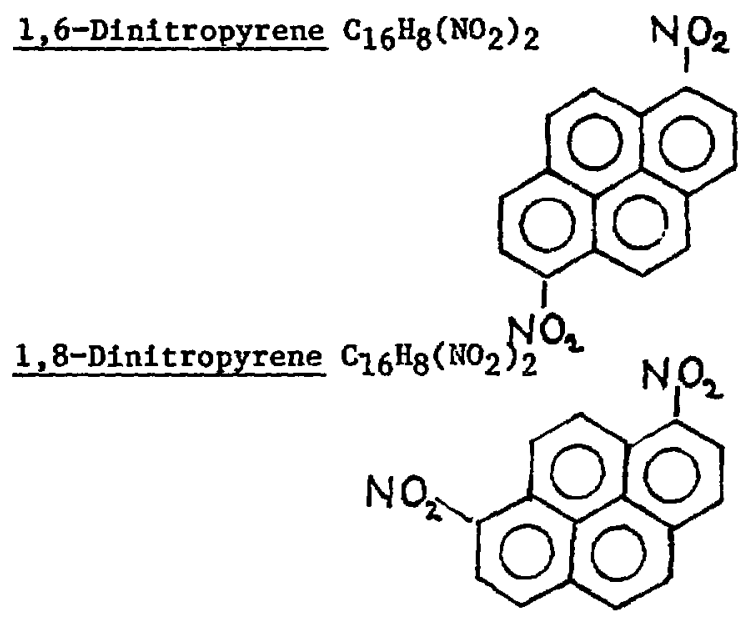

Mutagenic activity of 1-nitropyrene has been recognized by tests on Salmonella typhimurium $(5,6,10)$. Mutagenicity of di- and trinitropyrenes tested in cultured hamster ovary cells showed that while 1-NP and 1,3-DNP had only marginal direct-acting mutageniclty, 1,5-DNP, 1,8-DNP, and 1,3,6-TNP showed definite mutageniclty (8). The authors concluded that the positive mutagenic response of the nitropyrenes suggests that they are potentially carcinogentc, and that further research into their possible human health risk should be performed.

The study on the acute and genetic toxicity of 1-nitropyrene in rats showed that the oral dose of $5.0 \mathrm{~g} / \mathrm{kg}$ did not produce h1stologic alterations in major internal urgans. About $70 \%$ of the dose was recovered in feces as nitropyrene (NP) and about $2 \%$ was present as the reduced metabolite 1-aminopyrene (AP). Both NP as' AP showed low mutagenictty in ChInese hamster ovary cells in vitro. The authors concluded that the evidence of reductive metabolism of $N P$ in $r:$ is raises concern about the potential exposure of humans to this compound. However, the weak in vivo and in vitro genetic toxicity of NP at tilgh dase levels in mammalian systems suggests that the potential hazard may not be as high as predicted from bacterial mutagenicity data (9). 


\section{References}

1. ACGIH. 1980. Documentation of the threshold 11mit values. Fourth Edition. American Conference of Governmental Industrial Hygienists Inc., $\mathrm{OH}$.

2. Gosselin, R.E., H.C. Hodge, R.P. Sruth, and M.N. G1eason. 1979. Clincial toxicology of commerctal products. The Willians \& wilkins Co., MD, Pp. 86-92.

3. Guest, D., S.R. Schnell, D.E. Rickert, and J.G. Dent o 1982. Metabolism of 2,4-dinitrotoluene by intestinal microorganisms from rat, mouse and man. (Toxline Abstract). Toxicol. App1. Pharmaco1. 64: 160-8.

4. Helmes, C.T., V.A. Fung, B. Lewin, K.E. McCaleb, S. Malko, and A.M. Pawlovich. 1982. A study of aromatic nitro compounds for the selection of candidates for carcinogen bloassay. (Toxline Abstract). J. Environ. Sc1. Health Part A, Environ. Sc1. Eng. 17: 75-128.

5. Ho, C.H., B.R. Clark, M.R. GuerIn, B.D. Barkenbus, T.K. Rao, and J.L. Epler. 1981. Analytical and Blological Analyses of Test Materials From the Synthetic Fuel Technologles. IV. Studies of Chemical Structure-Mutagenic Activity Relationships of Aromatic Nitrogen Compounds Relevant to Synfuels. Mutation. Res. 85: 335-45.

6. Kinouchl, T., Y. Manabe, K. Waklsaka, and Y. Ohnishi. 1982. Biotransformation of 1-nitropyrene in intestinal anaerobic bacterla. (Toxline Abstract). Microbiol. Immunol. 26: 993-1,005.

7. Kirk-othmer. 1978. Encyclopedia of chemfcal technology. Third Edition. John Wiley \& Sons, NY.

8. I1, A.P. and J.S. Dutcher. 1983. Mutageniclty of mono-, di- and trinitropyrenes in Chinese hamster ovary cells. (Toxline Abstract). Mutat. Res. 119: 387-92.

9. Marsha11, T.C., R.E. Royer, A.P. LI, D.F. Kusewitt, and A.L. Brooks, 1982. Acute and genetic toxicity of 1-nitropyrene and its fate after single oral doses to rats. (Toxline Abstract). J. Toxicol. Environ. Health 10: 373-84.

10. P1tts, J.N. Jr., D.M. Lokensgard, W. Harger, T.S. Fisher, V. Mej1a, J.J. Schuler, G.M. Scorziell, and Y.A. Katzenstein. 1982. Mutagens in diesel exhaust particulate. Identification and direct activities of 6-nitrotenzola]pyrene, 9-nitroanthracene, 1-nitropyrene and 5Hphenantro[4,5-1scd]pyran-5-one. (Toxline Abstract). Mutal. Res. 103: 241-9.

11. Spanggord, R.J., Y.E. Mortelmans, A.F. Griffin, and V.F. 31mmon. 1982. Mutagenfcity in Salmonella typhimurium a d structure-activity relationships of waste-water components emarating from the manufacture of trinitrotoluene. (Toxline Abstract). Environ. Mutagen. 4 : 163-80. 


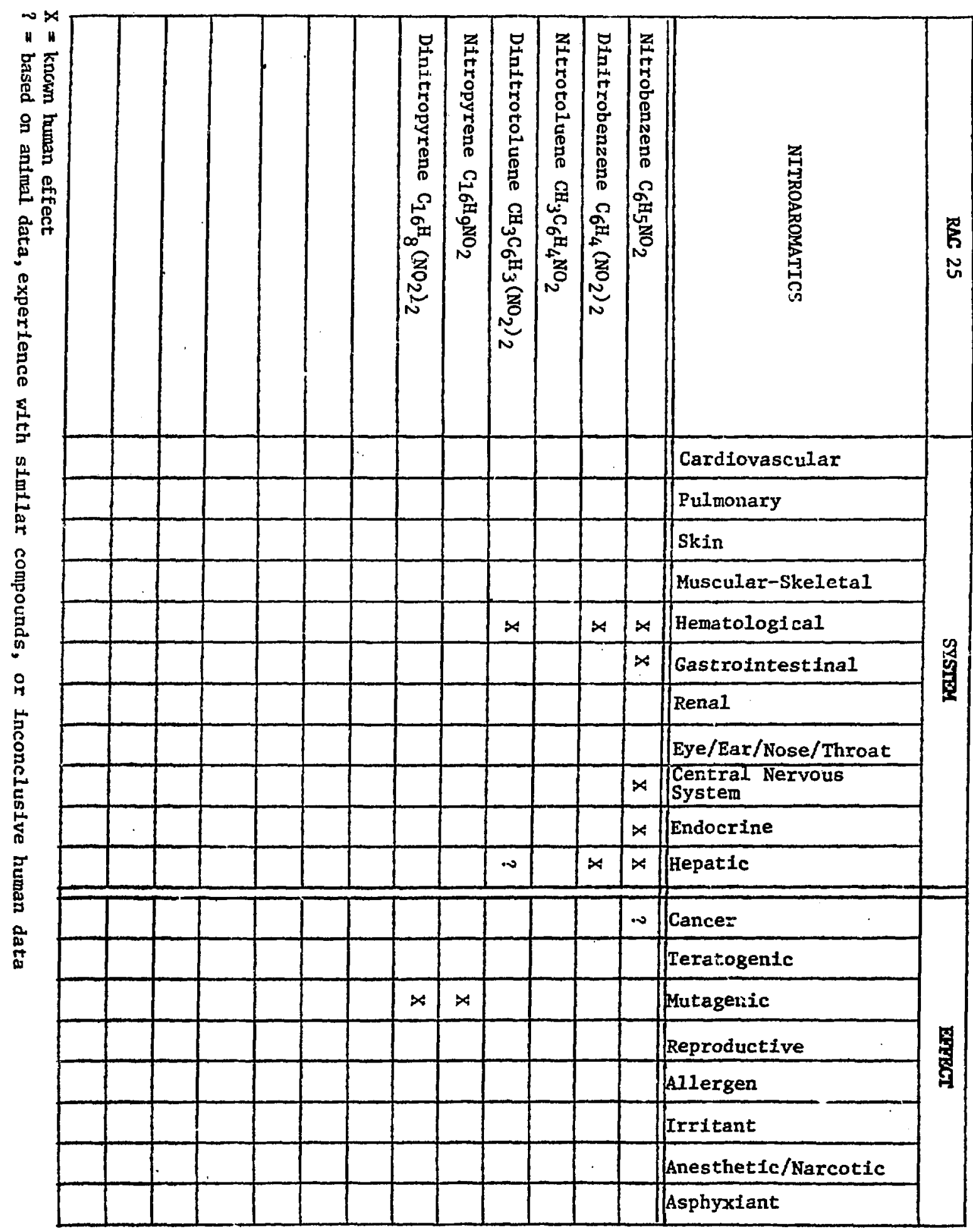


Ethyl Acetate (Ethyl Ester Acetic Acid) $\mathrm{CH}_{3} \mathrm{COOC}_{2} \mathrm{H}_{5}$<smiles>CC(C)=O</smiles>

Ethyl acetate is the only ester listed as a synthetic fuel product. Ethyl acetate is a colorless liquid with a fragrant, fruity odor. It is highly flammable and a dangerous fire and explosion hazard,

Ethyl acetate is used as a solvent for varnishes, aeroplane dopes, lacquers, and nitrocellulose, in artificial fruit essences, and in the manufacture of artificial silk and leather, perfumes, and photographic films.

Ethyl acetate has been widely used as a lacquer solvent and has the reputation of being one of the less toxic of the volatile organic solvents. According to Patty, workers exposed regularly at concentrations ranging from 375 to $1500 \mathrm{ppm}$ for several months showed no unusual signs or symptoms. There was, however, a report of the death of a taink painter ascribed to Inhalation of ethyl acetate. There have also been reports of poisoning due to inhalation of ethyl acetate (1).

Animals can withstand a dally. 4-hour exposure of ethyl acetate to $2000 \mathrm{ppm}$ for a period of 65 days, without apparent 111 effects. Ethyl acetate is only mildly narcotic even at concentrations well in excess of $46,000 \mathrm{mg} / \mathrm{m}^{3}$ (1). Short exposures of 8,600 to $20,000 \mathrm{ppu}$ have been considered dangerous to man. The vapors can be irritating to mucous membranes but provide good warning, since irritation occurs at approximately $400 \mathrm{ppm}$. Repeated or prolonged direct skin contact will cause drying and cracking of the skin. The threshold limit value (1) is $400 \mathrm{ppm}\left(1.4 \mathrm{mg} / \mathrm{m}^{3}\right)$. Appropriate ventilation should be used to maintain the concentration of vapor in the atr below the TLV. Repeated or prolonged contact with the skin should be avolded (2).

Study of the toxic activity of different industrial solvents on the human lymphocytes cultured in vitro showed that ethyl acetate belonged to the group of compounds which inhibited [3H] thymidine uptake in the absence 
of the metabolizing system ( $S 9 \mathrm{mix}$ ) but have no effect on cell viability (3). These chemicals were considered by authors to be cytotoxic, but their action was not immediately followed by cellular death.

References

1. ACGIH. 1980. Documentation of the threshold limit values. Fourth Edition. American Conference of Governmental Industrial Hygienists Inc., $\mathrm{OH}$.

2. Kirk-0thmer. 1978. Encyclopedia of chemical technology. Third Edition. John Wiley \& Sons, NY.

3. Perocco, P., S. Bolognesi, and W. Aiberghini. 1983. Toxic activity of seventeen industrial solvesis and halogenated compounds on human 1 ymphocytes cultured In vitro. (Toxline Abstract). Toxicol. Lett. 16: $69-75$. 


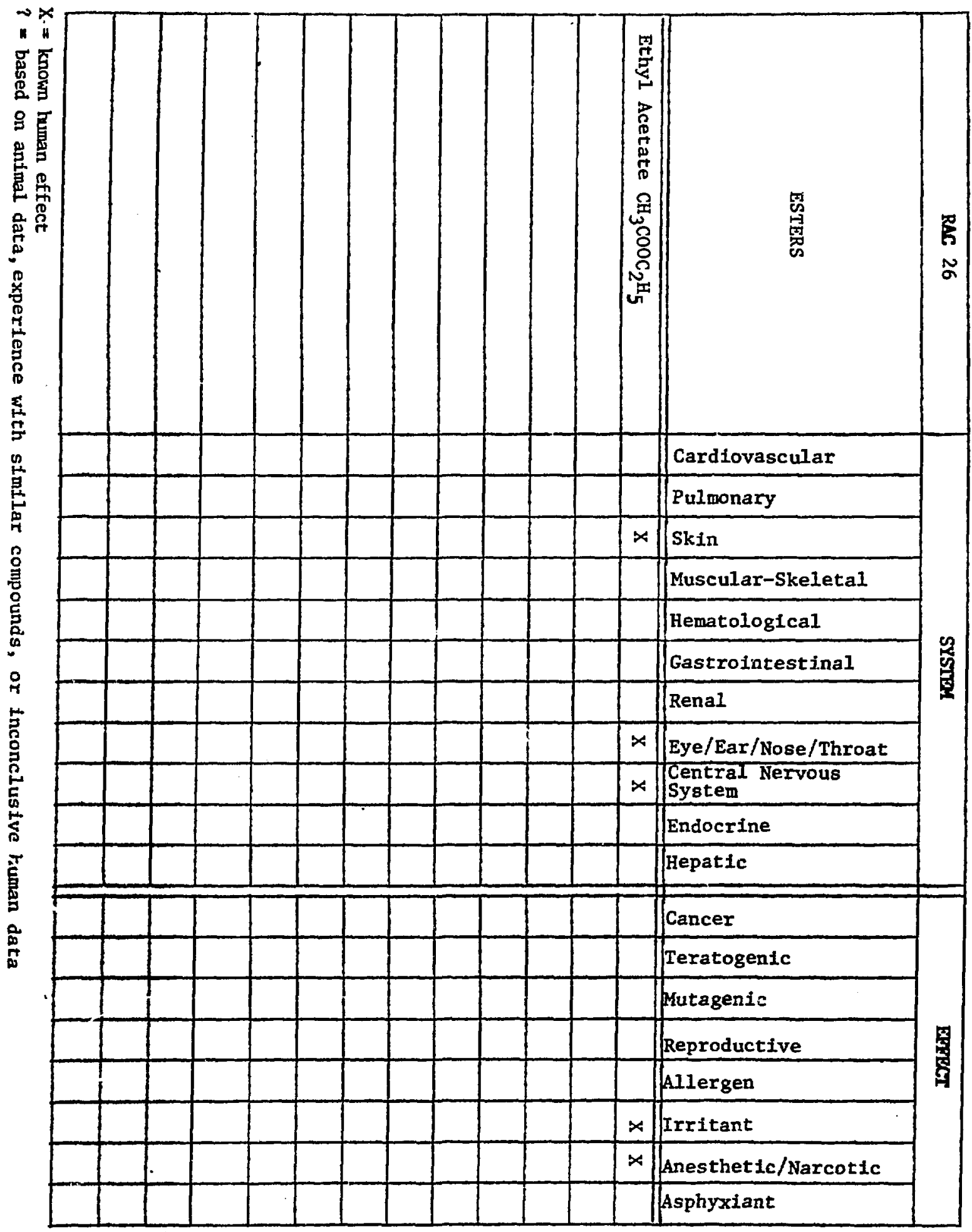


Amides are cerivatives of carboxylic acid compounds in which the $-\mathrm{OH}$ of the carboxylic acid is replaced by $-\mathrm{NH}_{2}$.

\section{Formamide (Formlc Acld Amlde; Methaneamide; Carbamaldehyde) $\mathrm{HCONH}_{2}$}

$$
\mathrm{H}-\mathrm{C} \stackrel{\mathrm{O}}{-\mathrm{NH}_{2}}
$$

Formamide is a clear viscous liquid used as a solvent in the chemical industry, and as a softener for paper and animal glues.

A11 toxicology data found about formamide are based on animal studies. It is relatively nontoxic by skin absorption, produces only mild eye Irritation, and shows low inhalation toxiclty. Teratogenic effects were produced in pregnant rats after injection of formamide $(1,3)$. No human data have beer found.

Because of the teratogenic effects found in animals, pregnant women should not be employed in the production and processing of formamide (3).

Acetamide (Ethanamide; Acetic Acid Amide) $\mathrm{CH}_{3} \mathrm{CONH}_{2}$<smiles>CC(N)=O</smiles>

Acetamide appears as colorless deliquescent hexagonal crystals, odorless when pure. It is used as a solvent, solubilizer, plasticizer, and stabilizer.

Acetamide is a mild irritant (5) for animals, and causes readily ceversible tissue changes which disappear after exposure. In high doses, it may act as a carcinogen (2). No human data were found. 
Benzamide (Benzolc Acid Amile; Benzoylamide) $\mathrm{C}_{6} \mathrm{H}_{5} \mathrm{CONH}_{2}$<smiles>NC(=O)c1ccccc1</smiles>

Benzamide forms crystals. No human data were found.

Methyl Benzamide (Methyl Benzoic Acid Amide) $\mathrm{C}_{6} \mathrm{H}_{4} \mathrm{CH}_{3} \mathrm{CONH}_{2}$ appears as isomers.

2-Methy1 Benzamide<smiles>Cc1ccccc1C(N)=O</smiles>

3-Methyl Benzamide

4-Methyl Benzamiue<smiles>Cc1cccc(C(N)=O)c1</smiles>

No human data have been found.<smiles>Cc1ccc(C(N)=O)cc1</smiles> 
Thioacetamide (Ethanethioamide) $\mathrm{CH}_{3} \mathrm{CH}_{2} \mathrm{NS}$

$$
\mathrm{CH}_{3}-\mathrm{CH}_{2} \rightarrow \mathrm{NS}
$$

Thioacetamide appears as crystals with a slight odor of mercaptian (thiols). Because of its more acceptable odor, thioacetamide represents a pleasant suistitute for hydrogen sulfide in the laboratory (4).

No human data were found.

\section{References}

1. ACGIH. 1980. Documentation of the threshold limit values. Fourth Edition. American Conference of Governmental Industrial Hygienista Inc., OH.

2. International Agency for Research on Cancer. 1979. IARC monographs on the Evaluation of Carcinogentc Risk of Chemicals to Man. World Health Organization.

3. Kirk-0thmer. 1978. Encyclopedia of chemical technology. Third Edition. John Wiley \& Sons, NY.

4. The Merck Index. 1976. An encyclopedia of chemicals and drugs. Ninth edition. Merck \& Co., Inc., Rahway, NJ.

5. Sax, N.I. 1975. Dangerous properties of industrial materials. Fourth Edition. Van Nostrand Reinhold Company, NY. 


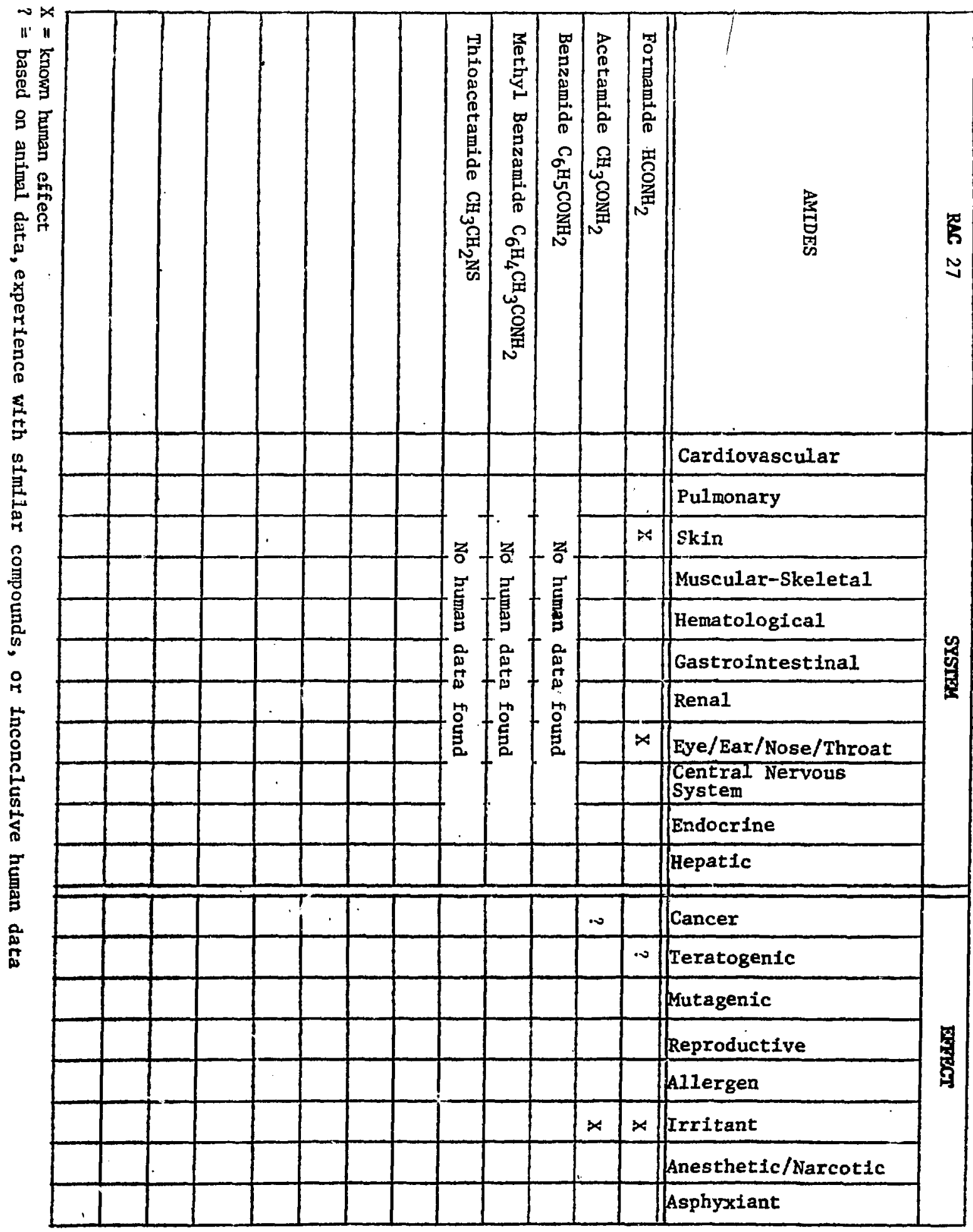


Nitriles are aliphatic or aromatic cyano compounds with the general formula $\mathrm{RC} \equiv \mathrm{N}$. Most cyano compounds have a characterfstic almond-1ike odor.

Aliphatic Nitriles

Aliphatic nitriles are colorless liquids with faint sweet odors.

Acetonitrile (Acetic Acid Nitrile, Ethane Nitrile, Ethyl Nitrile, Methyl Cyanide, Cyanomethane, Methane Carbonitrile) $\mathrm{CH}_{3} \mathrm{CN}$<smiles>CC#N</smiles>

Acetonitrile is used as a solvent in the extraction of hydrocarbons and fatty aclds, in spectrophotometry and electrochemistry, and as a catalyst and intermediate.

Severe toxic symptoms were reported in a case of 15 painters exposed to acetonitrfle vapor for 12 hours in a poorly ventllated tank. The symptoms ranged from nausea, headache, vomiting, respiratory depression, extreme weakness, and stupor to convulsions, shock, and coma. One worker died 14 hours after cessation of exposure. The autopsy showed high cyanide concentrations in the blood, and in various organs. A later analysis of the same case led, however, to the conclusion that the 3- to 12-hr delay in symptoms indicated that the symptoms could not have resulted from cyanide poisoning, and that they resulted from thlocyanate, the detoxification product of cyanide, rather than acetonitrile toxicity (9).

Experimental studies on humans show that inhalation of $40 \mathrm{ppm}$ for 4 hours produced tightness of the chest. Exposures of $160 \mathrm{ppm}$ caused flushlng of the face and tightness of the chest, but did not produce significant changes in blood cyanide and urinary thiocyanide concentratione $(2,8,9,13)$. 
Although acetonitrile has a low-order toxicity by ingestion, Inhaiation, and skin absorption, if splashed in the eye it can cause severe eye burns.

Acrylonitrile (Vinyl Cyanide; Propenenitrile; Propenic Acid Nitrile) $\mathrm{CH}_{2}=\mathrm{CH}-\mathrm{CN}$

$$
\mathrm{CH}_{2}=\mathrm{CH}-\mathrm{C} \equiv \mathrm{N}
$$

Acrylonitrile is used as a monomer for acrylic and modacrylic fibers. Acrylonitrfle is highly toxic by ingestion, Inhalation, or absorption through the skin. The toxic symptoms resemble that of cyanide poisoning. It: was thus considered that the toxic action of acrylonitrile was due to the liberation of cyanide ion. Although this is a possible secondary mechanism, there is now considerable evidence that the toxic action of acrylonitrile is due to its own structure, Independent of the liberation of the cyanide fon (8).

Preliminary epidemiologic studies conducted by chemical companies of a cohort of 470 acrylonitrile polymerization workers Indicated excess lung and colon cancer $(1,3)$. The excess of stomach and lung cancer (10) was also reported from the United Kingdom acrylonitrile polymerlzation workers (17). The epidemiologic studies colncide with experiments on animals indicating carcinogenic action of acrylonitrile $(1,14)$.

The blood serum of workers employed in acrylonitrile production was reported to show a decrease in free sulfur-containing mostly essential amino acids, free sulfhydryl groups, and the diminution of the activity of blood enzymes. The supply of a diet rich in amino acids affected positively the contant of free amino acids and the activity of serum enzymes (16). The excretion of acrylonitrile in the urine of exposed workers shows a concentration peak at the end of the workday and a rapid decrease until the beginning of the next workday. A similar Increase of acrylonitrile excretion has been observed in non-exposed workers who smoked (levels increased as the number of cigarettes smoked increased), but the 
concentration of acrylonitrile was much higher in the urine of exposed workers (6).

Several cases of mild jaundice accompanied by mild anemia and leucocytosis have been reported. Other symptoms of prolonged exposure to acrylonitrile include chronic fatigue, respiratory difficulty, and nervous symptoms ( 7 ).

prolonged skin contact with acrylonitrile causes formation of large vesicles after a latent period of 2 hours. They resembie second degree burns. Repeated skin exposure causes dermatitis.

Experiments testing the mutagenic effect of vinylic monomers on Salmonella showed the mutagenic activity of acrylonitrile (12). The mutagenic activity was enhanced by glutathione, thus supporting the hypothesis of a (liver mediated) formation of a mutagen involving glutathione (4). An increase in sister chromatid exchange and the unscheduled synthesis of DNA in human lymphocytes in vitro were also induced by acrylonitrile (11). Studies on the interaction of acrylonitrile with hepatic mfcrosomes showed the binding of acrylonitrile to human and rat but not to mouse microsomes (2). The basic metabolic pathway of labeled acrylonitrile to 2-cyanoethylene oxide was established in vitro, using subcellular fraction from rats and humans (5). This study also showed irreversible binding of radioactive label from acrylonitrile to protein and DNA.

No significant increase in cytogenic aberration in bone marrow of rat and mouse was recognized in mice given 7 to $21 \mathrm{mg} / \mathrm{kg} /$ day of acrylonitrile orally or 10 to $20 \mathrm{mg} / \mathrm{kg} / \mathrm{day}$ introperitoneally for 30 days, or in rats given $40 \mathrm{mg} / \mathrm{kg} /$ day orally for the same period (15).

Aromatic Nitriles

Benzonitrile (Benzoic Acid Nitrile, Cyanobnenzene, Pheny1 Cyanide) $\mathrm{C}_{6} \mathrm{H}_{5} \mathrm{CN}$

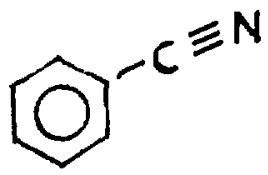


Benzonttrile is a liquid with an almond-1ike odor. It is used as a solvent.

No human data were found.

Dipheny1 Acetonitrile (Nitrile Diphenyl Acetic icid; -Cytanodipheny1 Methane) $\mathrm{C}_{12} \mathrm{HgCH}_{2} \mathrm{CN}$.

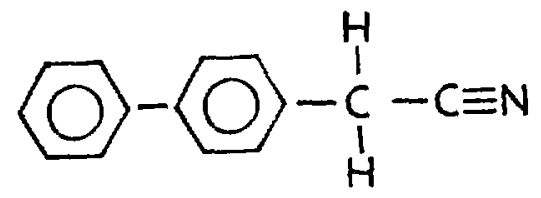

Diphenyl acetonitrile is a solid at room temperature.

No human data were found.

\section{References}

1. ACGIH. 1980. Documentation of the threshold 1imit values. Fourth Edition. American Conference of Governmental Industrial Hygienists Inc., OH.

2. Appe1, K.E., H. Peter, M. Bolt, and H.M. Bolt. 1981. Interaction of acrylonitrile with hepatic microsomes of rats and men. (Toxilne Abstract). Toxicol. Lett.(AMST) 7: 335-40.

3. Delzell, E. and R.R. Monson. 1982. Mortality among rubber workers: VI. Men with potential exposure to acrylonitrile. J. Occup. Med. 24: 767-9.

4. Duverger-Van Bogaert, M., M. Lambotte-Vandepaer, C. De Misester, M. Mercler, and F. Poncelet. 1982. Role of glutathlone in liver-mediated mutagenicity of acrylonitrile. (Toxline Abstract). Toxicol. Lett. (AMST) 11: 305-12.

5. Guengerich, F.P., L.E. Geiger, L.L. Hogy, and P.L. Wright. 1981 Invitro metabolism of acrylonitrile to 2-cyanoethylene oxide, reaction with glutathione and Irreversible binding to proteins and nucleic acids. (Toxllne Abstract). Cancer Res. 41: 4925-33.

6. Houthuljs, D., B. Remljn, H. Hillems, J. Boleij, and K. Blersteker. 1982. Blological monitoring of acrylonttrile exposure. Am. J. Ind. Med. 3: 313-20.

7. International Agency for Research on Cancer. 1979. IARC monographs on the Evaluation of Carcinogenic Risk of Chemicals to Man. World Health Organd.zation. 
8. Kirk-0thmer. 1978. Encyclopedia of chemical technology. Third Edition. John Wiley \& Sons, NY.

9. NIOSH. 1978. Criteria for a recommended standard.... occupational exposure to ketones. U.S. Department of Health, Education, and Welfare, Public Health Service, Center for Disease Control.

10. O'Berg, M.T. 1980. Epldemiologic study of workers exposed to acrylonitrile. J. Occup. Med. 22: 245-52.

11. Perocco, P., G. Pane, S. Bolognes1, and M. Zannott1. 1982. Increase of sister chromatid exchange and unscheduled synthesis of deoxyribonucleic acid by acrylonitrile in human lymphocytes in vitro. (Toxline Abstract). Scand J. Work. Environ. Health 8: 290-3.

12. Poncelet, F., C. De Meester, and B.M. Van-Duverger. 1980. Influence of experimental factors on the mutagenicity of vinylic monomers. (Toxllne Abstract). Arch. Toxicol. Suppl. 4: 63-6.

13. Proctor, N.H. and J.P. Hughes. 1978. Chemical hazards of the workplace. J.J. Lippincott Compary, PA.

14. Public Health Service. 1981. Second annual report on carcinogens. U.S. Department of Public Health and Human Services.

15. Rabello-Gay, M.N. and A.E. Ahmed. 1980. Acrylonitrile: In vivo cytogenetic studies in mice and rats. (Toxline Abstract). Mutat. Res. 79: 249-55.

16. Skvortsov, I. 1980. Change in the blood serum amino acid spectrum in workers engaged in the manufacture of acrylonitrile and the ways for its correction " la nutrition. (Toxline Abstract), Vopr. Pitan. 2: 31-3.

17. Werner, J.B. and J.T. Carter. 1981. Mortality of the UK acrylonftrile polyonerization workers. (Toxline Abstract). Br. J. Ind. Med. 38: 247-53. 


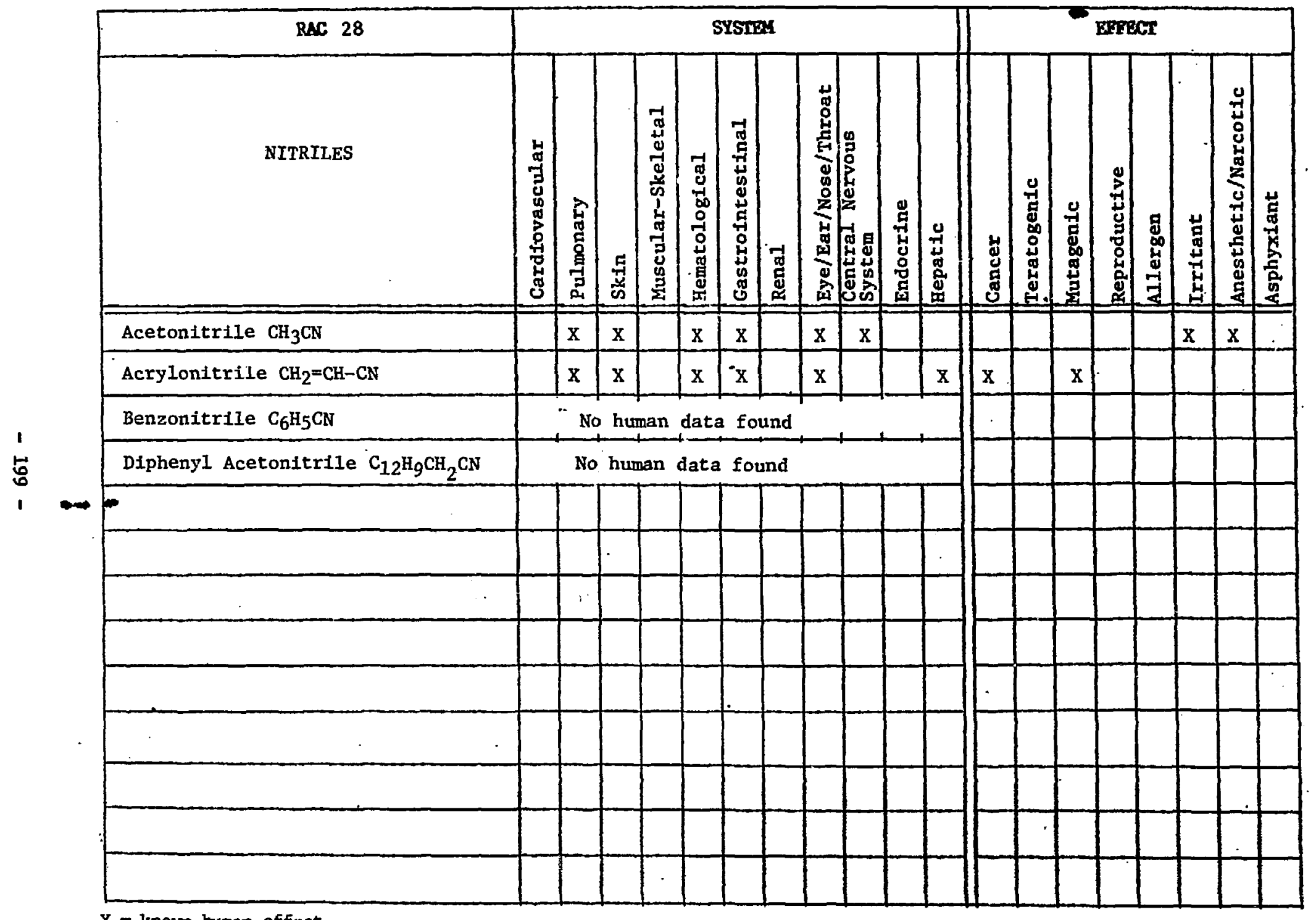

$X=$ known human effect

$?$ = based on animal data, experience with similar compounds, or Inconclusive human data 
Tars are viscous, bituminous 11quids obtained by destructive distillation of organic material. As such, they are mixtures of various chemical categorles classifled elsewhere in the RAC structure. The mix varles. Unfiltered cigarette tars contain 0.10 to $0.15 \mathrm{\mu g}$ benzo[a]pyrene, 0.2 to $0.3 \mu \mathrm{g}$ of pyrene, and $0.25 \mathrm{\mu g}$ chrysene 1 . The following compounds have been identifled in coal gassifler tar 2: $(1,2)$

Dimethylnaphthalene

Acenaphthene

Trimethylnaphthalene

Fluorene

Methylfluorene

Dibenzothiophene

Phenathrene

Anthracene

Methyidibenzothlophene

Methylphenanthrene

Dimethylphenanthrene

Fluoranthene

Pyrene

Phenylnaphthalene

Methylpyrene

Trimethylphenanthrene

Benzo(a)fluorene

Benzo[a]pyrene

No doseresponse functions were developed for "tars" $(1,2)$. Exposures to some of these compounds are treated with1n other RACs.

\section{References}

1. Committee on Blologic Effects of Atmospheric Pollutants. 1972. Particulate Polycyclic Organlc Matter, National Academy of Sclences, Washington, DC, p. 29.

2. Francls, C.W. and F.J. Wobber. 1982. Status of health and environmental research relative to solid wastes from coal conversion. U.S. Department of Energy (DOE/NBB-088/1), Washington, DC, p. 43. 


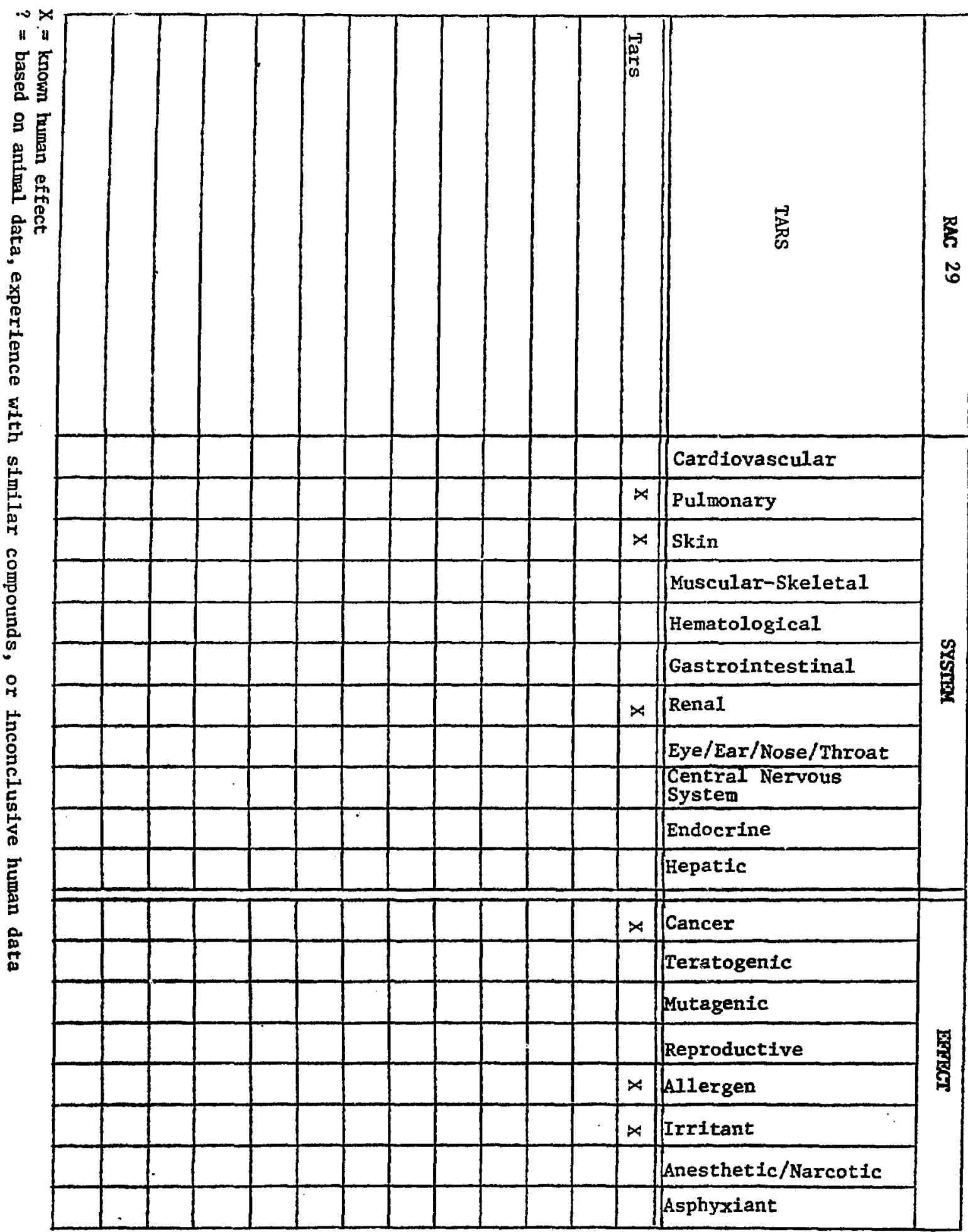


Respirable particles are composed of a wide variety of organic and inorganic compounds. They result from direct emission of small particles into the alr and from atmospheric chemical reactions of released gases.

A number of epidemlological studies have shown assoclations between airborne total particle levels and human health $(1,2)$. Dose-response indices have been developed from such studies. Fewer studies, however, have Included measurements of respirable particles, and dose-response functions are not avallable. Moreover, all these studies are based on exposure to particles in general urban air. The character of particles emitted by synthetic fuels plants may be much different.

The chemical constituents of particles are included in other RACB. Rather than develop dose-response functions for respirable particles per se, effects will be estimated on the basis of exposure to specific compounds. In some cases, a compound might be in either gaseous or particulate state. Health impact may depend on which state exposure takes place.

\section{References}

1. National Academy of Sciences Subcommittee on Alrborne Particles. 1977. Airborne Particles (EPA 600/1-77-053). National Research Council, National Academy of Sclences, Washington, DC.

2. U.S. Environmental Protection Agency. 1981. Draft Air Quality Criteria for Particulate Matter and Sulfur Dioxide. 


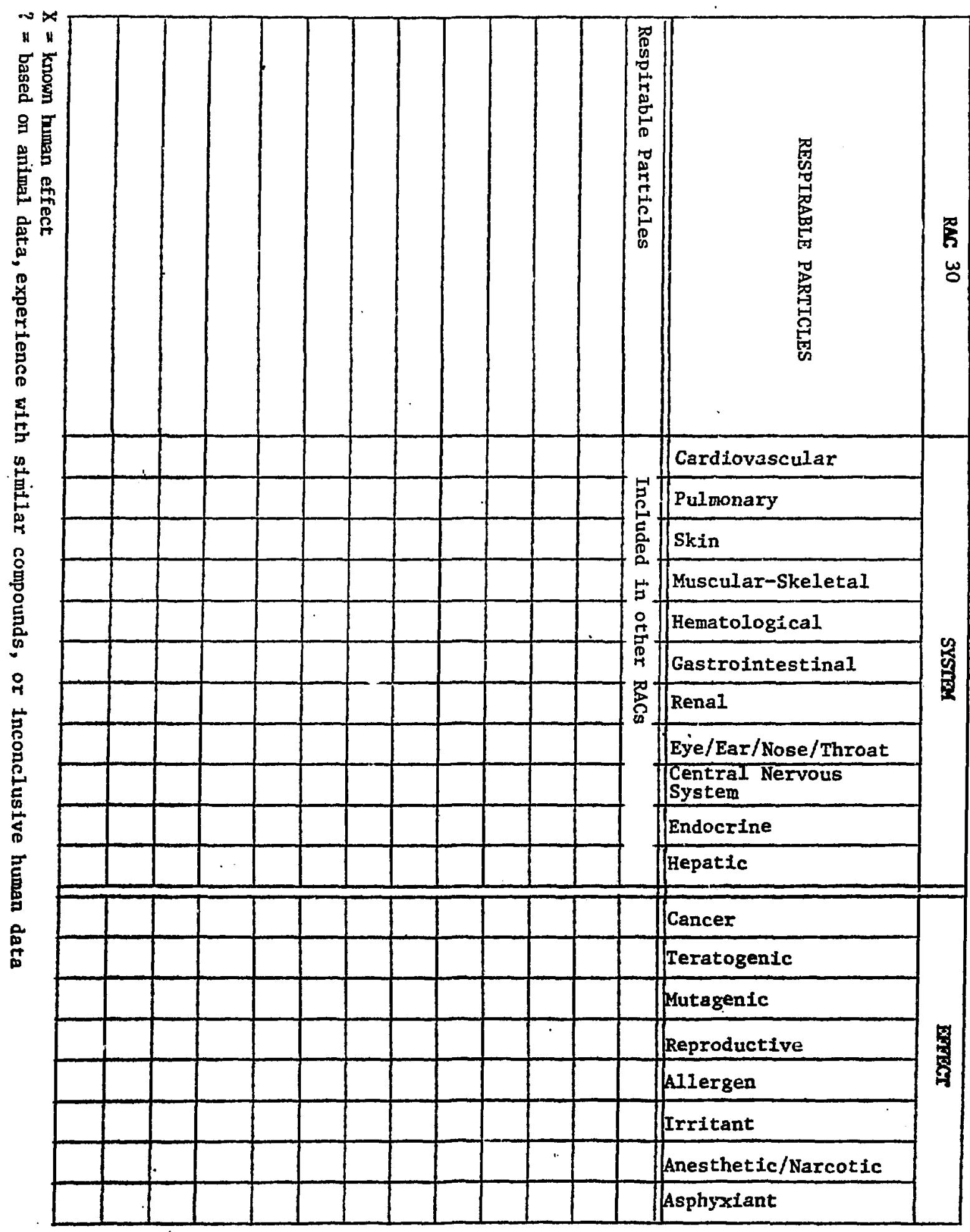


Arsenic, commercially produced as a by-product during the processing of nonferrous metal ores, is princlpally used in the production of agricultural pesticides, as an additive in metallurglc applications and glass production, as a catalyst in several manufacturing processes, and in medicine. Public exposure to arsenic currently occurs from air, food, and drinking water. The ICRP (4) estimates that the human intake from food and $1: 1$ ulds and from Inhalation is approximately 1.0 and $0.0014 \mathrm{mg} /$ day, respectively. Marine and freshwatar fish and invertebrates appear to be the largest source of arsenic exposure in the diet. Most Inhaled arsenic occurs in industrial areas, or in areas where coal is burned; background air concentrations in these regions may range from 1 to $83 \mathrm{ng} / \mathrm{m}^{3}$, with an average of $3 \mathrm{ng} / \mathrm{m}^{3}$.

The ACGIH TLV for arsenic has been set at $0.2 \mathrm{mg} / \mathrm{m}^{3}$, while the OSHA standard is $10 \mu \mathrm{g} / \mathrm{m}^{3}$. The US EPA is considering setting drinking water quality standards ranging from 0.0002 to $0.02 \mu \mathrm{g} / 1$. Similarly, EPA is in the process of developing a National Amblent Air Quality Standard for this pollutant. Acute and chronic health effects of arsenic have been reviewed by a large number of authors. This synopsis draws heavily on the work of Mushak et al. (6), Green (3), U.S. EPA (15), Dickerson (2), and the U.S. National Academy of Sciences (16).

Acute Effects

The main route of entry for nonoccupationally exposed individuals is by ingestion. Typical symptoms of acute oral arsenical poisoning appear within a few hours and include a burning sensation along the gastrointestinal system, nausea, vomiting, diarrhea, cramping, and cardiovascular alterations. Death from circulatory fallure may occur within hours or days of an acute lethal dose to trivalent arsenic reported to range from 70 to 80 mg. In less severe poisonings, there may be a delay period of 10 to 21 days before perfpheral neuropathy develops. This is reflected by a number of symptoms including weakness, paresthesia, and sensory loss. 
Chronic Effects

Effects of chronic arsenic exposure are principally known from occupational studies. Chronic arsenic polsoning through inhalation or Ingestion may manifest itself in many different ways.

Neurological disorders are often the most apparent consequence of chronic arsenic exposure. Usually, the sensory pathways are most affected, with overall neuropathy being described as insidious in onset. Polyneuritis, par- and hyper-esthesias, and symmetrical muscle weakness, primarily in distal muscle groups of the lower extremities are common complaints. Central nervous system effects may also occur. These disturbances closely follow peripheral events with symptoms ranging from memory loss and general mental confusion to convulstons, stupor, coma, and even death.

Significant cardlovascular effects have also been observed. Studies of copper smelter workers suggest that their cardlovascular disease mortality incidence rate was twice that of a control population (1). Similarly, vascular changes have been observed in vine dressers who had been exposed to arsenical insecticides for 20 years: vessels in the limbs of these workers had begun to atrophy and became blocked (6).

Documented blood abnormalities include leukopenia (low white cell counts) and anemia. The presence of porphyrin, hemoglobin precursor in the urine, is characteristic of cirronic arsenic polsoning. Pathologies affecting the blood do not appear to be permanent, and it has been observed that the blood system, usually returns to normal several weeks after exposures cease.

Teratogenic effects of arsenic compounds have been demonstiated in a number of animal studies. Extrapolation of these findings to analogous effects in man is, however, highly speculative. Human epidemiological evidence for teratogenic effects is limited. Increased evidence of spontaneous abortions, Infant congenital malformations, and decreased birth welghts have been reported for women in populations exposed to relatively high levels of airborne arsenic $(7,8)$. In this population, confounding exposures to other toxic pollutants make it difficult to ascribe the observed effects specifically to arsentc with any degree of confidence. 
Carcinogenic effects of arsentc have been seen among occupationally exposed Individuals. The atrongest links between arsenic and carcinogenesis exist for skin and lung cancers. Associations with other forms of cancer (1.e., liver, henanglosarcoma, lymphomas, leukemla, renal adenocarctnomas, and nasopharyngeal criclnona) have also been - suggested. Recent epidemiologic studies $(5,9,10)$ have been used by the Carcinogen Assessment Group (14) to derive a dose-response function for resplatatory exposure to arsenic. The dose-response relationship 182.8 respiratofy cancers per year per 100,000 persons exposed per $\mu \mathrm{g} / \mathrm{m}^{3}$. Ingestion of arsenic compounds has also been assoclated with an Increased risk of skin cancer. Tseng et al. (12) and Tseng (13) studied a 11mtted area in southwestern Ta1wan where artesian well water had extremely high concentrations of arsenic; the prevalence of skin cancer for the area was 10.6 per 100 . The EPA has established skin cancer risks given arsenic concentrations in drinking water from Tseng's data. A skin cancer risk of 1 per 100,000 is related to water arsenic concentrations of $0.02 \mu \mathrm{g} / 1$ (11). These risk levels were calculated by applying a modified "one-hit" extrapolation model to the human epidemiologic data. Because the extrapolation model ts linear at low doses, the additional lifetime risk is directly proportional to the water concentration. The resulting skin cancer risk is 5.9 cancers per 100,000 persons per $\mu g / 1$ arsenic.

\section{References}

1. Axelson, O., E. Dahlgren, C. Jansoon, and S.0. Rehnlund. 1978. Arsenic exposure and mortality: A case reference study from a Swedish copper smelter. Br. J. Ind. Med. 35: 8-15.

2. Dickerson, O.B. 1980. Arsenic, in H.A. Naldron, Editor. Metals in the Environment. Academic Press, New York, NY.

3. Green, P.G. 1981. Toxicity of Arsenic and Its Compounds (BNL 51510), Brookhaven National Laboratory, Upton, NY.

4. International Commission on Radiological Protection. 1975. Report of the Task Group on Reference Man. Pergamon Press, New York, NY.

5. Lee, A.M. and J.F. Fraument. 1969. Arsenic and respiratory cancer in man - an occupational study. J. Nat. Cancer Insi:. 42: 1,045. 
6. Mushak, P., W. Galke, V. Hasselblad, and L. Grant. 1980. Health Assessment Document for Arsenlc. U.S. Environmental Protection Agency, Washington, DC.

7. Nordstrom, S., L. Beckman, and I. Nordenson. 1978a, Occupational and environmental risks in and around a swelter in northern Sweden. Variations in birth weight. Hereditas 90: 291-6.

8. Nordstrom, S., L. Becknan, and I. Nordenson. 1978b. Occupational and environmental risks in and around a smelter in northern Sweden III. Frequencies of spontaneous abortion. Hereditas 88: 51-4.

9. Ott, M.G., D.B. Holder, and H.L. Gordon. 1974. Respiratory cancer occupational exposure to arsenicals. Arch. Environ. Hith. 29: 250.

10. PInto, S.S., P.E. Enterline, V. Henderson, and M.D. Varner. 1977. Mortality experience in relation to a measured trioxid exposure. H1th. Persp. 19: 127.

11. Sittig, M. 1980. Prlority Toxic Pollutants, Health Impacts and Allowable Limits. Noyes Data Corporation, Park RIdge, NJ.

12. Treng, W.P., H.M. Chu, and S.W. How. 1968. Prevalence of skin cancer In an endemic area of chronic arsenicism in Talwan. J. Nat. Cancer Inst. $40: 453-463$.

13. Tseng, W.P. 1977. Effects and dose-response relationships of kin cancer and blackfoot disease with arsenic. Environ. Hlth. Perspec. 19: 109 .

14. U.S. Environmental Protection Age.lcy. 1978. Carcinogen Assessment Group Report on Arsenic, Washington, DC.

15. U.S. Environmental Protection Agency. 1980. Ambient Water Quality Criteria - Arsentc. Washington, DC.

16. U.S. National Academy of Sciences. 1977. Arsenic - Medical and Blologic Effects of Environmental Pollutants. National Research Council, Publishing and Filiting Office, Washington, DC. 


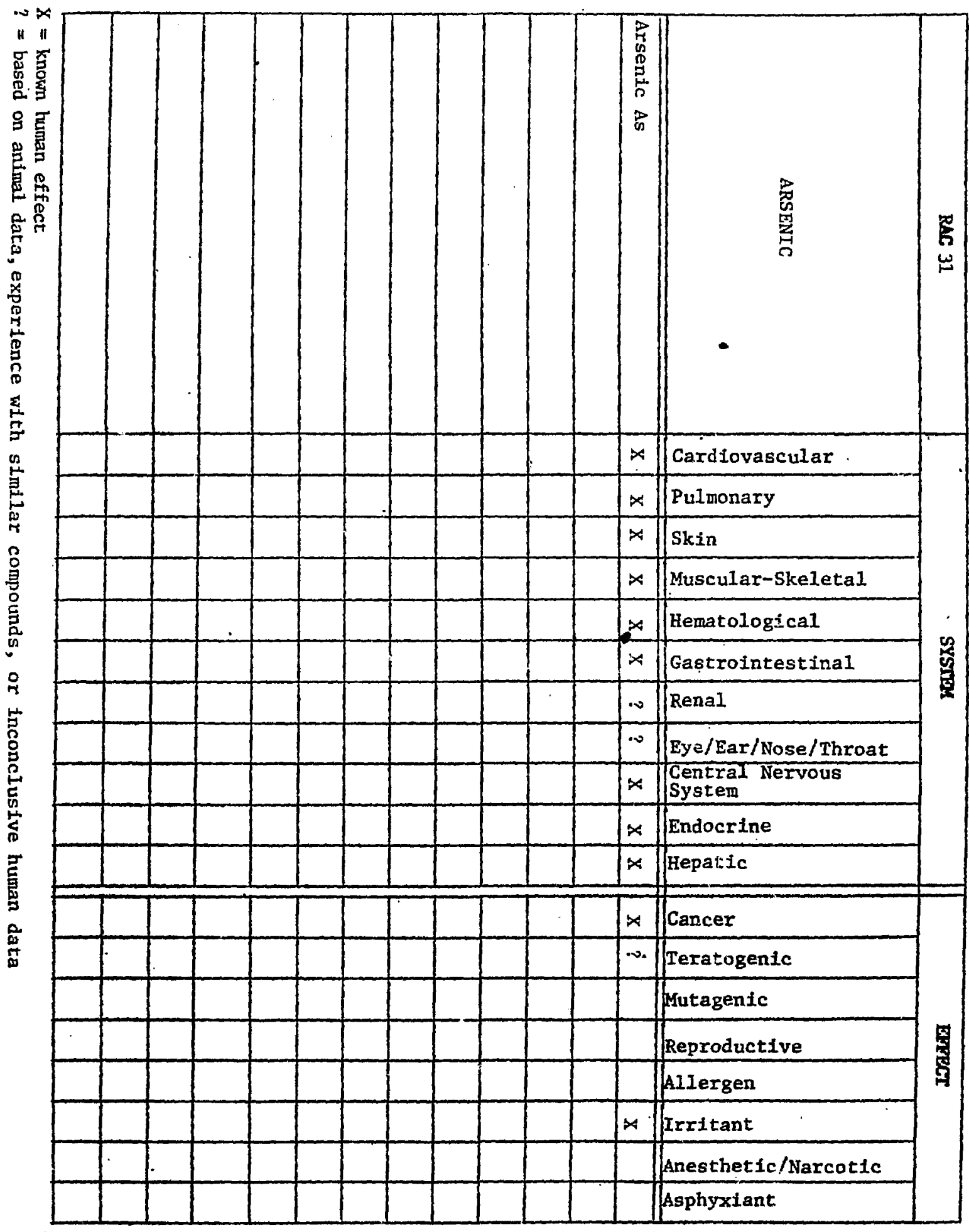


RAC \#32 - MERCURY

Mercury is a heavy metal whose toxic effects have been recognized since anclent times. Chronic mercury poisoning was well described in connection with mercury mining in Roman times (3). Although occupational mercurialism has become rare with regulation of mercury levels in today's work environments, epidemics of mercury poisoning have nevertheless occurred in recent years. In the 1950s, industrial discharge of alkyl mercury led to the polsoning of many people who consumed fish and shellfish from the Minimata Bay region of Japan. In the early 1970s, misuse of mercury-treated seed grain led to an outbreak of methyl mercury poisoning in Iraq.

Mercury is currently used in electrical apparatus cells for caustic soda and chlorine production; Instruments such as theimometers; laboratory applications; antifouling paint; and dental amalgams (5). Mercury is present In fossil fuels, particularly in crude ofl and natural gas deposits located near mecuric sulfide ore (cinnabar). Up to 21 ppm mercury has been found in ofl fields. Mercury concentrations in coal are low, but because of the vast quantities consumed annually. coal forms an important source of mercury released into the rilosphere (4).

Sources of human mercury exposure are air, water, and food. An ambient air concentration of $50 \mathrm{ng} / \mathrm{m}^{3}$ is estimated to give an average daily intake of about $1 \mathrm{Hg} / \mathrm{day}$ (d) by Inhalation, but in heavily polluted areas this could increase to $30 \mathrm{\mu g} / \mathrm{d}$ (4). Drinking water, with a mercury ievel of 50 $\mathrm{ng} / 1$, is estimated to contribute $0.1 \mathrm{\mu g} / \mathrm{d}$ to total intake, assuming a consumption of $2 \mathrm{1} / \mathrm{d}$. In the general population, intake of mercury from food is estimated to be between $1 \mu \mathrm{g} / \mathrm{d}$ and $20 \mu \mathrm{g} / \mathrm{d}$ of, which foods other than fish contribute about $5 \mathrm{\mu g} / \mathrm{d}$. Heavy fish eaters may ingest up to 200 g/d or more (4).

0ccupational exposure is generally to inorganic mercury by the Inhalation of elemental mercury vapor or to aerosols of mercuric salta (3). For this reason, inialation exposure to mercury vapor is the major concern of this RAC. However, other forms of mercury will be discussed. The TLV for mercury vapor is $0.05 \mathrm{mg} / \mathrm{m}^{3}$ and the STEL is $0.15 \mathrm{mg} / \mathrm{m}^{3}$. 
Acute Effects

Mercury vapor 18 absorbed readily and almost completely across the alveolar membranes of the lung. Inhalation of high concentrations of mercury vapor even for relatively brief periods can cause pneumonitis, bronchitis, chest pains, dyspnea, and coughing, as well as stomatitis, gingivitis, salivation, and diarrhea (1). Kidney damage with renal shutdown may occur within 1 to 2 days (2), and death may occur within a week (6). In contrast to chronic mercury polsoning, mental and nervous symptoms are not common in acute mercurlalism, although tremors have been described (4).

\section{Chronic Effects}

The critical organ affected by repeated or prolonged exposure to mercury vapor at low levels is the brain.

Chronic mercurialism is characterized by three features: Inflammation of the mouth, muscle tremors, and psychic irritability (3). Mouth changes include excessive flow of saliva, metallic taste, soft and spongy gums, and loose teeth. Muscular tremors usually come on slowly and first affect the muscles of the eyelids, tongue, and fingers. Later, tremors spread to the arms and legs; walking becomes difficult and handwriting is changed to a jerky scrawl so characteristic that periodic recording of hendwriting is used to detect early evidence of chronic mercury polsoning. Psychic irritaility or erethism is a mental disturbance characterized by an apprehensive timidity, shrinking from observation, sense of discouragement, 1088 of self-confidence; overreaction to criticism, loss of memory, and abnormal sleep patterns $(3,4)$.

Diagnosis of chronic mercury poisoning is not easy because of the nonspecificity of symptoms at low levels. Workers exposed to low concentrations of mercury vapor as a group show a linear relationship between urine mercury levels and the time-welghted average concentration to which they were exposed. However, a consistent relationship was not seen until after one year of exposure. Blood mercury levels are indicative only of recent exposure, since this metal is cleared rapid1y from the blood. However, mercury may persist in the blood stream long enough to cross blood-brain and placental barriers (3). 
Other Forms of Mercury

All forms of mercury are polsonous if absorbed (7). mucury toxicity depends on a single basic mechanism: the mercuric ion acts to precipitate proteln and to inhibit enzymes containing sulfhydryl groups (3). Exposure to mercuric salts, phenyl mercuric and methoxy methyl mercuric compounds, whether by inhalation or Ingestion, leads to kidney damage (4). Methyl mercury and other short-chain alkyl-mercury compounds are virulent neurotoxins upon either acute or chronic exposure and are especially hazardous because of their ability to rapidly penetrate the blood-brain barrler and the placenta $(1,7)$. Fetal methyl mercury poisoning (manifested by microcephaly and cellular changes in the brain) has been reporced by mothers showing no clinical evidence of polsoning (4). The relationships between intake of methyl mercury and concentrations in blood and hair have been studied in populations which have ingested methyl mercury-contaminated fish in Japan and contaminated bread in Iraq (4). The effects of methyl mercury have been found to be critically dependent on the dose, that is, the dose-response curve appears to be very steep (7). However, the amount of mercury needed to produce disease is not known and there is no specific biochemical test for a diagnostic aid (5).

\section{References}

1. ACGIH. 1980. Documentation of the threshold limit values. Fourth Edition. American Conference of Governmental Industrial Hygienists Inc., $\mathrm{OH}$.

2. Dreisbach, R.H. 1980. Handbook of Polsoning. Lange Medical Publications, Los Altos, CA.

3. Finkel, A.J. 1983. Hamilton and Hardy's Industrlal Toxicology. 4th edition, John Wright, PSG Inc., Littleton, MA.

4. Kazantz1s, C. 1980. Mercury. In H.A. Waldron, editor. Metals in the Environment. Academic Press, New York, NY.

5. National Academy of Sclences. 1977. Drinking Water and Health.

6. Rumack, HTEX.

7. Therapeutics Index. 


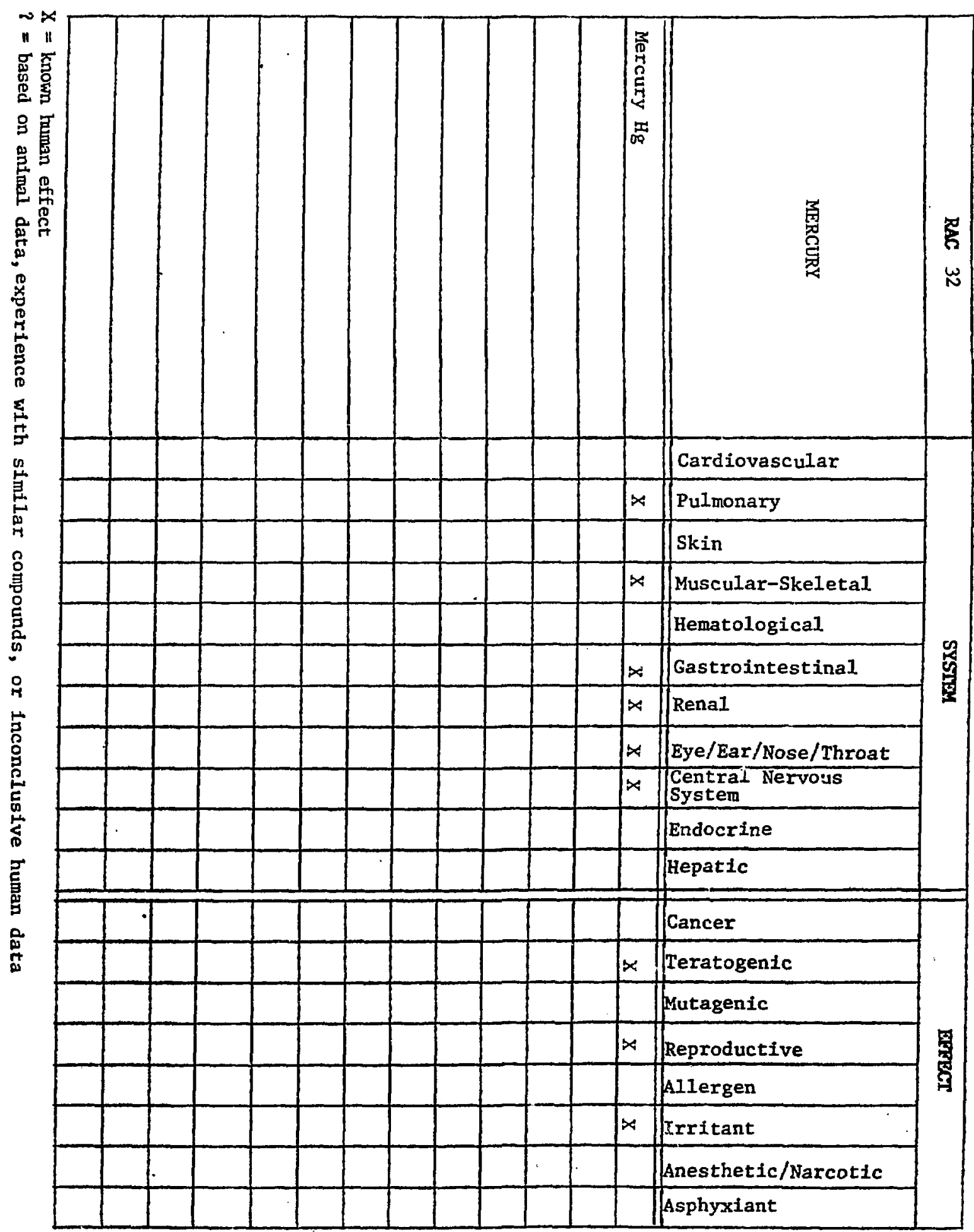


RAC \#33 - NICKEL

Nickel is a metallic element used in making high temperature and corrosion-resistant alloys (e.g., stainless steel) for numerous end-use products and in multiple industries, including welding, electroplating, products of catalysts, and storage batteries. Nickel occurs in nature primarily as elther oxide (laterite) or sulfide ore.

Water-insoluble nickel compounds include the oxides, $\mathrm{NiO}, \mathrm{Ni}_{2} \mathrm{O}_{3}$, carbonate, and sulfide. Trinickel disulfide $\left(\mathrm{Ni}_{3} \mathrm{~S}_{2}\right)$ is encountered in the refining of certain nickel ores. Soluble salts of nickel include chloride, sulfate, and nitrate.

The general population comes in contact with nickel through air, water, foodstuffs, soil, artifacts such as coins, nickel-plated jewelry, utensils, and cigarettes (two packs of cigarettes contain 3 to $15 \mu \mathrm{g}$ of nicke1). Daily dietary intake of nickel averages 165 to $500 \mu \mathrm{g}$. Concentrations in water range from 0.4 to $5.1 \mathrm{\mu g} / 1$. Air concentrations range from 0.002 to $0.008 \mu \mathrm{g} / \mathrm{m}^{3} \mathrm{in}$ nonurban air and an average of 0.021 $\mu \mathrm{g} / \mathrm{m}^{3}$ In urban air. Concentrations in soil vary from 5 to $5000 \mathrm{ppm}$ (4). Normal body serum concentration of nickel is 0.8 to $4.2 \mu \mathrm{g} / 1$ (5).

\section{Acute Effects}

Documented health effects from nickel or nickel compounds are the results of airborne inhalation. The toxicity level of nickel through oral intake is low, since there appears to be a mechanism in mamals that limits intestinal absorption of nickel (2). Symptoms of nickel toxicity from ingestion are malnly gastrointestinal irritation.

There are scattered reports of patients on kidney dialysis developing hypernickelemia, thought to be due to nickel leaching out of the nickel-plated stainless steel water heater tanks used in dialysis. Symptoms, which include nausea, vomiting, headaches, and palpitations, usually resolve 3 to 13 hours after the dialysis. There have also been reports of patients who have developed dermatitis or allerglc asthma after Implantation of a nlckel-containing prostheses (5).

Albumin and amino acids bind readily to nickel and therefore nickel may be a contaminant in intravenous solutions. Up to 235 ug of ntckel may be 
contained in a liter of albumin solution. Since nickel may increase coronary artery resistance and can have an oxytoclc effect on the uterus, it could have adverse effects on patients with acute myocardial infarctions and on pregnant women (5).

Nickel carbonyl $\left[\mathrm{Ni}(\mathrm{CO})_{4}\right]$, formed by the reaction of carbon monoxide with finely divided nickel is the only nickel compound known to have acute toxic effects. However, studies have not indicated whether nickel, carbon monoxide, or the combination is the primary cause of these effects. Exposure to $30 \mathrm{ppm}$ of nickel carbonyl for 30 minutes may be fatal. Initial symptoms are mlld and transitory and include frontal headache and nausea, possibly accompanied by vomting, dizziness, and occasionally sternal and epigastric pain. If exposure is severe, the initial symptoms are soon followed by other effects such as a cough, hyperpnea, cyanosis, pronounced weakness, and gastrolntestinal symptoms. In extreme cases pneumonia, delirium, and death can occur (6).

\section{Chronic Effects}

Resplratory effects such as pulmonary irritation, asthmatic-1ike lung disease, pneumoconiosis, pulmonary edema, and pulmonary fibrosis have been reported in workers exposed to nickel dust and fumes. These exposures, though, were compounded by concurrent exposures to other compounds (1). Changes in olfactory function, rhinitis, erosions, perforations, and ulcers of the nose have been observed in workers employed in the electrolytic refining of nickel and in nickel refineries.

Epidemiological studies have conclusively denonstrated an excess risk of cancer of the nasal cavity and lungs in nickel refinery workers. The cancer hazard seems to be assoclated with the early years of nickel refining which involved heavy exposure to dust from relatively crude nickel ore. Suspicion of cancer has been focused primarily upon respirable particles of nickel subsulfide and nickel oxide, and upon nickel carbonyl vapor $(3,5 \mathrm{~A})$.

A TLV of $0.1 \mathrm{mg} / \mathrm{m}^{3}$ has been set for nickel metal and insoluble compounds of nickel. A TLV of $0.1 \mathrm{mg} / \mathrm{m}^{3}$ and an STEL of $0.3 \mathrm{mg} / \mathrm{m}^{3}$ has been set for soluble inorganic nickel compounds.

For nickel carbonyl, the TLV is 0.05 ppm and for nickel sulfide roasting, dust, and fumes, the TLV is $1 \mathrm{mg} / \mathrm{m}^{3}$. 


\section{References}

1. Amblent Water Quality Criteria for Nickel. 1980. U.S. Environmeital Protection Agency, Washington, DC.

2. Drinking Water and Health, Vol. 3. National Research Counc11. National Academy Press, Washington, DC, 1980. pp. 345-350.

3. International Agency for Research on Cancer. 1979. IARC Monographs on the Evaluation of Carclnogenic Risk of Chemicals to Man. World Health Organization.

4. NIOSH. 1977. Criterla for a recommended standard...occupational exposure to Inorganic nickel, 1977 (pps. 77-164). National Institute for Occupational Safety and Health, U.S. Department of Health, Education, and Welfare, Hashington, DC.

5. Nurses' Drug Alert. 1983. Hazards of Nickel. Am. J. of Nursing 9: $1,328-9$.

5A. U.S. Department of Health and Human Services. 1981. Second Annual Report on Carcinogens. Public Health Service.

6. Waldron, H.A., ed. Metals in the Environment, Academic Pres, NY. 1980, pp. 269-286. 


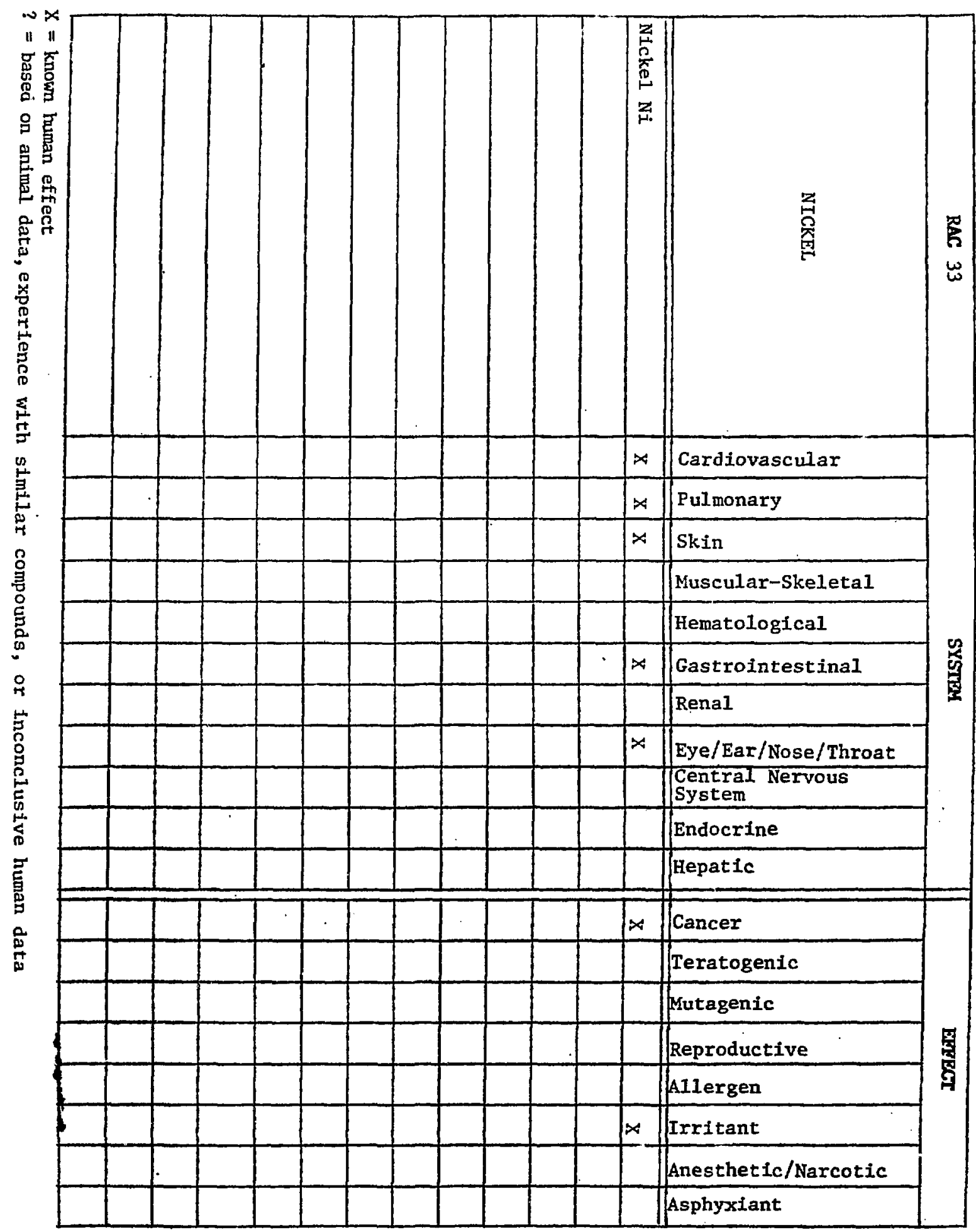


Cadmium is a nutritionally non-essential but ubiquitous trace element that occurs naturally at low levels in the food chain. Smelters processing zinc, lead, and copper ores are the prime source of environmental cadmium contamination (11). Other significant and widespread sources include incineration of waste materials, burning of fossil fuels, use of phosphate fertilizers, and disposal of sewage sludge ( 7 ). Human exposure to cadmium occurs through inhalation, ingestion, or skin absorption, although the last appears to occur very rarely and only under very limited occupational circumstances. Inhalation is the more efficient route of absorption and is of primary interest from an occupational standpoint. However, except for cigarette smoking (cigarettes contain approximately $1.7 \mathrm{\mu g} \mathrm{Cd} /$ cigarette), ingestion is the major route to the total body burden in the general public (8). Although acute and chronic effects on humans are well documented from occupational studies, 1ittle is known about the chronic toxic effects of cadmium as normally encountered in food, air, and water. Also, in occupational studies, the actual dose recelved or Iength of exposure is not always reported.

The current drinking water standard in the USA is $0.01 \mathrm{mg} /$ liter. The ACGIH (1) suggests a threshold limit value of $0.05 \mathrm{mg} / \mathrm{m}^{3}$ for the oxide and salts and a ceiling value of $0.05 \mathrm{mg} / \mathrm{m}^{3}$ for fumes. NIOSH (1976) has proposed a workplace time-weighted average $11 \mathrm{mit}$ of $0.04 \mathrm{mg} / \mathrm{m} 3$ for both fumes and dusts, and a short-term $11 \mathrm{mit}$ of $0.2 \mathrm{mg} / \mathrm{m}^{3}$ for not more than 15 minutes.

\section{Acute Effects}

Inhalation overexposure to cadmium fumes may produce symptoms, usually delayed for several hours, which include severe tracheo-bronchitis, pneumonitis, and pulmonary edema with a mortality rate of about $20 \%$. Fatalities have occurred at concentrations of about $8 \mathrm{mg} / \mathrm{m}^{3}$ for five hours. The lethal dose of cadmium oxide is about 2500 to $2900 \mathrm{mg} \mathrm{min} / \mathrm{m}^{3}(2-4)$ or 5 $\mathrm{mg} / \mathrm{m}^{3}$ (6) for an average $8-\mathrm{hr}$ working exposure (8). Mild pneumonitis 
occurs between $0.5 \mathrm{mg} / \mathrm{m}^{3}$ and $2.5 \mathrm{mg} / \mathrm{m}^{3}$ for a 3 -day period. The no-effect threshold for cedmim oxide fume is estinated to be $<1 \mathrm{mg} / \mathrm{m}^{3}$. The acute effects of other Cd compounds in man ( $\mathrm{CdCl}_{2}, \mathrm{CdS}$, etc.) via inhalation have not been reported in the literature (8). Acute oral intoxication results in severe nausea, vomiting, diarrhea, muscular cramps, and salivation. This may be followed by shock and death within 24 hours. Acute renal failure and cardio-pulnonary depression followed by death may occur in 7 to 14 days. A rough scale of acute oral toxicity of Cd in man 18 presented in Table 2.

Table 2. Oral Toxicity of Cadmium in Man (8)

\begin{tabular}{cl}
\hline Dose (mg) & \multicolumn{1}{c}{ Effects } \\
\hline $3-90$ & Emetic threshold \\
& Reported nonfatal 1ncidents \\
15 & Experimentally 1nduced vomiting \\
$10-326$ & Severe toxic symptoms but not fatal \\
$350-3500$ & Estimated lethal doses \\
$1530-8900$ & Reported lethal doses \\
\hline
\end{tabular}

Chronic Effects

The earliest and most distinctive indication of chronic effects of cadmium exposure is renal tubular dysfunction characterized by proteinuria $(7,10)$. Other chronic effects include liver damage, emphysema, osteomslecia, neurological Impalrment, anemia, and testicular, pancreatic, and adrenal damage. The Inhabitants of a region in Japan, after prolonged consumption of cadmium-contaminated water and rice crops, were struck by severe osteomalacia ("Itai-ital" disease) characterized by lower back and leg pain (7). Recent evidence suggests that a strong nutritional deficiency may have played an Important role however.

Chronic cadmium polsoning once established may progress without further exposure. Thus, workers exposed to $0.1 \mathrm{mg} / \mathrm{m}^{3}$ or 1 ess may experience effects a decade 1ater. 
Although the analysis of cadmium in blood, urine, and hair can be routinely performed, Ellis et al. (5) Indicate that these biological monitors of exposure are not reliable Indicators of body burden for the individual worker, and direct $\underline{\text { In }}$ vivo measurements of kidney and liver cadmium provide more accurate indices of cumulative exposure.

There is some evidence that high blood pressure is related to the body burden of cadmium. This relationship is still controversial, however (12).

A possible increase in prostatic malignancies in workers has also been reported. However, the small numbers involved, the Influence of unmeasured factors such as smoking or marital status, and the frequency of the disease In the general population make the relation uncertain (9).

\section{References}

1. ACGIH. 1980. Documentation of the threshold limit values. Fourth Edition. American Conference of Governmental Industrial Hyglentsts Inc., ОН.

2. Barrett, H.M., D.A. Irwin, and E. Semmons. Studies on the toxicity of inhaled cadmium. $I$. The acute toxicity of cadmium oxide by Inhalation. J. Ind. Hyg. Toxicol. 29: 279.

3. Barrett, H.M. and B.Y. Car1. 1947b. Study on the toxicity of Inhaled cadmium II. The acute lethal dose of cadmium for man. J. Ind. Hyg. Toxico1. 29: 279.

4. Benton, D.C., G.S. Andrews, H.J. Davies, L. Howe11s, and G.F. Smith. 1966. Acute cadmium fume polsoning, five cases with one death from renal neorosis. Brit. J. Med. 23: 292.

5. E1118, K., S. Yasumura, D. Vartsky, and S. Cohn. 1983. Evaluation of blological indicators of body burden of cadmium in humans. Fundamental and Applied Toxicology 3: 169-74.

6. Friberg, L. Proteinurla and kidney injury among workmen exposed to cadmium and nickel dust. 1948. J. Ind. Hyg. Toxicol. 30: 32 .

7. Lee, J.S. and K.L. White. 1980, A Review of the Health Effects of Cadmium. Am. J. Ind. Med. 1:307-317.

8. Novak, K.M. 1980. Toxiclty of Cadmlum and Its Compounds: A Review of the Literature Almed at Identffying Dose-Response Relationships, BNL 51511.

9. Plscator, M. 1981. Role of cadmium in carcinogenesis with special reference to cancer of the prostate. Env. Health Persp. 40: 107-20. 
10. Smith, T.J., R.J. Anderson, and J.C. Reading. 1980. Chronic Cadmium Exposure Associated with Kidney Function Effects. Am. J. Ind. Med. 1:319-33.

11. Waldron, H.A. (ed.). 1980. Metals in the Environment. Academic Press, New York, N.Y. PP. 61-110.

12. Yasumura, S., D. Vartsky, K.J. E11is, and S.H. Cohn. 1980. Cadmium in human beings. IN: Cadmlum in the Environment, Part I. J. Nriaga (ed.), John Wiley and Sons, Inc. 


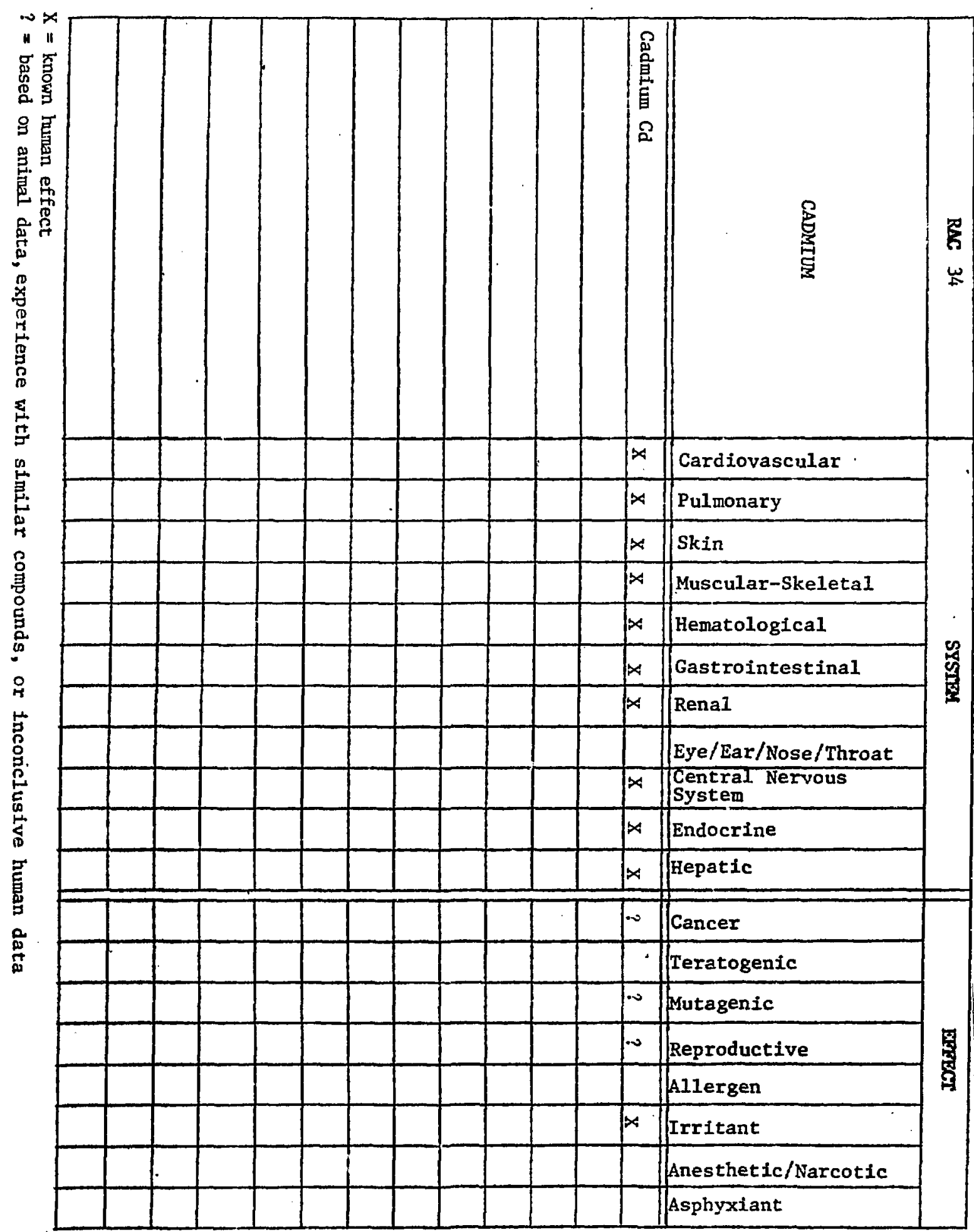


Lead is a toxic netal with no known essential function in nan. Its use as an antiknock additive in gasoline represencs a major fraction of lead use in the United States, and motor vehicle emissions constitute the primary source of lead to the environment (1). Combustion of waste ofl and solid wastes are major stationary sources of lead, along with iron and steel plants, smelters, battery manufacturing, and alkyl lead production. Although humans can be éxposed to lead via food, drink, or Inhalation, uptake with food predominates under most conditions. About 200 to $300 \mathrm{\mu g}$ of lead are taken up dally with food. Of that ingested, about 5 to $10 \%$ is absorbed by adults and somewhat more (up to 50\%) by children, depending on dlet. Besldes matural levels, lead is introduced by processing, packaging, and raw food stock. Lead in paint makes it available by ingestion, especially to young children (1). Also, in regions of soft water, lead may leach from the plumbing.

Inhalation of airborne lead is of great concern and has led to measures liwiting the lead content of gasoline. An average of 10 to $30 \mu \mathrm{g}$ of lead is inhaled dally, although this value may be much higher in urban areas. Inhaled lead is much more efficiently absorbed - up to $50 \%$ - than is ingested lead (5). The highest and most prolonged exposures to lead are found among workers in the lead smelting, refining, and manufacturing industries (1). In work areas, the major routes of exposure are by Inhalation and ingestion of lead bearing dusts and fumes.

Lead effects on humans have been well studled. Controlled environment laboratory studies on human volunteers have been performed (7). Also epidemiological observations of populations living in areas with differing air lead levels and occupationally exposed workers have been done. The ACGIH TLV for lead is $0.15 \mathrm{mg} / \mathrm{m}^{3}$ and the STEL $180.45 \mathrm{mg} / \mathrm{m}^{3}$ (2). The National Ambient Air Quality Standard (NAAQS) for lead $1 \mathrm{~s} 1.5 \mathrm{\mu g} / \mathrm{m}^{3}$ over a 3-month period.

\section{Acute Effects}

Acute lead poisoning is very rare. Ingestion of large amounts of any soluble lead salt (especially acetate, carbonate, or chromate) results in 
irritation of the alimentary tract. If absorption is sufficient, then pain, leg cramps, muscle weakness, paresthesia, depression, coma, and death may follow within one or two days. The dose for fatal polsoning is usually greater than $30 \mathrm{~g}$. Encephalopathy is a complication in about $50 \%$ of lead polsoning cases, and the mortality rate among these is $25 \%$. Of those that recover, about one-third may have permanent neurological damage (9).

Chronic Effects

Characteristic symptoms of lead poisoning are produced in the hematopoletic system, central and peripheral nervous system, and kidneys. Although more than $90 \%$ of the lead body burden in man is contained in the bones, this lead is considered to be metabolically and probably also toxicologically Inert (5). Blood lead levels are sensitive indicators of recent exposure. Normal blood levels are about 200 ppb; subclinical symptoms are noted in particularly sensitive persons at 400 to $600 \mathrm{ppb}$, and clinical symptoms can arise at more than $600 \mathrm{ppb}$ (5). The subclinical effects of lead exposure are mainly neurological, including altered nerve conduction time, electromyographical abnormalities, behavioral disorders, and Impairment of hand-eye coordination. Assoclations with mental retardation and hyperactivity have been reported, but not conclusively demonstrated (3).

Chronically exposed smelter workers have been shown to have a substantlally excess number of deaths from chronic renal disease, cerebra]. hemorrhage, and hypertension (6). There is no convincing epidemiological evidence that lead causes cancer in man. However, induction of renal tumors has been demonstrated in laboratory animals (4).

Evidence indicates that among human populations the fetus and young children, particularly those under 3 years old, have an increased risk of experiencing adverse effects from lead exposure as a consequence of a higher rate of intestinal absorption and a high rate of brain growth and maturation (4). Roels et al. (8) showed sensitivities to lead to be of the order childrer: > women > men. The U.S. National Academy of Sclences (4) mentions several sources of data on dose-response relationships for lead in men, but states that data are lacking for Infants, preschoolers, and pregnant women. 
The effects of organic lead compounds are slightly different from those of Inorganic lead. Since organic lead compounds are lipid-soluble, they accumulate preferentially in the nervous system and can cause disturbances in sleep patterns, hallucinations, anorexia, vomiting, vertigo, muscular weakness, and tremor (5).

\section{References}

1. Air Quality Criteria for Lead, EPA-600/8-77-017, December 1977.

2. ACGIH Documentation of TLV, 1980, pp. 243-5.

3. Chemical Contaminants in Nonoccupationally Exposed U.S. Residents, EPA-600/1-80-001, May 1980.

4. Drinking Water and Hea1th, National Academy of Sciences, 1977, Washington, DC.

5. Gerber, G.B., A. Leonard, and P. Jacquet. 1980. Toxicity, Mutagenicity and Teratogenicity of Lead. Mutation Research 76: 115-41.

6. McMlchael, A.J. and H.M. Johnson. 1982. Long-Term Mortality Profile of Heavily-Exposed Lead Smelter Workers. J. Occup. Med. 24(5): 375-8.

7. Rabinowitz, M., G.W. Wetherill, and J.D. Kopple. 1974. Studies of Human Lead Metabolism by Use of Stable Isotope Tracers. Environ. Health Persp. 145-53.

8. Roels, H., J.P. Buchet, R. Laruverys, and G. Hubermont. 1976. Impact of Alr Pollution by Lead on the Heme Blosynthetic Pathway in School-Age Children. Arch. Environ. Health: 310-6.

9. Therapeutics Index, p. 194. 


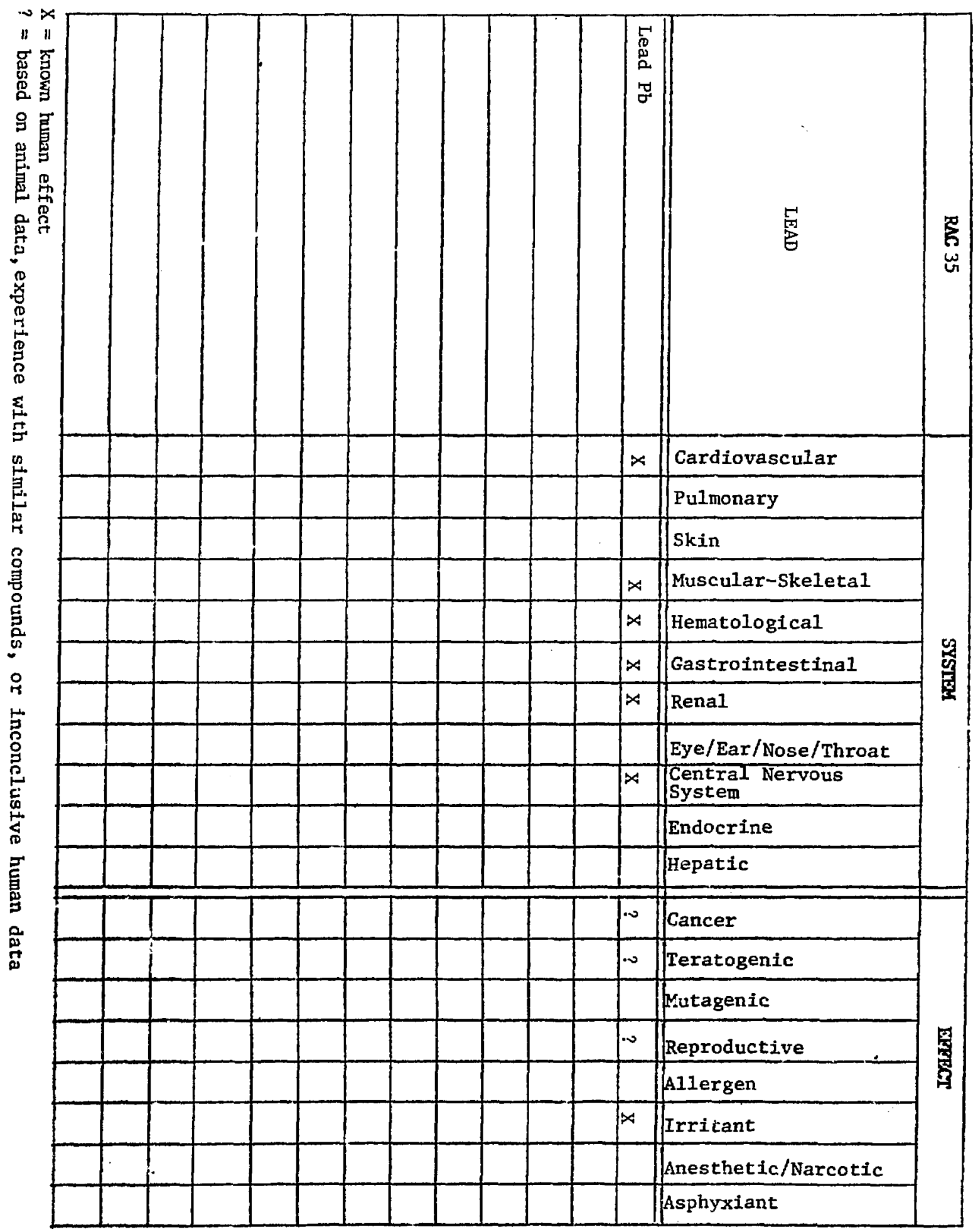


RAC \#37 - IONIZING RADIATION

\section{Definftions}

Radiation has been defined $(3, \mathrm{p} .45)$ as the emission and propagation of energy through matter or space by means of electromagnetic disturbances (gamma radioactivity, xrays, 11ght, microvaves, radiofrequency transmissions, etc.). The term has been extended to include streams of fast-moving particles (alpha and beta radloactivity, free neutrons, cosmic adiation, etc.). Nuclear radiation is that emitted from atomic nuclei in various nuclear reactions. Substances that spontaneously produce such emfssions, chiefly alpha, beta, and gamma radiation, and neutrons, are called radioactive.

Alpha particles are the nuclei of normal helium atoms, consisting of two protons and two neutrons. Because of their Inability to penetrate even a layer of air, alpha particles cannot be considered a hazard to human health unless emitted inside the human body as a result of ingestion or Inhalation of radioactive materials. Beta particles are electrons for positrons, their antimatter analog) and also have low penetrating power. Gamma rays are the highest-frequency form of electromagnetic waves. Neutrons are one of the constituents of atomic nuclei, the neutral (uncharged) analog of the proton. Gamma rays and neutrons exhibit varying degrees of penetrating power depending on their energies, and thus external sources of these are of concern for human health.

Ionizing and Non-Ionizing Radiations

Ionizing radiation displaces electrons from atoms or molecules, thereby producing lons ( 3 , p. 28). Charged particles (e.g., alpha and beta particles) and electromagnetic radiation above a certain frequency (short-wave ultraviolet 1ight, xrays, etc.) can directly ionize atoms. In addition, certain neutral particles (e.g., neutrons) can have significant indirect lonizing effects.

Non-ionizing radiation includes electromagnetic waves of lower frequency (longer wavelength) at all but the highest field strengths. 
Examples include visible light, microwaves, radio frequency transmissions, and radiation from electrical distribution networks.

Only the human health effects of ionizing radiation are covered in this review.

Primary Biologica1 Mechanisms

Ionizing radiation can directly disrupt cell nuclear material (DNA and RNA). More 1ikely is the production (primarily from water) of free radicals. These in turn can disrupt, permanently or temporarily, the normal functioning of the cell.

Gamma rays and leptons (electrons and muons) generally interact with cellular material via ionization only. Other forms of radiation (e.g., neutrons, protons, and alpha particles) also can interact directly with the nucleus of atoms transmuting the nucleus and in the process emitting more Ionizing radiation.

Units

The field of radiation protection has many special units. The most important and common ones are those measuring (radio)activity, absorbed dose, and biologically effective dose.

Activity. Activity refers to the number of nuclear disintegrations per unit time. It is proportional to the number of radioactive nuclei present divided by the half-life of that particular nuclide. The historic unit is the curie $\left(C_{1}\right)$ equal to $3.7 \times 10^{10}$ disintegrations per second. The SI (Systeme Internationale) unit is the becquerel (Bq) equal to 1 disintegration per second $\left(1 \mathrm{~Bq}=2.7 \times 10^{-11} \mathrm{CI}\right.$ ). 
Absorbed Dose. Absorbed dose is the energy deposited by lonizing radiation per unit mass of absorbing material (e.g., tissue). The rad is equal to $100 \mathrm{erg}$ per gram. The SI unit gray (Gy) is 1 joule per kilogram $(1 \mathrm{~Gy}=100 \mathrm{rad})$.

Blological Dose Equivalent. The human health effects for a given absorbed dose depends on the type of radiation Involved (alpha, gamma, etc.) and possibly the temporal distribution of that dose (e.g., whether single exposure or protracted over 11fetime). Multiplication of absorbed dose by factors measuring relative blological effectiveness of a radiation type $(Q)$ and measuring relative temporal effectiveness as well as other modifying considerations such as spatial distribution within the tissue (N) ylelds a dose which is independent of radiation type and temporal distributions (all other relevant factors being equal).

The historic unit is the rem (radiation equivalent man) and the SI unit is the slevert (Sv) (1 Sv = $100 \mathrm{rem}$ ). Since the multiplicative factors are dimensionless, the gray and slevert (or rad and rem) possess the same fundamental units but measure distinctly different quantities.

Effective Dose Equivalent. Finally, the dose equivalent received by each organ (tissue) can be welghted by a factor (w) which measures relative sensitivity of the tissue to radiation-induced cancer. If the results are summed over all tissues, the result is termed the effective dose equivalent to the whole body. The units are the same as dose equivalent, so care must be taken to understand which quantity is being measured.

Association of Types of Effects With Dose Leve1

Acute, nonstochastic human health effects are assoctated with high dose levels of lonizing radiation. On the other hand only chrontc, stochastic effects are associated with low levels. It is understood that 
if an Individual survives a high radiation dose, stochastic effects may subsequently develop.

Following a discussion of sources, the remainder of this article is divided Into two sections, one on high-dose effects and the other on possible low-dose effects. Speclallzed terms are defined, dose level ranges Indicated, possible human health effects enumerated, dose-response functions, if any, given, and appilcable federal protection standards listed.

Sources and Natural Background

Humans are, and always have been, exposed to radiation of a natural (not man made or induced) origin. The sources of natural irradiation can be grouped into three general categories, each of which can be further subdivided (1).

Primary cosmic rays are extraterrestrial elementary particles (e.g., protons). These cannot penetrate the earth's atmosphere to sea level, but primary cosmic rays can also interact with the atmosphere producing, directly or indirectly, penetrating secondary cosmic rays (e.g., mumesons). Cosmic rays irradiate the whole body.

Interactions of cosmlc rays can also produce so-called cosmogenic radionuclides. After being produced, these nuclides distribute in the biosphere and eventually contribute to the Internal irradiation of humans. The most 1mportant cosmogenic radionuclides are carbon-14, beryllium-7, sodium-22, and hydrogen-3 (tritium).

The final group is the primordial radionuclides. These long-1ived nuclides have been present since the formation of the earth. They in turn can be divided into two parts: (a) 1 ight radionuclides (e.g., potassium-40 and rubidium-87), and (b) the naturally occurring decay chains, those headed by urantum-238, uranium-235, and thorlum-232. Gamma-ray decays of any of these radionuclides externally irradiate the body; any decay mode internally irradiates.

The following table summarizes the typical amount of erfective dose equivalent from each of the groups. There are very large variations from location to location. 
Estimated per Caput Annual Effective Dose Equivalent From Natural Sources in Areas of Normal Background (2)

\begin{tabular}{|c|c|c|c|}
\hline \multirow[b]{2}{*}{ Source } & & \multicolumn{2}{|c|}{ Effective dose equivalent } \\
\hline & & $m S v a^{-1}$ & rem/year \\
\hline Cosmic rays & & 0.301 & 0.0301 \\
\hline Cosmogentc radionuclides & & 0.015 & 0.0015 \\
\hline \multicolumn{4}{|l|}{ Primordial radionuclides } \\
\hline \multirow[t]{2}{*}{$\begin{array}{l}40_{\mathrm{K}},{ }^{87} \mathrm{Rb} \\
238_{\mathrm{U}}, 235_{\mathrm{U}} \text { series } \\
232_{\mathrm{Th}} \text { series }\end{array}$} & & $\begin{array}{l}0.306 \\
1.044 \\
0.326\end{array}$ & $\begin{array}{l}0.0306 \\
0.1044 \\
0.0326\end{array}$ \\
\hline & Total & 2.0 & 0.200 \\
\hline
\end{tabular}

By far the largest man-made source of human 1rradiation is medical diagnosis and therapy. On a per caput basts, medical exposures amount to about $20 \%$ of the magnftude of natural exposure. In contrast, the other sources 1isted below are of the order of $1 \%$ of natural exposure.

coal contains trace amounts of the uranium and thorlum series radionuclides, and potassium-40 at levels comparable to normal soll. When pulverized or burned, the contalned radon (a radioactive noble gas) is released to the atmosphere. The ash content of coal is about $10 \%$. Therefore, the radionuclide concentration in bottom ash will be ten times the level in the original coal. Concentration of certain radionuclides may be even higher in $f l y$ ash because of enhancement mechanfsms. Humans may be exposed to minute levels of radiation if exposed to materials made from coal ash or from fly ash emitted to the atmosphere.

Other non-nuclear energy sources with related radloactivity are geothermal energy and natural gas. In the case of geothermal power plants, some radon is emftted to the atmosphere causing slightly elevated exposures to the local population. The burning of natural gas can elevate radon levels in unventilated kitchens. 
Another cause of enhanced exposure to radon similar to the situation with cooking with natural gas is the fact that some present day populations of humans live in relatively tight houses. This allows radon and its radioactive daughters which emanate frow underneath the house or from building materlals to bulld up to levels well above ambient outdoor levels. Gama-ray-emitting nuclides in building materials, especially those of the uranium and thorlum serles, Irradiate humans directly.

Phosphate rock generally contains concentrations of the uranium-238 serfes nuclides about twenty times that of normal soll. Enhanced human exposure is assoclated with the processing of phosphate ore, espectally the production of elewental phosphorus, the use of fertilizer, and the use of by-product gypsum.

Cosmic-ray flux Increases with altitude. Therefore, alrcraft passengers and alrline employees experience higher exposure to cosmic rays during flights, as do people living at high altitudes.

Finally, there may be exposure assoclated with miscellaneous products or devices: $x$-rays from television sets or scanning devices, radioluminous devices, heart pacemakers, smoke detectors, etc. Some of these sources Involve man-made radionuclides, for example, americlum-241 used in many smoke detectors.

Nuclear energy technologies produce radioactive substances found in nature only at infinitesimally small levels. Nuclear fission ylelds f1ssion products (e.g., strontium-90, lodine-131), transuranic radionuclides (neptunium, plutonium, etc.), and neutron-induced radionuclides (e.g., manganese-54, nicke1-63). Nuclear fusion produces (or uses as fuel) very light radionuclides and also induces radionuclides by neutron activation. The supply side of the nuclear fuel cycles release sma1l amounts of the naturally occurring uranlum and thorlum-232 decay serles. Reactor operation, fuel reprocessing, and decomissioning involve very small releases of fission products, transuranics, and Induced radionuclides. Only in nuclear war, an unusual occurrence connected with an atmospheric test of a nuclear device, or a very severe accident at a nuclear power plant from which the Immediate population 18 not evacuated, can exposure of any member of the general population be significant, that Is larger than one year's equivalent of natural background. 
Certain occupational categorles can be exposed to annual extra doses of radiation comparable to natural background. These jobs are related to the production of or products of nuclear fission, scientific research, $x$-ray machines, or high altitude flight.

\section{Standards}

National regulatory bodies have adopted comparable standards for radiation protection. An effective dose equivalent of $50 \mathrm{mSv}$ ( $5 \mathrm{rem}$ ) per year is the occupational dose 1imt. Exposure of any Individual of the general public should not exceed $50 \mathrm{~Sv} \mathrm{a}^{-1}\left(5_{\mathrm{m}} \mathrm{rem} / \mathrm{yr}\right)$ from the routine emissions of regulated sources. Actual exposures are generally an order of magnitude lower than the regulations. Guldelines state that in no instance shall a dose to an Indivydual exceed $5 \mathrm{mSv}$ (500 mrem). There are exceptions to and varlations on the general guidelines which involve the particular type of radiation, the target or critical organ, the specific radionuclides involved, the age and sex of the Individual, and even the source of the radiation. For example, nuclear power plants are regulated, but radioactive emlssions from coal burning plants and medical exposures are not.

\section{Acute Effects}

Acute effects of irradiation are nonstochastic in nature. There is usually a threshold below which no clinical effects would be observed in any human belng. As the dose level is increased, all human beings would exhibit about the same degree of effect at a given dose and the severity of the dose would Increase with Increasing dose.

In addition to dependence on total dose, the severity of the effect usually depends on the rate at which the dose was applied and the fraction of the organ in question irradiated. Severity increases with dose rate and fraction irradiated.

Finally, certain nonlethal acute effects may continue at some level to normal end of life (e.g., loss of hair). And, if the person does survive the acute effects, he will be at risk from the stochastic health effects described later. 
This summary of acute effects of radiation below is taken from the Reactor Safety Study (4).

When exposed to a very large dose of whole-body irradiation, death is most likely to occur from damage to the red bone marrow (acute anemia) in combination with damage to the lymphold tissue (reduced defense to infection) and damage to the vascular system (increased bleeding hazard). There is general agreement that in the absence of special treatment the 60 -day $L D_{50}$ is in the range 300 to $400 \mathrm{rad}$. The $L D_{10}$ to $L D_{90}$ range is about 200 to $500 \mathrm{rad}$. No deaths are expected below about $150 \mathrm{rad}$. The exception is prenatal death. One day after conception the median lethal dose is about 85 rad, with a minimal lethal dose as low as 10 rad. The sensitivity of the embryo/fetus decreases to adult values by the end of term.

With extensive medical treatment the 60-day $L D_{50}$ can be increased to almost 1000 rad. Treatment includes transfusions, bone marrow transplants, antibiotics, and protection from infection.

Chronic Effects

The two chronic effects of most concern in relation to radiation are cancer and, so-called, genetic effects, that 1s, adverse iealth consequences in the offopring of the irradiated person. At this time it is impossible to determine either experimentally or epidemiologically what the probebility of the effects are at very low dose levels ( 1 rem and below). In the absence of definitive data, observed effects in humans (or animals) from high doses of irradiation are extrapolated downwards. Especlally significant in this regard have been the Japanese survivors of the atom bomb, groups with large medical exposures, and certain spectal occupationai groups, e.g., radium dial painters and uranium miners. Since excess effects to an extra dose (of say 10 mrem) are unknown, much controversy exists on whether the extrapolation predictions are ten times too low, or ten times too high, or more.

Different tissues have shown difierent sensitivitles to radiationInduced cancer. Especially prominent at high doses have been female breast cancer, leukemia due to whole-body irradiation or bone seeking radionuclides, and lung cancer due to inhalation of radioactive materials. 
The BEIR III Comfttee (NAS 80) dose-response function at low doses for cancer mortality, based on the Japanese survivors, is $67 \times 10^{-4}$ per sievert effective dose equivalent using a Iinear-quadratic fit to the data and an absolute risk projection. Using a linear fit and a relative risk projection, the dose-response coefficient is $430 \times 10^{-4}$ per sievert. An even lower value would be obtained with a pure quadratic fit. The shape of the dose-response curve is certainly not universal over all radiation types (e.g., gamma vs aipha emissions) or all tissues. The dose-response for nonfatal cancers is comparable but even more uncertain.

Genetic disorders in humans due to low levels of extra radiation is an even harder fleld of study. Extrapolating primarily from high-dose animal data BEIR III estimated a first generation increase of 5 to $75 \times 10^{-4}$ serious genetic disorders in liveborn offspring per sievert of parental exposure. At genetic equilibrium, the figure is 6 to $110 \times 10^{-3}$ per sievert received in each generation.

Disruption of the normal proliferaton of the intestinal eptthelium may be fatal. Mortality from this cause comnences at doses above 1000 rad whole body or 1500 rad to the abdomen.

Nonlethal health effects include the prodromal symptoms, a generic term for anorexia, nausea, vomiting, and diarrhea associated with radiation exposure. About half the exposed people will show prodromal symptoms at an Instantaneous dose of 200 rad.

Other nonlethal effects are radialion dermatitis, loss of hair, cataracts, impairment of the immune system, male fertility impairment, and congenital malformation and growth retardation in the prenatally exposed. There are no established effects ouserved below 100 rad except that decreased sperm count has been observed at levels as low as 10 rads.

References

1. Eichholz, G.G. 1976. Environmental aspects of nuclear power. Ann Arbor Science Publishers, Ann Arbor, MI.

2. UNSCEAR. 1982. Ionizing radiation: Sources and biological effects. United Nations Scientific Comittee on the Effects of Atomic Radiation, New York, NY.

3. U.S. AEC. 1967. Nuclear terms: A glossary. United States Atomic Energy Commission, Oak Ridge, TN.

4. U.S. NRC. 1975. Reactor safety study. Appendix VI. WASH-1400 (NUREG-75/014). United States Nuclear Regulatory Commission, Washington, DC. 


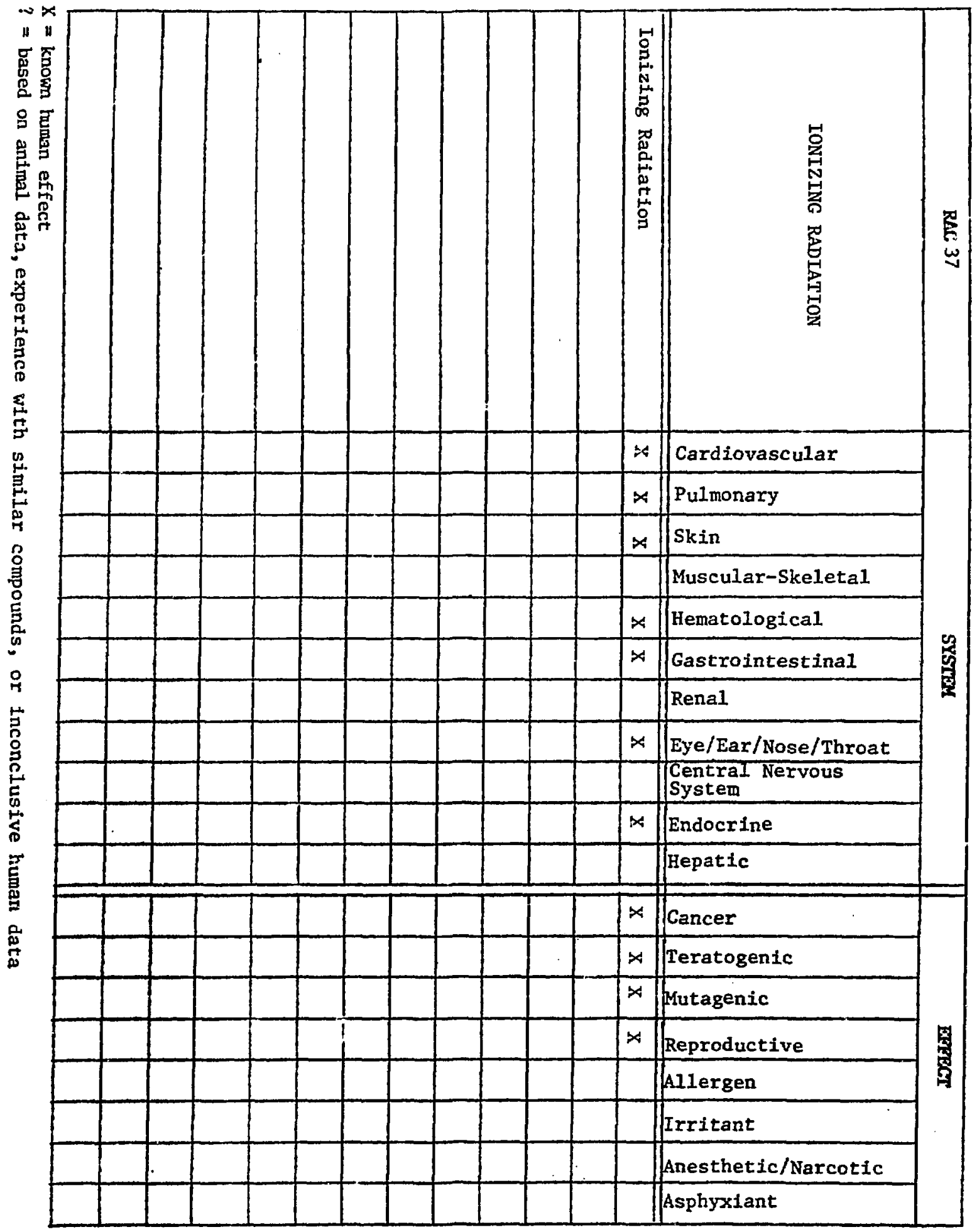


APPENDIX A

RISK-ASSESSHENT CATEGORIES

An adequate chemical-by-chemical health effects risk assessment is precluded because of the vast number of chemicals involved; the inability to characterize these compounds fully; the fact that many are chemically transformed in the environment; and gaps in toxicological information. Accordingly, the theme developed in this EPA program is to group pollutants in broad, chemically defined risk-assessment categorles (RACs). Table A-1 lists criteria developed by EPA and Oak Ridge National Laboratory for determining these categories.

Table A-1. Criteria for Determining Risk-Assessment Categories

a. Englneering Relevance. A goal of risk assessment is to provide useful guidance to industry. Therefore, p.ocess streams must be characterized in terms of their RAC content so that plant designers and operators can apply the results of the risk assessment.

b. Analysis Capability. The categories must correspond to practical chemical characterizations of the products and effluents of interest as revealed by biotesting. RACs that are divided more finely than existing chemical and biological analysis schemes will not be useful.

c. Completeness. Al1 constituents of the industry's products and effluents must be included in the system of RACs.

d. Nonoverlap. The RACs should be mutually exclusive; 1.e., none of the constituents should be assessed twice. Chemicals with multiple functional groups can be handled by assigning them to the RAC which they follow during chemical fractionation.

e. Data Compatibility. The correspondence between the RACs and commonly used chemical classes should be clear enough to allow use of existing data and regulatory standards in the risk assessment.

The current listing of 38 RACs is shown in Table $\mathrm{A}-2$. In practice it is difficult to devise groupings that fully satisfy all the above criteria. R.tok-assessment applications are evolving; those described here 
are presented in an example situation: development of synthetic fuel technologies. This application may lead to modificatious of the methods or the manner in which they are used, including possible restructuring of RACs; e.g., dividing some RACs into subgroups.

The RAC approach initially does not consider synergistic or other interactive effects. While interactions are known in some cases to be important, no available method takes all potential interactions into account in a broad approach such as this. This is an important area for further investigation and is addressed in more detall elsewhere in this program.

Table A-2. Risk-Assessment Categories

\begin{tabular}{|c|c|c|}
\hline $\begin{array}{l}\text { RAC } \\
\text { Number }\end{array}$ & Category & Description \\
\hline 1 & Carbon monoxide & Co \\
\hline 2 & Sulfur oxides & $\mathrm{SO}_{\mathbf{x}}$ \\
\hline 3 & Nitrogen oxides & $\mathrm{NO}_{x}^{\mathrm{x}}$ \\
\hline 4 & Acid gases & $\mathrm{H}_{2} \stackrel{\mathrm{S}}{\mathrm{S}}, \mathrm{HCN}$ \\
\hline 5 & Alkaline gases & $\mathrm{NH}_{3}$ \\
\hline 6 & Hydrocarbon gases & $\begin{array}{l}\mathrm{C}_{1}-\mathrm{C}_{4} \text { alkanes, alkenes, } \\
\text { a1kynes, and cyclo } \\
\text { compounds; bp }\left\langle \# 20^{\circ} \mathrm{C}\right.\end{array}$ \\
\hline 7 & Formaldehyde & HCHO \\
\hline 8 & Volatile organochlorines & $\begin{array}{l}\text { To bp } \# 120^{\circ} \mathrm{C} ; \mathrm{CH}_{2} \mathrm{Cl}_{2} \text {, } \\
\mathrm{CHCl}_{3}, \mathrm{CCl}_{4}\end{array}$ \\
\hline 9 & Volatile carboxylic acids & $\begin{array}{l}\text { To bp } \# 120^{\circ} \mathrm{C} ; \text { formic and } \\
\text { acetic acids on } 1 \mathrm{y}\end{array}$ \\
\hline 10 & Volatile 0 and $S$ heterocyclics & $\begin{array}{l}\text { To bp } \# 120^{\circ} \mathrm{C} \text {; furan, THF, } \\
\text { thiophene }\end{array}$ \\
\hline 11 & Volatile $N$ heterocyclics & $\begin{array}{l}\text { To bp } \# 150^{\circ} \mathrm{C} \text {; pyridine, } \\
\text { piperidine, pyrrolid }{ }^{2} \text {, } \\
\text { alkyl pyridines }\end{array}$ \\
\hline 12 & Benzene & Benzene \\
\hline 13 & $\begin{array}{l}\text { Aliphatic/alicyclic } \\
\text { hydrocarbons }\end{array}$ & $\begin{array}{l}\mathrm{C}_{5}\left(\mathrm{bp} ; 40^{\circ} \mathrm{C}\right) \text { and greater; } \\
\text { paraffins, olefins, } \\
\text { cyclo compounds, } \\
\text { terpenolds, } \\
\text { waxes, hydroaromatics }\end{array}$ \\
\hline 14 & $\begin{array}{l}\text { Mono/diaromatic hydrocarbons } \\
\text { (excluding benzene) }\end{array}$ & $\begin{array}{l}\text { Toluene, xylenes, } \\
\text { naphthalenes, b1phenyls, } \\
\text { alkyl derivatives }\end{array}$ \\
\hline 15 & $\begin{array}{l}\text { Polycycilc aromatic } \\
\text { hydrocarbons }\end{array}$ & $\begin{array}{l}\text { Three rings and greater; } \\
\text { anthracene, BaA, BaP, } \\
\text { lkyl derivatives }\end{array}$ \\
\hline
\end{tabular}


Table A-2. Risk-Assessment Categories (cont.)

\begin{tabular}{|c|c|c|}
\hline $\begin{array}{l}\text { RAC } \\
\text { Number }\end{array}$ & Category & Description \\
\hline 16 & Aliphatic amines & $\begin{array}{l}\text { Primary, secondary, and } \\
\text { tertiary nonheterocycilc } \\
\text { nitrogen, MeNH } 2, \text { DiMeNH, } \\
\text { TriMeN }\end{array}$ \\
\hline 17 & $\begin{array}{l}\text { Aromatic amines (excluding } \\
\text { N-heterocyclics) }\end{array}$ & $\begin{array}{l}\text { Anflines, naphthylanines, } \\
\text { aminopyrenes; } \\
\text { nonheterocyclic nitrogen }\end{array}$ \\
\hline 18 & $\begin{array}{l}\text { Alkaline nitrogen } \\
\text { heterocyclics ["azaarenes"] } \\
\text { (excluding "volatiles") }\end{array}$ & $\begin{array}{l}\text { Quinolines, acridines, } \\
\text { benzacridines excluding } \\
\text { pyridines }\end{array}$ \\
\hline 19 & $\begin{array}{l}\text { Neutral N,O,S heterocyclics } \\
\text { (excluding "volatiles") }\end{array}$ & $\begin{array}{l}\text { Indoles, carbazoles, } \\
\text { benzofurans, } \\
\text { dibenzothlophenes }\end{array}$ \\
\hline 20 & $\begin{array}{l}\text { Carboxylic acids (excluding } \\
\text { "volatiles") }\end{array}$ & $\begin{array}{l}\text { Butyric, benzolc, } \\
\text { phthalic, stearic acids }\end{array}$ \\
\hline 21 & Phenols & $\begin{array}{l}\text { Phenol, cresols, catechol, } \\
\text { resorcinol }\end{array}$ \\
\hline 22 & $\begin{array}{l}\text { Aldehydes and ketones } \\
\text { ["carbonyls"] (excluding } \\
\text { formaldehyde) }\end{array}$ & $\begin{array}{l}\text { Acetaldehyde, acrolein, } \\
\text { acetone, benzaldehyde }\end{array}$ \\
\hline 23 & Nonheterocyclic organo sulfur & $\begin{array}{l}\text { Mercaptans, sulfides, } \\
\text { disulfides, thiophenols, } \\
\mathrm{CS}_{2}\end{array}$ \\
\hline $\begin{array}{l}24 \\
25\end{array}$ & $\begin{array}{l}\text { Alcohols } \\
\text { N1troaromatics }\end{array}$ & $\begin{array}{l}\text { Methanol, ethanol } \\
\text { Nitrobenzenes, nitropyrenes }\end{array}$ \\
\hline 26 & Esters & $\begin{array}{l}\text { Acetates, phthalates, } \\
\text { formates }\end{array}$ \\
\hline 27 & Amides & $\begin{array}{l}\text { Acetamide, formamide, } \\
\text { benzamides }\end{array}$ \\
\hline $\begin{array}{l}28 \\
29 \\
30\end{array}$ & $\begin{array}{l}\text { Nitriles } \\
\text { Tars } \\
\text { Respirable particles }\end{array}$ & Acrylonttrile, acetonttrile \\
\hline 31 & Arsentc & As, all forms \\
\hline 32 & Mercury & $\mathrm{Hg}$, all forms \\
\hline 33 & Nickel & $\mathrm{N1}$, all forms \\
\hline 34 & Cadmium & Cd, all forms \\
\hline $\begin{array}{l}35 \\
36\end{array}$ & $\begin{array}{l}\text { Lead } \\
\text { Other trace elements }\end{array}$ & $\mathrm{Pb}$, all forms \\
\hline 37 & Radioactive materials & $226_{\mathrm{Ra}}$ \\
\hline 38 & Other remaining materials & \\
\hline
\end{tabular}




\section{PREFACE}

This profect was begun in the Medical Department of Brookhaven National Laboratory under the direction of M.B. Miller, then Principal Investigator of the EPA Synfuels Health Effects Clinical Program. A substantial amount of preliminary work was done at that time by $C$. Kramer, including a series of computerized blbllographic searches, gathering of 11terature, and preparation of summary tables of the kinds of effects expected from each Risk-Assesssment Category (RAC). The work drew heavily on a parallel review of animal literature being conducted in the Blomedical and Environmental Assessment Division (BEAD) and on the earlier experience of BEAD in working with the RAC concept and organizing chemicals within that structure.

In June 1983, responsibility for the project was transferred to BEAD as part of the EPA Health Risk Analysis Program (L.D. Hamilton, Principal Investigator). In the meanwhile, Mrs. Kramer had also transferred to the BEAD staff, and was given responsibility for the project.

Despite the preliminary work that had been done, it was difficult to do justice to the task and complete a report in the allotted time (September 1983). It was agreed upon with A.A. Moghiss1, the EPA Project officer, that, where authoritative reviews already existed, they would be summarlzed in 3 to 5 pages and the literature search would cover only information published after the review. The review of each RAC would vary -- from one page, where very little human information exists, to as many as twenty pages, where important studies exist that have not been previously reviewed. The expectation was a 100- to 200-page document. 